\section{Mantle Upwelling, Melt Generation, and Magma Transport Beneath Mid-Ocean Ridges}

by

\author{
Laura Suzan Magde
}

B. Sc. and B. A., University of California at Berkeley, 1992.

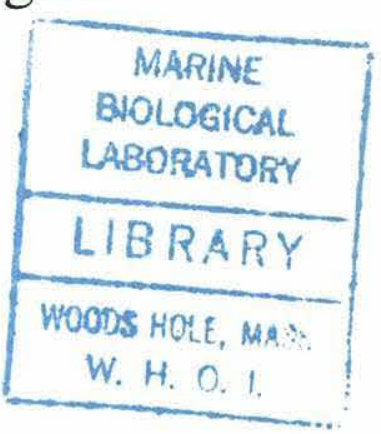

\section{SUBMITTED IN PARTIAL FULFILLMENT OF THE REQUIREMENTS FOR THE DEGREE OF DOCTOR OF PHILOSOPHY

at the
MASSACHUSETTS INSTITUTE OF TECHNOLOGY
and the
WOODS HOLE OCEANOGRAPHIC INSTITUTION

March, 1997

The author hereby grants to MIT and WHOI permission to reproduce and distribute copies of this thesis document in whole or in part.

Signature of Author Joint Program in Oceanography, Massachusetts Institute of Technology and Woods Hole Oceanographic Institution, February, 1997

Certified by $\wedge$ 1

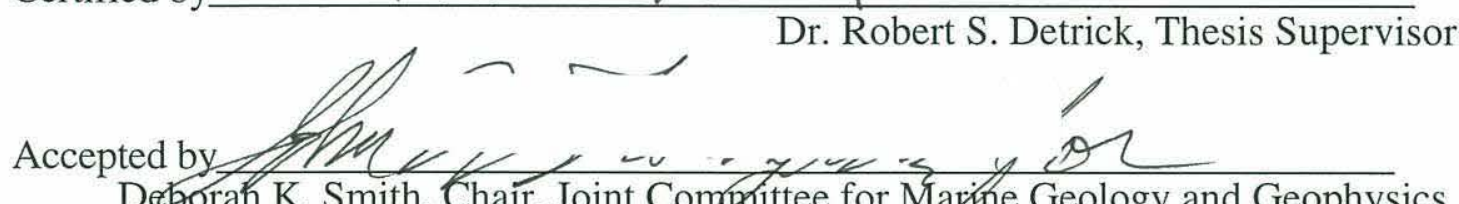

Deborah K. Smith, Chair, Joint Comnittee for Marthe Geology and Geophysics, Massachusetts Institute of Technology and Woods Hole Oceanographic Institution 


\title{
Mantle Upwelling, Melt Generation, and Magma Transport Beneath Mid-Ocean Ridges
}

\author{
Laura S. Magde \\ Submitted to the Department of Earth, Atmospheric, and Planetary Sciences \\ Massachusetts Institute of Technology \\ and \\ the Department of Geology and Geophysics, Woods Hole Oceanographic Institution, \\ March 1997 in partial fulfillment of the requirements for the degree of \\ Doctor of Philosophy
}

\begin{abstract}
The formation of new oceanic crust is the result of a complex geodynamic system in which mantle rises beneath spreading centers and undergoes decompression melting. The melt segregates from the matrix and is focused to the rise axis, where it is eventually intruded and/or erupted to form the oceanic crust. This thesis combines surface observations with laboratory studies and geodynamic modeling to study this crustalproduction system. Quantitative modeling of the crustal and mantle contributions to the axial gravity and topography observed at the East Pacific Rise shows that the retained melt fraction in the mantle is small $(<3 \%)$ and is focused into a narrow column extending up to $70 \mathrm{~km}$ beneath the ridge axis. Consistent with geochemical constraints, the extraction of melt from the mantle therefore appears to be efficiently focus melt toward the ridge axis. A combination of laboratory and numerical studies are used to constrain the pattern of mantle flow beneath highly-segmented ridges. Even when the buoyant component of mantle flow is constrained to be two-dimensional, laboratory studies show that a segmented ridge will drive three-dimensional mantle upwelling. However, using reasonable mantle parameters in numerical models, it is difficult to induce large-amplitude three-dimensional mantle upwelling at the relatively short wavelengths of individual segments $(\sim 50 \mathrm{~km})$. Instead, a simple model of three-dimensional melt migration shows that the observed segment-scale variations in crustal thickness can be explained by focusing of melt as it upwells through a more two-dimensional mantle flow field. At the Reykjanes Ridge, the melt appears to accumulate in small crustal magma chambers, before erupting in small batches to form numerous overlapping hummocky lava flows and small volcanoes. This suggests that crustal accretion, particularly at slow-spreading centers, may be a highly discontinuous process. Long-wavelength variations in crustal accretion may be dominated by variations in mantle upwelling while short-wavelength, segment-scale variations are more likely controlled by a complex three-dimensional processes of melt extraction and magma eruption.
\end{abstract}

Thesis supervisor: $\quad$ Robert S. Detrick

Title:

Senior Scientist, Woods Hole Oceanographic Institution 


\section{ACKNOWLEDGMENTS}

First and foremost, I would like to thank my advisor, Bob Detrick, for all of the help, encouragement, and patience he has provided over the last four and a half years. $\mathrm{He}$ has always been supportive and extremely generous, through both the good and bad times, and the numerous digressions to participate in conferences, cruises, and field trips. I could not have asked for a better advisor.

In addition, I would like to thank Dave Sparks, Chris Kincaid, Marcia McNutt, Jian Lin, and Debbie Smith for all of their help in conducting the various studies which went into making this thesis. And I also thank my friends, particularly my housemates, for being understanding during the late nights and stressful periods.

During my first three years in the Joint Program, I was supported by an National Science Foundation Graduate Student Fellowship. Other support has been derived from National Science Foundation grants OCE-9296017, OCE-9224738, OCE-9215544, and EAR grant 93-07400. 


\section{VITA}

Education

1992-Present MIT/WHOI Joint Program in Oceanography, Woods Hole, MA

Dissertation: Mantle Upwelling, Melt Generation, and Magma Transport Beneath Mid-Ocean Ridges

1988-1992 University of California at Berkeley, Berkeley, CA B.A. with Highest Honors in Geophysics B.S. with Highest Honors in Chemistry Undergraduate thesis advisor: Dr. Walter Alvarez

\section{Professional Experience}

1995-1997 Research Assistant, MIT/WHOI Joint Program in Oceanography

1995 Teaching Assistant, Computational Data Analysis Massachusetts Institute of Technology, Cambridge, MA Instructors: Marcia McNutt and Alan Chave

1989

1987 Summer Researcher, Scripps Institute of Oceanography, La Jolla, CA. Advisor: Nan Bray Jr. Chemist, Johnson-Matthey Inc., San Diego, CA Programmer, White Industries, San Diego, CA

Awards and Fellowships

"Outstanding Student Paper Award", Tectonophysics Section, Fall 1996 AGU Meeting National Science Foundation Graduate Fellowship, 1992-1995

Paul M. Fye Fellowship, 1992-1996

First Alternate for University Medal, University of CA at Berkeley, 1992

Departmental Citation in Geology and Geophysics, University of CA at Berkeley, 1992

ARCS Fellowship for excellence in Earth Sciences, 1991

SLSTP training program, Kennedy Space Center, 1990

Reagents Scholarship, University of CA at Berkeley, 1988-1992

Alumni Scholarship, University of CA at Berkeley, 1988-1989

Nobel Visit Award (Grand Prize), International Science Fair, 1988

\section{Professional Activities}

Member, American Geophysical Union, 1993-present

Co-chair, AGU Fall Meeting, "Mid Ocean Ridge IV Posters", 1994

Presentation at "The Icelandic Plume and its Influence on the Evolution of the NE Atlantic", Arthur Holmes European Res. Conference, Reykjavik, Iceland, 1994.

Participation in "Segmentation and Fluxes at Mid-Ocean Ridges: A symposium and Workshops", InterRidge, Durham, UK, 1993.

Participation in "Faulting and Magmatism at Mid-Ocean Ridges", RIDGE Theoretical Institute, Lake Tahoe, 1995.

Member, Phi Beta Kappa, 1991-present

Member, Sigma Iota Pi, 1991-present

Member, Sigma Xi, 1995-present 


\section{$\underline{\text { Research Cruise and Field Experience }}$}

Shipboard Scientist, High resolution geological, chemical, and biological survey of a superfast spreading center at $17^{\circ} \mathrm{S}$ on the EPR; ARGO deep-tow system with sidescan sonar, Mesotech sonar, still cameras, video imagery, CTD, magnetometer, and transmissometer; DSL 120 deep-towed side-scan sonar with magnetometer: R/V Melville; Oct-Nov, 1996.

Shipboard Scientist, ALVIN submersible work studying hydrothermal vents at $9^{\circ} \mathrm{N}$ on the EPR including water chemistry, ambient light measurements, geologic and biological sampling; deep-towed CTD, transmissometer, and filtration of plume particulates: $R / V$ Atlantis II; April, 1996.

Shipboard Scientist, Multichannel, Single channel, and Seismic Refraction survey of crustal structure at ODP drill hole 504B (Eastern Pacific Ocean, $1^{\circ} \mathrm{N}$ ); ocean bottom seismometers, $4 \mathrm{~km}$ streamer, sonabuoys, 10 and 20-gun tuned airgun arrays: $R / V$ Maurice Ewing, Oct-Nov, 1994.

Shipboard Scientist, Fine-scale, near bottom geological and geophysical survey of ONR Atlantic Natural Laboratory (Atlantic Ocean, $24^{\circ} \mathrm{N}$ ); DSL 120 deep-towed side-scan sonar, JASON/Medea ROV system w/ DSL 200 swath-bathymetric side-scan sonar, Mesotech profiling sonar, and video imagery, deep-towed magnetometer, dredge and ROV sampling: R/V Knorr, April-May, 1993.

Shipboard Scientist, Benthic biological survey on California continental slope; water column sediment traps, sediment box core sampling, time-lapse video imagery: $R / V$ New Horizon, July, 1991.

Geological field exploration of the Bay of Islands Ophiolite, New Foundland, 1993; Basin and Range Province, Western N. America, 1994; and Active Volcanism in Hawaii, 1996. Geodynamics Seminar, WHOI/MIT Joint Program.

Field Camp, led by Clark Burchfiel and Kip Hodges of MIT, Southern Nevada, Jan, 1996.

Field trips to the North and West Rift Zones and Southern Glaciers in Iceland, 1994 and 1996.

Field trip to the Oman Ophiolite, 1997. 


\section{PUBLICATIONS}

\section{$\underline{\text { Papers }}$}

Magde, L. S., C. Kincaid, D. W. Sparks, and R. S. Detrick, Combined laboratory and numerical studies of the interaction between buoyant and plate-driven upwelling beneath segmented spreading centers, J. Geophys. Res., 101, 22,107-22,122, 1996.

Magde, L. S., R. S. Detrick, and TERA Group, The Crustal and Upper Mantle Contribution to the Axial Gravity Anomaly at the Southern East Pacific Rise, $J$. Geophys. Res., 100, 3747-3766, 1995.

Magde, L. S. and D. K. Smith, Seamount Volcanism at the Reykjanes Ridge: Relationship to the Iceland Hot Spot, J. Geophys. Res., 100, 8449-8468, 1995.

Magde, L. S., H. J. B. Dick, and S. R. Hart, Tectonics, Alteration, and the Fractal Distribution of Hydrothermal Veins in the Lower Ocean Crust, Earth and Planet. Sci. Lett., 129, 103-119, 1995.

Magde, L. S., D. W. Sparks, and R. S. Detrick, The relationship between buoyant mantle flow, melt migration, and gravity bull's-eyes at the Mid-Atlantic Ridge between $33^{\circ} \mathrm{N}$ and $35^{\circ} \mathrm{N}$, Earth Planet. Sci. Lett., in press.

Magde, L. S. and D. W. Sparks, Three-dimensional mantle upwelling, melt generation, and melt migration beneath segmented slow-spreading ridges, J. Geophys. Res., submitted.

\section{$\underline{\text { Abstracts }}$}

Magde, L. S., R. S. Detrick, and D. W. Sparks, The relationship between buoyant mantle flow, melt migration, and the mantle Bouguer anomaly patters observed along the MAR from $33^{\circ} \mathrm{N}$ to $35^{\circ} \mathrm{N}$, EOS Trans. Amer. Geophys. Un., 77, 723, 1996.

Sparks, D. W., and L. S. Magde, Three-dimensional mantle upwelling, melt generation, and melt migration beneath segmented slow-spreading centers, EOS Trans. Amer. Geophys. Un.,77, 730, 1996.

Magde, L. S., D. W. Sparks, and R. S. Detrick, The contribution of buoyant mantle flow to the mantle Buoguer anomaly patterns observed along the MAR from $33^{\circ} \mathrm{N}$ to $35^{\circ} \mathrm{N}$, Journal of Conference Abstracts, 1, 821-822, 1996.

Magde, L. S., C. Kincaid, D. W. Sparks, and R. S. Detrick, Combined laboratory and numerical studies of the interaction between buoyant and plate-driven upwelling beneath segmented spreading centers, EOS Trans. Amer. Geophys. Un., 76, 609, 1995.

Magde, L. S. and D. K. Smith, Seamount Volcanism at the Reykjanes Ridge: Relationship to the Iceland Hot Spot, EOS Trans. Amer. Geophys. Un., 75, 659, 1994.

Magde, L. S. and R. S. Detrick, The Crustal and Upper Mantle Contribution to the Axial Gravity Anomaly at the Southern East Pacific Rise, EOS Trans. Amer. Geophys. Un., 75, 641, 1994.

Magde, L. S., H. J. B. Dick, and S. R. Hart, Fractal Analysis of Veins in ODP Core 735B, EOS Trans. Amer. Geophys. Un., 74, 652, 1993. 


\section{TABLE OF CONTENTS}

Abstract 3

Acknowledgments $\quad 4$

Vita 5

$\begin{array}{ll}\text { Publications } & 7\end{array}$

Chapter 1.

THE INFLUENCE OF LITHOSPHERIC SEGMENTATION ON

MANTLE CONVECTION AND MELT MIGRATION 13

Introduction $\quad 13$

$\begin{array}{ll}\text { Thesis Overview } & 14\end{array}$

$\begin{array}{lr}\text { References } & 16\end{array}$

Chapter 2.

CRUSTAL AND UPPER MANTLE CONTRIBUTION TO THE AXIAL GRAVITY ANOMALY AT THE SOUTHERN EAST PACIFIC RISE 19

$\begin{array}{ll}\text { Abstract } & 21\end{array}$

$\begin{array}{ll}\text { Introduction } & 21\end{array}$

Tectonic Setting and Seismic Results 22

Free-Air and Mantle Bouguer Anomalies $\quad 24$

Crustal and Mantle contributions to the Axial Gravity Anomaly 25

Modeling Crustal Density Anomalies $\quad 27$

Variation in Layer 2A Thickness $\quad 27$

Elevated Temperatures in the Lower Crust $\quad 27$

Modeling the Mantle Density Structure $\quad 30$

Combining Crustal and Mantle Contributions 31

Comparison With Observed Bathymetry 32

Discussion and Implications 35

$\begin{array}{ll}\text { Conclusions } & 38\end{array}$

References $\quad 38$ 
Chapter 3.

SEAMOUNT VOLCANISM AT THE REYKJANES RIDGE: RELATIONSHIP TO THE ICELAND HOT SPOT 41

$\begin{array}{ll}\text { Abstract } & 43\end{array}$

Introduction 43

Overview of Tectonic Setting and Previous Work 44

Data Description and Study Areas $\quad 46$

$\begin{array}{ll}\text { Area A } & 46\end{array}$

$\begin{array}{ll}\text { Area B } & 46\end{array}$

$\begin{array}{ll}\text { Area C } & 47\end{array}$

Methods 48

Seamount Identification and determination of Population Parameters From Hydrosweep Data $\quad 48$

Determination of Surface Morphology From Side Scan Data 51

Seamount Population Parameters $\quad 52$

Reykjanes Ridge Seamount Population 52

Area A 53

Area B $\quad 53$

$\begin{array}{ll}\text { Area C } & 54\end{array}$

Morphological Seamount Types $\quad 55$

Seamount Morphology by Study Area $\quad 56$

Hummocky Seamounts $\quad 56$

Smooth Seamounts $\quad 56$

Discussion: Volcanism at the Reykjanes Ridge $\quad 57$

$\begin{array}{ll}\text { Conclusions } & 60\end{array}$

$\begin{array}{ll}\text { References } & 61\end{array}$

Chapter 4.

COMBINED LABORATORY AND NUMERICAL STUDIES OF THE

INTERACTION BETWEEN BUOYANT AND PLATE-DRIVEN UPWELLING

BENEATH SEGMENTED SPREADING CENTERS 63

$\begin{array}{ll}\text { Abstract } & 65\end{array}$

Introduction $\quad 65$

$\begin{array}{ll}\text { Previous Studies } & 66\end{array}$ 
Methods $\quad 66$

Laboratory Apparatus $\quad 66$

$\begin{array}{ll}\text { Numerical Simulations } & 67\end{array}$

$\begin{array}{ll}\text { Experimental Design } & 68\end{array}$

$\begin{array}{ll}\text { Results } & 70\end{array}$

$\begin{array}{ll}\text { Buoyant Flow } & 70\end{array}$

$\begin{array}{ll}\text { Plate-Driven Flow } & 70\end{array}$

Combined Buoyant and Plate-Driven Flow 73

$\begin{array}{ll}\text { Discussion } & 76\end{array}$

$\begin{array}{ll}\text { Conclusions } & 79\end{array}$

$\begin{array}{ll}\text { References } & 79\end{array}$

Chapter 5.

THREE DIMENSIONAL MANTLE UPWELLING, MELT MIGRATION, AND MELT MIGRATION BENEATH SEGMENTED SLOW-SPREADING RIDGES 81

$\begin{array}{ll}\text { Abstract } & 81\end{array}$

Introduction $\quad 82$

Design of Flow Model 83

Segmentation Geometries $\quad 85$

Wavelength of Mantle Flow and Melting 85

Effect of Mantle Viscosity on Wavelength of Along-Axis Variations 86

$\begin{array}{lr}\text { Controls on Average Crustal Thickness } & 88\end{array}$

$\begin{array}{ll}\text { Three-Dimensional Melt Migration } & 88\end{array}$

$\begin{array}{ll}\text { Discussion } & 91\end{array}$

$\begin{array}{ll}\text { Conclusions } & 93\end{array}$

$\begin{array}{ll}\text { Appendix A } & 94\end{array}$

$\begin{array}{ll}\text { References } & 98\end{array}$

$\begin{array}{ll}\text { Tables } & 104\end{array}$

$\begin{array}{ll}\text { Figures } & 107\end{array}$

Chapter 6.

THE RELATIONSHIP BETWEEN BUOYANT MANTLE FLOW, MELT MIGRATION, AND GRAVITY BULL'S-EYES AT THE MID-ATLANTIC RIDGE BETWEEN $33^{\circ} \mathrm{N}$ AND $35^{\circ} \mathrm{N}$ 
$\begin{array}{ll}\text { Abstract } & 119\end{array}$

$\begin{array}{ll}\text { Introduction } & 119\end{array}$

$\begin{array}{ll}\text { Study Area } & 120\end{array}$

$\begin{array}{ll}\text { Methods } & 121\end{array}$

Predicted MBA with Two-dimensional Melt Migration 122

Predicted MBA with Three-dimensional Melt Migration 123

$\begin{array}{ll}\text { Implications } & 124\end{array}$

$\begin{array}{ll}\text { References } & 126\end{array}$

$\begin{array}{lr}\text { Figures } & 129\end{array}$

Chapter 7.

CONCLUSIONS 137

Summary of Findings $\quad 137$

$\begin{array}{ll}\text { Future Work } & 138\end{array}$

$\begin{array}{ll}\text { References } & 140\end{array}$ 


\section{CHAPTER 1}

\section{The Influence of Lithospheric Segmentation on Mantle Convection and Melt Migration}

\section{Introduction}

Mid-ocean ridges form the worldwide network of spreading centers where oceanic plates diverge. Far from being straight lines, the ridges are composed of distinct spreading segments (20-200 km long) separated by offsets (anywhere from 2-200 km long) along which transverse motion is accommodated. As the plates separate, mantle upwells beneath the ridge segments, and undergoes decompression melting to provide the basaltic melt which forms the oceanic crust. Mantle flow beneath mid-ocean ridges is the result of the interaction between the plate-driven and buoyant components of the flow. Even without a segmented ridge, numerical modeling [Parmentier and Phipps Morgan, 1990; Jha et al., 1994; Sparks and Parmentier, 1993] and laboratory experiments [Whitehead et al., 1984; Kincaid et al., 1996] indicate that there will be along-axis variations in upwelling and crustal production due to focusing of the buoyant flow. However, the plate-driven flow associated with a segmented ridge will further enhance this three dimensionality [e.g., Sparks et al., 1993; Rabinowicz, 1993].

In addition to influencing mantle convection, ridge segmentation may also effect the three-dimensional migration of melt as it is extracted from the mantle. There is evidence, at least in some cases, that there must be relative horizontal motion between melt and mantle [i.e., Dick, 1989, Spiegelman, 1996]. One mechanism by which this may occur is through the transport of melt along the top of the melting region or the base of the lithosphere [Sparks and Parmentier, 1994; Spiegelman, 1993]. Cooling of the lithosphere beneath transforms and non-transform offsets will depress the top of the melting region, creating a topographic gradient which may drive melt toward segment centers. Thus, lithospheric segmentation may have a large role (by effecting both mantle convection and melt migration) in the focusing of crustal accretion beneath segment midpoints.

The most often-cited expression of the focusing of mantle flow and melt production is the mantle Bouguer anomaly (MBA) "bull's-eye" lows (attributed to thicker crust and/or warmer mantle) and shallower topography observed at the centers of many segments along the Mid-Atlantic Ridge (MAR) [Kuo and Forsyth, 1988; Lin et al., 1990]. There is a strong correlation between along-axis variations in crustal thickness and spreading rate. 
Slow spreading ridges display much greater along-axis crustal thickness variations than fast spreading ridges [e.g., Lin and Phipps Morgan, 1992], but even at fast spreading ridges, there is some evidence for focusing of mantle flow [Wang and Cochran, 1993]. Segment and offset lengths appear to be related to the amount of along-axis variation in MBA and crustal thickness, particularly at slow spreading ridges. At the MAR, there is a systematic increase in the magnitude of the axial MBA variation with increasing segment length and increasing offset length [Lin et al., 1990; Detrick et al., 1995]. This would be consistent with increased focusing of melt beneath longer segments, especially those adjacent to longer offsets, suggesting that the degree of focusing may be related to the details of the spreading center geometry.

This thesis uses a combination of observational, laboratory, and numerical approaches to investigate the role of lithospheric segmentation on the three-dimensional behavior of mantle flow and melt migration. Rather than invoking three-dimensional mantle convection to create segments in the overlying ridge, this work imposes representative segment geometries as a boundary condition and investigates the effect this segmentation has on the underlying mantle flow and extraction of melt.

\section{Thesis Overview}

Observational data including a gravity survey at the super-fast spreading East Pacific Rise (EPR) and a high-resolution topographic survey of the slow-spreading Reykjanes Ridge form the basis for Chapters 2 and 3. Quantitative modeling of the crustal and mantle contributions to the axial gravity and topography observed at the EPR has shown that the retained melt fraction in the mantle is small $(<3 \%)$ and is focused into a narrow column extending as far as $70 \mathrm{~km}$ beneath the ridge axis. Consistent with geochemical constraints, the extraction of melt from the mantle appears to be an efficient

process. However, at slow spreading ridges, the process of crustal accretion are highly discontinuous. Similar to other sections of the Mid-Atlantic Ridge (MAR), the oceanic crust at the Reykjanes Ridge is formed by numerous small overlapping hummocky lava flows and small volcanoes. Despite the increased overall crustal thickness due to proximity of the Iceland hot spot, crustal formation appears to take place via small eruptions from isolated, ephemeral crustal magma chambers.

A combination of laboratory and numerical studies are then used to constrain the pattern of mantle flow beneath highly-segmented ridges. In Chapter 4, a viscous fluid with a strongly temperature-dependent viscosity (Karo syrup) in a laboratory 
tank is used to visualize the interaction of buoyant and plate-driven mantle upwelling beneath a variety of plate geometries. Numerical simulations of the tank experiments are also used to identify the relative importance of individual physical processes on the overall pattern of flow. Even with two-dimensional mantle upwelling, a segmented ridge will drive three-dimensional mantle upwelling. The three dimensionality increases with spreading rate and offset length. The results suggests that mantle upwelling velocities decrease at the ends of segments and the centers of upwelling may be offset from the ridge axis toward offsets.

In Chapter 5, numerical models are used to expand the range of plate geometries and mantle conditions, and to explicitly include melt production and crustal accretion which could not be simulated in the tank. Using reasonable mantle parameters, it is difficult to induce three-dimensional mantle upwelling at the relatively small length-scale of individual segments $(\sim 50 \mathrm{~km})$. In addition, overall crustal production decreases with decreasing mantle temperature, slower spreading rates, and increased ridge segmentation.

A simple model of three-dimensional melt migration along the base of the lithosphere is used in Chapter 6 to show that observed along-axis variations in crustal thickness can be explained by focusing of melt as it upwells through a more twodimensional mantle flow field. Long-wavelength variations in crustal accretion may be therefore be caused by variations in mantle upwelling while short-wavelength, segmentscale variations are more likely controlled by a complex three-dimensional processes of melt extraction and magma eruption.

Finally, Chapter 7 summarizes the main conclusions of Chapters 2 through 6 and discusses some further questions about the process of crustal formation which are raised by this work.

Chapter 2 was published in the Journal of Geophysical Research, 1995. My coauthor was Robert Detrick. We also recognized the TERA Group (Graham Kent, Alistar Harding, John Orcutt, John Mutter, and Peter Buhl) for their role in collecting the original gravity data. Chapter 3 was co-authored by Debbie Smith and was published in the Journal of Geophysical Research, 1995. Chapter 4 was published in the Journal of Geophysical Research, 1996. For this work, my co-authors were Chris Kincaid, David Sparks, and Robert Detrick. Chapter 5 has been submitted to the Journal of Geophysical Research as a manuscript co-authored with Dave Sparks. Chapter 6, co-authored by Dave Sparks and Robert Detrick, is in press in Earth and Planetary Science Letters. In all cases, I was the 
primary author and, with advice from my co-authors, was responsible for both the data analysis/synthesis, and the writing of the manuscript.

The full citations for the papers corresponding to each of the chapters are:

Magde, L. S., R. S. Detrick, and TERA Group, The Crustal and Upper Mantle Contribution to the Axial Gravity Anomaly at the Southern East Pacific Rise, $J$. Geophys. Res., 100, 3747-3766, 1995.

Magde, L. S. and D. K. Smith, Seamount Volcanism at the Reykjanes Ridge: Relationship to the Iceland Hot Spot, J. Geophys. Res., 100, 8449-8468, 1995.

Magde, L. S., C. Kincaid, D. W. Sparks, and R. S. Detrick, Combined laboratory and numerical studies of the interaction between buoyant and plate-driven upwelling beneath segmented spreading centers, J. Geophys. Res., 101, 22,107-22,1222, 1996.

Magde, L. S. and D. W. Sparks, Three-dimensional mantle upwelling, melt generation, and melt migration beneath segmented slow-spreading ridges, J. Geophys. Res., submitted.

Magde, L. S., D. W. Sparks, and R. S. Detrick, The relationship between buoyant mantle flow, melt migration, and gravity bull's-eyes at the Mid-Atlantic Ridge between $33^{\circ} \mathrm{N}$ and $35^{\circ} \mathrm{N}$, Earth Planet. Sci. Lett., in press.

\section{References}

Detrick, R. S., H. D. Needham, and V. Renard, Gravity anomalies and crustal thickness variations along the Mid-Atlantic Ridge between $33^{\circ} \mathrm{N}$ and $40^{\circ} \mathrm{N}$, J. Geophys. Res., 100, 3767-3787, 1995.

Dick, H. J. B., Abyssal peridotites, very slow spreading ridges and ocean ridge magmatism, in Magmatism in the Ocean Basins, A. D. Sounders and M. J. Norry eds., Geological Society Special Publication No. 42, 71-105, 1989.

Jha, K., E. M. Parmentier, and J. Phipps Morgan, The role of mantle-depletion and meltretention buoyancy in spreading-center segmentation, Earth Planet. Sci. Lett., 125, 221-234, 1994.

Kincaid, C., D. W. Sparks, and R. S. Detrick, The relative importance of plate-driven and buoyancy-driven flow at mid-ocean ridge spreading centers, J. Geophys. Res., 101, 16,177-16,193, 1996. 
Kuo, B.-Y., and D. W. Forsyth, Gravity anomalies of the ridge-transform system in the South Atlantic between 31 and $34.5^{\circ} \mathrm{S}$ : Upwelling centers and variations in crustal thickness, Mar. Geophys. Res., 10, 205-232, 1988.

Lin, J., and J. Phipps Morgan, The spreading rate dependence of three-dimensional midocean ridge gravity structure, Geophys. Res. Lett., 19, 13-16, 1992.

Lin, J., G. M. Purdy, H. Schouten, J.-C. Sempere, and C. Zervas, Evidence from gravity data for focused magmatic accretion along the Mid-Atlantic Ridge, Nature, 344, 627-632 1990.

Parmentier, E. M., and J. Phipps Morgan, Spreading rate dependence of three-dimensional structure in oceanic spreading centers, Nature, 348, 325-328, 1990.

Rabinowicz, M., S. Rouzo, J.-C. Sempere, and C. Rosemburg, Three-dimensional mantle flow beneath mid-ocean ridges, J. Geophys. Res., 98, 7851-7869, 1993.

Sparks, D. W., and E. M. Parmentier, The generation and migration of partial melt beneath oceanic spreading centers, in Magmatic Systems, Academic Press, edited by M. P. Ryan, 55-76, 1994.

Sparks, D. W., E. M. Parmentier, and J. Phipps Morgan, Three-dimensional mantle convection beneath a segmented spreading center: Implications for along-axis variations in crustal thickness and gravity, J. Geophys. Res., 98, 21,977-21,205, 1993.

Spiegelman, M., Geochemical consequences of melt transport in 2-D: The sensitivity of trace elements to mantle dynamics, Earth Planet. Sci. Lett., 139, 115-132, 1996.

Spiegelman, M., Physics of melt extraction: theory, implications and applications, Phil. Trans. R. Soc. London A, 342, 23-41, 1993.

Wang, X., and J. R. Cochran, Gravity anomalies, isostasy, and mantle flow at the East Pacific Rise Crest, J. Geophys. Res., 98, 19,505-19,531, 1993.

Whitehead, Jr., J. A., H. J. B. Dick, and H. Schouten, A mechanism for magmatic accretion under spreading centers, Nature, 312, 146-147, 1984. 


\section{CHAPTER 2}

Crustal and Upper Mantle Contribution to the Axial Gravity Anomaly at the Southern East Pacific Rise 
Magde, L. S., R. S. Detrick, and TERA Group, The Crustal and Upper Mantle Contribution to the Axial Gravity Anomaly at the Southern East Pacific Rise, J. Geophys. Res., 100, 3747-3766, 1995. Copyright by the American Geophysical Union. Reprinted with permission. 


\title{
Crustal and upper mantle contribution to the axial gravity anomaly at the southern East Pacific Rise
}

\author{
Laura S. Magde, ${ }^{1,2}$ Robert S. Detrick, ${ }^{1}$ and the TERA Group ${ }^{3}$
}

\begin{abstract}
This paper reassesses the crustal and upper mantle contribution to the axial gravity anomaly and isostatic topography observed at two segments $\left(14^{\circ} \mathrm{S}\right.$ and $\left.17^{\circ} \mathrm{S}\right)$ of the southern East Pacific Rise (SEPR) in order to determine what constraints these data place on the amount of melt present in the underlying mantle. Gravity effects due to seafloor topography and relief on the Moho (assuming a constant crustal thickness and density) overpredict the amplitude of the gravity high at the EPR by $8-10 \mathrm{mGal}$. About $70 \%$ of this mantle Bouguer anomaly (MBA) low (6-7 mGal) can be explained by a region of partial melt and elevated temperatures in the mid-to-lower crust beneath the rise axis. Compositional density reductions in the mantle due to melt extraction are shown to make a negligible contribution to the amplitude of the observed MBA. Temperature-related mantle density variations predicted by a simple, plate-driven, passive flow model with no melt retention can adequately account for the mantle contribution to the observed MBA within the experimental uncertainty $( \pm 1 \mathrm{mGal})$. However, the retention of a small amount of melt $\left(\leq 1-2 \%\right.$ at $14^{\circ} \mathrm{S} ; \leq 4 \%$ at $\left.17^{\circ} \mathrm{S}\right)$ in a broad region (tens of kilometers wide) of upwelling mantle is also consistent with the observed gravity data given the uncertainty in crustal thermal models. The anomalous height of the narrow, topographic high at the EPR provides the strongest evidence for the existence of significant melt fractions in the underlying mantle. It is consistent with the presence of a narrow ( $\sim 10 \mathrm{~km}$ wide) partial melt conduit that extends to depths of 50-70 km with melt concentrations up to $2 \%$ higher than the surrounding mantle. Along-axis variations in mantle melt fraction that might potentially indicate focused upwelling are only marginally resolvable in the gravity data due to uncertainties in crustal thermal models. The good correlation between along-axis variations in depth, and changes in axial volume and gravity, argue against the mantle melt conduit as being the major source of this along-axis variation. Instead, this variability can be adequately explained by a combination of along-axis changes in crustal thermal structure and/or along-axis crustal thickness changes of a few hundred meters.
\end{abstract}

\section{Introduction}

Pressure release melting of mantle upwelling beneath midocean ridges generates magma that forms oceanic crust. The rheology of this partially molten aggregate depends critically on the grain-scale distribution of the melt phase [Kohlstedt, 1992]. If permeability is very low, the melt content of ascending mantle rocks will continuously increase as melting progresses. Once the retained melt exceeds a certain value $(\sim 5 \%)$, creep resistance will decrease dramatically reducing viscosities a factor of 10 to 50 [Hirth and Kohlstedt, 1994]. On the other hand, if permeability is high the melt will be rapidly drained from the rock and the

\footnotetext{
${ }^{1}$ Department of Geology and Geophysics, Woods Hole Oceanographic Institution, Woods Hole, Massachusetts.

${ }^{2}$ Also at WHOI/MIT Joint Program, Woods Hole, Massachusetts.

${ }^{3}$ Graham M. Kent, Department of Geology and Geophysics, Woods Hole Oceanographic Instistution, Woods Hole, Massachusetts; Alistar J. Harding and John A. Orcutt, Scripps Institution of Oceanography, University of California, San Diego; and John C. Mutter and Peter Buhl, Lamont-Doherty Earth Observatory, Palisades, New York.
}

Copyright 1995 by the American Geophysical Union.

Paper number 94JB02869.

0148-0227/95/94JB-02869\$05.00 mantle will behave like an almost melt-free aggregate, even though it is undergoing up to $20-25 \%$ partial melting as it rises through the melting regime [Ahren and Turcotte, 1979]. The amount of interstitial melt will have important implications on both the pattern of mantle flow beneath ridges (which is strongly affected by rheology), as well as the geochemistry of the magma that is produced.

Chemical analyses of isotopes and trace elements in mid-ocean ridge basalts [Salters and Hart, 1989] and abyssal peridotites [Johnson et al., 1990] suggest that melt can be effectively segregated from the residual crystalline phases at melt contents as small as $0.1 \%$. This result is consistent with laboratory experiments on olivine-basalt aggregates that show that the melt phase is interconnected at very small porosities [Daines and Richter, 1988; Watson, 1991]. Furthermore, experiments by Riley et al. [1990] and work by Ahren and Turcotte [1979] show that melt migration by porous flow can be quite rapid. The amount of melt required to explain the anomalous upper mantle S-wave velocities observed below the East Pacific Rise [Nishimura and Forsyth, 1989] depends on the geometry of the melt distribution, but if some fraction of the melt is distributed in the form of thin films wetting the faces of grains, Forsyth [1992] showed that only $\sim 0.5 \%$ melt is required to explain the observed velocity anomaly.

Several lines of evidence thus suggest that the retained melt in the mantle beneath spreading centers is quite small $(<1 \%)$. 
However, the existence of much more melt (up to 20-30\%) has been proposed as one mechanism for substantially reducing mantle viscosity in order to focus upwelling and explain the narrowness of the neovolcanic zone [Buck and Su, 1989]. Recent studies of the gravity anomaly observed at the East Pacific Rise have also suggested that substantial amounts of retained melt (3$9 \%$ ) are required in the upper mantle down to depths of 30-50 km in the axial region [Wang and Cochran, 1993; Wilson, 1992] (X. Wang et al., Gravity anomalies, crustal thickness, and the pattern of mantle flow at the fast spreading East Pacific Rise, $9^{\circ} \mathrm{N}-10^{\circ} \mathrm{N}$ : Evidence for three-dimensional upwelling, submitted to Journal of Geophysical Research, 1994; hereafter referred to as Wang et al., submitted manuscript, 1994). Along-axis variations in the magnitude of this compensating mass have been used to suggest that mantle flow is as highly focused and three-dimensional at fast spreading ridges as it is at slow spreading ridges [Wang and Cochran, 1993].

In this paper we reassess the crustal and upper mantle contribution to the axial gravity anomaly and isostatic topography at the East Pacific Rise (EPR) to determine what constraints these data place on the melt fraction present in the underlying mantle. We use gravity and seismic data from the southern portion of the EPR in this study [Detrick et al., 1993]. This area is of particular interest because it is among the fastest spreading segments of the global mid-ocean ridge system with total opening rates of 150 $162 \mathrm{~mm} / \mathrm{yr}$ [DeMets et al., 1990]. It also includes the site of the mantle electromagnetic and tomography (MELT) experiment [Forsyth, 1993].

This study differs from previous efforts to model the gravity anomaly at the EPR in three major respects: (1) we use more realistic crustal thermal models [Henstock et al., 1993; Phipps Morgan and Chen, 1993] based on seismic studies from the EPR [e.g., Solomon and Toomey, 1992] that show the axial magma chamber is a narrow, sill-like body confined to the mid-crust while the lower crust is largely solidified, (2) we include mantle density effects due to three different sources: temperature, compositional changes caused by the extraction of partial melt, and melt retention, and (3) we calculate the distribution of anomalous mass in the mantle by incorporating the effects of both plate-driven and buoyancy flow using a new mantle flow model developed by Sparks et al. [1993b]. We show that about $70 \%(6-7 \mathrm{mGal})$ of the mantle Bouguer anomaly (MBA) low found at the EPR can be explained by a region of partial melt and elevated temperatures in the mid-to-lower crust beneath the rise axis that lowers crustal densities compared to those at equivalent depths off-axis. The remainder of this anomaly can be adequately explained by temperature-related mantle density variations with no melt retention, although the presence of small amounts of melt (a few percent) in a broad region (tens of kilometers wide) of upwelling mantle cannot be precluded. We show that the strongest evidence for the existence of significant amounts of retained melt (2-3\%) in the upwelling mantle comes from the anomalous height of the narrow, axial bathymetric high found at the EPR which can be explained by the existence of a narrow $(\sim 10 \mathrm{~km}$ wide) melt conduit which extends to depths of $50-70 \mathrm{~km}$.

\section{Tectonic Setting and Seismic Results}

The tectonic setting of the ultrafast-spreading (150-162 $\mathrm{mm} / \mathrm{yr}$ ) southern East Pacific Rise (SEPR) south of the Garrett fracture zone has been well established by Sea Beam and
SeaMARC II surveys [Lonsdale, 1989; Macdonald et al., 1988] and from extensive dredging [Sinton et al., 1991]. Between the Garrett fracture zone and the $20.7^{\circ} \mathrm{S}$ propagator the SEPR is uninterrupted by any large ridge offsets, however there are several small discontinuities including overlapping spreading centers (OSCs) at $15^{\circ} 55^{\prime}, 16^{\circ} 25^{\prime}$, and $17^{\circ} 55^{\prime} \mathrm{S}$; and three smaller OSCs between 18 and $19^{\circ} \mathrm{S}$ (Figure 1). The ridge axis is uniform in depth between $13.4^{\circ} \mathrm{S}$ and $18^{\circ} \mathrm{S}$, then gradually deepens southward toward the large $20.7^{\circ} \mathrm{S}$ discontinuity which Macdonald et al. [1988] describe as a dueling propagator (Figure 2). This change in axial depth is associated with a systematic change in the dimensions of the axial topographic high [Scheirer and Macdonald, 1993]. The shallowest and broadest sections of the SEPR are located near $14^{\circ} \mathrm{S}$ and between 17 and $18^{\circ} \mathrm{S}$, while southward toward the $20.7^{\circ} \mathrm{S}$ propagator the axial high is deeper and narrower (Figure 2). This portion of the EPR is magmatically segmented on various scales [Sinton et al., 1991]. A primary magmatic segmentation, occurring at the largest physical offsets, has been attributed to mantle source variations, while a secondary magmatic segmentation, usually corresponding to sections of ridge bounded by OSCs, is thought to reflect alongaxis variations in the extent of melting [Sinton et al., 1991].

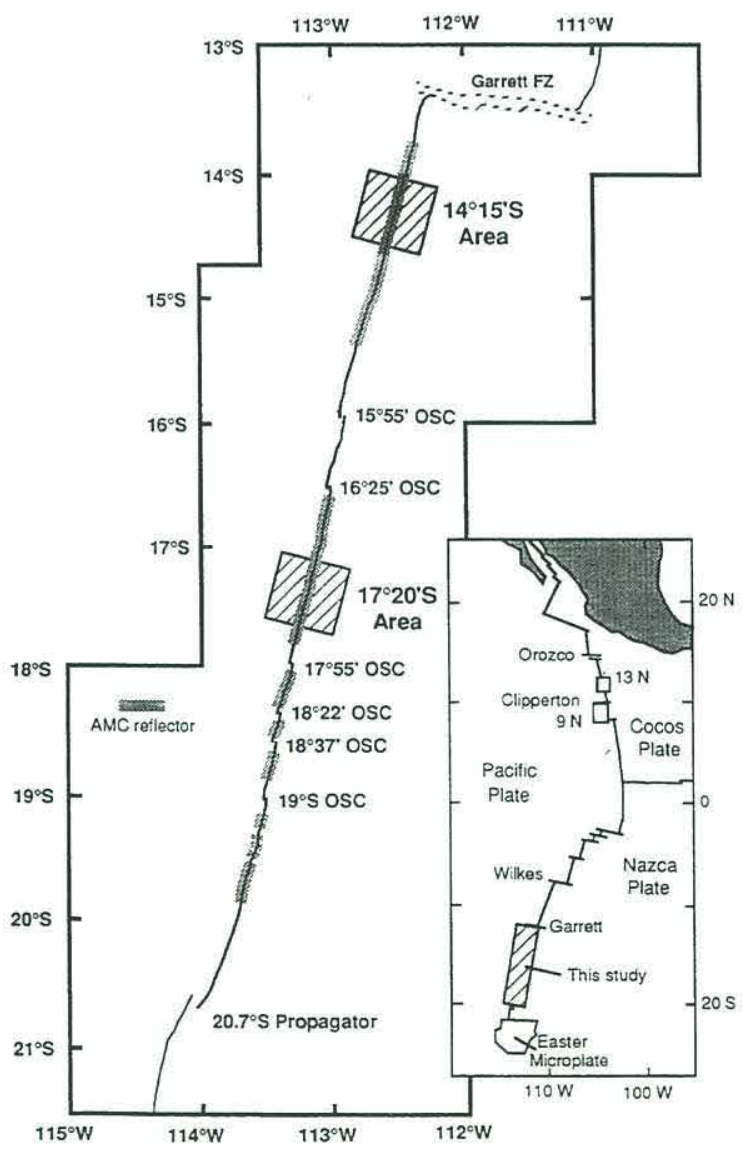

Figure 1. Tectonic map of southern East Pacific Rise (EPR) showing location of two detailed study areas at $14^{\circ} \mathrm{S}$ and $17^{\circ} \mathrm{S}$. Shaded portions of rise axis indicate where magma chamber reflector was observed by Detrick et al. [1993]. 

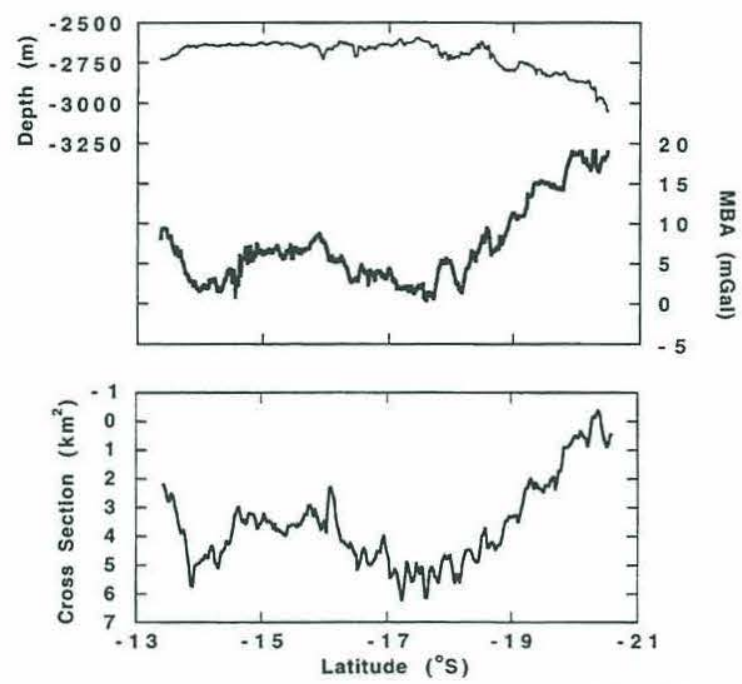

Figure 2. Variation in axial depth (light line), mantle Bouguer anomaly (MBA) (heavy line), and (bottom) cross-sectional area of axial high along the EPR south of the Garrett transform. Cross-sectional area estimates are from Scheirer and Macdonald [1993]. Note the good correlation between along-axis variations in MBA and axial cross-sectional area with the broadest sections of ridge associated with the most negative MBA. Between $14^{\circ} \mathrm{S}$ and $18^{\circ} \mathrm{S}$ axial depth is approximately constant and not well correlated with either MBA or axial cross-sectional area.

There is also a regional, across-axis asymmetry in both bathymetry and gravity along this section of the EPR that has been attributed to higher mantle temperatures to the west of the rise axis [Cormier and Macdonald, 1993].
A two-ship multichannel seismic reflection (MCS) and refraction experiment was conducted along the SEPR in 1991 [Detrick et al., 1993]. MCS reflection, gravity, and Hydrosweep multibeam bathymetry data were obtained on a composite alongaxis profile extending from the Garrett fracture zone at $13.4^{\circ} \mathrm{S}$ to the $20.7^{\circ} \mathrm{S}$ propagating rift. More detailed seismic reflection, refraction and gravity data were obtained in two areas, one centered at $14^{\circ} 15^{\prime} \mathrm{S}$ and a second located near $17^{\circ} 20^{\prime} \mathrm{S}$ (Figure 1). These areas were selected because they represent "normal" sections of the ridge, relatively far from the influence of transforms, overlapping spreading centers, or other major ridge axis discontinuities. They are also centered over areas where the ridge axis is broad and shallow [Scheirer and Macdonald, 1993] suggesting a relatively robust magma supply (Figure 2).

These seismic data [Detrick et al., 1993; Kent et al., 1994] provide excellent constraints on the crustal structure of this portion of the EPR (Figure 3). In both the $14^{\circ} \mathrm{S}$ and $17^{\circ} \mathrm{S}$ areas, the rise axis is underlain by a thin $(\sim 175 \mathrm{~m})$ extrusive volcanic layer (seismic layer $2 \mathrm{~A}$ ) that approximately doubles in thickness within a few kilometers of the rise axis. A narrow ( $<1 \mathrm{~km}$ wide), thin $(<100 \mathrm{~m})$ melt lens is located $\sim 1 \mathrm{~km}$ below the seafloor and is believed to mark the top of an axial magma chamber (AMC). Near $17^{\circ} 25^{\prime} \mathrm{S}$ the AMC is unusually shallow $(<900 \mathrm{~m}$ below the seafloor [Detrick et al., 1993]) and submersible observations suggest this may be the site of recent or ongoing volcanic activity [Auzende et al., 1994]. Preliminary analyses of refraction data from both the $14^{\circ} \mathrm{S}$ and $17^{\circ} \mathrm{S}$ areas indicate the melt lens is underlain by a crustal low velocity zone similar to that observed along the northern EPR [Harding et al., 1989; Toomey et al., 1990; Vera et al., 1990]. Earlier studies have suggested this lowvelocity zone is largely solidified, but associated with elevated crustal temperatures [Caress et al., 1992; Solomon and Toomey, 1992]. Moho reflections are observed on some reflection profiles and can be traced to within a kilometer of the melt lens [Kent et

Finite Difference Migration: SEPR 70

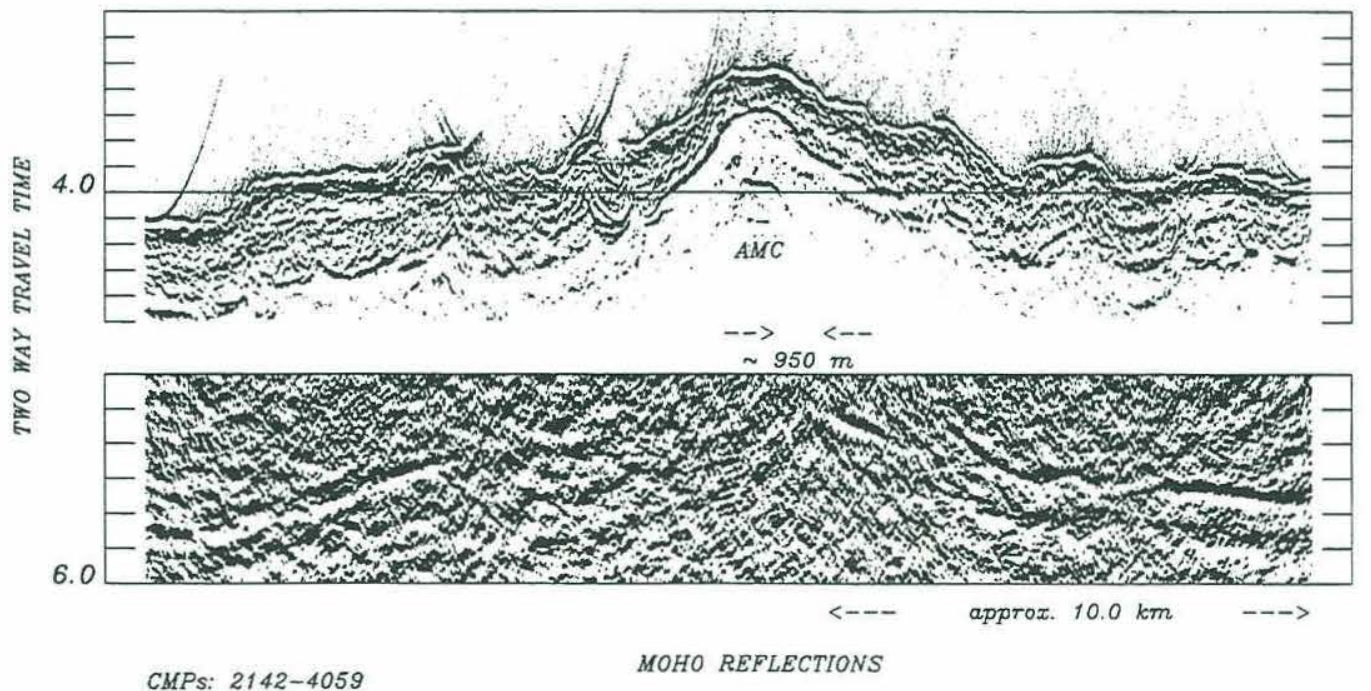

Figure 3. Migrated seismic profile of the southern East Pacific Rise (SEPR) line 70 across the EPR at $14^{\circ} 20^{\prime} \mathrm{S}$ displayed in two windows of different gains to enhance both shallow and depth (Moho) reflectors [from Kent et al., 1994]. Note the rapid off-axis thickening of the reflection from the base of seismic layer $2 \mathrm{~A} 0.25-0.50 \mathrm{~s}$ below the seafloor, the narrow $(\sim 1 \mathrm{~km}$ wide) magma chamber reflector at $\sim 1 \mathrm{~km}$ depth beneath the rise axis, and the Moho reflection which approximately parallels the seafloor and can be traced to within a kilometer of the ridge axis. 
al., 1994]. The available data indicate a remarkably uniform crustal structure and thickness along this section of the EPR [Kent et al., 1994].

\section{Free-Air and Mantle Bouguer Anomalies}

The gravity data used in this study were collected aboard the R/V Maurice Ewing during the SEPR seismic experiment using a Bodenseewerk KSS-30 marine gravimeter mounted on a gyrostabilized platform. Gravity measurements were logged every 6 s. The raw gravity data were smoothed with a 3-min weighted average filter to remove ship motions and were resampled at 1 . min intervals (the KSS-30 meter is not subject to cross-coupling errors). Speed and true heading were derived from Global Positioning System (GPS) satellite navigation and used to apply an Eötvös correction. A theoretical gravity field calculated from the 1980 Geodetic Reference System [Moritz, 1984] was removed from the observed gravity values to derive a free-air anomaly. Uncertainties in the free-air anomaly data were estimated from the distribution of cross-over errors found from all intersecting lines in the two detailed survey areas (Figure 4). In the $14^{\circ} \mathrm{S}$ area, the standard deviation $(\sigma)$ of the 166 crossover errors was $1.62 \mathrm{mGal}$; in the $17^{\circ} \mathrm{S}$ area the 230 crossover points had a $\sigma$ of $1.27 \mathrm{mGal}$.

Bathymetry and free-air anomaly maps for the $14^{\circ} \mathrm{S}$ and $17^{\circ} \mathrm{S}$ areas are shown in Figures 5a, 5b, 6a, and 6b. These maps were produced from the swath bathymetry and gravity data by resampling the original data onto grids with a $400 \mathrm{~m}$ spacing for bathymetry and an $800 \mathrm{~m}$ spacing for the free-air anomaly using a minimum curvature algorithm [Smith and Wessel, 1990]. There is a clear correspondence between features observed in the bathymetry and gravity maps. The axial topographic high is $\sim 10-$ $15 \mathrm{~km}$ wide and stands $300-500 \mathrm{~m}$ above the surrounding seafloor. It is associated with a gravity high that is somewhat broader ( $20-30 \mathrm{~km}$ wide) and $\sim 15 \mathrm{mGal}$ in amplitude. A few small, near-axis seamounts are present in both areas. There is little along-axis variation in either bathymetry or gravity within these small areas. As previously noted by Cormier and Macdonald [1993] there is a distinct across-axis E-W asymmetry in both depth and gravity with shallower depths and more negative free-air anomalies west of the rise axis. The axial topographic high and free-air anomaly associated with the rise axis in these areas are very similar to those observed along other sections of the EPR (at $8^{\circ} \mathrm{S}, 9^{\circ} \mathrm{N}, 13^{\circ} \mathrm{N}$ ) where detailed gravity studies have been conducted [Madsen et al., 1990; Wang and Cochran, 1993; Wang et al., submitted manuscript, 1994].

a)

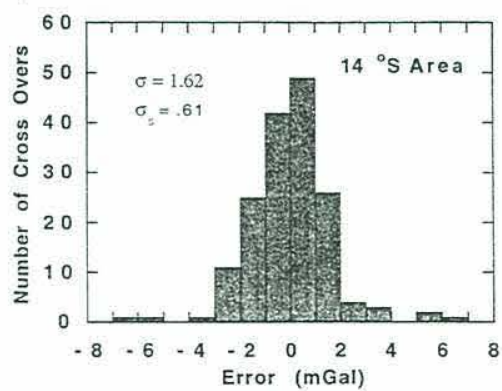

The largest contribution to the free-air anomaly observed at ridge crests comes from variations in water depth. In order to investigate more subtle variations in crustal or upper mantle density, or variations in crustal thickness, a common procedure is to calculate the mantle Bouguer anomaly (MBA) [Kuo and Forsyth, 1988; Prince and Forsyth, 1988]. The MBA is obtained by subtracting from the observed free-air anomaly the predicted gravity signature for a uniform thickness $(6 \mathrm{~km})$, constant density $\left(2.7 \mathrm{Mg} / \mathrm{m}^{3}\right)$ crust overlying a $3.3 \mathrm{Mg} / \mathrm{m}^{3}$ mantle referenced to the observed bathymetry. Although the MBA involves assumptions that are clearly incorrect at the EPR (as we will show below), it is a useful starting point for the analysis of these data and facilitates comparison with other studies that have used this approach.

MBA maps for the $14^{\circ} \mathrm{S}$ and $17^{\circ} \mathrm{S}$ areas are shown in Figures $5 \mathrm{c}$ and $6 \mathrm{c}$. The axial gravity high has been overcompensated by this correction, leaving a broad MBA low of -6 to $-10 \mathrm{mGal}$ centered on the ridge axis. The negative value of the MBA indicates an excess of low density material as compared to the constant thickness, constant density crustal model. The magnitude of the MBA low observed in the $14^{\circ} \mathrm{S}$ and $17^{\circ} \mathrm{S}$ areas is similar to that reported by Madsen et al. [1990] and Wang et al. (submitted manuscript, 1994) from the northern EPR and by Wang and Cochran [1993] from the EPR at $8^{\circ} \mathrm{S}$. There is comparatively little along-axis variation in MBA in the $14^{\circ} \mathrm{S}$ and $17^{\circ} \mathrm{S}$ areas, even over the shallow AMC reflector at $17^{\circ} 20^{\prime} \mathrm{S}$. However, on a larger scale the axial MBA varies by $10-15 \mathrm{mGal}$ along the SEPR (Figure 2). As noted by Cormier and Macdonald [1993] the MBA becomes systematically more positive between $18^{\circ} \mathrm{S}$ and the $20.7^{\circ} \mathrm{S}$. A similar but shorter wavelength increase in the MBA is observed toward the Garret transform at $13.5^{\circ} \mathrm{S}$. However, even along sections of the SEPR not bounded by large ridge offsets (e.g., between $14^{\circ} \mathrm{S}$ and $17^{\circ} \mathrm{S}$ ), variations in MBA of $>5 \mathrm{mGal}$ occur where the axial depth is essentially constant. Both the long- and short-wavelength variations in MBA correlate well with along-axis changes in Scheirer and Macdonald's [1993] estimate of the cross-sectional area of the axial high (Figure 2). This correlation suggests that changes in the width of the axial high and along-axis variations in gravity have a similar origin.

The MBA anomaly low observed at the EPR can be partially explained by crustal and mantle density changes due to the cooling of the lithosphere with age. Following Kuo and Forsyth [1988] we have used the plate-driven, passive-flow model of Phipps Morgan and Forsyth [1988] to calculate the gravity effect of temperature variations due to lithospheric cooling and have

b)

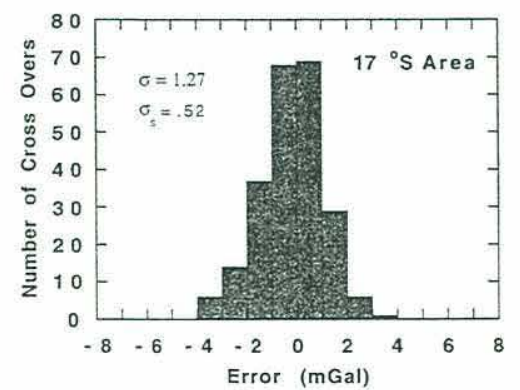

Figure 4. Histograms of crossover errors for (a) 166 track crossings in the $14^{\circ} \mathrm{S}$ area and (b) 230 track crossings in the $17^{\circ} \mathrm{S}$ area. One standard deviation of the error distribution $(\sigma)$ is $1.62 \mathrm{mGal}$ in the $14^{\circ} \mathrm{S}$ area and $1.27 \mathrm{mGal}$ in the $17^{\circ} \mathrm{S}$ area. Standard deviations calculated for the stacked profiles $\left(\sigma_{\mathrm{S}}\right)$ in each area are also included. 
a)

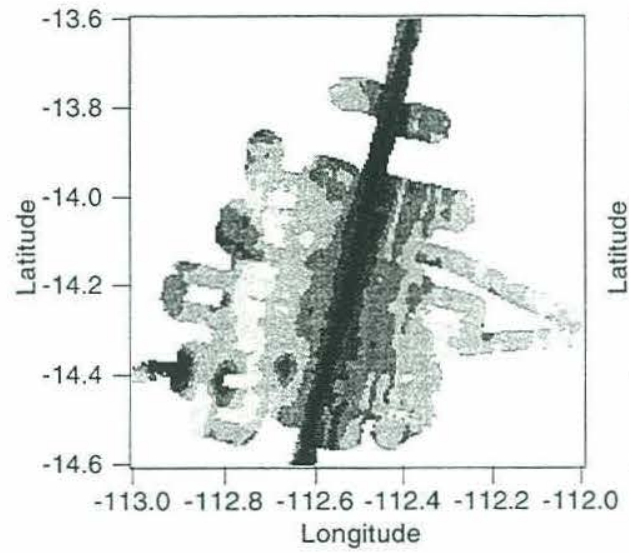

c) Mantle Bouguer Anomaly (mGal)

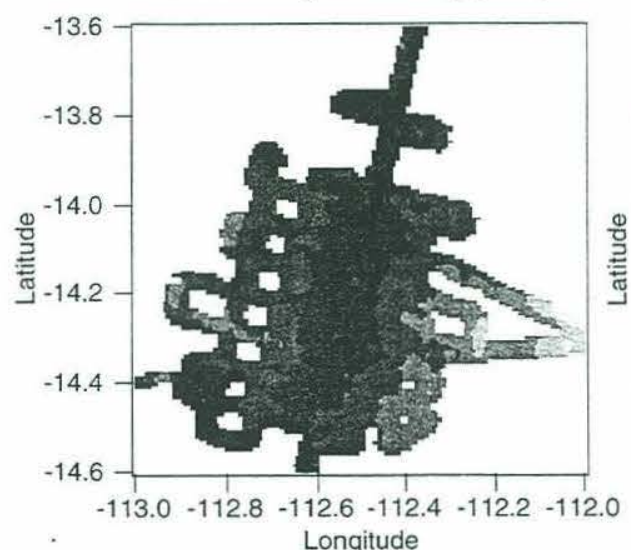

Longitude b) Free Air Gravity (mGal)

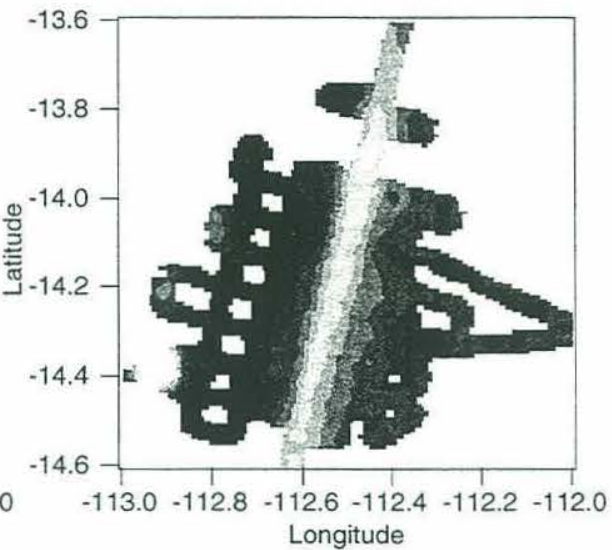

d)

Residual MBA Gravity (mGal)

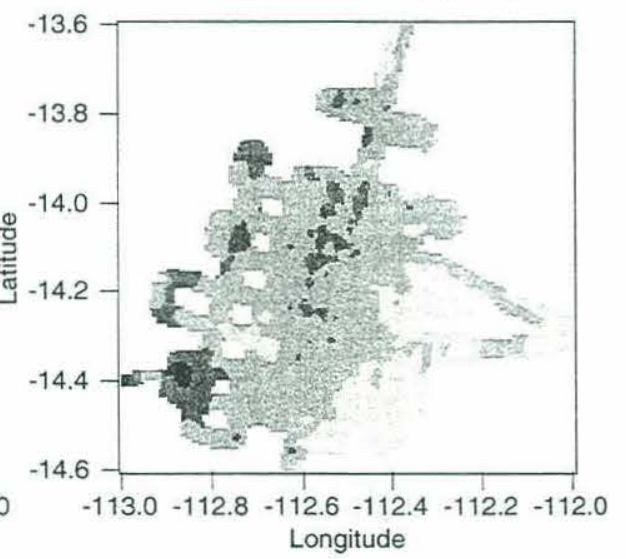

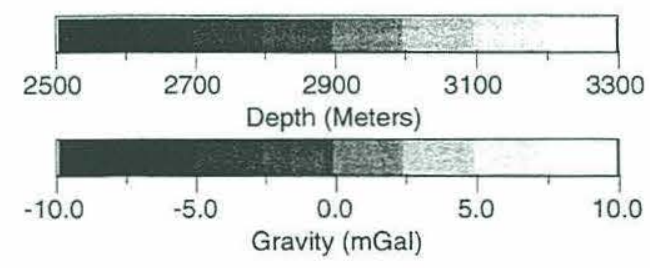

Figure 5. Results of gravity analysis in the $14^{\circ} \mathrm{S}$ area. (a) observed bathymetry (contour interval $100 \mathrm{~m}$ ), (b) observed free-air anomaly (contour interval $2.5 \mathrm{mGal}$ ), (c) mantle Bouguer anomaly (contour interval $2.5 \mathrm{mGal}$ ), and (d) residual mantle Bouguer anomaly (contour interval $2.5 \mathrm{mGal}$ ).

subtracted this anomaly from the MBA. The resulting residual MBA (RMBA) is shown in Figures 5d and 6d. A RMBA of approximately -3 to $-4 \mathrm{mGal}$ is observed at the ridge axis in these two areas, comparable to that reported by Madsen et al. [1990] from the northern EPR. Thus about half of the MBA observed at the SEPR can be explained by lithospheric cooling at the ridge axis, but there is still a significant body of low density material that has not been accounted for by these corrections.

\section{Crustal and Mantle Contributions to the Axial Gravity Anomaly}

The negative RMBA observed at the EPR indicates that the assumptions that went into the calculation (constant thickness crust, and density variations predicted only by lithospheric cooling for a simple, plate-driven mantle flow model) are not correct. The largest effect ignored in the MBA calculation is the 

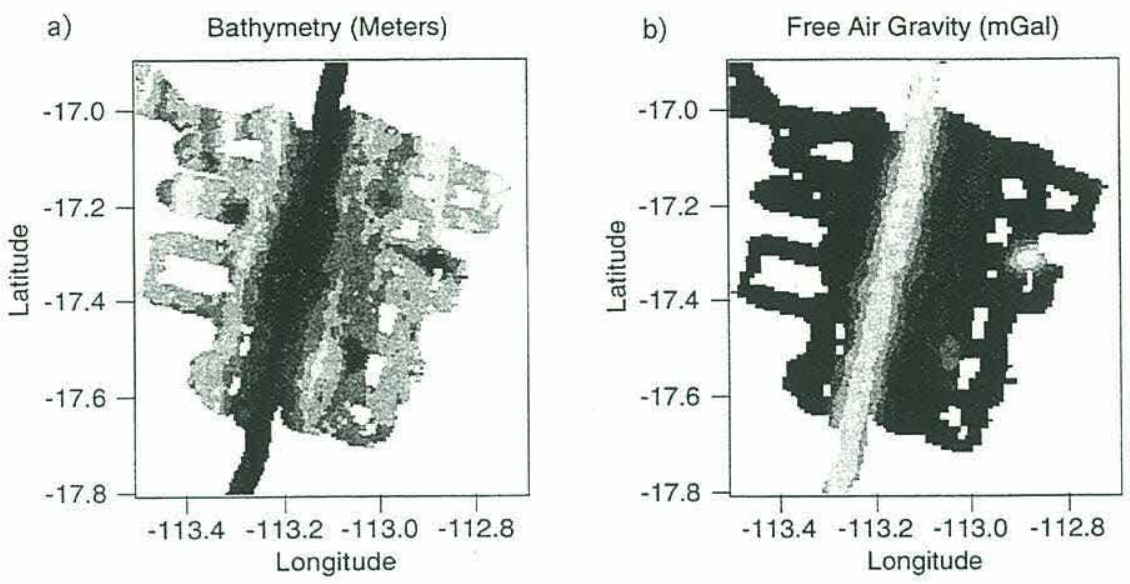

c) Mantle Bouguer Anomaly (mGal)

d) Residual MBA Gravity (mGal)
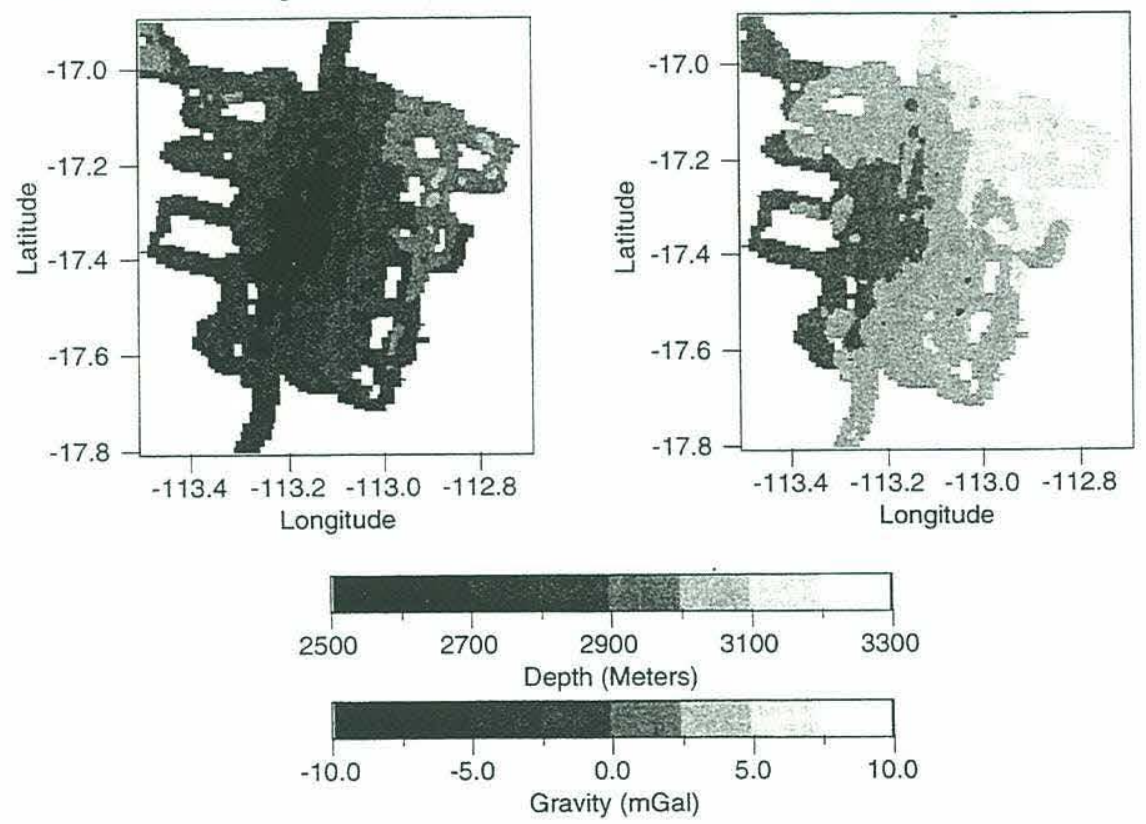

Figure 6. Results of gravity analysis in the $17^{\circ} \mathrm{S}$ area. (a) observed bathymetry (contour interval $100 \mathrm{~m}$ ), (b) observed free-air anomaly (contour interval $2.5 \mathrm{mGal}$ ), (c) mantle Bouguer anomaly (contour interval $2.5 \mathrm{mGal}$ ), and (d) residual mantle Bouguer anomaly (contour interval $2.5 \mathrm{mGal}$ ).

presence of a region of partial melt and elevated temperatures in the mid-to-lower crust beneath the rise axis [Sinton and Detrick, 1992]. This will result in lower crustal densities in the axial region than at comparable crustal depths off axis. The rapid offaxis thickening of layer $2 \mathrm{~A}$ documented seismically at the EPR [Christeson et al., 1992; Harding et al., 1991; Kent et al., 1994; Vera and Diebold, 1994] will also contribute to a small variation in crustal density with age that is not accounted for in the MBA calculation. In addition, RMBA corrections made using simple lithospheric cooling models do not account for the effects of hydrothermal circulation on crustal temperatures. The effects of both melt extraction [Oxburgh and Parmentier, 1977] and melt retention in the upwelling mantle are also ignored in this calculation.

To assess the relative importance of these various effects on the origin of the gravity anomaly observed at the EPR, we carried out forward gravity calculations for several possible crustal and upper mantle density models. Although these calculations are model-dependent and thus nonunique, we believe they are useful in isolating the relative importance of these various effects. We 
will model the observed free-air anomaly and bathymetry rather than MBA or RMBA. To facilitate this modeling, we use stacked (averaged) and mirrored bathymetric and gravity profiles from the $14^{\circ} \mathrm{S}$ and $17^{\circ} \mathrm{S}$ areas (seamounts were excluded). The axial crustal structure is relatively two-dimensional in these areas [Kent et al., 1994], and by stacking the profiles we average out features not common to all profiles. This procedure also averages the E-W asymmetry in gravity and bathymetry across the EPR in this area noted above (see Figures 5 and 6). The stacked profiles show an $\sim 400 \mathrm{~m}$ axial topographic high with a half width of $\sim 10 \mathrm{~km}$ that is associated with a positive free-air gravity high of about $15 \mathrm{mGal}$ (Figure 7). A 95\% uncertainty $\left(2 \sigma_{\mathrm{s}}\right)$ of $\pm 1.2 \mathrm{mGal}$ in the $14^{\circ} \mathrm{S}$ area and of $\pm 1.0 \mathrm{mGal}$ in the $17^{\circ} \mathrm{S}$ area has been assigned to the gravity profiles (shown by dashed lines throughout this paper). These uncertainty intervals are based on the standard deviation of the crossover errors shown in Figure 4 scaled by the square root of the number of stacked profiles in each area (seven profiles in the $14^{\circ} \mathrm{S}$ area, six profiles in the $17^{\circ} \mathrm{S}$ area).

\section{Modeling Crustal Density Anomalies}

\section{Variation in Layer 2A Thickness}

Seismic studies along both the northern [Christeson et al., 1992; Harding et al., 1991; Vera and Diebold, 1994] and southern EPR [Kent et al., 1994] have documented an approximate doubling in the thickness of seismic layer $2 \mathrm{~A}$ within
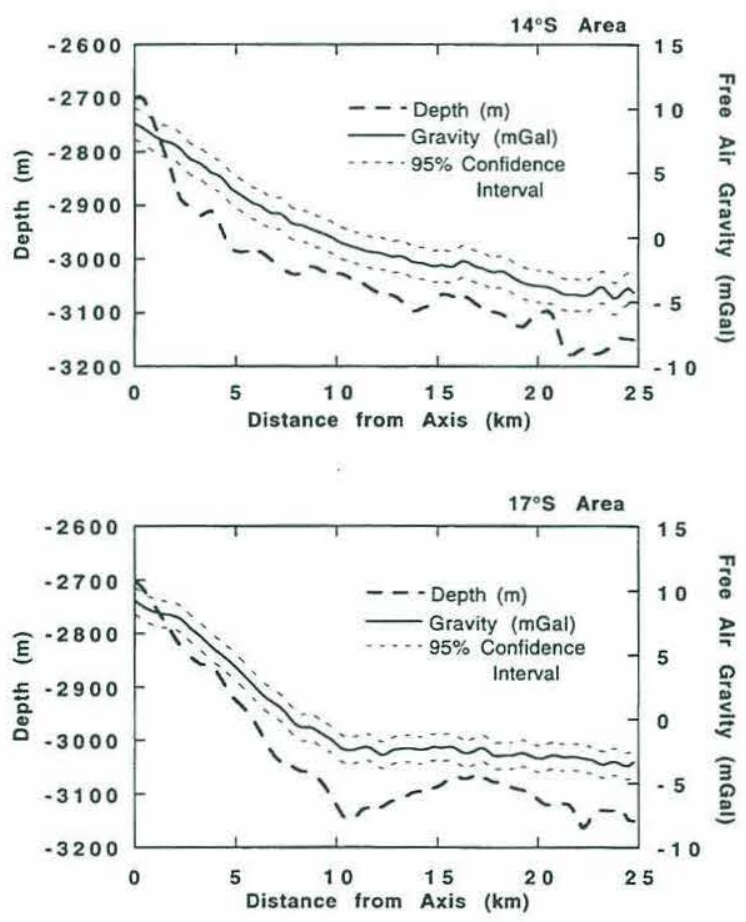

Figure 7. Stacked bathymetry and free-air gravity profiles for the $14^{\circ} \mathrm{S}$ and $17^{\circ} \mathrm{S}$ areas. The dashed lines represent $95 \%$ uncertainty estimates derived from the cross-over errors shown in Figure 4. The rise axis in both areas is characterized by a 300 to $500 \mathrm{~m}$ high topographic high with a half width of $10-15 \mathrm{~km}$ and an $\sim 15 \mathrm{mGal}$ free-air anomaly.
1-2 $\mathrm{km}$ of the rise axis (see Figure 3). Layer $2 \mathrm{~A}$ is interpreted as the extrusive layer and is characterized by low seismic velocities $(2.5-5.5 \mathrm{~km} / \mathrm{s})$ that suggest both high bulk crustal porosities and low densities [Harding et al., 1993; Vera and Diebold, 1994]. On-bottom gravity measurements at the Juan de Fuca Ridge [Stevenson et al., 1994] were used to estimate the density of this near-surface layer to be about $2.6 \mathrm{Mg} / \mathrm{m}^{3}$ and a similar experiment at $9^{\circ} \mathrm{N}$ on the EPR (J. M. Stevenson and J. A. Hildebrand, A seafloor gravity survey of the East Pacific Rise at $9^{\circ} 50^{\prime} \mathrm{N}$, submitted to Journal of Geophysical Research, 1994) resulted in a density estimate of only $2.4 \mathrm{Mg} / \mathrm{m}^{3}$.

The off-axis thickening of this low density extrusive layer will result in a relative gravity high at the rise axis that will be underestimated by the MBA correction. To determine the magnitude of this effect, we have modeled the gravity signature of three different layer $2 \mathrm{~A}$ structural crosssections based on multichannel seismic lines in this region [Kent et al., 1994]. In each case, the density of the lower crust was taken to be 2.8 $\mathrm{Mg} / \mathrm{m}^{3}$, and the density of layer $2 \mathrm{~A}$ was varied between 2.8 and $2.4 \mathrm{Mg} / \mathrm{m}^{3}$. Even assuming a density as low as $2.4 \mathrm{Mg} / \mathrm{m}^{3}$ for layer $2 \mathrm{~A}$, the maximum gravity anomaly associated with the thickening of layer $2 \mathrm{~A}$ off axis is only about $0.5 \mathrm{mGal}$. Since the uncertainty in the stacked free-air anomaly profiles is estimated above to be about $\pm 1 \mathrm{mGal}$, the effect of the thickening of layer $2 \mathrm{~A}$ off-axis is too small to be resolved in our data; therfore we have ignored it in the following analysis.

\section{Elevated Temperatures in the Lower Crust}

The presence of a region of elevated temperatures in the midto-lower crust beneath the rise axis, as is assumed in most recent geological models of the EPR [e.g., Sinton and Detrick, 1992], will significantly lower average crustal densities relative to those observed off axis, potentially explaining at least a portion of the MBA low observed at the rise axis. Previous investigators have used various approaches to estimate the magnitude of this effect. Madsen et al. [1990] assumed a simple trapezoidal body and calculated the gravity anomaly for a range of density contrasts. Wilson [1992] used a thermal model in which hydrothermal heat removal in the upper crust and magmatic heat input were adjusted to yield subsolidus temperatures in the crust at distances greater than $3 \mathrm{~km}$ from the rise axis (which was, at the time, thought to be the width of the magma sill as reported by Detrick et al. [1987]).

Here we use the two-dimensional crustal thermal structure predicted from two sill injection models of crustal formation, one proposed by Phipps Morgan and Chen [1993], hereafter referred to as PM\&C, and the other from Henstock et al. [1993], hereafter referred to as HEN. These models were chosen because they are consistent with recent seismic constraints on the crustal structure of the EPR that show the existence of a thin lens of melt overlying a lower crust that is mostly solidified [Solomon and Toomey, 1992] and because they explicitly incorporate the effects of hydrothermal cooling on axial thermal structure. Both models kinematically explain the formation of the lower crust by sill injection at high crustal levels and sub-solidus flow of the crystallizing gabbro down and flankward from this body, while the upper crust is formed by dike injection and eruption of lava from this mid-crustal magma body.

Although kinematically similar, there are some differences between the two models. They both assume that the lower crust is formed from the intrusion of sills at the boundary between the dike and gabbro portions of the crust and that all latent heat for 
Table 1. Crustal Density Model Parameters

\begin{tabular}{lll}
\hline \multicolumn{1}{c}{ Parameter } & PM\&C Model & HEN Model \\
\hline Spreading rate, $\mathrm{mm} / \mathrm{yr}$ & 160 & 160 \\
Thickness of Gabbro, $\mathrm{km}$ & 5 & 5 \\
Depth to melt sill, $\mathrm{km}$ & 1 & 1 \\
Width of melt sill, $\mathrm{km}$ & 1 & 1 \\
Crustal viscosity & variable & constant \\
Thermal diffusivity $\mathrm{\kappa}, \mathrm{m}^{2} / \mathrm{s}$ & $10^{-6}$ & $7 \times 10^{-7}$ \\
Latent heat of fusion $L, \times 10^{5} \mathrm{~J} / \mathrm{kg}$ & 3.34 & 3.40 \\
Thermal expansion & & 3.0 \\
$\quad$ coefficient $\alpha, \mathrm{x} 10^{-5}{ }^{\circ} \mathrm{C}^{-1}$ & 3.0 & 3.0 \\
\hline
\end{tabular}

The PM\&C model is that of Phipps Morgan and Chen [1993], and the HEN model is that of Henstock et al. [1993].

the underlying gabbro section is released in the sill. The PM\&C model assumes a steady state magma lens $1 \mathrm{~km}$ wide and $250 \mathrm{~m}$ thick with a depth controlled by the magma solidus (taken to be $1200^{\circ} \mathrm{C}$ ) while $\mathrm{HEN}$ assumes episodic injection every 50 years of a magma lens $2 \mathrm{~km}$ wide, $20 \mathrm{~m}$ thick, and $1 \mathrm{~km}$ below the seafloor (based on the periodicity suggested by Macdonald [1982]). PM\&C includes a variable viscosity lower crust, while

\section{PM\&C Crustal Model}
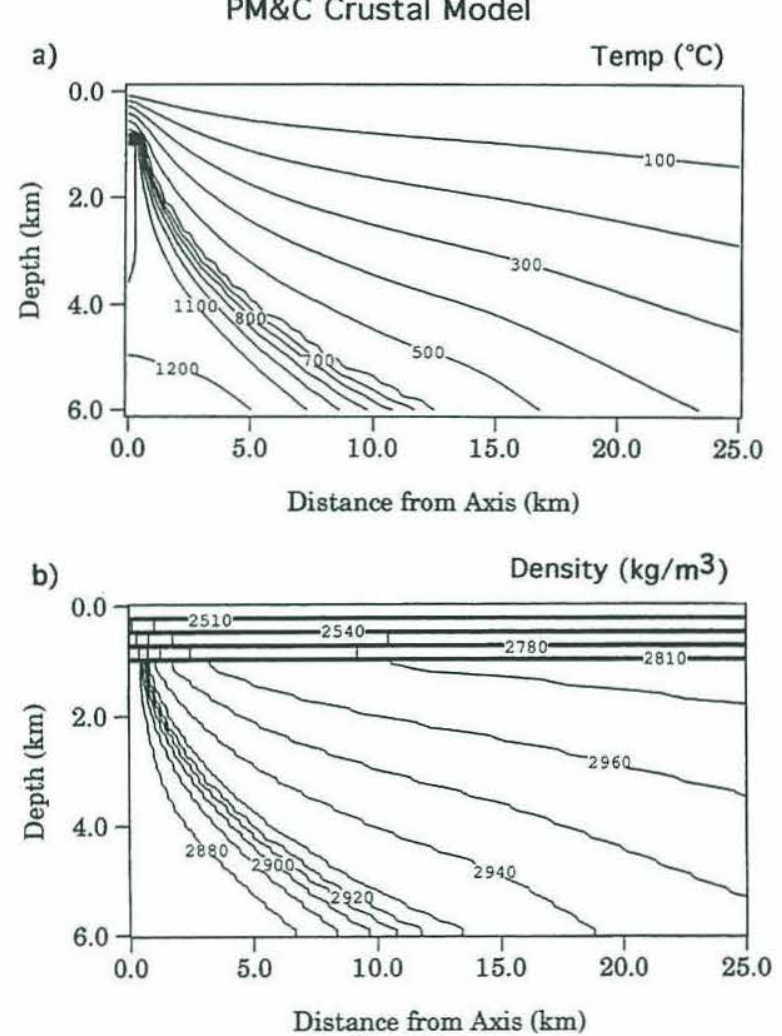

HEN assumes a constant viscosity lower crust. In both models, the temperature structure is calculated from the balance between heat input (material injected into the sill and heat conducted into the crust from the mantle) with heat output (convected to the sea via hydrothermal circulation and advected away with crust leaving the sill). Hydrothermal cooling is simulated in both models by an enhanced thermal diffusivity; however in the HEN model, hydrothermal cooling is restricted to the upper (dike/lava) section of the crust, while in the PM\&C model, hydrothermal cooling can extend to the base of the crust. The two models also use different values for the background level of thermal diffusivity $\left(10^{-6} \mathrm{~m}^{2} / \mathrm{s}\right.$ for PM\&C and $7 \times 10^{-7} \mathrm{~m}^{2} / \mathrm{s}$ for HEN) Because of these differences both models were investigated in an attempt to see how sensitive the magnitude of the crustal density signal is to these different assumptions.

The model parameters used in this study are summarized in Table 1. The PM\&C crustal temperature model was gridded with $250 \mathrm{~m}$ spacing in $x$ and $z$ and extended $6 \mathrm{~km}$ deep and $25 \mathrm{~km}$ off axis while the HEN temperature model was gridded with a $50 \mathrm{~m}$ spacing and extended $6 \mathrm{~km}$ deep and $20 \mathrm{~km}$ off axis (Figure 8). Differences in grid spacing did not have a significant effect on the accuracy of the resulting gravity calculations, but in both cases the stated resolution was retained throughout. The models were run for a full spreading rate of $160 \mathrm{~mm} / \mathrm{yr}$, an assumed
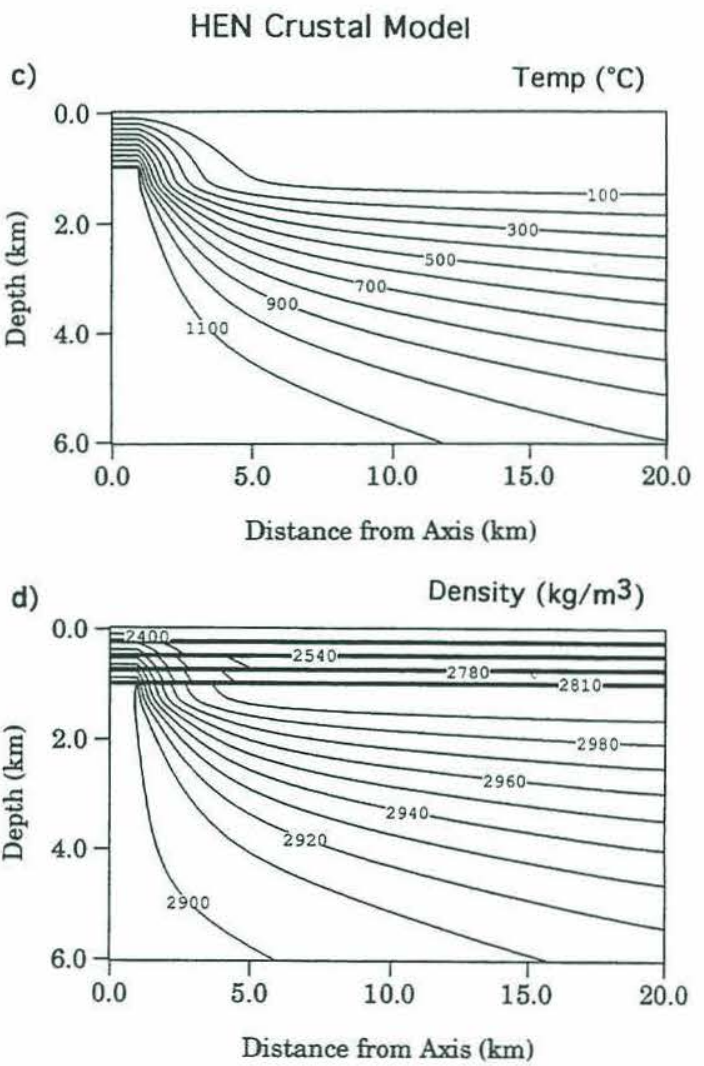

Figure 8. (a) Temperatures and (b) derived densities for the PM\&C [Phipps Morgan and Chen, 1993] crustal thermal model, and (c) and (d) for the HEN [Henstock et al., 1993] crustal thermal model for a cross-axis profiles extending $25 \mathrm{~km}$ and $20 \mathrm{~km}$ off axis, respectively. Densities were derived from temperature using a reference crustal density model from Carlson and Herrick [1990] using a thermal expansion coefficient of $3.0 \times 10^{-5}{ }^{\circ} \mathrm{C}^{-1}$. Vertical exaggeration is 2:1. 
crustal thickness of $6 \mathrm{~km}$, and a melt lens depth of $1 \mathrm{~km}$, as constrained by seismic observations at the SEPR (see Figure 3).

The crustal temperature and density distributions for these two models are shown in Figure 8. Temperatures were converted to crustal density using a uniform thermal expansion coefficient $(\alpha)$ of $3.0 \times 10^{-5}{ }^{\circ} \mathrm{C}^{-1}$. Reference densities were selected for each crustal layer so that the density structure away from the axis matched the global averages summarized by Carlson and Herrick [1990]. Layer 2 was split into four, 250-m-thick layers with densities (top to bottom) of $2.4 \mathrm{Mg} / \mathrm{m}^{3}, 2.53 \mathrm{Mg} / \mathrm{m}^{3}, 2.67 \mathrm{Mg} / \mathrm{m}^{3}$, and $2.8 \mathrm{Mg} / \mathrm{m}^{3}$ to approximate a gradient in density with depth. Layer 3 was referenced to a uniform density of $2.95 \mathrm{Mg} / \mathrm{m}^{3}$. The choice of reference densities has little effect on the resulting gravity anomaly or isostatic topography since only lateral variations in density contribute to either of these calculations.

The calculated temperature and density distributions for the two models are generally similar. Both models predict a triangular-shaped region of high temperatures $\left(>1100^{\circ} \mathrm{C}\right)$ and anomalously low density $\left(<2.90 \mathrm{Mg} / \mathrm{m}^{3}\right)$ beneath the melt lens that extends to the base of the crust. Off axis, temperatures gradually decrease and densities increase as the crust cools. In the PM\&C model, the hot, low-density region beneath the melt lens is narrower and associated with a larger temperature anomaly than in the HEN model. Off axis, the HEN model is hotter than the PM\&C model at comparable depths. These differences are a consequence of the different assumptions made in the two models about the depth extent of hydrothermal circulation. By allowing hydrothermal circulation to extend to the base of the crust, PM\&C cools the crust more rapidly. Note that the width of the hot, low-density region beneath the melt lens in both models approximately corresponds to the width of the axial topographic high in Figure 7.

In order to calculate the gravity anomaly associated with the density models shown in Figure 8, the density models were extended to $40 \mathrm{~km}$ off axis by repetition of the far-axis reference density structure assuming the water depth follows a square root of time subsidence curve appropriate for this area. The free-air anomaly was calculated using the two-dimensional line integral method of Talwani et al. [1959], assuming a uniform density of $1.0 \mathrm{Mg} / \mathrm{m}^{3}$ for water and $3.3 \mathrm{Mg} / \mathrm{m}^{3}$ for mantle. In each case, the structure was mirrored about the ridge axis, so both ridge flanks were included. To prevent edge effects, the density model was continued to $\pm 1500 \mathrm{~km}$ from the ridge axis and to depths of 200 $\mathrm{km}$.

The predicted gravity anomalies for the PM\&C and HEN crustal density models are shown in Figures 9 and 10 for the $14^{\circ} \mathrm{S}$ and $17^{\circ} \mathrm{S}$ areas, respectively. They are compared with the observed free-air anomalies and the anomaly predicted assuming the same uniform density $\left(2.8 \mathrm{Mg} / \mathrm{m}^{3}\right)$, constant thickness crust (UDC) used to calculate the MBA. In both areas, the UDC model overpredicts the axial gravity high by $8-10 \mathrm{mGal}$, resulting in a large negative MBA as noted earlier. The higher temperatures and lower densities in the lower crust predicted by both the PM\&C and HEN crustal models reduce the amplitude of this anomaly by $6-7 \mathrm{mGal}$, an $\sim 70 \%$ improvement over the UDC model. We therefore conclude that a significant part (but not all) of the MBA low observed at the EPR is due to temperaturerelated density variations within the crust. The remaining gravity anomaly must therefore be attributed to density variations in the mantle. There appears to be a small difference in the magnitude of this mantle contribution between the $14^{\circ} \mathrm{S}$ and $17^{\circ} \mathrm{S}$ areas with the more negative residual anomaly in the $17^{\circ} \mathrm{S}$ area suggesting slightly lower mantle densities in this area.
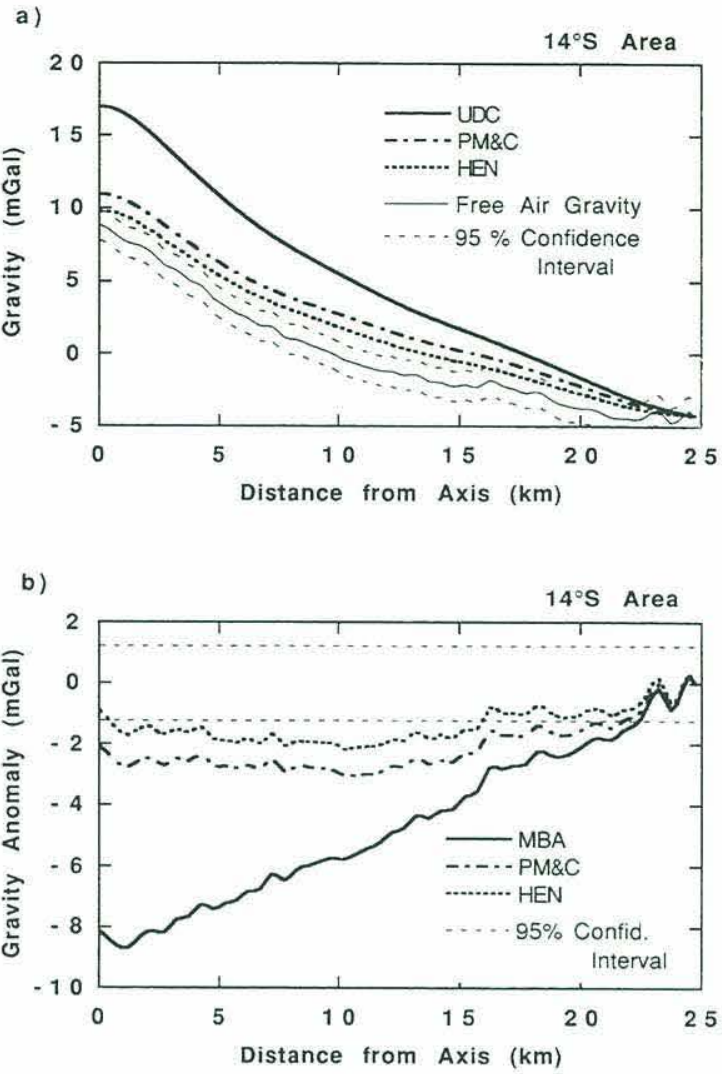

Figure 9. (a) Stacked free-air anomaly profile for the $14^{\circ} \mathrm{S}$ area compared with predicted free-air anomaly for PM\&C [Phipps Morgan and Chen, 1993] and HEN [Henstock et al., 1993] density models from Figure 8 . Also shown is the predicted freeair anomaly for a uniform density $\left(2.7 \mathrm{Mg} / \mathrm{m}^{3}\right)$, constant thickness $(6 \mathrm{~km})$ crust overlying a uniform density $\left(3.3 \mathrm{Mg} / \mathrm{m}^{3}\right)$ mantle (UDC). (b) The difference between each of the predicted gravity signatures and the observed free-air anomaly. The traditional mantle Bouguer anomaly (MBA) is derived by subtracting the UDC predicted gravity from the observed free-air anomaly. The horizontal dashed lines are the $95 \%$ uncertainty levels for the observed free-air anomaly. Note that about $70 \%$ of the MBA low can be explained by lower crustal densities in the axial region predicted by the PM\&C and HEN models.

The higher temperatures in the HEN crustal model compared to the PM\&C model (as a result of shallower depth of hydrothermal circulation) results in somewhat smaller (by $\sim 1$ $\mathrm{mGal}$ ) residual gravity anomalies. This observation reveals that our limited knowledge of the depth and extent of hydrothermal cooling introduces some uncertainty into our estimate of crustal contribution to the axial gravity anomaly. Another source of error in this estimate is the choice of a value for the thermal expansion coefficient $(\alpha)$. Here we have used $\alpha=3.0 \times 10^{-5}{ }^{\circ} \mathrm{C}^{-1}$ (similar to the value assumed by Wilson [1992]). However, Madsen et al. [1990] give a range of 2.5-3.5 $\times 10^{-5}$ for $\alpha$, while Wang and Cochran [1993] assume a value of $3.2 \times 10^{-5}$. If $\alpha$ were $15 \%$ higher than we have assumed, the crustal contribution to the observed MBA could be increased by about $0.75 \mathrm{mGal}$. A 

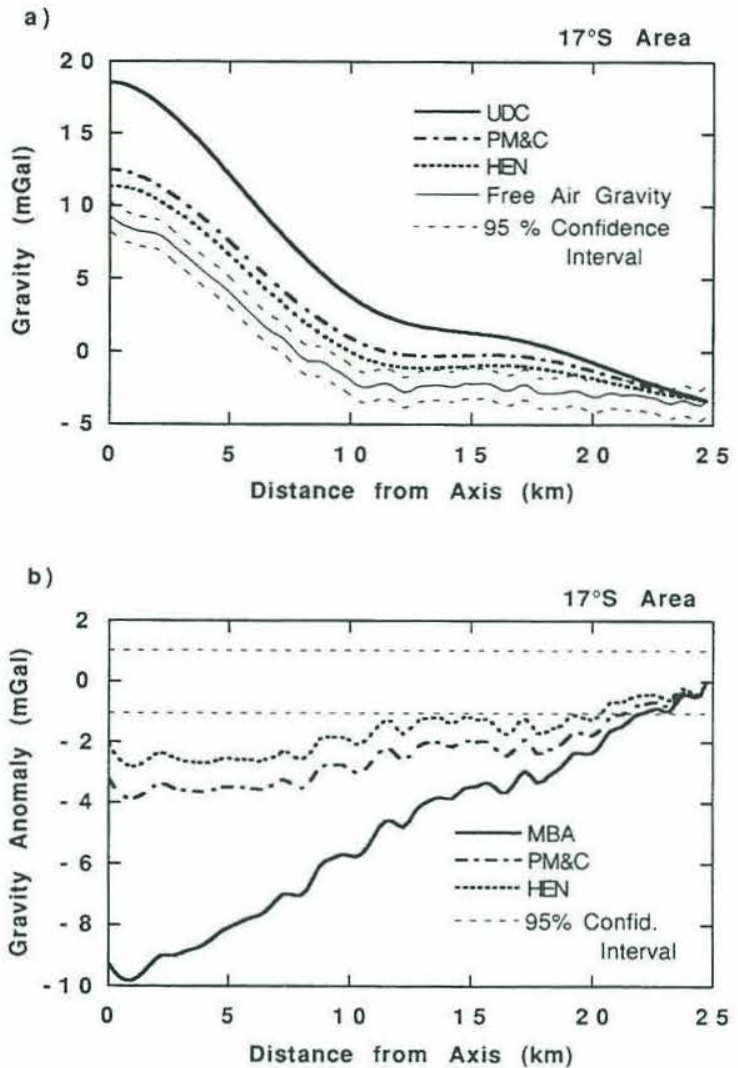

Figure 10. (a) Stacked free-air anomaly profile for the $17^{\circ} \mathrm{S}$ area compared with predicted free-air anomaly for PM\&C [Phipps Morgan and Chen, 1993] and HEN [Henstock et al., 1993] density models from Figure 8. (b) The difference between each of the predicted gravity signatures and the observed free-air anomaly. See Figure 9 for explanation of symbols.

more realistic uncertainty of $\pm 10 \%$ in $\alpha$ introduces an error of only about $0.5 \mathrm{mGal}$ in this calculation. Thus although there are some uncertainties in our estimate, they are small enough that it is clear that the low density region underlying the axial high must extend into the upper mantle. Using compensation depth arguments, Madsen et al. [1984], Wilson [1992], and Wang and Cochran [1993] have reached a similar conclusion.

\section{Modeling the Mantle Density Structure}

There are three possible sources of anomalously low mantle densities beneath the rise axis: (1) thermal expansion due to the presence of hotter mantle, (2) compositional density reductions due the extraction of partial melt which reduces the $\mathrm{Fe} / \mathrm{Mg}$ ratio of the residual mantle [Oxburgh and Parmentier, 1977], and (3) the presence of retained melt in the upwelling mantle. Modeling of these effects is complicated by the fact that the pattern of upwelling, and thus the distribution of anomalous mass due to these factors, is influenced by both the magnitude of these buoyancy forces and the viscosity structure of the upwelling mantle [Sparks et al., 1993a].

We will use the numerical flow model of Sparks et al. [1993b], incorporating the method of calculating melt fractions from Jha et al. [1994], (hereafter referred to as Sparks) to investigate the relative importance of these three factors on the gravity anomaly observed at the EPR. The Sparks model was used because, unlike simple lithospheric cooling models [Wilson et al., 1988] or mantle thermal structures calculated using a passive, plate-driven flow [Phipps Morgan and Forsyth, 1988], it explicitly includes the effects of thermal, compositional, and melt retention buoyancy and determines both the buoyant and platedriven components of the flow. The major simplifying assumption in the Sparks model is that the viscosity in the upwelling asthenosphere is constant. We will consider the implications of a variable mantle viscosity for our results in a later section.

The model parameters assumed in this study are summarized in Table 2. All models were run with a constant viscosity halfspace $\left(5 \times 10^{18} \mathrm{~Pa}-\mathrm{s}\right)$ overlain by a rigid lithosphere $\left(\mathrm{T}<1100^{\circ} \mathrm{C}\right)$ spreading at a full rate of $160 \mathrm{~mm} / \mathrm{yr}$. The temperature at $300 \mathrm{~km}$ depth was prescribed to be $1380^{\circ} \mathrm{C}$ and the calculation was carried out to a distance of $800 \mathrm{~km}$ from the ridge axis, although only a $200 \mathrm{~km} \times 400 \mathrm{~km}$ region in $z$ and $x$ nearest the ridge axis was utilized in the gravity calculation. The compositional density effect for $25 \%$ melt depletion was assumed to be equivalent to $375^{\circ} \mathrm{C}$ of thermal expansion, while the density difference between melt and solid was assumed to be $0.5 \mathrm{Mg} / \mathrm{m}^{3}$. The retained melt fraction was calculated using the one-dimensional steady state model of melt migration developed by Jha et al. [1994]. Different melt fractions were obtained by varying the ratio of mantle permeability to melt viscosity. The resulting maximum amounts of melt retention for five separate runs were $0.2 \%, 1.1 \%, 2.6 \%, 4.0 \%$, and $6.2 \%$. As the amount of retained melt increased, the melt region narrowed from a width of about $300 \mathrm{~km}$ for $0.2 \%$ melt to about $70 \mathrm{~km}$ for $6.2 \%$ melt. Because the upwelling rates in the melting region increase as the upwelling becomes more focused, the amount of crustal production also increases by about $1.3 \mathrm{~km}$ from the $0.2 \%$ model to the $6.2 \%$ model.

Figure 11 shows the calculated density structure for three models with melt retention percentages of $0.2 \%, 1.1 \%$, and $4 \%$, respectively. For comparison, the variation in mantle density for

Table 2. Mantle Density Model Parameters

\begin{tabular}{ll}
\hline \multicolumn{1}{c}{ Parameter } & Sparks Mantle Model \\
\hline Spreading rate, $\mathrm{mm} / \mathrm{yr}$ & 160 \\
Mantle viscosity, $\mathrm{Pa} \mathrm{s}$ & $5 \times 10^{18}$ \\
Thermal diffusivity $\mathrm{K}, \mathrm{m}^{2} / \mathrm{s}$ & $10^{-6}$ \\
Latent heat of fusion $L, \mathrm{~kJ} / \mathrm{kg}$ & 600 \\
Density $\rho, \mathrm{Mg} / \mathrm{m}^{3}$ & 3.30 \\
Specific heat $\mathrm{c}_{\mathrm{p}}, \mathrm{kJ} / \mathrm{kg}^{\circ} \mathrm{C}$ & 1.0 \\
Thermal expansion coefficient $\alpha,{ }^{\circ} \mathrm{C}^{-1}$ & $3 \times 10^{-5}$ \\
Compositional density parameter $\beta$ & 0.045 \\
Temperature at base of lithosphere, ${ }^{\circ} \mathrm{C}$ & 1100 \\
Reference temperature, ${ }^{\circ} \mathrm{C}$ & 1300 \\
Density difference between solid & \\
$\quad$ and melt $\Delta \rho, \mathrm{Mg} / \mathrm{m}^{3}$ & 0.5 \\
Permeability/melt viscosity, & $125,62.5,12.5$, \\
$\quad \mathrm{m}^{2} / \mathrm{Pa} \mathrm{x} \times 10^{-16}$ & $6.25,3.125$ \\
Maximum retained melt, $* \%$ & $0.20,1.09,2.64$, \\
& $4.04,6.18$ \\
\hline
\end{tabular}

\footnotetext{
* Five separate runs
} 


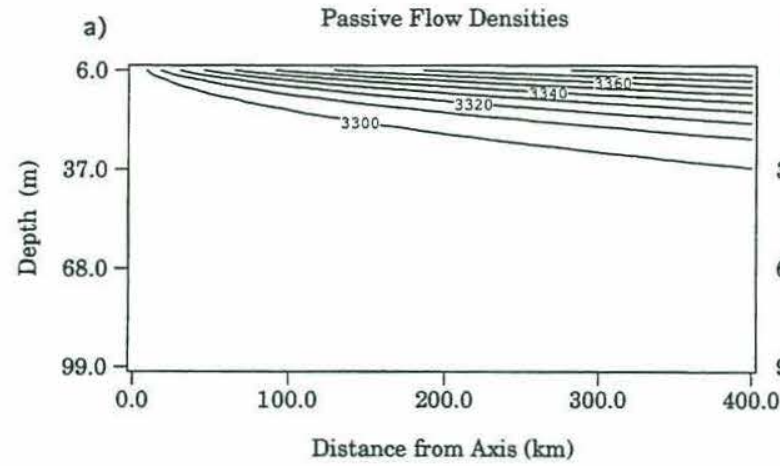

c) Densities from Sparks Mantle with $1.1 \%$ Melt Retention

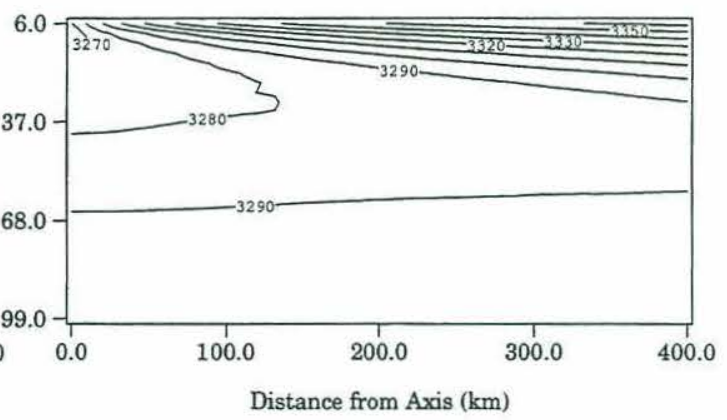

b) Densities from Sparks Mantle with $0.2 \%$ Melt Retention

d) Densities from Sparks Mantle with $4.0 \%$ Melt Retention
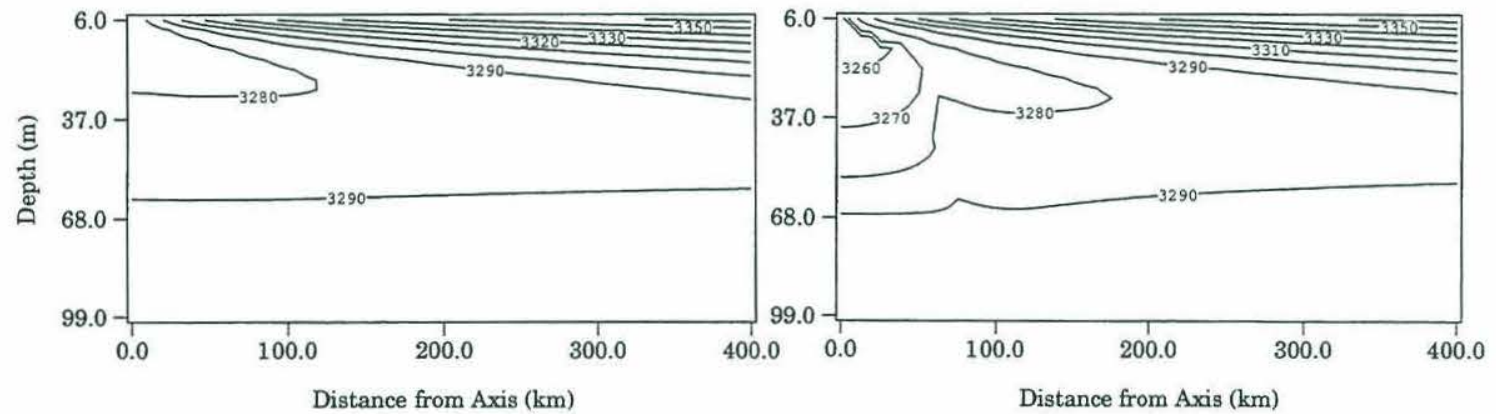

Figure 11. Mantle density structures for (a) a passive flow model from Phipps Morgan and Forsyth [1988] and three models from Sparks et al. [1993b] with (b) a maximum of $0.2 \%$ melt retention, (c) a maximum of $1.1 \%$ melt retention, and (d) a maximum of $4.0 \%$ melt retention. Depths begin at the Moho ( $6 \mathrm{~km}$ depth) and extend to 100 $\mathrm{km}$. Vertical exaggeration is $2: 1$.

the passive, plate-driven flow model of Phipps Morgan and Forsyth [1988] is also shown in Figure 11. Including temperature and compositional density reduction, and the effects of melt retention, creates a broad region $(\sim 150 \mathrm{~km}$ wide) of lowdensity material extending $\sim 50 \mathrm{~km}$ below the ridge axis. In the passive flow model, not only is melt retention ignored, but so are the thermal and compositional effects of mantle melting. As the mantle melts, compositional changes tend to decrease the mantle density; however, at the same time, adsorption of latent heat reduces the temperature in the melting region and therefore tends to increase the mantle density. The two components tend to counteract each other resulting in a relatively small (about 10-20 $\mathrm{kg} / \mathrm{m}^{3}$ ) density anomaly (compare Figures $11 \mathrm{a}$ and $11 \mathrm{~b}$ ). In contrast, melt retention can lead to much larger density anomalies $\left(>40-50 \mathrm{~kg} / \mathrm{m}^{3}\right)$ if the melt fraction is greater than a few percent (see Figure 11d). Increasing the melt retention also results in increased focusing of the flow as buoyant upwelling becomes more important.

The gravity anomaly associated with each of these mantle density structures was calculated using the same procedure described above for density grids with a spacing of $3 \mathrm{~km}$ in the vertical direction and $6 \mathrm{~km}$ in the horizontal direction. Since the effect of relief on the Moho was included in the crustal calculation, the contribution of mantle density variations to the free-air anomaly was calculated by suspending each of the mantle density grids at a uniform depth $6 \mathrm{~km}$ below the mean water depth $(3032 \mathrm{~m})$. Since the crustal calculations are referenced to the observed gravity $25 \mathrm{~km}$ off axis, the resulting gravity anomaly for each mantle structure was referenced to $0 \mathrm{mGal}$ at $25 \mathrm{~km}$ off axis.

Figure 12 shows the gravity signature due to each of the mantle density structures in Figure 11. Density variations due to the thermal expansion of hot, upwelling mantle (the only effect included in the passive flow calculation) can produce an anomaly of about $-1.5 \mathrm{mGal}$ within $25 \mathrm{~km}$ of the rise axis. Including compositional density reduction due to melt extraction (Sparks model with $0.2 \%$ melt retention) has a negligible effect on gravity since this effect is counteracted by adsorption of latent heat as discussed above. In comparison, increasing the retained melt fraction can result in a relatively large $(-5 \mathrm{mGal}$ for $6 \%$ melt retention) gravity anomaly. Two effects contribute to this anomaly. One is the density difference between melt and mantle; the other is the tendency for the upwelling flow to become much more focused as melt fraction increases, concentrating the thermal anomaly over a narrower region [Sparks et al., 1993a]. Since the mantle contribution to the observed MBA low is only $\sim 2-3 \mathrm{mGal}$, these results effectively preclude large percentages $(>4-6 \%)$ of retained melt over an upwelling region several tens of kilometers across.

\section{Combining Crustal and Mantle Contributions}

The crustal and upper mantle density anomalies calculated in the previous two sections can be combined to derive a best fitting 


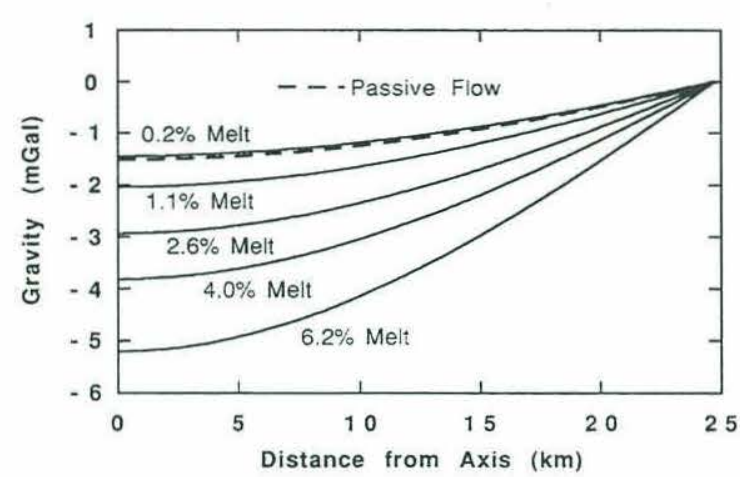

Figure 12. Gravity anomaly associated with six different mantle density structures. The dashed line is the gravity anomaly for a passive flow model which includes only temperature-related density effects. All other models include temperature, composition, and melt retention density effects. The model with $0.2 \%$ melt is essentially identical to the passive flow model indicating compositional density variations have a negligible effect on the axial gravity anomaly.

model that explains the free-air anomaly observed at the EPR. Various combinations are shown for both the $14^{\circ} \mathrm{S}$ (Figure 13) and $17^{\circ} \mathrm{S}$ areas (Figure 14) as the difference between the observed free-air anomaly and the calculated anomaly assuming either the PM\&C or HEN crustal density model and mantle densities derived from the Sparks mantle flow model with different percentages of melt retention. For comparison, the conventional MBA is also shown. A quantitative "goodness of fit" measure was estimated for each model by calculating the RMS error between the observed and calculated free-air anomalies (see Table 3). A model which perfectly fits the observed data would give a "zero" RMS error and residual anomaly; however, models (indicated by asterisks in Table 3 ) that fit the observed data to within the $95 \%$ uncertainties assigned to the stacked, free-air profiles $\left( \pm 1.0 \mathrm{mGal}\right.$ at $14^{\circ} \mathrm{S}$ and $1.2 \mathrm{mGal}$ at $17^{\circ} \mathrm{S}$ shown as thin dashed lines in Figures 13 and 14) were considered to be indistinguishable.

The results shown in Figures 13 and 14 indicate that the MBA low observed at the EPR can be explained, to within the uncertainty of the free-air anomaly data, by a combination of anomalous lower crustal densities in the axial region and temperature-related mantle density changes with zero melt retention. However, small amounts (a few percent) of interstitial melt in the upwelling mantle are also consistent with the observed gravity data. Models with 1-2\% melt retention can explain the gravity anomaly observed at $14^{\circ} \mathrm{S}$, while models with up to $4 \%$ melt can fit the gravity data at $17^{\circ} \mathrm{S}$ to within the experimental uncertainty of the data (Table 3 ). However, these melt concentrations are only marginally resolvable given the uncertainty in the gravity anomaly data and the density structure of the crust. PM\&C thermal model generally requires $1-2 \%$ more retained melt than HEN because it makes different assumptions about the depth extent of hydrothermal circulation (whole crust versus only upper crust). Thus the larger MBA anomaly at $17^{\circ} \mathrm{S}$ can be explained either by a higher melt fraction in the mantle or by a hotter crust, or by some combination of these effects. Given the uncertainty in crustal thermal models, as well as the limited information on crustal thickness variability along most sections of the EPR, we conclude that gravity data alone do not provide definitive evidence for the existence of significant amounts of retained melt $(>1-2 \%)$ in the mantle beneath the axis of the SEPR.

\section{Comparison With Observed Bathymetry}

Isostatic topography is a very sensitive indicator of integrated density structure. To determine if the observed axial topography is consistent with the combined crust/mantle density models that fit the free-air gravity data, we have computed isostatic topography for the four "best fitting" models from Figures 13 and 14. Previous gravity studies have shown that the axial region of the EPR is characterized by very small effective elastic plate thicknesses [Madsen et al., 1984] so we have assumed local isostasy. The seafloor topography $\left(w_{d}\right)$ supported by each combined density model was therefore calculated from:

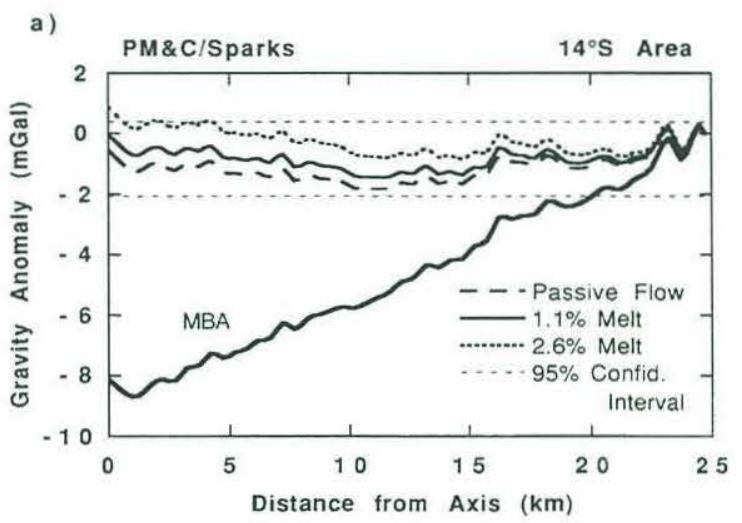

b)

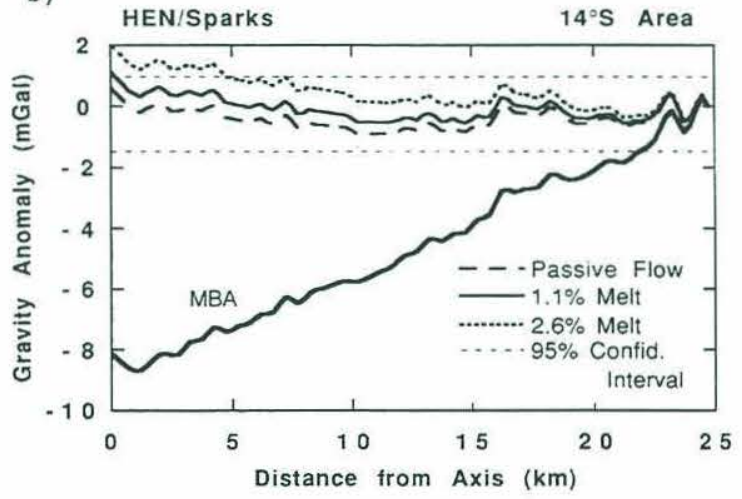

Figure 13. Residual gravity profiles for the $14^{\circ} \mathrm{S}$ area calculated using (a) PM\&C [Phipps Morgan and Chen, 1993] and (b) HEN [Henstock et al., 1993] thermal models for the crust and various mantle thermal models. Horizontal dashed lines indicate $95 \%$ confidence interval for the observed gravity data centered about the model with the minimum RMS error (Table 3). Models with residual anomalies lying within the dashed lines are considered indistinguishable. In this area an acceptable fit can be obtained using either crustal thermal model and temperature-related mantle density effects with no melt retention in the mantle (the passive flow case). However, models with small amounts of melt retention $(<1-2 \%)$ are also consistent with the observed data. 

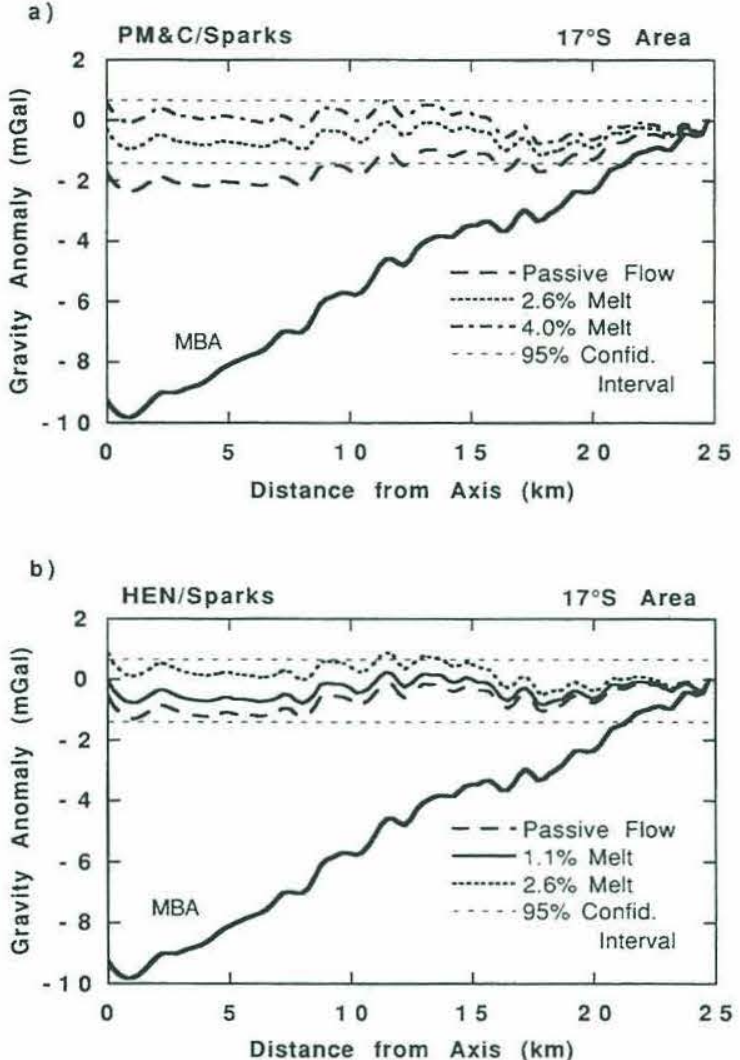

Figure 14. Residual gravity profiles for the $17^{\circ} \mathrm{S}$ area calculated using (a) PM\&C [Phipps Morgan and Chen, 1993] and (b) HEN [Henstock et al., 1993] thermal models for the crust and various mantle thermal models. Horizontal dashed lines indicate 95\% confidence interval for the observed gravity data centered about the model with the minimum RMS error (Table 3). Models with residual anomalies lying within the dashed lines are considered indistinguishable. The larger MBA in this area requires $2-3 \%$ melt in the mantle if the PM\&C crustal thermal model is assumed; however, if the HEN thermal model is used for the crust, an acceptable fit can be obtained with either no melt retention in the mantle (the passive flow case) or a melt fraction of about $1 \%$.

$$
w_{d}=\frac{\sum h\left(\rho-\rho_{m}\right)}{\rho_{w}-\rho_{m}}
$$

where $h$ and $\rho$ are the height and density of each block, $\rho_{m}$ is mantle density, $\rho_{w}$ is water density, and the sum is taken over all of the blocks in a column.

The resulting isostatic topography is compared with the observed, stacked bathymetry profiles in Figure 15. Although the combined density models can explain the gradual subsidence of the seafloor greater than $10 \mathrm{~km}$ from the ridge axis, they underestimate the amplitude of the axial high by about $200 \mathrm{~m}$ and misfit the observed topography out to $5-10 \mathrm{~km}$ from the ridge axis. The PM\&C crustal thermal model, which has a narrower, hotter region of low densities in the lower crust beneath the rise axis, can isostatically support a larger portion of the axial topographic high than can the HEN thermal structure. However, neither model can adequately explain the height or width of the axial high observed along this section of the EPR even though they satisfactorily fit the observed free-air anomaly.

The difference between the observed and predicted axial topography is $200 \mathrm{~m}$ for the PM\&C model and $\sim 300 \mathrm{~m}$ for the HEN model. The isostatic calculation depends on the choice of thermal expansion coefficient; however, the misfit is not particularly sensitive to this choice. We have used $\alpha=3.0 \times 10^{-5}$ ${ }^{\circ} \mathrm{C}^{-1}$ which is somewhat lower than the $\alpha=3.2 \times 10^{-5}{ }^{\circ} \mathrm{C}^{-1}$ used by Wang and Cochran [1993] or the mantle value of $3.45 \times 10^{-5}$ ${ }^{\circ} \mathrm{C}^{-1}$ suggested by Wilson [1992]. A $10 \%$ increase in $\alpha$, balanced by about a $1 \%$ reduction in retained melt in the mantle, would still provide a reasonable fit to the gravity data, but it would only increase the isostatically supported topography by about $20-30 \mathrm{~m}$. Therefore the density structure which we found to be consistent with the observed gravity cannot isostatically support the axial topographic high.

There are two possible additional sources of support for the axial high. The axial region could be dynamically supported by a narrow upwelling of material beneath the rise axis. Alternatively, there could be an additional low-density body centered under the ridge axis that isostatically supports the axial topography but that does not produce a resolvable gravity anomaly. We will focus on the feasibility of the latter mechanism and investigate whether this extra anomalous mass can be confined to the crust or must extend into the upper mantle beneath the ridge axis.

The striped areas in Figure 15 represent the difference between the observed topography and the topography that can be isostatically supported by the density model (based on the PM\&C crustal structure) we derived to fit the observed gravity. The

Table 3. Comparison of Model Predictions with Observed Gravity

\begin{tabular}{llll}
\hline Crustal Model & Mantle Model & $\begin{array}{l}14^{\circ} \text { S Area } \\
\text { RMS Error, } \\
\text { mGal }\end{array}$ & $\begin{array}{l}17^{\circ} \text { S Area } \\
\text { RMS Error, } \\
\text { mGal }\end{array}$ \\
\hline Uniform & Uniform & 2.57 & 2.90 \\
Uniform & Passive flow & 2.12 & 2.46 \\
PM\&C & Uniform & 0.82 & 1.03 \\
PM\&C & Passive flow & $0.45^{*}$ & 0.59 \\
PM\&C & Sparks, 0.2\% melt & $0.47^{*}$ & 0.61 \\
PM\&C & Sparks, 1.1\% melt & $0.39^{*}$ & $0.45^{*}$ \\
PM\&C & Sparks, 2.6\% melt & $0.42^{*}$ & $0.28^{*}$ \\
PM\&C & Sparks, 4.0\% melt & 0.59 & $0.33^{*}$ \\
PM\&C & Sparks, 6.2\% melt & 0.97 & 0.67 \\
HEN & Uniform & 0.58 & 0.77 \\
HEN & Passive flow & $0.34^{*}$ & $0.38^{*}$ \\
HEN & Sparks, 0.2\% melt & $0.34^{*}$ & $0.39^{*}$ \\
HEN & Sparks, 1.1\% melt & $0.38^{*}$ & $0.29^{*}$ \\
HEN & Sparks, 2.6\% melt & 0.56 & $0.33^{*}$ \\
HEN & Sparks, 4.0\% melt & 0.79 & 0.53 \\
HEN & Sparks, 6.2\% melt & 1.20 & 0.93 \\
\hline
\end{tabular}

The PM\&C model is that of Phipps Morgan and Chen [1993], HEN is that of Henstock et al. [1993], and Sparks is that of Sparks et al., [1993b] and Jha et al., [1994].

* Models that fit observed gravity to within $95 \%$ uncertainties. 
a)

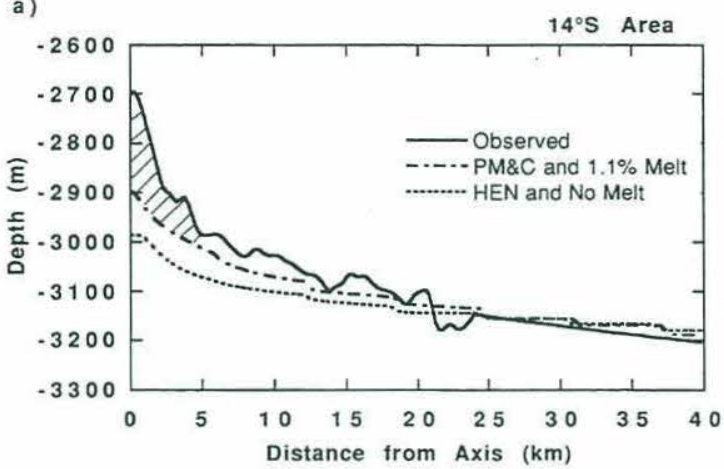

b)

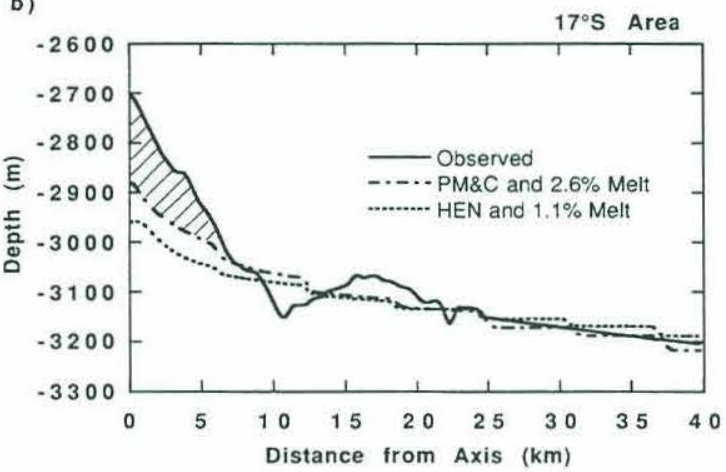

Figure 15. Observed bathymetry compared to isostatically supported topography calculated for the "best fit" models to gravity data. (a) $14^{\circ} \mathrm{S}$ area isostatic topography computed for PM\&C [Phipps Morgan and Chen, 1993] crustal thermal model with $1.1 \%$ mantle melt retention and HEN [Henstock et al., 1993] thermal model with $0.2 \%$ mantle melt fraction. (b) $17^{\circ} \mathrm{S}$ area isostatic topography computed for PM\&C crustal thermal model with $2.6 \%$ mantle melt retention and HEN thermal model with $1.1 \%$ mantle melt fraction. None of these models can adequately explain the amplitude of the axial topographic high even though they satisfactorly match the observed gravity. The stripped region indicates the excess topography which must be accounted for by another mechanism.

average excess topography within $5 \mathrm{~km}$ of the axis is $131 \mathrm{~m}$ in the $17^{\circ} \mathrm{S}$ area and $112 \mathrm{~m}$ in the $14^{\circ} \mathrm{S}$ area. This translates into about $2.8 \times 10^{5} \mathrm{~kg} / \mathrm{m}^{2}$ of excess mass per meter along axis. We first consider if this anomalous mass could be compensated by a crustal body with densities lower than those predicted by the PM\&C or HEN crustal thermal models. We assume a trapezoidal-shaped region, $1 \mathrm{~km}$ wide at the top and $10 \mathrm{~km}$ wide at its base, extending from the melt lens to the base of the crust (Figure 16a). An average $\Delta p=-0.102 \mathrm{Mg} / \mathrm{m}^{3}$ would be required in this body to compensate the excess topography. Assuming a density contrast of $0.20 \mathrm{Mg} / \mathrm{m}^{3}$ between basaltic melt and gabbro [Hooft and Detrick, 1993] this $\Delta \rho$ corresponds to $50 \%$ extra melt. This would imply that the axial low velocity zone contains a substantial fraction of molten material which is not supported by seismic observations at the EPR [e.g., Solomon and Toomey, 1992]. Furthermore, the gravity signal of such a body would be $-4.8 \mathrm{mGal}$ which is incompatible with the negligible residual gravity anomaly we observe after correcting for other predictable crustal and upper mantle density variations. Thus the additional isostatic support for the axial high must come from the underlying mantle.

An alternative mechanism, originally suggested by Wilson [1992], is that a narrow (10-15 km wide) conduit exists in the upper mantle beneath the ridge axis. The amount of melt required to support the excess axial topography will decrease as the vertical extent of this narrow, partial melt conduit increases.

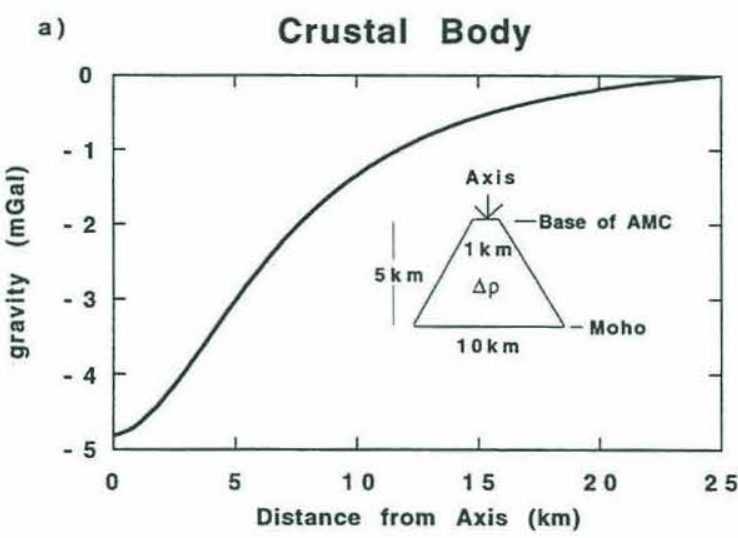

b)

Mantle Body

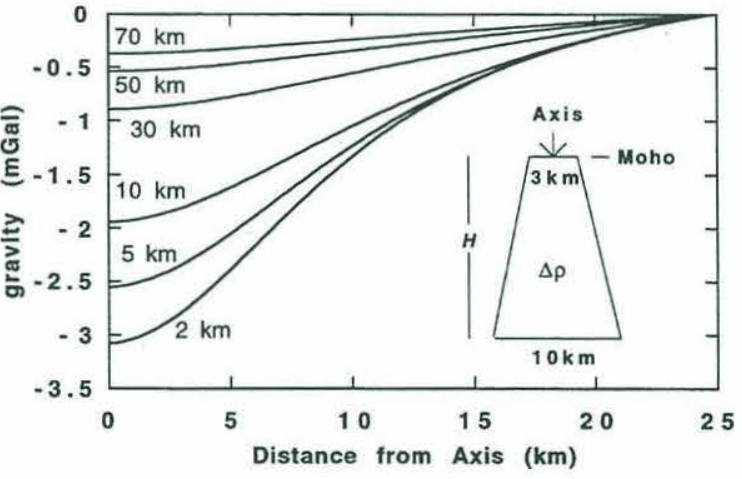

Figure 16. The gravity signatures of various low density bodies which can isostatically support the excess axial topography shown in Figure 15. (a) A lower crustal body $1 \mathrm{~km}$ wide at the top and $10 \mathrm{~km}$ wide at its base located between the top of the melt lens and the Moho. A $\Delta \rho=-0.102 \mathrm{Mg} / \mathrm{m}^{3}$ is required to support the excess topography. The associated gravity anomaly (about $-5 \mathrm{mGal}$ ) is much too large to be consistent with the negligible gravity anomaly remaining after correcting for other predictable crustal and upper mantle density variations. (b) A family of trapezoid-shaped melt conduits in the upper mantle 3 $\mathrm{km}$ wide at the top and $10 \mathrm{~km}$ wide at the base which extend a distance $H$ into the mantle from the base of the crust. The $\Delta p$ required to explain the excess axial topography, and the associated gravity anomaly, varies with the vertical extent of the body. If the melt conduit extends to depths of at least $50-70 \mathrm{~km}$ the gravity anomaly associated with this body will be unresolvable $(\leq 0.5 \mathrm{mGal})$. For a body extending to these depths, the amount of associated melt will be only $1.5-2 \%$. 
A family of gravity anomalies for melt regions extending to different depths is shown in Figure 16b. For these calculations, the width at the base of the high melt region was fixed at $10 \mathrm{~km}$ to correspond to the width of the excess topography observed at the rise axis (Figure 15). The width at the top of the melt region was tapered to $3 \mathrm{~km}$. This geometry was chosen to be consistent with a geochemically derived fractal tree model of magma conduits which focus melt into ever coarser transport networks as the melt gets closer to the surface [e.g., Hart, 1993]. In each case the $\Delta p$ was chosen to balance the excess topography. If this melt conduit is confined to the uppermost $20 \mathrm{~km}$ of the mantle, its gravity anomaly will be too large to be consistent with the negligible residual anomaly we infer (see Figure 16b). However, if a body of these dimensions extends to $50-70 \mathrm{~km}$ depth (with a corresponding $\Delta \rho$ of -0.0086 to $-0.0062 \mathrm{Mg} / \mathrm{m}^{3}$ ), the associated gravity anomaly will be effectively unresolvable $(<0.5 \mathrm{mGal})$. If a density contrast of $0.4-0.5 \mathrm{Mg} / \mathrm{m}^{3}$ between basaltic melt and hot peridotite is assumed [Sparks et al., 1993b; Wilson, 1992], only an extra $\sim 1.5-2 \%$ melt is required in a body $10 \mathrm{~km}$ wide at the base and $50-70 \mathrm{~km}$ high to support the excess topography of the axial high.

We recognize that this model of an instantaneous jump from zero to $\sim 1.5 \%$ melt retention at $70 \mathrm{~km}$ depth ignores the fact that melting occurs over a range of depths. However, the details of the melting processes and the mechanics of melt transport are not well understood. As melt migrates upward in a vein transport network, the retained melt fraction may increase steadily toward the surface [e.g., Jha et al., 1994], rapidly reach a constant value [e.g., Ahren and Turcotte, 1979], or even begin to decrease at shallow depths [Nicolas, 1990]. Fortunately, as we have shown, the observed gravity is very insensitive to the details of melt distribution at these depths. The primary constraint is that the vertically integrated density anomaly must isostatically support the topographic high. For example, if we assume that retained melt fraction increases with the square root of the height above the base of the melting conduit [Jha et al., 1994], then we can fit the observed bathymetry with a $70-\mathrm{km}$ trapezoidal conduit in which melt retention increases from $0 \%$ at the base to $2.3 \%$ at the Moho (a melting rate of $0.035 \mathrm{~kg} \cdot \mathrm{m}^{-7 / 2}$ ). The gravity signature of such a conduit would be only $0.1 \mathrm{mGal}$ larger than one with a constant $\Delta \rho$; this is far below the resolution of our data.

\section{Discussion and Implications}

The results of our analysis are summarized in Figures 17 and 18 in the form of a composite crustal and upper mantle density model for the SEPR at $14^{\circ} \mathrm{S}$ and the various crustal and mantre contributions to the observed MBA and axial topography. A similar model can explain the gravity and topography in the $17^{\circ} \mathrm{S}$ area. However, the larger MBA low observed across the ridge at $17^{\circ} \mathrm{S}$ requires a hotter crust (e.g., favoring the HEN model over PM\&C), slightly greater amounts of interstitial melt in the mantle, or some combination of the these effects. The similarity of the axial gravity anomaly and topography observed in these two areas to other sections of the EPR suggest that our results may be generally applicable to the interpretation of other gravity data from this fast spreading ridge.

We have shown that about $70 \%$ of the MBA low (6-7 mGal) can be accounted for by a region of partial melt and elevated temperatures in the mid-to-lower crust beneath the rise axis that has lower crustal densities compared to those at equivalent depths off axis (Figure 18a). The remainder of the MBA low can be explained, to within the experimental uncertainty of the gravity data ( $\pm 1 \mathrm{mGal})$, by mantle density variations predicted by a simple, plate-driven, passive flow model with no interstitial melt (Figure 18a). However, the retention of a small amount of melt $\left(\leq 1-2 \%\right.$ at $14^{\circ} \mathrm{S}$ ) in a broad region (tens of kilometers wide) of upwelling mantle is also consistent with the observed gravity data given the uncertainties in the data and in the choice of a crustal thermal model. The height of the narrow, topographic high at the EPR cannot be fully explained by the combination of lower crustal densities in the axial region and thermal expansion of the hot, upwelling mantle that account for the observed gravity (Figure 18b). Following Wilson [1992] we suggest the additional isostatic support for the axial high is provided by a narrow $(\sim 10$ $\mathrm{km})$ partial melt conduit that extends to depths of $50-70 \mathrm{~km}$ beneath the rise axis and has melt concentrations $1.5-2 \%$ greater than the surrounding mantle. This melt conduit has a negligible gravity signature (Figure 18a) but can explain up to half the height of the axial topographic high (Figure 18b).

To facilitate the comparison of our model to those presented in previous studies, Figure 19 shows how the mean density anomaly $(\Delta \rho)$, averaged over a band $12 \mathrm{~km}$ wide centered on the rise axis, varies as a function of depth. We focus on this narrow zone to highlight the density anomaly responsible for the axial gravity and topographic high. The density anomaly is calculated with reference to the density structure $25 \mathrm{~km}$ off axis. The resulting density anomaly combines all the factors (temperature variations, chemical depletion, and retained melt) that affect density as previously discussed. The anomalous density versus depth curve illustrates that the compensation of the EPR axial high is due to both crustal and upper mantle density anomalies (Figure 19). The largest mean density anomaly $\left(\Delta \rho\right.$ up to $-0.07 \mathrm{Mg} / \mathrm{m}^{3}$ ) is located in the lower crust, but a significant portion of the isostatic support for the axial high extends into the underlying mantle with anomalous densities of $-0.005 \mathrm{Mg} / \mathrm{m}^{3}$ extending to $70 \mathrm{~km}$ depth. The "center of mass" of this compensating body is located well below the base of the crust at $20.7 \mathrm{~km}$ depth.

The distribution of anomalous mass with depth shown in Figure 19 can explain some of the inconsistencies in previous estimates of the depth of compensation of the axial high. Madsen et al. [1984] found an "average" compensation depth of 6-7 km for the axial high but argued that a portion of the isostatic support for this feature came from density anomalies in the underlying mantle. However, both Wilson [1992] and Wang and Cochran [1993] estimated much greater depths to the center of the compensating mass ( $>15 \mathrm{~km}$ for Wilson and $11-19 \mathrm{~km}$ for Wang and Cochran). Our results indicate that the largest $\Delta \rho$ is centered near the base of the crust. By assuming a single compensation depth, Madsen et al.'s [1984] estimate may have been dominated by this large, comparatively shallow density anomaly. However, the compensation of the axial high extends well into the mantle, and the center of mass of this body in our model is much more consistent with the estimates of Wilson [1992] and Wang and Cochran [1993].

We do not require the relatively large residual melt retention (4-9\%) in the mantle inferred by Wang and Cochran [1993] to explain the compensation of the axial high or the amplitude of the axial gravity anomaly. We believe this is primarily a result of the different crustal thermal model employed in this study. Wang and Cochran [1993] used a $t^{1 / 2}$ cooling model to account for crustal and mantle temperature variations and attributed all of the remaining density variability to melt trapped in the mantle. However, a t ${ }^{1 / 2}$ cooling model is not a good approximation to the variation in either depth or crustal temperatures in the immediate vicinity $(<10 \mathrm{~km})$ of the EPR. We have shown that a significant 


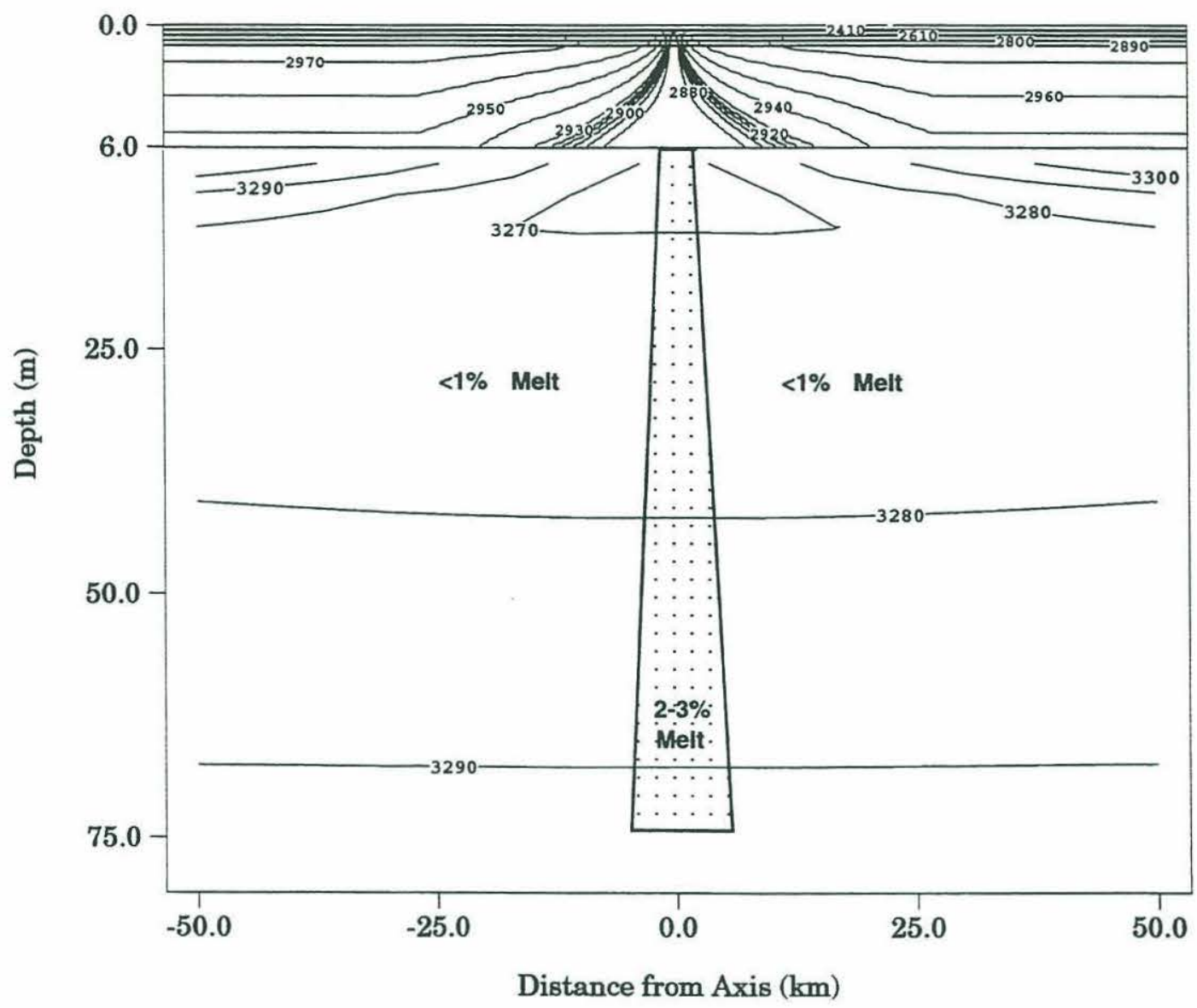

Figure 17. Composite density model which can explain the observed gravity and axial topography at the East Pacific Rise in the $14^{\circ} \mathrm{S}$ area. This density model incorporates crustal density variations due to the presence of an axial magma chamber and a broader region of elevated temperatures in the lower crust, and mantle density variations due to temperature, melt retention, and compositional changes resulting from melt extraction. Crustal densities are based on the PM\&C [Phipps Morgan and Chen, 1993] thermal model. Mantle densities were computed from the Sparks mantle flow model [Sparks et al., 1993b] assuming 1.1\% melt retention, although a model with no melt retention would fit the observations equally well. A narrow ( $\sim 10 \mathrm{~km}$ wide) melt conduit extending to depths of $50-70 \mathrm{~km}$ with an additional $1.5-2 \%$ melt is required to explain the amplitude of the axial topographic high.

portion of the isostatic support for the axial high is due to the presence of elevated temperatures in the mid-to-lower crust. By removing the predictable crustal component before modeling the required mantle anomaly, we have shown that, at most, only a few percent melt may be present in a narrow zone in the mantle beneath the rise axis and little or no melt may be retained in a broader region of the surrounding mantle.

Our model is most similar to one proposed by Wilson [1992] even though we used a different crustal thermal model and explicitly included the effects of thermal, compositional, and melt buoyancy on both the pattern of mantle flow and the observed gravity. The most important feature common to both models is the existence of a narrow melt conduit beneath the rise axis (Figure 17). In our model, the existence of this conduit is required to explain the amplitude of the axial topographic high. The predictable crustal and upper mantle density variations that satisfactorily explain the axial gravity anomaly cannot account for the full height of the axial high (Figure 18b), and the narrow melt conduit provides this additional isostatic support. If this melt conduit exists, it suggests a far greater degree of across-axis focusing of upwelling than was obtained in our mantle flow calculations using the constant-viscosity Sparks et al. [1993b] model. Variable-viscosity two-dimensional mantle models have been able to predict such a conduit, but the melt retention required depends on the assumed relationship between viscosity and melt fraction. Buck and $S u$ [1989] require 20-30\% melt retention to reduce mantle viscosities sufficiently to generate this kind of flow, whereas Su and Buck [1993], making different assumptions, find that only $10 \%$ melt is required. Our gravity data suggest melt fractions this high are unlikely, even in a narrow melt conduit. However, Hirth and Kohlstedt [1994] report a dramatic weakening at $5 \%$ melt retention. Under some 
a)

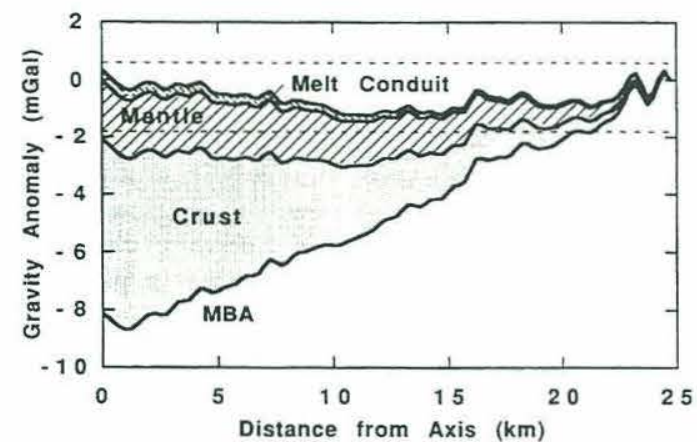

b)

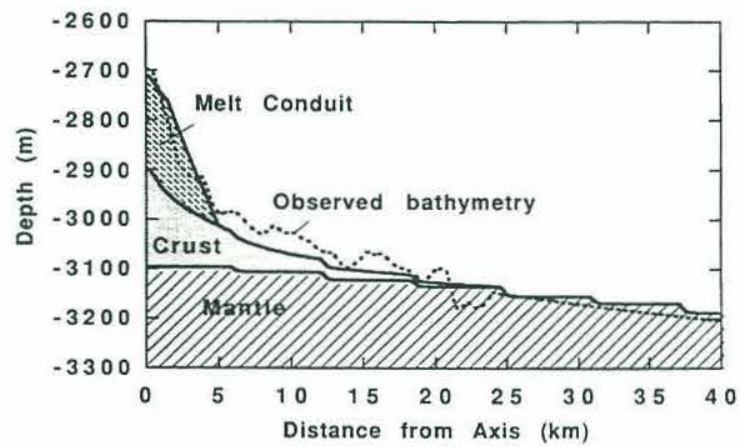

Figure 18. Crustal and upper mantle contributions to (a) the mantle Bouguer anomaly (MBA) low and (b) the axial topography observed at the southern East Pacific Rise at $14^{\circ} \mathrm{S}$. Calculations are based on the composite crustal and upper mantle density model shown in Figure 17. Horizontal dashed lines in Figure $18 \mathrm{a}$ indicate the $95 \%$ confidence interval for the MBA. Note that temperature-related crustal density changes can explain about $70 \%$ of the MBA low and about half of the amplitude of the axial topographic high. Temperature-related mantle density differences with or without a small amount of retained melt $(<1 \%)$ can explain the remainder of the MBA but cannot account for the full height of the axial topographic high. The anomalous height of the axial high is consistent with the presence of a narrow ( $\sim 10 \mathrm{~km}$ wide) partial melt conduit that extends to depths of $50-70 \mathrm{~km}$ with melt concentrations $1-2 \%$ higher than the surrounding mantle. This melt conduit has a negligible gravity signature.

circumstances a decrease in viscosity of $\sim 1$ order of magnitude could occur with melt retention as low as $3 \%$ (G. Hirth, personal communication, 1994).

Along-axis variations in MBA of up $10-15 \mathrm{mGal}$ over distances on the order of $100 \mathrm{~km}$ or more have been observed along the SEPR (Figure 2) and other sections of the EPR [Wang and Cochran, 1993]. These variations have been interpreted as evidence for along-axis focusing of mantle upwelling similar to that inferred at the Mid-Atlantic Ridge [Cormier and Macdonald, 1993; Wang and Cochran, 1993; Wang et al., submitted manuscript, 1994]. However, we have seen that along-axis variations in mantle melt fraction (e.g., between the $14^{\circ} \mathrm{S}$ and $17^{\circ} \mathrm{S}$ areas) that might potentially indicate focused upwelling are only marginally resolvable given the uncertainties in crustal thermal models (Figures 13 and 14). The strong correlation among axial depth, axial volume, and along-axis variation in MBA illustrated in Figure 2 argues against the presence or absence of a mantle melt conduit as being the major cause of this along-axis variation. Since the melt conduit has a comparatively minor effect on gravity but a large effect on axial depth (Figure 18 ), along-axis variations in the existence of the melt conduit would be expected to result in along-axis variations in axial depth that are uncorrelated with variations in gravity. Instead, we observe (Figure 2) regions with modest along-axis gravity variation $(\sim 5 \mathrm{mGal})$ and no variation in axial depth (i.e., 14$\left.18^{\circ} \mathrm{S}\right)$, and regions where along-axis gravity and depth variations are highly correlated (i.e., $18-21^{\circ} \mathrm{S}$ ). We cannot rule out correlations between gravity and bathymetry that are causal but indirect (such as variations in crustal thickness which result from variations in melt delivery from a varying conduit). However, the observed correlations are most consistent with along-axis variations in crustal thermal structure and/or crustal thickness.

Determining the relative contributions of variations in crustal thickness and thermal structure to the along-axis MBA signal is difficult since available seismic data do not constrain regional crustal thickness variations along the SEPR. Evidence that variations in crustal thermal structure are important comes from the correlation between MBA highs and locations where the AMC reflector is not observed (Figures 1 and 2). This correlation is particularly striking at the $15^{\circ} 55^{\prime} \mathrm{S}$ OSC, near the Garrett transform, and south of $19^{\circ} \mathrm{S}$. In areas where the AMC reflector is apparently absent, the thermal structure of the crust may be substantially cooler than the structure predicted by either the PM\&C model or the HEN model. In the limit where the crust has had time to completely cool since the most recent episode of

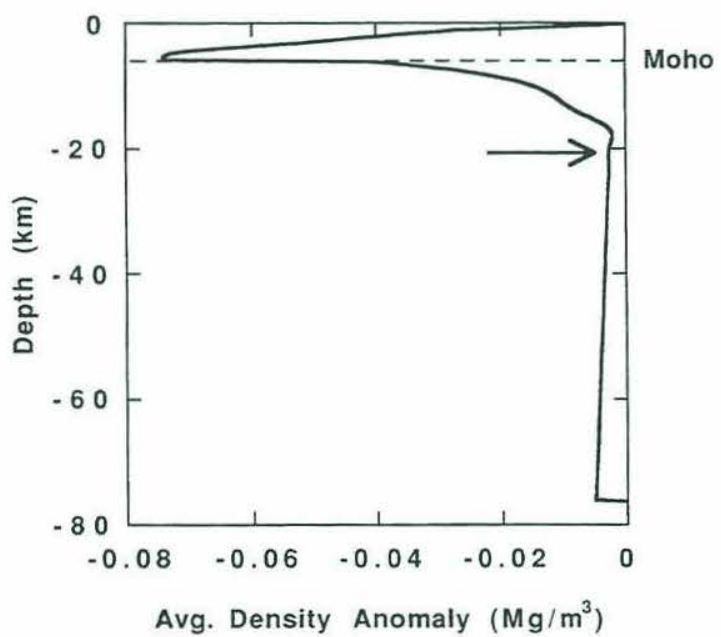

Figure 19. The mean near-axis density anomaly calculated as a function of depth for the composite crustal and upper mantle density model shown in Figure 17. This anomaly is the average anomalous density within $12 \mathrm{~km}$ of the ridge axis calculated with reference to the desnity structure $25 \mathrm{~km}$ off axis. The largest mean density anomaly $\left(\Delta \rho\right.$ up to $\left.-0.07 \mathrm{Mg} / \mathrm{m}^{3}\right)$ is located in the lower crust, but a significant portion of the isostatic support for the axial high extends into the underlying mantle with anomalous densities of $-0.005 \mathrm{Mg} / \mathrm{m}^{3}$ extending to $70 \mathrm{~km}$ depth. The "center of mass" of this compensating body, indicated by the arrow, is located well below the base of the crust at $20.7 \mathrm{~km}$ depth. 
magma emplacement, this cooling could account for as much as 6 $\mathrm{mGal}$ (or nearly half) of the observed along axis MBA variation and depth changes of up to $\sim 200 \mathrm{~m}$ along-axis (Figure 18). If the remainder of the along-axis variation in MBA is due to differences in crustal thickness, then crustal thickness variations of $<500 \mathrm{~m}$ are required. If we assume no along-axis changes in crustal thermal structure, then differences in crustal thickness of as much as $0.5-1.0 \mathrm{~km}$ would be required to explain the 10-15 $\mathrm{mGal}$ variation in MBA observed along the SEPR. In either case, the variation in crustal thickness along the SEPR $(<1 \mathrm{~km}$ over distances of several hundred kilometers) is far less than that observed along the Mid-Atlantic Ridge ( $>3 \mathrm{~km}$ over distances of 50-100 km) [Detrick et al., 1994; Lin et al., 1990; Neumann and Forsyth, 1993; Tolstoy et al., 1993]. Thus, based on observed along-axis crustal thickness variations, upwelling appears to be less focused and more two-dimensional along the SEPR than at the Mid-Atlantic Ridge. It is possible that along-axis ductile flow in the lower crust at the EPR, and efficient along-axis transport of magma in an axial magma chamber, is masking a highly threedimensional upwelling pattern [Bell and Buck, 1992; Lin and Phipps Morgan, 1992]. However, the only way to distinguish this mechanism from a more two-dimensional upwelling is to resolve a mantle signature of focused upwelling due either to variations in mantle temperature or retained melt fraction. Sparks et al. [1993b] have shown that since mantle temperatures in the melting regime are buffered near the solidus, temperature-related density effects due to focused upwelling, and their associated gravity signal, are quite small. Variations in mantle melt fraction potentially have a larger gravity signal (Figure 12), but our results have shown that this anomaly is marginally resolvable given the uncertainty in crustal thermal models and variations in crustal thickness. In this sense, gravity data alone do not provide definitive evidence either for or against along-axis focusing of mantle upwelling at the EPR similar to that inferred at the MidAtlantic Ridge.

\section{Conclusions}

On the basis of our modeling of gravity and topography data from the SEPR we draw the following conclusions:

1. Gravity effects due to seafloor topography, and relief on the Moho (assuming a constant crustal thickness and density crust), overpredict the amplitude of the gravity high at the SEPR by $8-10$ $\mathrm{mGal}$. The resulting MBA low indicates that the axial topographic high is underlain by some combination of lower crustal and upper mantle densities in the axial region (a significantly thicker crust beneath the axial high along the SEPR is precluded by available seismic data).

2. About $70 \%$ of the MBA low found at the SEPR $(6-7 \mathrm{mGal})$ can be explained by a region of partial melt and elevated temperatures in the mid-to-lower crust beneath the rise axis that lowers crustal densities compared to those at equivalent depths off axis. The remainder of the MBA low is caused by density variations in the underlying mantle which have three possible sources: (1) thermal expansion of the hot, upwelling mantle beneath the rise axis, (2) compositional density reductions due to the extraction of partial melt, and (3) the retention of partial melt in the mantle.

3. Compositional density reductions in the mantle due to the extraction of partial melt do not contribute significantly to the axial gravity anomaly observed at the EPR. Temperature-related mantle density variations predicted by a simple, plate-driven, passive flow model with no melt retention can adequately account for the mantle contribution to the observed MBA low within the experimental uncertainty of the free-air anomaly data $( \pm 1 \mathrm{mGal})$. However, the retention of small amounts of melt $(\leq$ $1-2 \%$ at $14^{\circ} \mathrm{S} ; \leq 4 \%$ at $17^{\circ} \mathrm{S}$ ) in a broad region (tens of kilometers wide) of upwelling mantle is also consistent with the observed gravity data given the uncertainty in crustal thermal models.

4. The anomalous height of the narrow, topographic high at the EPR provides the strongest evidence for the existence of significant melt fractions in the underlying mantle. The amplitude of this high cannot be fully explained by a combination of lower crustal densities in the axial region and thermal expansion of the hot, upwelling mantle. The axial high, and its associated gravity anomaly, are consistent with the existence of a narrow ( $10 \mathrm{~km}$ wide) partial melt conduit that extends to depths of $50-70 \mathrm{~km}$ with melt concentrations $1-2 \%$ higher than the surrounding mantle.

5. Gravity data from the SEPR do not provide definitive evidence for along-axis focusing of mantle upwelling on the same scale or of the same magnitude as that observed at the MidAtlantic Ridge. Along-axis variations in mantle melt fraction that might potentially indicate focused upwelling are only marginally resolvable in gravity data due to uncertainties in crustal thermal models. The good correlation between along-axis variations in depth, and changes in axial volume and gravity, argue against the mantle melt conduit as being the major source of this along-axis variation. Instead, this variability can be adequately explained by a combination of along-axis changes in crustal thermal structure and/or along-axis crustal thickness changes of a few hundred meters.

Acknowledgments. This work was supported under National Science Foundation grant OCE-9296017. We thank Jason Phipps Morgan, John Chen, and Tim Henstock for providing the crustal temperature models and Dave Sparks for providing the mantle density models. We are also grateful to Greg Hirth, Dave Sparks, and one anonymous reviewer for their insightful comments and suggestions. This is Woods Hole Oceanographic Institution contribution 8744

\section{References}

Ahren, J. L., and D. L. Turcotte, Magma migration beneath an ocean ridge, Earth Planet. Sci. Lett., 45, 115-122, 1979.

Auzende, J.-M., et al., Nautile observations of present-day activity at super-fast spreading: Volcanic, hydrothermal and tectonic studies of the EPR $17-19^{\circ} \mathrm{S}$, RIDGE Events Newslett., 5, 1, 1994.

Bell, R. E., and W. R. Buck, Crustal control of ridge segmentation inferred from observations of the Reykjanes Ridge, Nature, 357, 583$586,1992$.

Buck, R., and W. Su, Focused mantle upwelling below mid-ocean ridges due to feedback between viscosity and melting, Geophys. Res. Lett. 16, 641-644, 1989.

Caress, D. W., M. S. Burnett, and J. A. Orcutt, Tomographic image of the axial low-velocity zone at $12^{\circ} 50^{\prime} \mathrm{N}$ on the East Pacific Rise, $J$. Geophys. Res., 97, 9243-9263, 1992.

Carlson, R. L., and C. N. Herrick, Densities and porosities in the oceanic crust and their variations with depth and age, J. Geophys. Res., 95, 9153-9170, 1990.

Christeson, G. L., G. M. Purdy, and G. J. Fryer, Structure of young upper crust at the East Pacific Rise near $9^{\circ} 30^{\prime}$ N, Geophys. Res. Lett., 19, 1045-1048, 1992.

Cormier, M.-H., and K. C. Macdonald, EPR, $18-22^{\circ} \mathrm{S}$ : Gravity evidence for focused mantle upwelling, Eos Trans. AGU, 74 (16), Spring Meeting suppl., 297, 1993.

Daines, M. J., and F. M. Richter, An experimental method for directly determining the interconnectivity of melt in a partially molten system, Geophys. Res. Lett., 15, 1459-1462, 1988. 
DeMets, C., R. G. Gordon, D. F. Argus, and S. Stein, Current plate motions, Geophys. J. Int., 101, 425-478, 1990.

Detrick, R. S., et al., Multichannel seismic imaging of a crustal magma chamber along the East Pacific Rise, Nature, 326, 35-41, 1987.

Detrick, R. S., et al., Seismic structure of the southem East Pacific Rise, Science, 259, 497-503, 1993.

Detrick, R. S., H. D. Needham, and V. Renard, Gravity anomalies and crustal thickness variations along the Mid-Atlantic Ridge between $33^{\circ} \mathrm{N}$ and $40^{\circ} \mathrm{N}, J$. Geophys. Res., in press, 1994.

Forsyth, D. Geophysical constraints on mantle flow and melt generation beneath mid-ocean ridges, in Mantle Flow and Melt Generation at Mid-Ocean Ridges, Geophys. Monogr. Ser., vol. 71, edited by J. Phipps Morgan, D. K. Blackman and J. M. Sinton, pp. 1-65, AGU, Washington D. C., 1992

Forsyth, D. W., Investigating the distribution of melt beneath the East Pacific Rise with seismic tomography and magnetollurics: The MELT Experiment, Eos Trans. AGU, 74 (16), Spring Meeting suppl., 297, 1993.

Harding, A. J., et al., Structure of young oceanic crust at $13^{\circ} \mathrm{N}$ on the East Pacific Rise from expanding spread profiles, J. Geophys. Res., 94, 12,163-12,196, 1989.

Harding, A. J., G. M. Kent, M. E. Kappus, and J. A. Orcutt, Examination of Layer $2 \mathrm{~A}$ between $8^{\circ} 50^{\prime} \mathrm{N}$ and $9^{\circ} 50^{\prime} \mathrm{N}$ on the East Pacific Rise using CDP data, Eos Trans. AGU, 72 (44), Fall Meeting suppl., 494, 1991.

Harding, A. J., G. M. Kent, and J. A. Orcutt, A multichannel seismic investigation of upper crustal structure at $9^{\circ} \mathrm{N}$ on the East Pacific Rise: Implications for crustal accretion, J. Geophys. Res., 98, 13,925 $13,944,1993$.

Hart, S.R., Equilibration during mantle melting: A fractal tree model, Proc. Natl. Acad. Sci. U.S.A., 90, 11,914-11,918, 1993

Henstock, T. J., A. W. Woods, and R. S. White, The accretion of oceanic crust by episodic sill intrusion, J. Geophys. Res., 98, 4143-4161, 1993.

Hirth, G., and D. L. Kohlstedt, Experimental constraints on the dynamics of the partially molten upper mantle: Deformation in the diffusion creep regime., J. Geophys. Res., in press, 1994.

Hooft, E. E., and R. S. Detrick, The role of density in the accumulation of basaltic melts at mid-ocean ridges, Geophys. Res. Lett., 20, 423 426, 1993.

Jha, K., E. M. Parmentier, and J. Phipps Morgan, The role of mantledepletion and melt-retention buoyancy in spreading-center segmentation, Earth Planet. Sci. Lett., 125, 221-234, 1994.

Johnson, K. T. M., H. J. B. Dick, and N. Shimizu, Melting in the oceanic upper mantle: An ion microprobe study of diopsides in abyssal peridotites, J. Geophys. Res., 95, 2661-2678, 1990.

Kent, G. M., et al.., The uniform accretion of oceanic crust south of the Garrett Transform at $14^{\circ} 15^{\prime}$ S on the East Pacific Rise, J. Geophys. Res., 99, 9097-9116, 1994.

Kohlstedt, D. L., Structure, rheology and permeability of partially molten rocks at low melt fractions, in Mantle Flow and Melt Generation at Mid-Ocean Ridges, Geophys. Monogr. Ser., vol. 71, edited by J. Phipps Morgan, D. K. Blackman and J. M. Sinton, pp. 103-121, AGU, Washington D. C., 1992.

Kuo, B.-Y., and D. W. Forsyth, Gravity anomalies of the ridge-transform system in the South Atlantic between 31 and $34.5^{\circ} \mathrm{S}$ : Upwelling centers and variations in crustal thickness, Mar. Geophys. Res., 10, 205-232, 1988

Lin, J., and J. Phipps Morgan, The spreading rate dependence of threedimensional mid-ocean ridge gravity signature, Geophys. Res. Lett. 19. 13-16, 1992.

Lin, J., et al., Evidence for focused magmatic accretion along the MidAtlantic Ridge, Nature, 344, 627-632, 1990.

Lonsdale, P., Segmentation of the Pacific-Nazca spreading center, $1^{\circ} \mathrm{N}$ $20^{\circ}$ S, J. Geophys. Res., 94, 12,197-12,225, 1989.

Macdonald, K. C., Mid-ocean ridges: Fine scale tectonic, volcanic and hydrothermal processes within the plate boundary zone, Annu. Rev. Earth Planet. Sci., 10, 155-190, 1982.

Macdonald, et al., Deep-tow and Sea Beam studies of dueling propagating ridges on the East Pacific Rise near $20^{\circ} 40^{\prime} \mathrm{S}, J$. Geophys. Res., 93, 2875-2898, 1988

Madsen, J. A., D. W. Forsyth, and R. S. Detrick, A new isostatic model for the East Pacific Rise crest, J. Geophys. Res., 89, 9997-10,015, 1984.

Madsen, J. A., et al., A two- and three-dimensional analysis of gravity anomalies associated with the East Pacific Rise at $9^{\circ} \mathrm{N}$ and $13^{\circ} \mathrm{N}, J$. Geophys. Res., 95, 4967-4987, 1990.

Moritz, H., Geodetic Reference System 180, Bull. Geod., 58, 388-398, 1984

Neumann, G. A., and D. W. Forsyth, The paradox of the axial profile: Isostatic compensation along the axis of the Mid-Atlantic Ridge?, $J$. Geophys. Res., 98, 17,891-17,910, 1993.

Nicolas, A., Melt extraction from mantle peridotites: Hydrofracturing and porous flow, with consequences for oceanic activity, in Magma Transport and Storage, edited by M. P. Ryan, pp. 159-173, John Wiley, New York, 1990.

Nishimura, C. E., and D. W. Forsyth, The anisotropic structure of the upper mantle in the Pacific, Geophys. J., 96, 203-229, 1989.

Oxburgh, E. R., and E. M. Parmentier, Compositional and density stratification in oceanic lithosphere - Causes and consequences, $J$. Geol. Soc. London, 133, 343-355, 1977.

Phipps Morgan, J., and Y. J. Chen, The genesis of oceanic crust: Magma injection, hydrothermal circulation, and crustal flow, J. Geophys. Res., 98, 6283-6298, 1993.

Phipps Morgan, J., and D. W. Forsyth, 3-D flow and temperature perturbations due to a transform offset: Effects on oceanic crustal and upper mantle structure, J. Geophys. Res., 93, 2955-2966, 1988.

Prince, R. A., and D. W. Forsyth, Horizontal extent of anomalously thin crust near the Vema Fracture Zone from the three-dimensional analysis of gravity anomalies, J. Geophys. Res., 93, 8051-8063, 1988

Riley, G. N., Jr., D. L. Kohlstedt, and F. M. Richter, Melt migration in a silicate liquid-olivine system: An experimental test of compaction theory, Geophys. Res. Lett., 17, 2101-2104, 1990.

Salters, V. J. M., and S. R. Hart, The hafnium paradox and the role of garnet in the source of mid-ocean ridge basalts, Nature, 342, 420 $422,1989$.

Scheirer, D. S., and K. C. Macdonald, Variation in cross-sectional area of the axial ridge along the East Pacific Rise: Evidence for the magmatic budget of a fast spreading center, J. Geophys. Res., 98, 7871-7886, 1993.

Sinton, J. M., and R. S. Detrick, Mid-ocean ridge magma chambers, $J$. Geophys. Res., 97, 197-216, 1992.

Sinton, J. M., S. M. Smaglik, J. J. Mahoney, and K. C. Macdonald, Magmatic processes at superfast spreading mid-ocean ridges: Glass compositional variations along the East Pacific Rise $13^{\circ}-23^{\circ} \mathrm{S}, J$. Geophys. Res., 96, 6133-6155, 1991.

Smith, W. H. F., and P. Wessel, Gridding with continuous curvature splines in tension, Geophysics, 55, 293-305, 1990.

Solomon, S. C., and D. R. Toomey, The structure of mid-ocean ridges, Annu. Rev. Earth Planet. Sci., 20, 329-364, 1992.

Sparks, D. W., E. M., Parmentier, and K. Jha, The effect of melt migration on 3-D mantle flow beneath spreading centers: relative effects of thermal, compositional, and melt-retention buoyancy, Eos Trans. AGU, 74 (16), Spring Meeting suppl., 304, 1993a.

Sparks, D. W., E. M. Parmentier, and J. Phipps Morgan, Threedimensional mantle convection beneath a segmented spreading center: Implications for along-axis variations in crustal thickness and gravity, J. Geophys. Res., 98, 21,977-21,995, 1993b.

Stevenson, J. M., J. A. Hildebrand, M. A. Zumberge, and C. G. Fox, An ocean bottom gravity study of the southern Juan de Fuca Ridge, $J$. Geophys. Res., 99, 4875-4888, 1994.

Su, W., and W. R. Buck, Buoyancy effects on mantle flow under MidOcean Ridges, J. Geophys. Res., 98, 12,191-12,205, 1993.

Talwani, M., J. L. Worzel, and M. Landisman, Rapid gravity computations for two-dimensional bodies with application to the Menodcino submarine fracture zone, J. Geophys. Res., 64, 49-59, 1959.

Tolstoy, M., A. J. Harding, and J. A. Orcutt, Crustal thickness on the 
Mid-Atlantic Ridge: Bull's eye gravity anomalies and focused accretion, Science, 262, 726-729, 1993.

Toomey, D. R., G. M. Purdy, S. C. Solomon, and W. S. D. Wilcock, The three-dimensional seismic velocity structure of the East Pacific Rise near latitude $9^{\circ} 30^{\prime} \mathrm{N}$, Nature, 347, 639-645, 1990.

Vera, E. E., and J. B. Diebold, Seismic imaging of oceanic layer $2 \mathrm{~A}$ between $9^{\circ} 30^{\circ} \mathrm{N}$ and $10^{\circ} \mathrm{N}$ on the East Pacific Rise from two-ship wide-aperture profiles, J. Geophys. Res., 99, 3031-3042, 1994.

Vera, E. E., et al., The structure of $0-0.2 \mathrm{My}$ old oceanic crust at $9^{\circ} \mathrm{N}$ in the East Pacific Rise from expanded spread profiles, J. Geophys. Res. 95, 15,529-15,556, 1990.

Wang, X., and J. R. Cochran, Gravity anomalies, isostasy, and mantle flow at the East Pacific Rise crest, J. Geophys. Res., 98, 19,505$19,532,1993$.

Watson, E. B., Diffusion in fluid-bearing and slightly-melted rocks: Experimental and numerical approaches illustrated by iron transport in dunite, Contrib. Mineral. Petrol., 107, 417-434, 1991.
Wilson, D., Focused mantle upwelling beneath mid-ocean ridges: Evidence from seamount formation and isostatic compensation of topography, Earth Planet. Sci. Lett., 113, 41-55, 1992.

Wilson, D., S., D. A. Clague, N. H. Sleep, and J. L. Morton, Implications of magma convection for the size and temperature of magma chambers at fast spreading ridges, J. Geophys. Res., 93, 11.974-11,984, 1988.

P. Buhl and J. Mutter, Lamont-Doherty Earth Observatory, Palisades, NY 10964.

R. S. Detrick, G. M. Kent, and L. S. Magde, Department of Geology and Geophysics, Woods Hole Oceanographic Institution, Woods Hole, MA 02543.

A. J. Harding and J. A. Orcutt, Scripps Institution of Oceanography, University of California, San Diego, La Jolla, CA 92093.

(Received June 30, 1994; revised October 17, 1994;

accepted November 2, 1994.) 


\section{CHAPTER 3}

Seamount Volcanism at the Reykjanes Ridge:

Relationship to the Iceland Hot Spot 
Magde, L. S. and D. K. Smith, Seamount Volcanism at the Reykjanes Ridge: Relationship to the Iceland Hot Spot, J. Geophys. Res., 100, 8449-8468, 1995. Copyright by the American Geophysical Union. Reprinted with permission. 


\title{
Seamount volcanism at the Reykjanes Ridge: Relationship to the Iceland hot spot
}

\author{
Laura S. Magde ${ }^{1}$ and Deborah K. Smith \\ Department of Geology and Geophysics, Woods Hole Oceanographic Institution, Woods Hole, Massachusetts
}

\begin{abstract}
The axial zone of the Reykjanes Ridge is covered with small (0.5-3 km in diameter) volcanoes that pile together to form larger axial volcanic ridges. This style of volcanism is similar to that at the Mid-Atlantic Ridge (MAR) and may be common to slow spreading ridges despite proximity of the Reykjanes Ridge to the Iceland hot spot. In this study we quantitatively investigate the population of seamounts in three study areas at the Reykjanes Ridge. Areas A and B are centered at $62^{\circ} \mathrm{N}$ and $60^{\circ} \mathrm{N}$, respectively. Area C is centered at $58^{\circ} \mathrm{N}$ and is located south of the transition in ridge morphology from an axial high to an axial graben. Using multibeam bathymetry data, 541 seamounts (summit height $H>50 \mathrm{~m}$ ) were identified in the three areas, and their size and shape statistics were compiled. Additionally, 105 seamounts in areas B and C were recognized in deep-towed side scan images, and their surface morphologies (hummocky or smooth) were recorded. On the basis of estimated population parameters, we find that seamounts at the Reykjanes Ridge are more abundant $\left(310 \pm 20\right.$ per $\left.10^{3} \mathrm{~km}^{2}\right)$, on average, than at the MAR between $24^{\circ}$ and $30^{\circ} \mathrm{N}\left(200 \pm 10\right.$ per $\left.10^{3} \mathrm{~km}^{2}\right)$. Significant along-axis variations exist at the Reykjanes Ridge, however, which are not simply related to distance from the hot spot: area B has nearly twice the abundance of seamounts as either area A or area C. Variation in the characteristic height of the seamount population is also observed between the Reykjanes Ridge $(68 \pm 2 \mathrm{~m})$ and the $\operatorname{MAR}(58 \pm 2 \mathrm{~m})$, but no significant variation is found between our three study areas. A dramatic change in seamount surface morphology occurs between areas B and C (there are no side scan data from area A). Area $\mathrm{C}$ has $78 \%$ hummocky seamounts (similar to the proportion observed at the MAR), while area B has $83 \%$ smooth seamounts. On the basis of these results, we present a conceptual model for building the shallow crust at the slow spreading Reykjanes Ridge that takes into account the possible influence of the Iceland hot spot on the crustal melt delivery system and its influence on variables that control seamount abundances, sizes, shapes, and surface morphologies. In this model we suggest that the increased seamount production and proliferation of smooth seamounts in area B may be associated with a pulse of hot spot material, in the form of asthenosphere of higher temperature, that has recently affected area B.
\end{abstract}

\section{Introduction}

The axial zone of the slow spreading $(10 \mathrm{~mm} / \mathrm{yr}$ half rate) Reykjanes Ridge is dominated by en echelon volcanic ridges [Shih et al., 1978; Laughton et al., 1979; Jacoby, 1980; Searle and Laughton, 1981; Johnson and Jakobsonn, 1985], which recent detailed studies [Murton and Parson, 1993; Parson et al., 1993a; Applegate and Shor, 1994] have shown to be constructed of small (0.5-3.0 km in diameter) seamounts, ridges, and flows. This type of volcanic morphology, consisting of myriad small volcanoes and hummocky flows combining to build axial volcanic ridges, is similar to that observed in multibeam bathymetry data and deep-towed side scan sonar images of the median valley floor of the Mid-Atlantic Ridge (MAR) at $24^{\circ}$ $30^{\circ} \mathrm{N}$ [Smith and Cann, 1992, 1993; Smith et al., 1995] and may be common to slow spreading ridges. By contrast, small volcanic edifices are rare at the axis of the fast spreading East Pacific Rise

\footnotetext{
${ }^{1}$ Also at WHOIMIT Joint Program in Oceanography, Woods Hole, Massachusetts.
}

Copyright 1995 by the American Geophysical Union.

Paper number 95JB00048.

0148-0227/95/95JB-00048\$05.00 [e.g., Fornari et al., 1987], where the style of volcanism is characterized by low-relief flows [e.g., Macdonald et al., 1989]. The formation of small volcanoes at the axis of the Reykjanes Ridge suggests that the shallow crustal plumbing system is the same as that at other slow spreading ridges.

The Reykjanes Ridge is not a typical slow spreading ridge, however. It is located next to the Iceland hot spot, and while small volcanoes are built at the axis as at other slow spreading ridges, the large-scale topography north of $59^{\circ} \mathrm{N}$ is an axial high similar to that observed at fast spreading centers. South of $59^{\circ} \mathrm{N}$, the large-scale topography is a well-defined axial graben, typical of slow spreading centers [Laughton et al., 1979]. This change in the overall topography has been attributed to higher temperatures under the northern part of the Reykjanes Ridge due to the proximity of the Iceland hot spot [Laughton et al., 1979; Jacoby, 1980; Searle and Laughton, 1981]. It has been suggested that such increases in mantle temperature might coincide with larger fractions of melting and therefore a larger magma supply than spreading rate alone would predict [e.g., White, 1989]. If this is the case, it is intriguing that the increased melt supply appears to affect only the overall topography of the axial zone and not the construction of the smaller-scale volcanic edifices which form the shallow crust.

An investigation of the population of small volcanoes at the Reykjanes Ridge provides important information on the 
processes controlling crustal accretion. Moreover, the proximity of the Reykjanes Ridge to the Iceland hot spot provides an ideal setting in which to differentiate between the influence of spreading rate and the influence of hot spots on these processes. In this study we look quantitatively at the numerous small, nearcircular volcanoes (seamounts) found within the axial zone of the Reykjanes Ridge as well as those volcanoes observed off axis. Three areas located at varying distances from the Iceland hot spot were investigated (Figure 1): areas $\mathrm{A}$ and $\mathrm{B}$, centered at $62^{\circ} \mathrm{N}$ and $60^{\circ} \mathrm{N}$, respectively, which both have axial highs, and area C centered at $58^{\circ} \mathrm{N}$, which has an axial graben. Multibeam bathymetry maps exist for each area [Murton and Parson, 1993; Parson et al., 1993; Applegate and Shor, 1994]; in addition, deep-towed side scan sonar data [Murton and Parson, 1993; Parson et al., 1993a] have been collected in the two southern regions. Using the multibeam bathymetry data, 541 seamounts greater than $50 \mathrm{~m}$ high were identified in the three areas, and their size and shape parameters were determined. Of these, 105 were recognized in the side scan sonar images. The seamounts exhibit two surface morphologies in the side scan images: hummocky (bulbous) and smooth. The surface morphology of each seamount was recorded.

In this paper we show that the seamounts at the Reykjanes Ridge are, on average, taller and more abundant than their MAR counterparts between $24^{\circ}$ and $30^{\circ} \mathrm{N}$ described by Smith and Cann [1992]. Moreover, seamount abundances do not vary systematically as a function of distance from the Iceland hot spot: area $\mathrm{B}$ has nearly twice the abundance than either area $\mathrm{A}$ or area C. In contrast, no significant along-axis variation in volcano height is found. We also show that a dramatic change in seamount volcanic morphology occurs between the southern study areas: area $\mathrm{C}$, with an axial graben, has $78 \%$ hummocky seamounts, while area B, with an axial high, has $83 \%$ smooth seamounts (there are no side scan data for area A). With these results in mind, we speculate on how the Iceland hot spot might influence the crustal melt delivery system, as well as its possible effects on the physical parameters (e.g., lava density and viscosity, eruption rates, vent geometries) that control seamount shape, size, and volcanic morphology.

\section{Overview of Tectonic Setting and Previous Work}

The Reykjanes Ridge is a 900-km-long continuation of the Mid-Atlantic Ridge system which extends from the Bight Transform zone at $56^{\circ} 45^{\prime} \mathrm{N}$, where the ridge axis is at a depth of $2500 \mathrm{~m}$, to $63^{\circ} 30^{\prime} \mathrm{N}$, where the ridge rises to the sea surface and continues subaerially as the Reykjanes Peninsula (Figure 2). Seismic refraction studies [Bunch and Kennett, 1980; Reykjanes Ridge Seismic Experiment (RRISP) Working Group, 1980] indicate that this shoaling of the ridge is accompanied by a gradual thickening of the oceanic crust, from the typical $6 \mathrm{~km}$ to $8 \mathrm{~km}$ at $59^{\circ} \mathrm{N}$ and $10 \mathrm{~km}$ at $62^{\circ} \mathrm{N}$. Both of these characteristics have been attributed to increasing mantle temperatures associated with proximity to the Iceland hot spot [e.g., Searle and Laughton, 1981]. Also attributed to the influence of the hot spot is the change in strike of the axis, at the Bight Transform. North of the Bight Transform, the ridge axis bends to trend directly toward Iceland at $036^{\circ}$, highly oblique to the $099^{\circ}$ spreading direction [Shih et al., 1978; Laughton et al., 1979] (Figure 1).

Although axial depths increase as a function of increasing distance from the hot spot, a region of anomalously shallow depths near $60^{\circ} \mathrm{N}$ has been attributed to elevated mantle temperatures underneath this section of the Reykjanes Ridge [e.g., Searle and Laughton, 1981]. It has been postulated that this

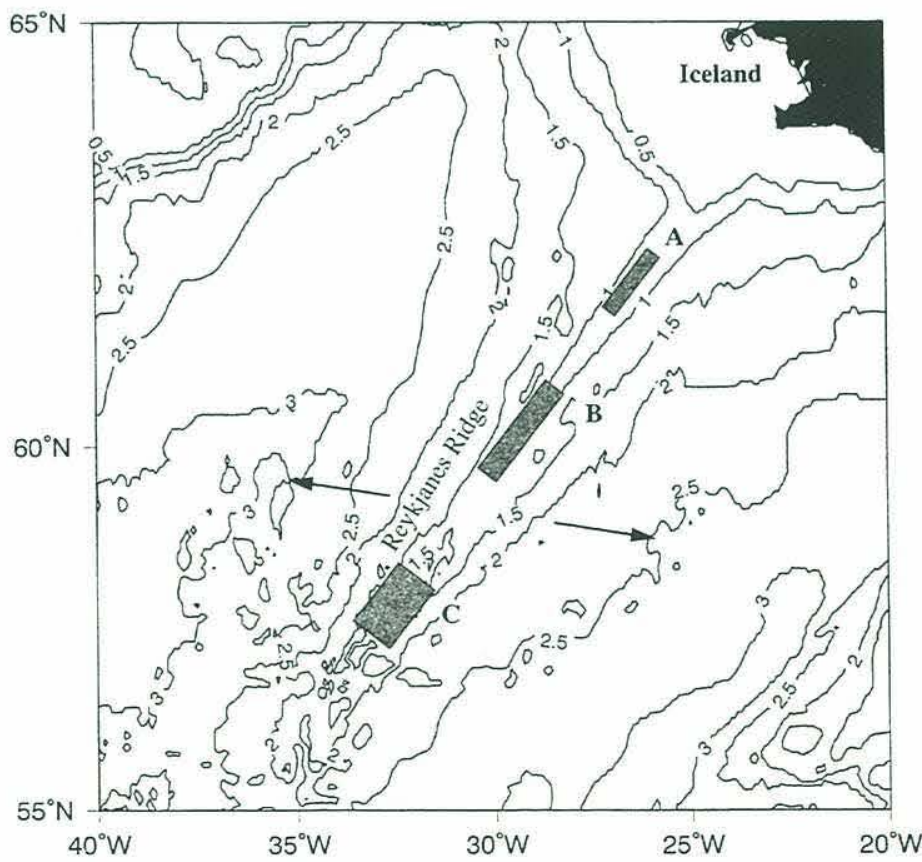

Figure 1. Simplified bathymetry of the Reykjanes Ridge showing location of the three study areas. Arrows indicate spreading direction [Shih et al., 1978; Laughton et al., 1979], which is highly oblique relative to the strike of the ridge. 


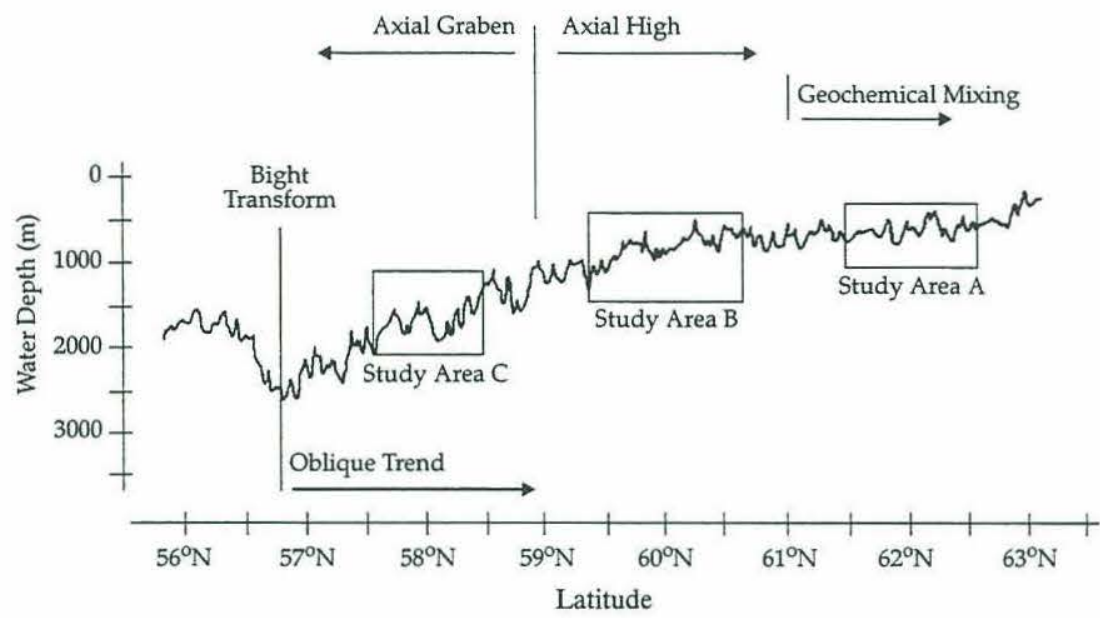

Figure 2. Along axis depth profile for the Reykjanes Ridge. Also noted are various physical parameters that change along axis [after Applegate and Shor, 1994]. The oblique trend of the Reykjanes Ridge begins at the Bight Transform. The change in overall morphology from an axial graben to an axial high occurs near $59^{\circ} \mathrm{N}$. Evidence for direct incorporation of hot spot magma into erupted basalts extends from Iceland to $61^{\circ} \mathrm{N}$. The locations of the three study areas are indicated.

area is isostatically supported by hot material derived from the Iceland hot spot [e.g., Murton and Parson, 1993]. This hypothesis is supported by the identification of southward pointing, V-shaped topographic ridges which have been interpreted as the result of successive pulses of hot spot material moving away from Iceland along the Reykjanes Ridge [Vogt, 1971; Vogt and Avery, 1974; Owens, 1994]. The southern end of this region of anomalously shallow depths roughly corresponds to the location of the change from an axial high (north of $59^{\circ} \mathrm{N}$ ) to an axial graben (Figure 2).

The direct contribution of Iceland hot spot material to the construction of the Reykjanes Ridge was established by the analysis of dredged samples [Hart et al., 1973; Schilling, 1973; Johnson and Jakobsonn, 1985], which revealed that the volcanics forming the Reykjanes Ridge are compositionally similar to volcanic rocks analyzed from the Reykjanes Peninsula and other parts of Iceland. Hart et al. [1973] found a rapid transition from high to low ${ }^{87} \mathrm{Sr} /{ }^{86} \mathrm{Sr}$ ratios near $62^{\circ} \mathrm{N}$ and attributed this to a transition between two mantle sources. In addition, Schilling $[1973,1986]$ demonstrated that from $64^{\circ}$ to $61^{\circ} \mathrm{N}$ (see Figure 2) there is a distinct decrease in the concentration of many large incompatible trace elements (e.g., $\mathrm{K}$ and $\mathrm{La}$ ) and minor elements (e.g., $\mathrm{Ti}$ and $\mathrm{P}$ ). South of $61^{\circ} \mathrm{N}$ the various chemical concentrations show no further change. Schilling [1986] interpreted this as the mixing of two end-member compositions: a primordial hot mantle plume source which dominates north of $64^{\circ} \mathrm{N}$ and a typical source of mid-ocean ridge basalt which dominates south of $61^{\circ} \mathrm{N}$. Interestingly, this location corresponds neither to the break in slope of the along-axis water depth profile nor to the change from an axial high to an axial graben, both of which occur near $59^{\circ} \mathrm{N}$

Superimposed on the long-wavelength trends of the Reykjanes Ridge is a pattern of intermediate- and short-wavelength segmentation [Shih et al., 1978; Searle and Laughton, 1981; Murton and Parson, 1993; Applegate and Shor, 1994]. The intermediate wavelength $(15-65 \mathrm{~km})$ segmentation corresponds to the second- and third-order segments (delineated by overlapping spreading centers and other nontransform offsets) at the MAR which have been related to zones of focused mantle upwelling beneath the ridge [e.g., Kuo and Forsyth, 1988; Lin et al., 1990]. The short-wavelength $(5-30 \mathrm{~km})$ segmentation corresponds to individual volcanic systems or axial volcanic ridges (AVRs) which are also common at the MAR [e.g., Sempere et al., 1993]. The AVRs at the Reykjanes Ridge display $100-400 \mathrm{~m}$ of vertical relief and are arranged en echelon, dextrally offset from one another with a mean offset of $5.4 \mathrm{~km}$ and up to $50 \%$ overlap [e.g., Applegate and Shor, 1994].

Although the overall trend of the Reykjanes Ridge is oblique to the spreading direction (Figure 1), individual AVRs are perpendicular to the spreading direction [e.g., Searle and Laughton, 1981; Johnson and Jakobsonn, 1985]. Faults and fissures observed within the axial zone are also perpendicular to the spreading direction [e.g., Jacoby, 1980; Murton and Parson, 1993] indicating that far-field tectonic stresses dominate in this region. For additional discussions of the interplay of tectonic and volcanic processes at the axis of the Reykjanes Ridge, see Jacoby [1980], Searle and Laughton [1981], Murton and Parson [1993], Parson et al. [1993a], and McAllister et al. [1995].

Work by Applegate and Shor [1994] as well as the studies by Murton and Parson [1993] and Parson et al. [1993a] included the identification of axial seamounts. Applegate and Shor [1994] noted that the region of the axis near $59^{\circ} 50^{\prime} \mathrm{N}$ has an anomalously high abundance of seamounts. This is the region discussed above with anomalously shallow water depths. It is part of our area B (Figure 1), and we discuss its significance in later sections of this paper. Murton and Parson [1993a] and Parson et al. [1993] examined variations in seamount shapes and morphologies with respect to AVR characteristics and suggested that they were related to various stages in the evolutionary life cycle of an AVR. In this paper our approach is different in that we quantitatively characterize and compare seamount populations, within and outside the axial zone, in three study areas along the ridge. Our aim is to better understand the influence of the Iceland hot spot on the processes that control seamount construction. 
Seamounts similar to those in our study regions have been identified from multibeam bathymetry data between $24^{\circ}$ and $30^{\circ} \mathrm{N}$ at the MAR [Smith and Cann, 1992,1993]. Smith and Cann [1992] characterized the abundances, distribution, and shapes of this population of 481 seamounts and suggested that in combination with flows, seamounts pile up and coalesce to form large AVRs. This is also how AVRs appear to form at the Reykjanes Ridge. In addition, Smith et al. [1995] used deeptowed side scan sonar data to classify the surface morphology of 109 MAR seamounts. At the tens of meters scale, two morphological forms were recognized: hummocky ( $83 \%)$ and smooth (17\%). These forms are analogous to the hummocky and smooth forms recognized in this study.

Our characterization of the seamount populations observed both within and outside the axial zone along the Reykjanes Ridge uses the same techniques that were applied to the MAR population [Smith and Cann, 1992; Smith et al., 1995]. Here, we investigate changes in seamount character with distance from the Iceland hot spot and, by inference, the possible influence of the hot spot on shallow crust formation. In doing so, we further refine our understanding of the process of crustal construction at the Reykjanes Ridge and how it compares to the process occurring at more typical slow spreading mid-ocean ridges.

\section{Data Description and Study Areas}

The data used in this study were collected in 1990 using the Hydrosweep multibeam sonar system and British towed ocean bottom instrument (TOBI) deep-towed side scan sonar system [Parson et al., 1993a]. The hull-mounted Hydrosweep multibeam echo sounder generally returns 59 cross-track depths for every sounding ping. The swath width is about twice the water depth. In water depths of $1 \mathrm{~km}$ (typical in areas A and B), each data point represents a patch of seafloor approximately $35 \mathrm{~m}$ on a side; in water depths of $2 \mathrm{~km}$ (typical in area $\mathrm{C}$ ), data points represent patches $70 \mathrm{~m}$ on a side. The $30-\mathrm{kHz}$ TOBI side scan system [Murton et al., 1992], built and operated by the Institute of Oceanographic Sciences Deacon Laboratories in Wormley, England, is towed approximately $400-600 \mathrm{~m}$ above the seafloor, giving a total swath width of $6 \mathrm{~km}$. The resolution of the side scan images is a function of range, but in general, the image pixel size is about $10 \mathrm{~m}$; features with diameters of a few tens of meters or greater are well resolved.

Cruise tracks for both Hydrosweep and TOBI side scan data collection are shown in Figure 3. Within each of the three areas, the Hydrosweep surveys were designed to image the entire axial region and to obtain as much off-axis data as time permitted. Typical sections of multibeam bathymetry data for each area are shown in Figure 4. The characteristics of each area are described below and are summarized in Table 1. For a detailed description of these regions, see Parson et al. [1993a] and Murton and Parson [1993].

\section{Area A}

This northernmost area is a $117-\mathrm{km}$-long section of the Reykjanes Ridge centered at $62^{\circ} \mathrm{N}$. Figure 4 shows that the large-scale topography consists of an axial high topped by a series of dextrally offset AVRs averaging $\sim 20-30 \mathrm{~km}$ in length and $\sim 3 \mathrm{~km}$ wide, and overlapping each other by as much as $50 \%$ (up to $15 \mathrm{~km}$ ). Area A is in the region identified by Schilling [1973,1986] where hot spot magma is directly incorporated into the erupted magma. The crust in this area is approximately 10 $\mathrm{km}$ thick [RRISP Working Group, 1980]. The average water depth of the ridge crest is roughly $900 \mathrm{~m}$. Multibeam bathymetry covers $690 \mathrm{~km}^{2}$ of seafloor from 0 to $0.4 \mathrm{Ma}$. No side scan data were collected in area A.

\section{Area B}

This large central study area is located just north of the break in slope of the along-axis water depth profile (Figure 2). The study area is $141 \mathrm{~km}$ long, centered near $60^{\circ} \mathrm{N}$. The large-scale topography (Figure 4) is an axial high topped by AVRs similar to those observed in area A. These AVRs are somewhat larger than those in area $\mathrm{A}$ and include one very large AVR at $60^{\circ} 15^{\prime}$ which is about $30 \mathrm{~km}$ long, $6 \mathrm{~km}$ wide, and $400 \mathrm{~m}$ high. As in area A, these AVRs are dextrally offset from each other and can overlap as much as $50 \%$. Area B is south of the region of direct hot spot influence on magma chemistry [Schilling, 1973; 1986] on crust approximately $8 \mathrm{~km}$ thick [Bunch and Kennett, 1980]. The
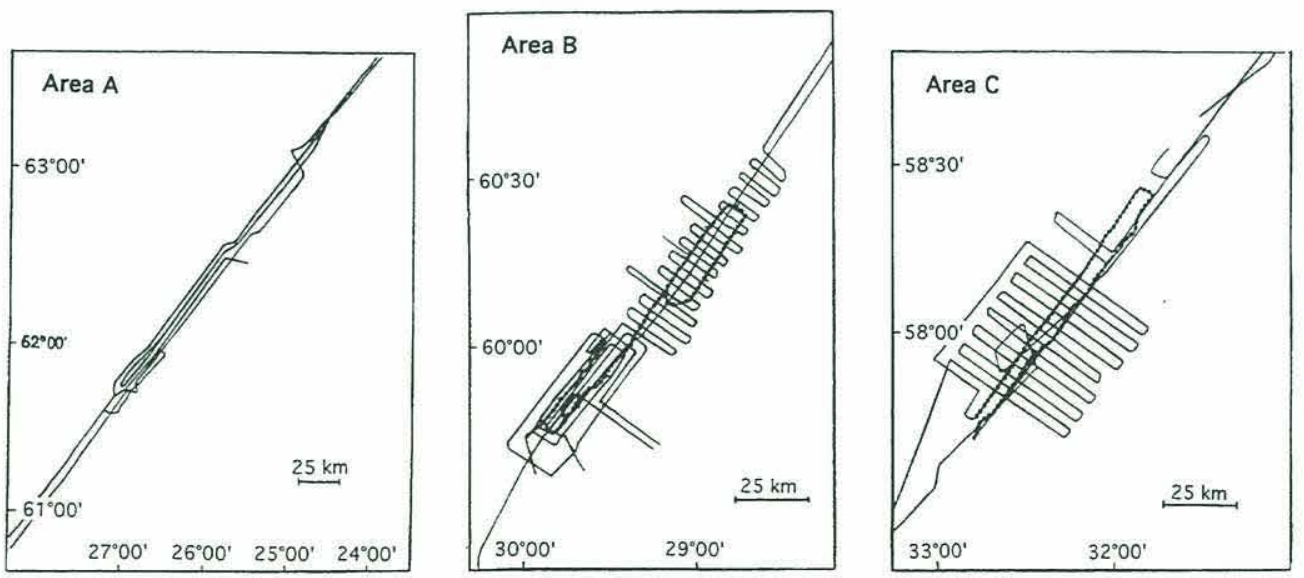

Figure 3. Track lines showing Hydrosweep coverage for all three study areas. In areas B and C track lines showing towed ocean bottom instrument (TOBI) side scan coverage (dotted lines) are also included. Redrawn from Parson et al. [1993b]. 


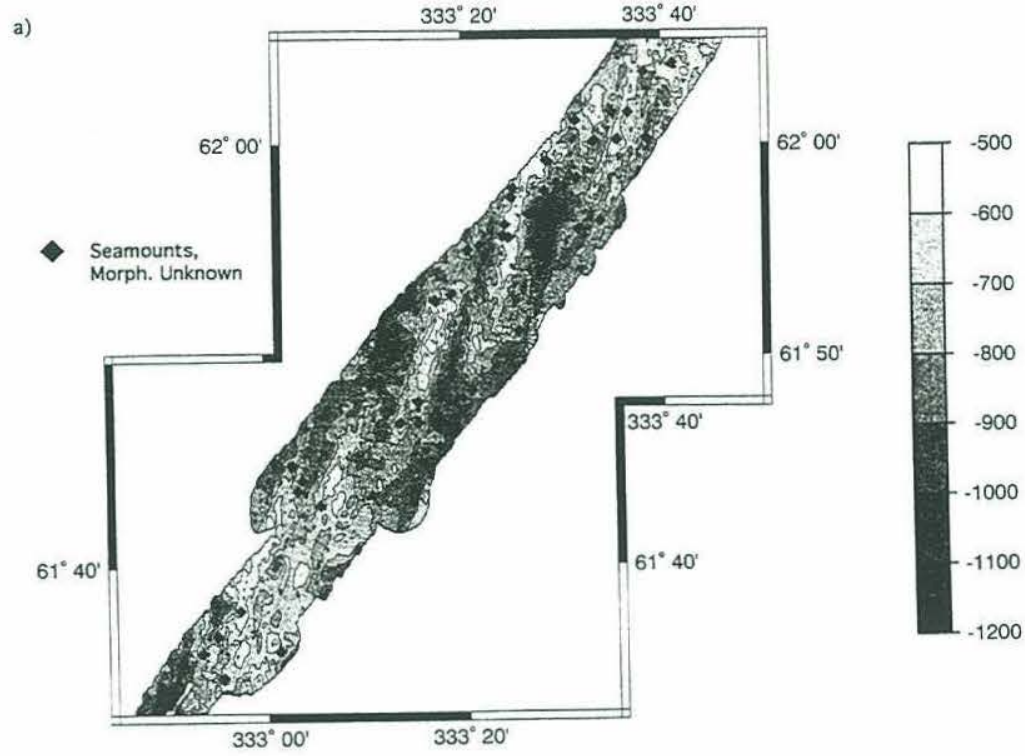

Figure 4a. Sample of Hydrosweep bathymetry data showing representative section of area A with an axial high morphology. The contour interval is $100 \mathrm{~m}$. Note that these data are gridded for illustration purposes whereas the original ungridded Hydrosweep swaths were used for volcano identification. Seamount locations are indicated.

average water depth is $1100 \mathrm{~m}$ on the axial high and $1300 \mathrm{~m}$ outside the axial zone. A total of $1780 \mathrm{~km}^{2}$ of Hydrosweep data were collected: $1340 \mathrm{~km}^{2}$ in the axial zone ( 0 to $0.7 \mathrm{Ma}$ ) and 440 $\mathrm{km}^{2}$ outside the axial zone ( 0.7 to $\left.1.6 \mathrm{Ma}\right)$. In addition, 1030 $\mathrm{km}^{2}$ of side scan sonar data were collected within the axial zone.

\section{Area C}

The 108-km-long southernmost study area (centered at $58^{\circ} \mathrm{N}$ ) is south of the transition from an axial high to an axial graben morphology (Figure 4). The AVRs are similar in size to those in area $\mathrm{A}$ but do not overlap as much as those in the northern study areas. The area is well south of the region of hot spot influence on magma chemistry [Schilling, 1973; 1986]. Crustal thickness is estimated to lie between 6 and $7 \mathrm{~km}$, typical of normal ocean crust, and $8 \mathrm{~km}$ as observed farther north. The average water depth in the axial valley is $1900 \mathrm{~m}$, while that on the uplifted flanks is $1600 \mathrm{~m}$. A total of $2605 \mathrm{~km}^{2}$ of multibeam bathymetry data were collected: $865 \mathrm{~km}^{2}$ in the axial valley and $1740 \mathrm{~km}^{2}$ off

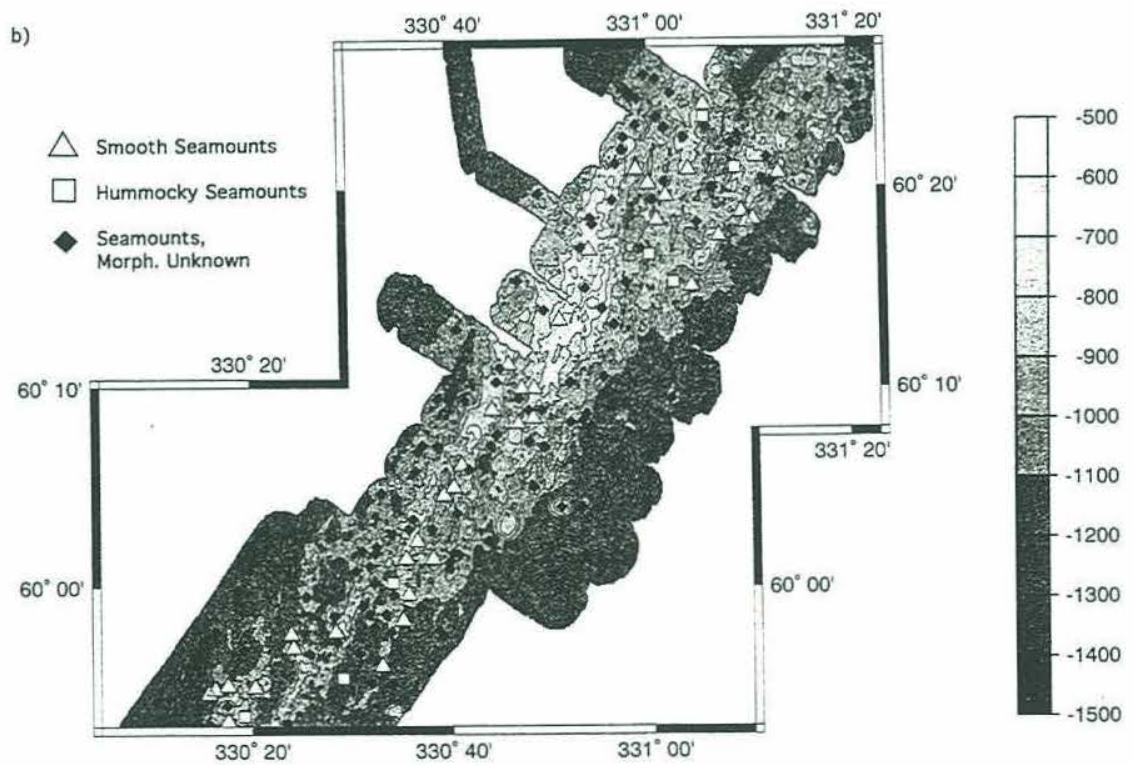

Figure 4b. Same as Figure 4a but for area B with an axial high morphology. 
c)

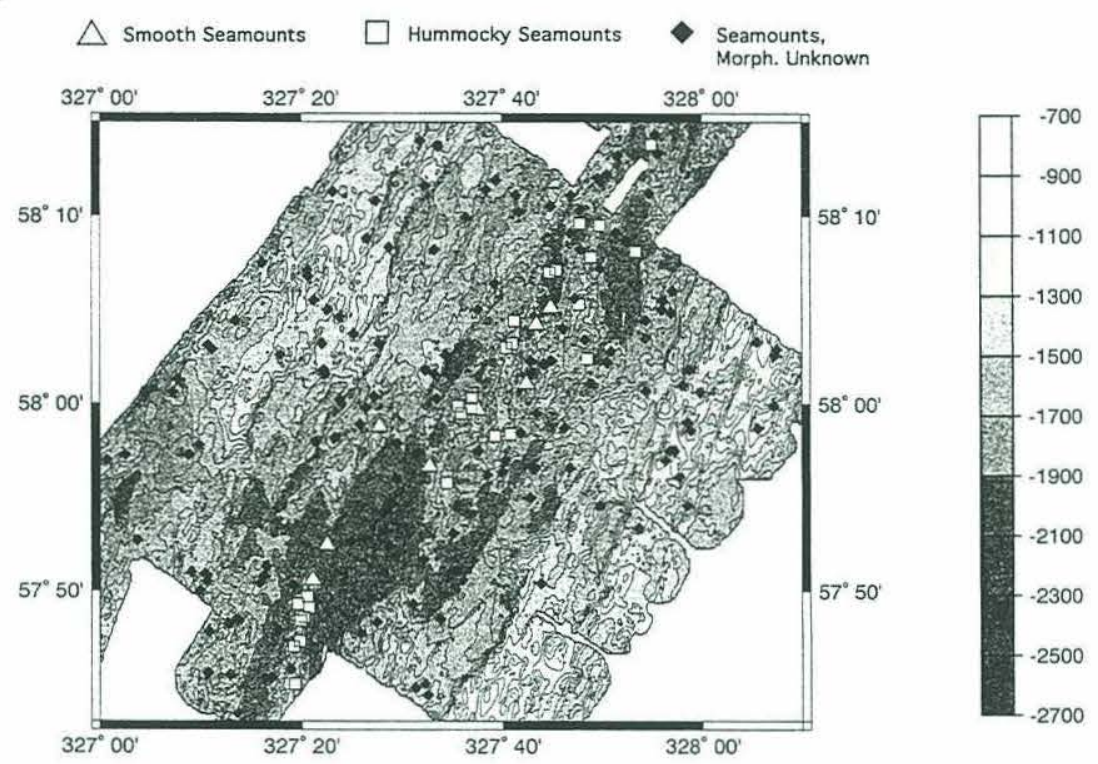

Figure 4c. Same as Figure 4a but for area $C$ with an axial graben morphology.

axis. The maximum age of the crust within the axial zone, defined by the area between the first two large-throw (typically $>150 \mathrm{~m}$ ) normal faults, is $0.6 \mathrm{Ma}$. Off-axis coverage is extensive, including crust with ages between 0.6 and $2.7 \mathrm{Ma}$. Within the axial valley, $1060 \mathrm{~km}^{2}$ of side scan sonar data were also collected.

\section{Methods}

Seamount Identification and Determination of Population Parameters From Hydrosweep Data

Seamounts were identified from Hydrosweep swaths plotted at a scale of 41.0 inches per degree and contoured at a $25-\mathrm{m}$ interval. Following the method of Smith and Cann [1992], seamounts were identified as topographic highs having approximately equant shapes (ratio of maximum to minimum diameter less than 2) and having a relief greater than $50 \mathrm{~m}$ on all sides. Figure 4 shows the location of seamounts identified in typical sections of each study area. The shape of each seamount was approximated by a flat topped cone. The plan shape of the seamount was defined by drawing a closed curve starting at the shallowest point of the break in slope at the seamount's base and continuing along the break in slope until the seamount was circumscribed. The plan shape of the top was derived in a similar manner by following a near-summit break in slope. If no break in slope was present, the diameter of the "flat top" was defined to be zero, making the seamount a standard cone. Examples of our interpretation of small sections of Hydrosweep data from areas B and $C$ are shown in Figures 5 and 6 . This procedure identified a total of 541 seamounts in the three study regions. We also recognized hundreds of features that may be seamounts but did not meet our counting criteria because their contours formed only sections of circles. These may be partially buried seamounts or seamounts abutting preexisting features. If this is the case, our counts are likely to significantly underestimate the seamount population on and near the axis of the Reykjanes Ridge.

For each seamount, we recorded latitude, longitude, and water depth to summit $\left(W_{d}\right)$ and measured basal diameter $(D)$, top diameter $(d)$, height of the cone $(h)$, and summit height of the seamount $(H)$. The summit height is the difference between the average basal depth and the shallowest depth of the seamount. The height of the cone is the average relief measured between the outlined base and the outlined flat top. In addition, the presence

Table 1. Area Descriptions

\begin{tabular}{ccccccc}
\hline Area & $\begin{array}{c}\text { Along-axis } \\
\text { length, } \mathrm{km}\end{array}$ & $\begin{array}{c}\text { Age Range, } \\
\text { Ma }\end{array}$ & $\begin{array}{c}\text { Axial } \\
\text { Topography }\end{array}$ & $\begin{array}{c}\text { Water Depth, } \\
\mathrm{m}\end{array}$ & $\begin{array}{c}\text { Multibeam } \\
\text { Data, } \mathrm{km}^{2}\end{array}$ & $\begin{array}{c}\text { TOBI } \\
\text { Data, } \mathrm{km}^{2}\end{array}$ \\
\hline $\mathrm{A}\left(62^{\circ} \mathrm{N}\right)$ & 117 & 0 to 0.4 & high & 900 & 690 & 0 \\
$\mathrm{~B}\left(60^{\circ} \mathrm{N}\right)$ & 141 & 0 to 0.7 & high & 1100 & 1340 & 1030 \\
$\mathrm{C}\left(58^{\circ} \mathrm{N}\right)$ & 108 & 0 to 0.6 & valley & 1900 & 865 & 1060 \\
Off-axis B & 69 & 0.7 to 1.6 & high & 1300 & 440 & 0 \\
Off-axis C & 108 & 0.6 to 2.7 & valley & 1200 & 1740 & 0 \\
\hline
\end{tabular}

TOBI, towed ocean bottom instrument. 
a)

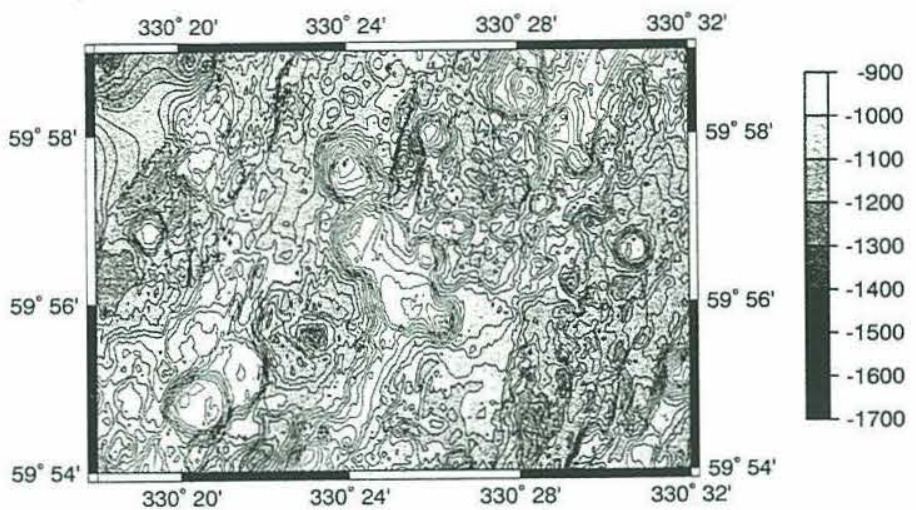

b)

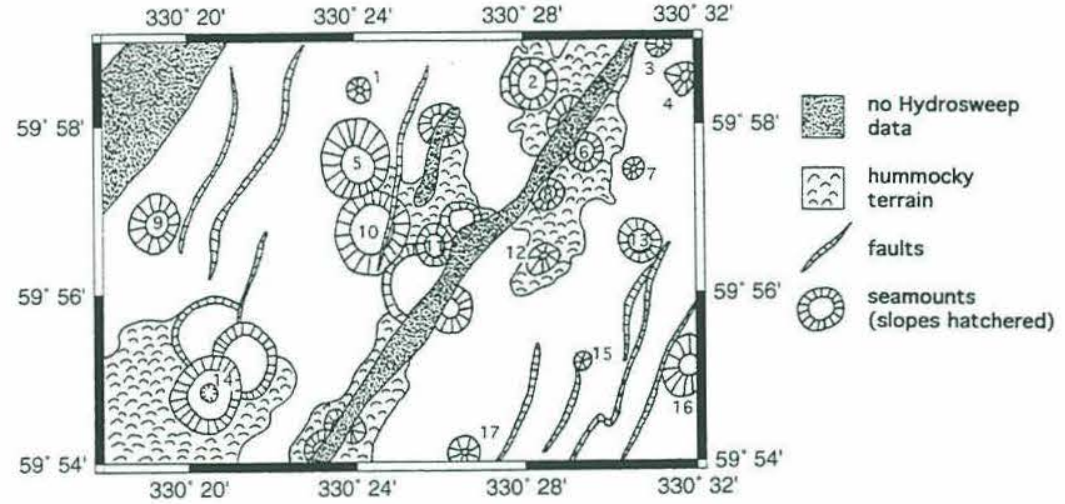

c)

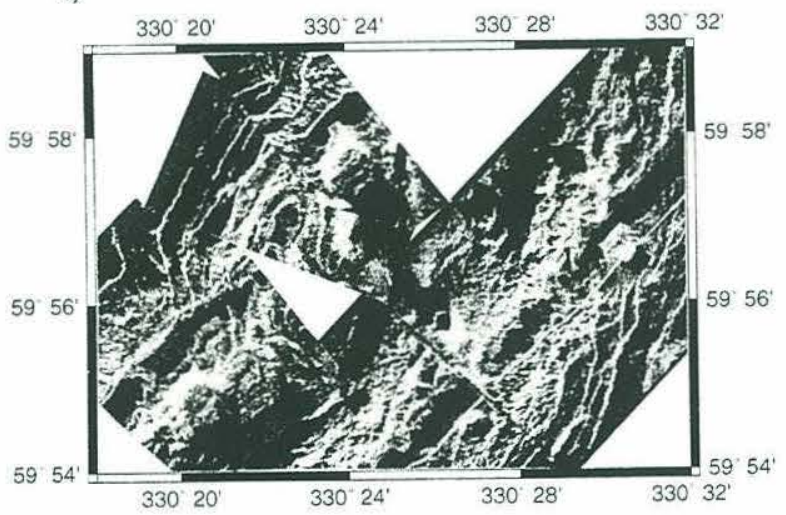

Figure 5. (a) Selected portion of area B showing gridded Hydrosweep bathymetry. Contour interval is $25 \mathrm{~m}$. (b) Interpretation of the Hydrosweep data in Figure 5a. Numbers mark features which meet our requirements for inclusion in the seamount counts. A third central circle on seamount number 14 indicates a crater. Note the numerous semicircular features in the bathymetry which are not included. (c) TOBI side scan sonar data coverage corresponding to the area shown in figure 5a. The track of the TOBI vehicle is at the center of a swath; scalloping along the track is an artifact caused by a bottom-tracking problem. Each swath is $6 \mathrm{~km}$ wide, and in general, data located within $500 \mathrm{~m}$ either side of the vehicle track are considered unreliable. Bright is a reflection, and dark is a shadow or attenuated return from sediment-covered terrain. Image pixel size varies but is about $10 \mathrm{~m}$. These mosaics have been constructed by hand, and swaths have been rotated to correct for vehicle turns. Using these data, seamounts are classified by surface texture as being smooth or hummocky. Seamounts $5,6,10,13$, 14, and 17 are smooth seamounts. Seamount 15 is a hummocky seamount. Morphology is unknown for seamounts 1-4, 7$9,11,12$, and 16. 
a)

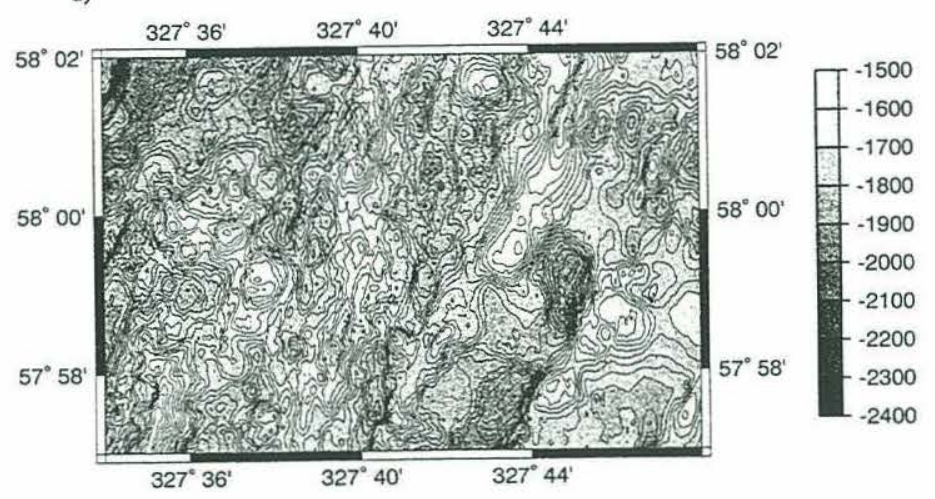

b)

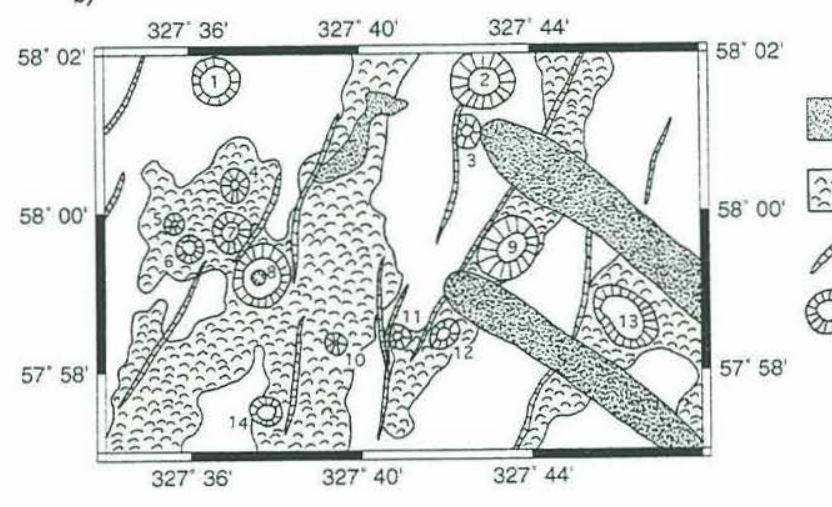

no Hydrosweep

data

ลิ․․ hummocky

$\&$ faults

Stat seamounts

(slopes hatchered)

c)

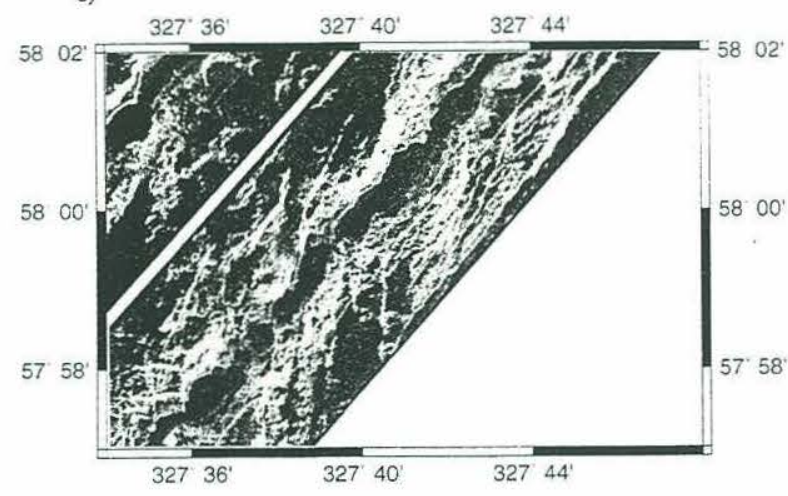

Figure 6. (a) Selected portion of area $\mathrm{C}$ showing gridded Hydrosweep bathymetry. Contour interval is $25 \mathrm{~m}$. (b) Interpretation of the Hydrosweep bathymetry in figure 6a. Numbers mark features which meet our requirements for inclusion in the seamount counts. A third central circle on seamount number 8 indicates a crater. (c) TOBI side scan data coverage corresponding to the area shown in Figure 6a. See Figure $5 \mathrm{c}$ for a description of the TOBI data. Data along two parallel tracks are shown; only a portion of the upper left swath falls in this region. Using the side scan images, seamounts are classified by surface texture as smooth or hummocky. In this region, seamounts 1,3, and 8 are smooth seamounts. Seamounts $4-7,10$, and 11 are hummocky. Surface morphology can not be determined for seamounts 2,9 , and 12-14.

of craters was recorded along with the diameter and the apparent depth of the crater. From these variables, we calculated the flatness, the ratio of top diameter to basal diameter $(f=d / D)$, the summit height-to-basal diameter ratio $\left(\xi_{d}=H / D\right)$, and the slope angle $(\Phi=\arctan (2 h /(D-d))$. Of these three parameters, only two are independent.

To characterize objectively the abundance and size distribution of the seamounts, we applied the analysis techniques of Smith 
and Jordan [1988]. The seamount size distribution is nearly exponential over a large range of seamounts heights. Therefore, the average number of seamounts with summit height $\geq H$ has the expected value: $\mathrm{v}(H)=\mathrm{v}_{0} \mathrm{e}^{-\beta H}$, where $\mathrm{v}_{\mathrm{o}}$ is the expected number of seamounts per unit area and $\beta^{-1}$ is the characteristic height of the population. Finally, using the values of the population parameters estimated from the size-frequency distribution and average values of the shape parameters, we estimated the volume of seamount per unit area of seafloor: $V=8 \pi \xi_{d}\left(1+f+f^{2}\right) v_{0} /\left(\xi_{d} \beta\right)^{3}$ This is equivalent to the thickness of a uniform layer over the area of interest.

\section{Determination of Surface Morphology From Side Scan Data}

Where TOBI data are available (axial zones for areas B and C; see Figure 3 ) the seamounts identified in the multibeam data were also identified on the side scan images. As can be seen in Figure 3. the side scan sonar coverage is not as extensive as the multibeam bathymetry coverage. In addition, many of the seamounts are located directly under the vehicle track, where no image is obtained. Nonetheless, a total of 105 features were imaged in areas B and $\mathrm{C}$, and their morphology was recorded. We recognize two distinct morphological types of seamounts on
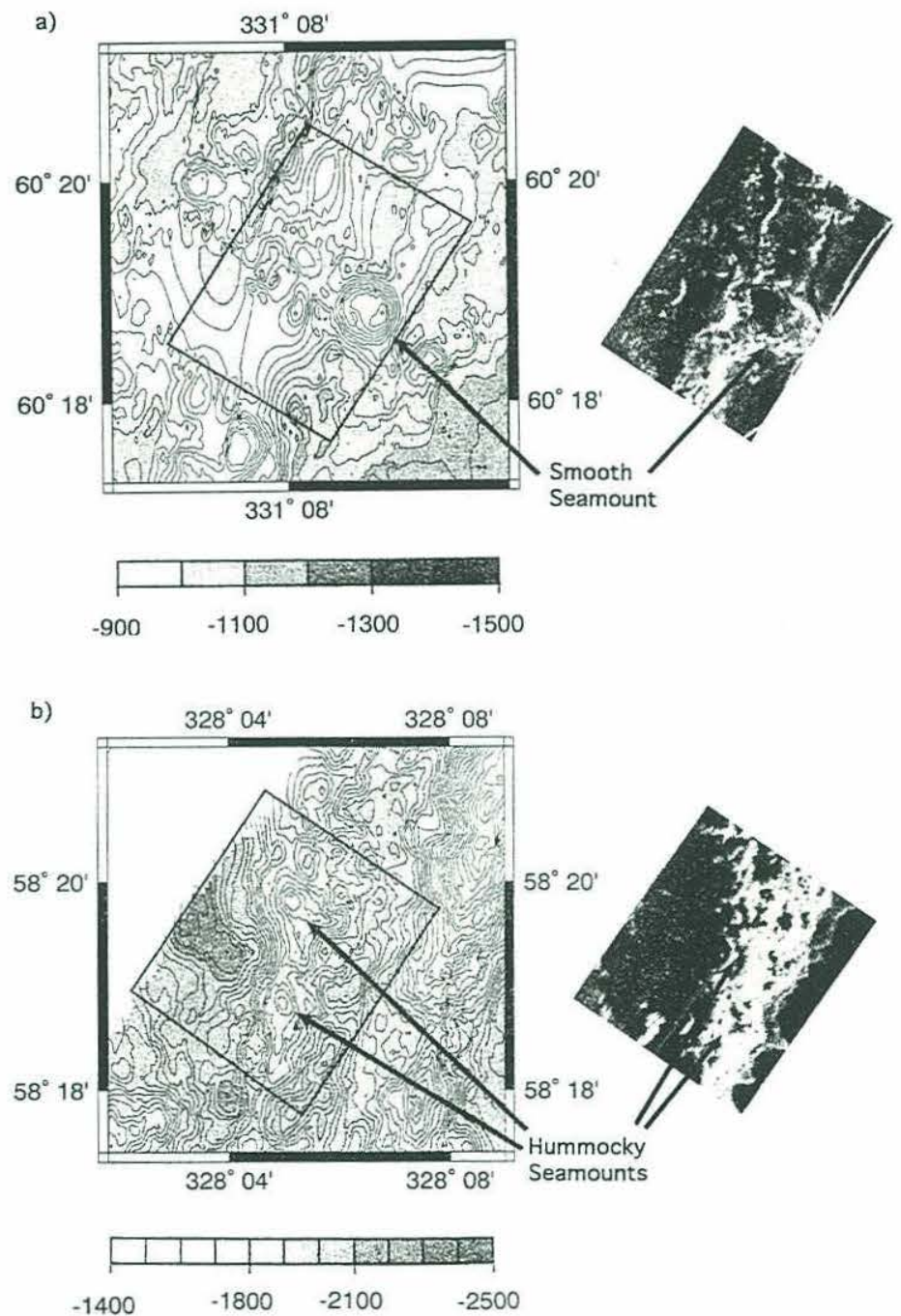

Figure 7. (a) Example of a smooth seamount located in area B. Gridded Hydrosweep data are shown in the left panel. Contour interval is $25 \mathrm{~m}$. TOBI side scan sonar data corresponding to the box on the bathymetry data are shown in the right panel. The box is approximately $2.5 \mathrm{~km}$ by $3.5 \mathrm{~km}$. See Figure $5 \mathrm{c}$ for a description of the TOBI data. The side scan data are illuminated from the southeast. The smooth seamount is located on the southeast edge of the box. The linear features casting shadows in the side scan images are faults. (b) Example of two hummocky seamounts located at the top of an axial volcanic ridge (AVR) in area C. Gridded Hydrosweep data are shown in the left panel. Contour interval is $25 \mathrm{~m}$. TOBI side scan sonar data corresponding to the box on the bathymetry data are shown in the right panel. The box is approximately $3 \mathrm{~km}$ by $3.5 \mathrm{~km}$. The side-scan data are illuminated from the southeast. Hummocky seamounts have a bulbous morphology on the scale of tens of meters. 


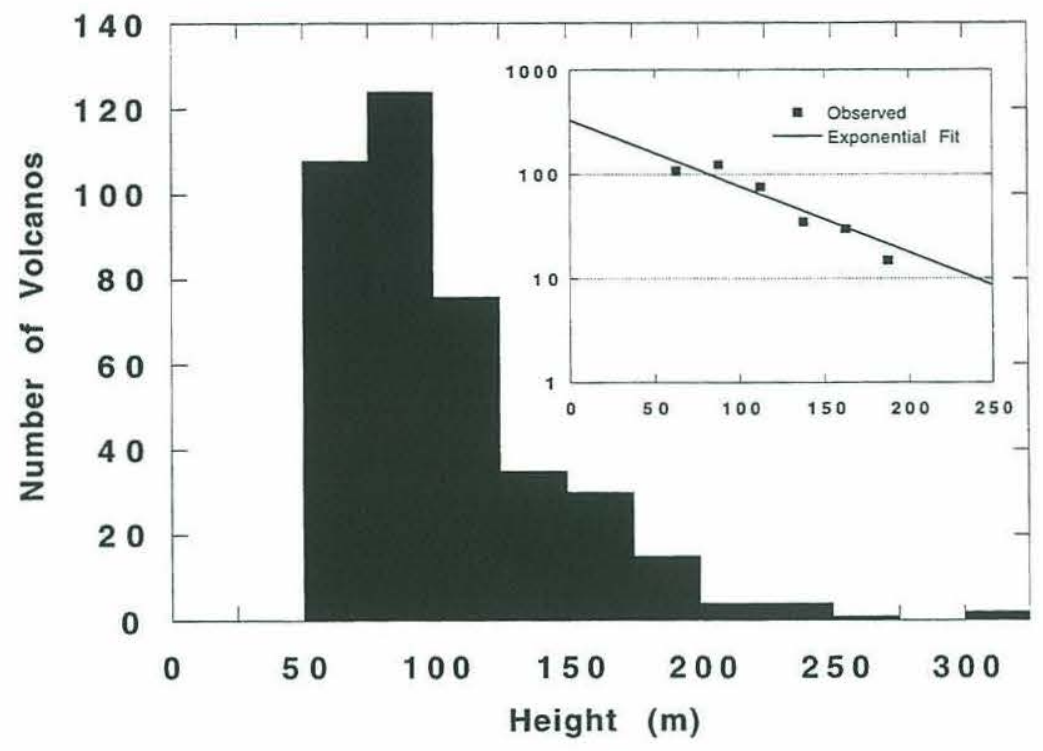

Figure 8. Summit height distribution for all seamounts identified within the axial zones of areas A, B, and C. Heights have been sorted into $25-\mathrm{m}$ bins. The distribution of volcano summit heights $(H)$ is not Gaussian but is instead skewed, with many more small volcanoes than large volcanoes. We approximate the distribution with an exponential size-frequency model. In the inset, squares are counts observed in 25-m height intervals and the solid line is a maximum likelihood fit of an exponential curve over the height interval $50-200 \mathrm{~m}$. Values of the parameters associated with this fit are given in the text.

the side scan sonar images: "smooth" (Figure 7a) and "hummocky" (bulbous) (Figure 7b). Whether the smooth and hummocky seamounts are constructed of pillows or sheet flows cannot be detected from the TOBI data. The spatial locations of the different morphological types of seamounts identified in typical sections of our study areas are shown in Figure 4.

Our analysis of the side scan data also revealed 10 craters (all on smooth seamounts) that are not evident on the Hydrosweep bathymetry. These were included in tabulations of crater populations with the recognition that crater abundances in areas lacking side scan sonar data are likely to be underestimates of true crater populations.

\section{Seamount Population Parameters}

One of the major goals of this study is to document whether volcano sizes and shapes are predictable within and between study regions, how changes correlate with proximity to the Iceland hot spot, and how the parameters compare to those compiled from other volcano studies. In this section we first consider the entire Reykjanes Ridge population as a whole and then discuss the individual study areas.

\section{Reykjanes Ridge Seamount Population}

A total of 399 seamounts were identified from the axial zones of areas A, B, and C. The summit height distribution of the axial Reykjanes Ridge seamount population is shown in Figure 8. It is approximated by an exponential distribution (Figure 8 ) with a characteristic height $\beta^{-1}=69 \pm 2 \mathrm{~m}$ and a seamount abundance $v_{0}$ $=31 \pm 2 \times 10^{-8} \mathrm{~m}^{-2}$ or $310 \pm 20$ seamounts per $10^{3} \mathrm{~km}^{2}$. (All uncertainty estimates in this paper are reported as one standard deviation from the mean.) Owing to small sample size at the large seamount heights, only seamounts with summit heights in the range $50-200 \mathrm{~m}$ were used in the maximum likelihood fitting procedure [Smith and Jordan, 1988]. Here, and in most other height distributions presented later, there are fewer seamounts in the 50- to $75-\mathrm{m}$ bin than an exponential distribution would predict. This likely reflects under sampling of small seamounts on Hydrosweep maps contoured at a $25-\mathrm{m}$ interval. Alternatively, we may be observing a more fundamental process that preferentially builds seamounts in the height range $75-100 \mathrm{~m}$.

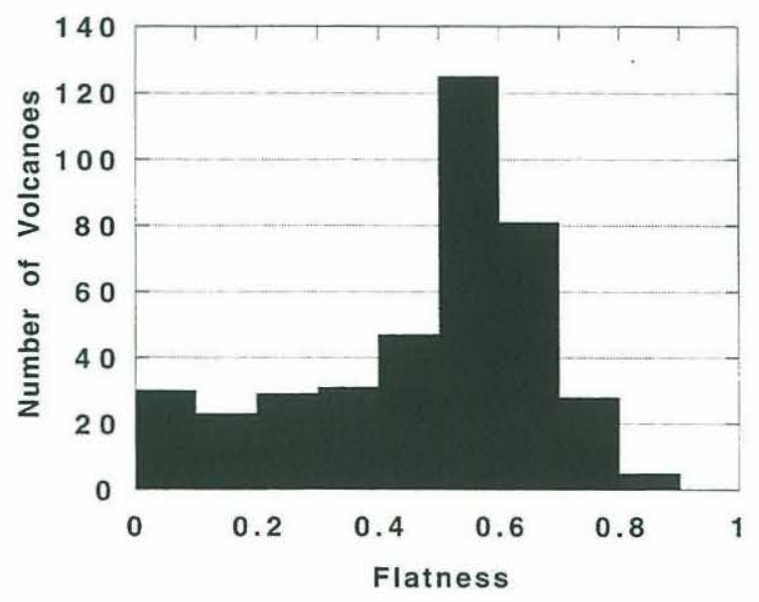

Figure 9. Distribution of flatness (top diameter/basal diameter) for all 399 seamounts identified within the axial zones of areas A, $\mathrm{B}$, and $\mathrm{C}$. The distribution peaks near $f=0.6$. The sample mean is $f=0.46 \pm 0.20$. 
Table 2. Comparison of Reykjanes Ridge and MAR Seamount Parameters

\begin{tabular}{ccccccccc}
\hline Region & $\begin{array}{c}\text { Sample } \\
\text { Size }\end{array}$ & $\begin{array}{c}\text { Age Range, } \\
\text { Ma }\end{array}$ & $\begin{array}{c}\mathrm{v}_{\mathrm{o}}, \\
10^{-8} \mathrm{~m}^{-2}\end{array}$ & $\begin{array}{c}\beta^{-1}, \\
\mathrm{~m}\end{array}$ & $\begin{array}{c}V, \\
\mathrm{~m}\end{array}$ & $\xi_{d}$ & $f$ & $\Phi$ \\
\hline $\begin{array}{c}\text { Axial } \\
\left(57^{\circ}-62^{\circ} \mathrm{N}\right) \\
\mathrm{MAR}^{*}\end{array}$ & 399 & 0 to 0.7 & $31 \pm 2$ & $68 \pm 2$ & 15 & $0.13 \pm 0.05$ & $0.46 \pm 0.20$ & $23 \pm 6$ \\
$\left(24^{\circ}-30^{\circ} \mathrm{N}\right)$ & 481 & 0 to 0.4 & $20 \pm 1$ & $58 \pm 2$ & 8 & $0.11 \pm 0.03$ & $0.31 \pm 0.16$ & $15 \pm 4$ \\
\hline
\end{tabular}

MAR, Mid-Atlantic Ridge.

* From Smith and Cann [1992].

Nevertheless, exponential curves provide a reasonable fit to the data and also allow us to compare our results to other seamount studies that have employed this method.

The 399-point sample mean of the height-to-diameter ratio is $\xi_{d}=0.12 \pm 0.05$, and the mean slope angle is $\Phi=23^{\circ} \pm 6^{\circ}$. The distribution of flatness is broad, extending from $f=0$ to $f=0.9$ with a sample mean of $f=0.46 \pm 0.20$ (Figure 9). The volume of seamounts per unit area, $V$, calculated from these parameters is equivalent to a uniform layer approximately $15 \mathrm{~m}$ thick. These characteristics, as well as those of the near-axis Reykjanes Ridge and MAR populations discussed below, are summarized in Table 2 .

An additional 142 seamounts were identified off-axis in areas B (27 seamounts) and C (115 seamounts). The characteristic height of the off-axis population is estimated to be $\beta^{-1}=66 \pm 3$ $\mathrm{m}$, the same height as the axial population. The estimated total expected number of seamounts off-axis is $v_{o}=16 \pm 1 \times 10^{-8} \mathrm{~m}^{-2}$ $\left(160 \pm 10\right.$ seamounts per $\left.10^{3} \mathrm{~km}^{2}\right)$, or about half of that observed within the axial zone. The shape parameters are also similar to those of the axial population. Sample means of the 142 seamounts are $\xi_{d}=0.12 \pm 0.06, f=0.42 \pm 0.20$, and $\Phi=23^{\circ}+$ $7^{\circ}$. The seamount volume per unit area is $V=6 \mathrm{~m}$, less than half that calculated for the axial seamounts. One explanation for the decrease in seamount abundance off-axis would be that seamount production rates may have increased at about $0.7 \mathrm{Ma}$. More likely, assuming that volcano formation is restricted to the axial zone and that the rate of production has been roughly uniform through time, this decrease in $v_{0}$ and $V$ suggests that about $50 \%$ of the seamounts are destroyed by faulting while moving out of the axial zone. In either case, a significant seamount population exists outside the axial zone, and its sizes and shapes are similar to the those of the axial volcano population.

We compared the axial populations of seamounts at the Reykjanes Ridge to the population of 481 seamounts ( $H \geq 50 \mathrm{~m}$ ) described on the inner valley floor of the Mid-Atlantic Ridge between $24^{\circ}$ and $30^{\circ} \mathrm{N}$ [Smith and Cann, 1992] (Table 2). Abundances and characteristic heights vary between these two populations. Smith and Cann [1992] report a smaller characteristic height of $\beta^{-1}=58 \pm 2 \mathrm{~m}$ and a lower expected seamount abundance of $v_{0}=20 \pm 1 \times 10^{-8} \mathrm{~m}^{-2}$. yielding $200 \pm 10$ seamounts per $10^{3} \mathrm{~km}^{2}$ for the axial MAR volcanoes. This difference in seamount size and abundance is also apparent in the volume calculation. The volume of seamounts per unit area at the MAR is $V=8 \mathrm{~m}$ compared to $V=15 \mathrm{~m}$ for the Reykjanes Ridge.

The mean value of flatness at the MAR is $f=0.31 \pm 0.16$ with flatnesses ranging from $f=0$ to $f=0.7$. This is similar to the range at the Reykjanes Ridge $(f=0-0.9)$, however, the distributions look very different. At the MAR, $50 \%$ of the seamounts have flatnesses in the range $f=0.2-0.4$, whereas the Reykjanes Ridge distribution peaks at larger flatness values, with $50 \%$ of seamounts between $f=0.5$ and $f=0.7$. This difference was confirmed by a chi-square test for distribution similarity which concluded with $>99.9 \%$ confidence that the two distributions were from different populations. The mean heightto-diameter ratio at the MAR $\left(\xi_{d}=0.11 \pm 0.03\right)$ is essentially the same as that calculated in this study and is consistent with the values obtained in other studies at the MAR [Kong et al., 1988] and in the Pacific [Abers et al., 1988; Smith and Jordan, 1988], suggesting a more universal control on this shape parameter.

\section{Area A}

Area A, closest to the Iceland hot spot, has an axial high (Figures 1 and 4). In area A, 72 volcanoes were identified from the Hydrosweep data in an area of $690 \mathrm{~km}^{2}$. Craters were observed on five seamounts. An exponential fit to the binned seamount height distribution (Figure 10) in the range $50 \leq H \leq$ $200 \mathrm{~m}$ yields a characteristic height of $\beta^{-1}=70 \pm 5 \mathrm{~m}$, and a volcano abundance of $v_{0}=24 \pm 3 \times 10^{-8} \mathrm{~m}^{-2}(240 \pm 30$ seamounts per $10^{3} \mathrm{~km}^{2}$ ). The estimate of abundance is smaller than the value for the entire axial population, $v_{0}=31 \pm 2 \times 10^{-8}$ $\mathrm{m}^{-2}$. The average height-to-diameter ratio in area $\mathrm{A}$ is $\xi_{d}=0.10$ \pm 0.04 . The average slope angle is $\Phi=22^{\circ} \pm 6^{\circ}$. The average flatness, $f=0.51 \pm 0.20$, is larger than the overall average $(f=$ $0.46 \pm 0.20$ ) on the Reykjanes Ridge (Figure 11). However a chisquare test finds no significant difference in the distributions. The volume of seamounts per unit area in area $A$ is $V=16 \mathrm{~m}$.

\section{Area B}

Area B looks morphologically very similar to area A, with an axial high (Figures 1 and 4 ). Here, 242 volcanoes were identified in an area of $1340 \mathrm{~km}^{2}$. Twenty four craters were identified from the Hydrosweep maps. An exponential fit to the binned summit height distribution (Figure 10) $(50 \leq H \leq 175 \mathrm{~m})$ gives a characteristic height of $\beta^{-1}=72 \pm 3 \mathrm{~m}$, similar to area $A$. However, the volcano abundance $v_{0}=40 \pm 3 \times 10^{-8} \mathrm{~m}^{-2}$ (yielding $400 \pm 30$ seamounts per $10^{3} \mathrm{~km}^{2}$ ) is almost twice that observed in area A. Despite an increased volcano abundance, the shape characteristics of the two northern areas are very similar. In area B the average value of height-to-diameter ratio is $\xi_{d}=0.12 \pm$ 0.05 , the average slope is $\Phi=24^{\circ} \pm 7^{\circ}$, and the average flatness is $f=0.46 \pm 0.20$, the same as the overall average (Figure 11). Chi-square tests find no significant difference between the flatness distributions in areas A and B. The volume of seamounts per unit area derived from the population and shape parameters is $V=20 \mathrm{~m}$, the largest among the three study areas.

Circular edifices observed outside the axial zone in area B are 

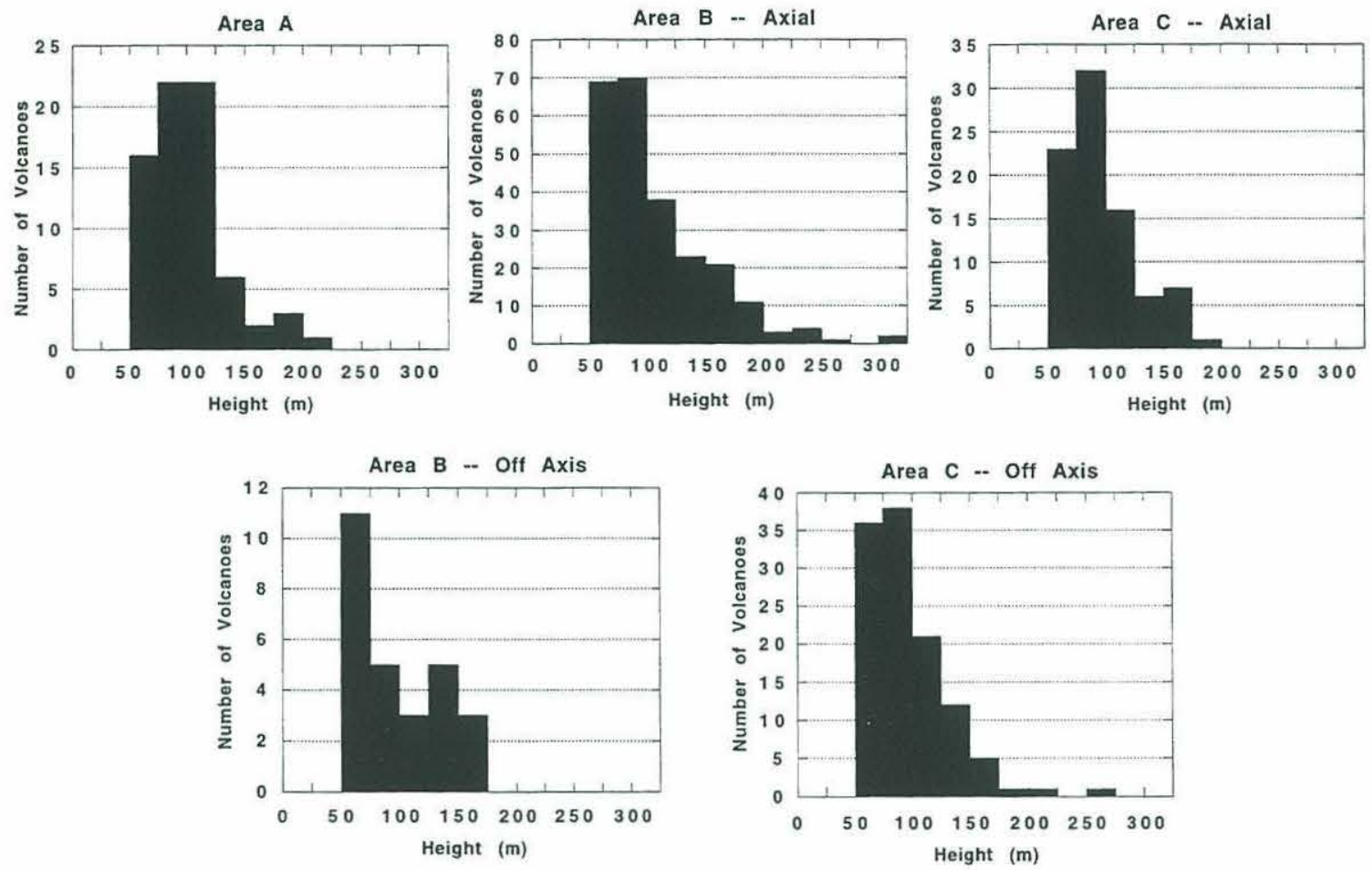

Figure 10. Summit height distributions for each of the three study regions including off-axis populations in area B and $\mathrm{C}$. Heights have been sorted into 25 -m bins. Note the changing frequency scale. For example, area B, offaxis, has a small sample size. The observed falloff of number with height is generally consistent with the exponential size-frequency model.

similar in size and shape to those in the axial zone itself. However, off axis there are many fewer features that meet our seamount-counting criteria. Many structures that we interpret to be severely faulted or dismembered volcanoes are not included in our counts. Due to limited aerial coverage $\left(440 \mathrm{~km}^{2}\right)$, only 27 intact volcanoes were identified. Of these, four are cratered. Because of the statistical problems with such a small sample size, we do not estimate $\beta^{-1}, v_{0}$, or $V$, although the summit height distribution is included in Figure 10. The average height-todiameter ratio of the off-axis volcanoes in area B is $\xi_{d}=0.10 \pm$ 0.04 , and average slope angle is $\Phi=23^{\circ} \pm 7^{\circ}$. The average flatness is $f=0.50 \pm 0.20$, with a distribution indistinguishable (based on a chi-square test) from the axial population in area B (Figure 11).

\section{Area C}

Moving farther southward, away from Iceland, the large-scale axial topography of the Reykjanes Ridge changes from an axial high (as is present in areas A and B) to a well-defined valley bounded by normal faults as observed in area $\mathrm{C}$ (Figures 1 and 4). The axial zone (with edges defined here by normal faults with throws $>150 \mathrm{~m})$ is also somewhat narrower $(\sim 7 \mathrm{~km})$ than the axial zone farther north $(\sim 8.5 \mathrm{~km})$. Eighty five volcanoes were identified on $865 \mathrm{~km}^{2}$ of the valley floor. From the Hydrosweep data, craters are seen on five seamounts. Fitting an exponential curve to the binned summit height distribution $(50 \leq$ $H \leq 175 \mathrm{~m}$, Figure 10) gives $\beta^{-1}=72 \pm 4 \mathrm{~m}$ and $v_{0}=26 \pm 3 \mathrm{x}$
$10^{-8} \mathrm{~m}^{-2}$, yielding $260 \pm 30$ seamounts per $10^{3} \mathrm{~km}^{2}$. Volcano abundance is essentially identical to the abundance estimated in area $A$, but is only two thirds of that in area B (Table 3 ). The average height-to-diameter ratio is $\xi_{d}=0.13 \pm 0.05$, and the average slope angle is $\Phi=23^{\circ} \pm 7^{\circ}$, similar to both areas $A$ and B (Table 4). The flatness distribution (Figure 11), however, is much more uniform in area C. The average flatness is $f=0.40 \pm$ 0.22 with values ranging between $f=0$ and $f=0.8$. Chi-square tests indicate that the distribution is different from the distributions in areas $\mathrm{A}$ and $\mathrm{B}$; the null hypothesis that they are of the same population can be rejected with $90 \%$ confidence. The seamount volume per unit area is $V=12 \mathrm{~m}$, less than in either area $\mathrm{A}$ or area $\mathrm{B}$.

In the area outside the axial graben, 115 volcanoes were identified (five with craters visible on Hydrosweep maps) in an area of $1740 \mathrm{~km}^{2}$. As in the off-axis region of area B, there are dozens of topographic highs that we interpret as seamounts that are faulted and deformed; these are not included in the seamount counts. In many cases, seamounts appear to have been cut by normal faults. Only the half on the hanging wall is identifiable, and consists of a semicircular high which is invariably concave toward the axis. The other half of the volcano is inferred to be located on the down-dropped block on the side of the fault closer to the ridge axis. The characteristic volcano height of the off axis population in area $\mathrm{C}$ from a fit to seamounts in the height range $50 \leq H \leq 175 \mathrm{~m}$ (Figure 10) is $\beta^{-1}=62 \pm 3 \mathrm{~m}$, smaller than on axis $\left(\beta^{-1}=72 \pm 4 \mathrm{~m}\right)$. The seamount abundance is $v_{0}=17 \pm 2 \mathrm{x}$ $10^{-8} \mathrm{~m}^{-2}$, yielding $170 \pm 20$ seamounts per $10^{3} \mathrm{~km}^{2}$, only $65 \%$ of 

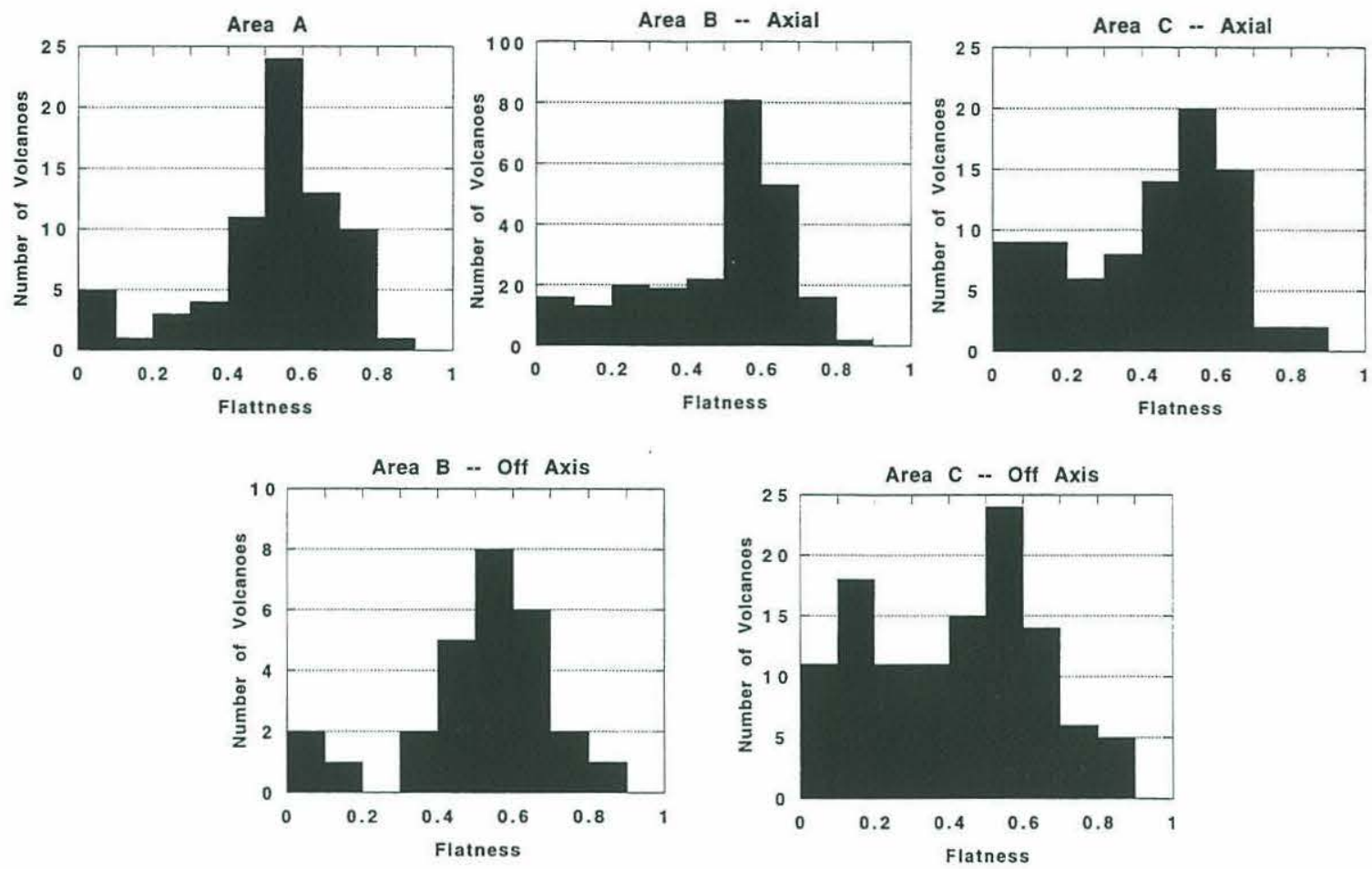

Figure 11. Distribution of seamount flatness (top diameter/basal diameter) for each of the three study regions including off-axis populations in areas B and C. The distribution is more concentrated, with a peak near $f=0.6$ in areas $\mathrm{A}$ and $\mathrm{B}$, whereas the distribution is more uniform in area $\mathrm{C}$. Chi-square tests reveal that the distributions in areas A and B (both on and off axis) are indistinguishable. Similarly, the axial and off-axis distributions in area C are indistinguishable. However, the flatness distributions in areas A and B are markedly different from area $\mathrm{C}$.

that of the axial population $\left(v_{0}=26 \pm 3 \times 10^{-8} \mathrm{~m}^{-2}\right)$. The decreased seamount abundance compared with the axial population can be attributed to the destruction of seamounts by faulting during movement out of the axial zone. It is not clear, however, if the same destructive processes can also explain the decrease in characteristic height. An alternative explanation is that seamounts may be formed off axis.

The area $C$ off-axis volcanoes exhibit the same shape characteristics as the axial population (Table 4). The average height-to-diameter ratio is $\xi_{d}=0.13 \pm 0.06$ and the average slope angle is $\Phi=23^{\circ} \pm 7^{\circ}$. The average flatness is $f=0.40 \pm 0.23$ with a uniform distribution similar to the axial population in area $\mathrm{C}$ (Figure 11). Chi-square tests confirm that the axial and offaxis area $\mathrm{C}$ flatness distributions are statistically the same but that the off-axis Area $C$ flatness distribution is different from those of areas A and B (with $>99.5 \%$ confidence). The seamount volume per unit area is $V=5 \mathrm{~m}$, less than half that determined for the area $\mathrm{C}$ axial population.

\section{Morphological Seamount Types}

The aim of the side scan sonar analysis is to document the surface morphology of seamounts in areas B and C in a manner similar to the analysis by Smith et al. [1995] in four areas at the MAR, $25^{\circ}-29^{\circ} \mathrm{N}$. Below we compare our results to those documented at the MAR. In addition, our goal is to quantify any relationships among seamount size, shape, and volcanic morphology.

Tabie 3. Seamount Distribution Parameters by Study Area

\begin{tabular}{cccccc}
\hline Area & $\begin{array}{c}\text { Seamount Count, } \\
H>50 \mathrm{~m}\end{array}$ & $\begin{array}{c}\mathrm{v}_{\mathrm{o}}, \\
10^{-8} \mathrm{~m}^{-2}\end{array}$ & $\begin{array}{c}\beta^{-1}, \\
\mathrm{~m}\end{array}$ & $\begin{array}{c}V, \\
\mathrm{~m}\end{array}$ & $\begin{array}{c}\text { Number of } \\
\text { Craters }\end{array}$ \\
\hline A & 72 & $24 \pm 3$ & $70 \pm 5$ & 16 & 5 \\
$\mathrm{~B}$ & 242 & $40 \pm 3$ & $72 \pm 3$ & 20 & 31 \\
$\mathrm{C}$ & 85 & $26 \pm 3$ & $72 \pm 4$ & 12 & 5 \\
Off-axis B & 27 & --- &.-- & - & 4 \\
Off-axis C & 115 & $17 \pm 2$ & $62 \pm 3$ & 5 & 5 \\
\hline
\end{tabular}


Table 4. Seamount Shape Parameters by Study Area

\begin{tabular}{cccc}
\hline Area & $\xi_{d}$ & $f$ & $\Phi$ \\
\hline A & $0.12 \pm 0.04$ & $0.51 \pm 0.20$ & $22 \pm 6$ \\
B & $0.14 \pm 0.05$ & $0.46 \pm 0.20$ & $24 \pm 7$ \\
C & $0.14 \pm 0.05$ & $0.40 \pm 0.22$ & $23 \pm 6$ \\
Off-axis B & $0.12 \pm 0.04$ & $0.50 \pm 0.22$ & $23 \pm 7$ \\
Off-axis C & $0.14 \pm 0.06$ & $0.40 \pm 0.23$ & $23 \pm 7$ \\
\hline
\end{tabular}

\section{Seamount Morphology by Study Area}

As at the MAR at $25^{\circ}-29^{\circ} \mathrm{N}$ [Smith et al., 1995], an analysis of the TOBI side scan sonar images in our two study areas shows that there are two distinct morphological types of seamounts at the Reykjanes Ridge. Hummocky seamounts have a bulbous surface morphology on the scale of tens of meters; smooth seamounts appear to have little relief at this scale. Detailed examples of each are shown in Figure 7. As was mentioned previously, we are not able to determine from these data whether the textures observed on the side scan sonar images are constructed from pillow lavas or sheet flows. For example, submersible dives on Serocki volcano, a flat-topped, smoothtextured volcano at the MAR near $23^{\circ} \mathrm{N}$ [Bryan et al. 1994] showed that the smooth, flat top is constructed primarily of pillow flows rather than sheet flows as one might infer from the sonar images.

In area $\mathrm{B}$, centered at $60^{\circ} \mathrm{N}$ and having an axial high, we identified a total of 65 seamounts in the TOBI side scan images. Of these seamounts, $54(83 \%)$ are smooth-textured and $11(17 \%)$ are hummocky. In area $\mathrm{C}$, centered at $58^{\circ} \mathrm{N}$ and having an axial graben, 40 seamounts were identified in the side scan images. In contrast to area $\mathrm{B}$, area $\mathrm{C}$ has a majority of hummocky-textured seamounts. Of the 40 seamounts in area C, only $9(22 \%)$ are smooth textured, while $31(78 \%)$ are hummocky (Table 5). At the MAR between $25^{\circ}$ and $29^{\circ} \mathrm{N}$, all four study regions are dominated by hummocky seamounts. Of the 109 seamounts identified by Smith et al. [1995] in deep-towed side scan sonar images, $83 \%$ are hummocky textured. Therefore the proportion of hummocky seamounts in area $\mathrm{C}$ is essentially identical to that observed farther south at the MAR. In contrast, area B, located closer to the Iceland hot spot on an axial high, has predominantly smooth seamounts.

We also document variations between areas $\mathrm{B}$ and $\mathrm{C}$ in the spatial locations of the smooth seamounts. The few smooth
Table 5. Seamount Morphology Counts

\begin{tabular}{cccc}
\hline Area & $\begin{array}{c}\text { Total Identified } \\
\text { on TOBI }\end{array}$ & $\begin{array}{c}\text { Hummocky } \\
\text { Seamounts }\end{array}$ & $\begin{array}{c}\text { Smooth } \\
\text { Seamounts }\end{array}$ \\
\hline B & 65 & $11(17 \%)$ & $54(83 \%)$ \\
C & 40 & $31(78 \%)$ & $9(22 \%)$ \\
MAR* & 109 & $90(83 \%)$ & $19(17 \%)$ \\
\hline
\end{tabular}

* From Smith et al. [1995].

seamounts in area $\mathrm{C}$ are primarily located at the edges of AVRs, often extending out into the flanking deep. These seamounts have lower than average height-to-diameter ratios $\left(\xi_{d}<0.14\right)$, indicating that they grow preferentially by increasing their diameter. In contrast, area B smooth seamounts are found scattered over the entire AVRs and have a wider range in heightto-diameter ratios $\left(\xi_{d}=0.05-0.30\right)$, although seamounts with low aspect ratios are still dominant. Smooth seamounts evidently play a more important role in building the axial volcanic ridges in area $\mathrm{B}$ than in area $\mathrm{C}$.

\section{Hummocky Seamounts}

In this section we characterize the sizes and shapes of the population of 42 hummocky seamounts identified in areas B and C. Their height distribution is shown in Figure 12 and their shape parameters are summarized in Table 6. Unlike the distributions observed when all morphological seamount types are included, the hummocky seamount height distribution is not exponential. Instead, all but two seamounts are in the height range $50-125 \mathrm{~m}$. The average height-to-diameter ratio of the hummocky seamounts is $\xi_{d}=0.15 \pm 0.04$. The average slope angle is $\Phi=23^{\circ} \pm 5^{\circ}$. The average flatness is $f=0.40 \pm 0.22$; with values ranging from $f=0$ to $f=0.8$ (Figure 13). Although chi-square tests reveal that the hummocky seamount flatness distribution is similar to that in all three study areas, it is most different ( $85 \%$ confidence interval) from area A. No craters were observed in the hummocky seamounts.

\section{Smooth Seamounts}

We investigated the population of 63 smooth seamounts to characterize their sizes and shapes and to identify any differences between the smooth and hummocky populations. The height distribution of smooth seamounts is shown in Figure 12. Fitting
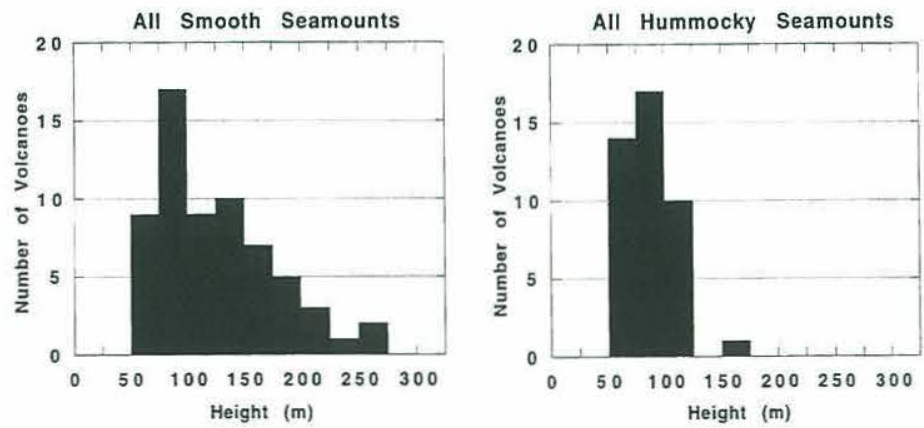

Figure 12. Summit height distributions for smooth and hummocky seamounts. Heights are sorted into $25-m$ intervals. The smooth seamounts have a wide range of heights, while the hummocky seamounts cluster tightly between 50 and $125 \mathrm{~m}$. 
Table 6. Seamount Shape Parameters for Different Morphologies

\begin{tabular}{lccc}
\hline Seamount Type & $\xi_{d}$ & $f$ & $\Phi$ \\
\hline Hummocky & $0.15 \pm 0.04$ & $0.40 \pm 0.22$ & $23 \pm 5$ \\
Smooth & $0.13 \pm 0.05$ & $0.54 \pm 0.14$ & $24 \pm 7$ \\
\hline
\end{tabular}

an exponential curve to the binned height distribution in the range $50 \leq H \leq 200 \mathrm{~m}$ gives $\beta^{-1}=136 \pm 6 \mathrm{~m}$. This large characteristic height reflects the increased size of the smooth seamounts as compared with the overall seamount population. Whereas hummocky seamounts are predominantly small $(50-125 \mathrm{~m}$ in relief), large features, ranging up to $275 \mathrm{~m}$ in height, are predominantly smooth seamounts. The average height-todiameter ratio of the smooth seamounts is $\xi_{d l}=0.13 \pm 0.05$, essentially the same as for hummocky seamounts (Table 6 ). The average slope angle is $\Phi=24^{\circ} \pm 7^{\circ}$. The average flatness is $f=$ $0.54 \pm 0.14$, with values ranging between $f=0$ and $f=0.9$. In contrast to the uniform distribution observed for hummocky seamounts, the flatness distribution for the smooth seamounts shows a distinct peak near $f=0.6$ (Figure 13). Chi-square tests reveal that this distribution is different (at the $97.5 \%$ confidence level) from the hummocky seamount flatness distribution. The smooth seamount distribution is indistinguishable (on the basis of chi-square tests) from flatnesses distributions observed in areas A and B. However, the smooth seamount distribution is very different from the flatness distributions observed both on axis ( $>98.5 \%$ confidence level) and off axis ( $>99.9 \%$ confidence level) in area C. In addition, $36 \%$ of the smooth seamounts have summit craters (15 visible on multibeam bathymetry maps and 8 more identified from side scan images).

\section{Discussion: Volcanism at the Reykjanes Ridge}

Multibeam bathymetry and deep-towed side scan sonar data show that the axial zone of the Reykjanes Ridge is covered with small $(0.5-3 \mathrm{~km}$ in diameter), near-circular volcanic edifices. These small seamounts, along with small volcanic ridges and flows, pile up to form larger axial volcanic ridges. This style of volcanism, small volcanic units combining to build larger ridges, is observed along the entire length of the Reykjanes Ridge. Moreover, it is similar to that observed at the MAR between $24^{\circ}$ and $30^{\circ} \mathrm{N}$ [e.g., Smith and Cann, 1993] and may be common to slow spreading ridges.

The large-scale morphology of the Reykjanes Ridge does not behave as simply. Near $59^{\circ} \mathrm{N}$ the ridge changes going northward from an axial graben typical of a slow spreading ridge to an axial high typical of a fast spreading ridge. This change in overall topography has been related to higher mantle temperatures beneath the northern section of the ridge due to the proximity of the Iceland hot spot [e.g., Laughton et al., 1979; Jacoby, 1980; Searle and Laughton, 1981]. Therefore while proximity to the Iceland hot spot may affect the shape of the large-scale axial topography at this slow spreading ridge, it does not appear to alter the fundamental crustal melt delivery system that builds the shallow crust and, ultimately, seamounts on the seafloor.

Nonetheless, there are differences in the characteristics of the seamount populations between the slow spreading Reykjanes Ridge $\left(58^{\circ}-62^{\circ} \mathrm{N}\right)$ and the slow spreading MAR $\left(24^{\circ}-30^{\circ} \mathrm{N}\right)$. A comparison of population parameters in Table 2 shows first of all that seamounts at the Reykjanes Ridge are more abundant $\left(310 \pm 20\right.$ per $\left.10^{3} \mathrm{~km}^{2}\right)$, on average, than their MAR counterparts $\left(200 \pm 10\right.$ per $\left.10^{3} \mathrm{~km}^{2}\right)$. Significant along-axis variations in seamount abundance have been observed at the Reykjanes Ridge, however (Table 3 ), and we find that the high overall seamount abundance is dominated by area B $\left(400 \pm 30\right.$ per $\left.10^{3} \mathrm{~km}^{2}\right)$. By comparison, area $\mathrm{A}\left(240 \pm 30\right.$ per $\left.10^{3} \mathrm{~km}^{2}\right)$ and area $\mathrm{C}(260 \pm 30$ per $10^{3} \mathrm{~km}^{2}$ ) have lower abundances that are similar to the MAR The possible controls on along-axis variation in seamount abundances at the Reykjanes Ridge are discussed below.

Variations in characteristic height are also observed between the Reykjanes Ridge $\left(\beta^{-1}=68 \pm 2 \mathrm{~m}\right)$ and the MAR $\left(\beta^{-1}=58 \pm 2\right.$ $\mathrm{m})$. Unlike seamount abundances, however, the characteristic height does not vary significantly along the axis of the Reykjanes Ridge, suggesting that there is little net change in the variables that control seamount height (e.g., magma pressure, volume, and volatile content). However, since seamounts are taller, on average, at the Reykjanes Ridge than at the MAR, there must be fundamental differences in one or more of the controlling variables between these two ridges.

Seamount shape characteristics also differ between the Reykjanes Ridge and the MAR. The sample mean of the
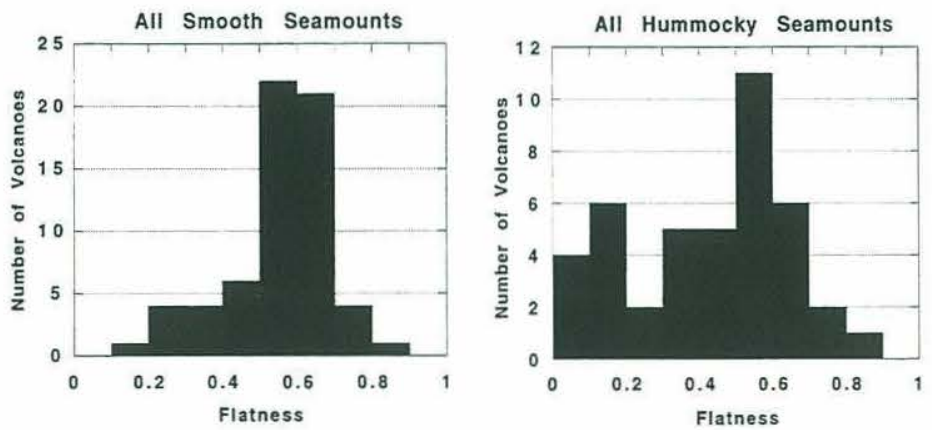

Figure 13. Distribution of seamount flatness (top diameter/basal diameter) for smooth and hummocky seamounts. The smooth seamounts show a peaked distribution centered near $f=0.6$, while the hummocky seamounts have a more uniform distribution. Chi-square tests indicate that the hummocky seamount distribution has characteristics in common with the flatness distributions observed in all three study areas (see Figure 11). In contrast, the smooth seamount population is compatible only with areas A and B. This suggests that hummocky seamounts are present in all three study areas but that smooth seamounts are a significant component only in areas A and B. 
flatnesses is larger at the Reykjanes Ridge $(f=0.46 \pm 0.2)$ than at the MAR $(f=0.31 \pm 0.16)$. More significantly, chi-square tests reveal that the two flatness distributions are different at the $>99.9 \%$ confidence level. The Reykjanes Ridge flatness distribution peaks near $f=0.6$, while the MAR distribution is concentrated near $f=0.3$. To explain why seamounts have flat tops, we follow the ideas of Barone and Ryan [1990]. We envision that a seamount grows as a pointed cone until it reaches a critical height (controlled by variables such as magma pressure, volume, and volatile content as mentioned above). If magma supply is sufficient and it is able to reach the summit after the maximum height is attained, then the seamount will build outward creating a flat top. The shift toward larger seamount flatness values at the Reykjanes Ridge suggests that volumelimited eruptions may be less common there than at the MAR.

As was mentioned above, there are large changes in seamount abundance along the Reykjanes Ridge which are not simply related to distance from the Iceland hot spot. Area A (closest to Iceland) and area $C$ (farthest from Iceland) have very similar seamount abundances. Area B, on the other hand, has nearly twice the abundance of seamounts as these two areas. Moreover, we observe a dramatic change in the surface texture of seamounts between areas B and C. A comparison of the values in Table 5 shows many more smooth seamounts in area B $(83 \%)$ than in area $\mathrm{C}(22 \%)$.

In order to explain the high abundances of seamounts as well as the larger proportion of smooth textured edifices in area B, we consider the location of area $B$ with respect to the overall characteristics of the Reykjanes Ridge. Area B lies immediately north of the transition from an axial graben to an axial high along the Reykjanes Ridge [e.g., Parson et al., 1993a] (Figure 2). This transition has been explained in two fundamentally different ways. One is that mantle temperature and magma supply increase as the Iceland hot spot is approached, resulting in a modification of the large-scale axial morphology from that characteristic of a slow spreading ridge to that characteristic of a fast spreading ridge [Laughton et al., 1979; Jacoby, 1980; Searle and Laughton, 1981]. In this case, increased mantle temperature and magma supply are taken to be proxies for spreading rate. The other explanation is that pulses of hot spot material propagate southward along the axis, influencing the large-scale axial morphology. The pattern of southward pointing V-shaped ridges evident in bathymetry and satellite gravity maps supports this idea [Vogt, 1971; Vogt and Avery, 1974; Owens, 1994]. On this basis, the axial high, which tapers southward ending south of area B, may represent the latest phase of propagation, succeeding a previous phase of reduced hot spot influence. It is also possible that both effects are important in creating the transition from an axial high to an axial graben and that they presently coincide south of area B.

The high abundance of seamounts at area B suggests a period of increased magmatic activity in the area. This does not appear to be related to higher mantle temperatures associated with proximity to the Iceland hot spot because the same high seamount abundances are not observed in area $\mathrm{A}$. We believe that a more likely explanation for the increased seamount production at area $\mathrm{B}$ is that it may be associated with along-axis propagation of pulses of hot spot material. If these pulses take the form of asthenosphere of higher temperature, then as the hot asthenosphere moves into cooler regions, the advected heat increases local temperatures, leading to larger degrees of partial melting [e.g., White, 1989] and presumably more magma supply to the ridge axis. Interestingly, this increased magma supply results in the construction of additional seamounts rather than low-relief flows that are generally associated with larger melt supply (and fast spreading ridges).

We do not know the across-axis extent of the increased magmatic activity near area B. However, surface-towed side scan sonar images obtained over area B [Applegate and Shor, 1994] show no evidence for off-axis volcanism. In addition, our off-axis counts normalized to seafloor area indicate that seamount densities are significantly lower than on-axis densities. This is most likely due to the destruction of seamounts by faulting during their transport off axis. The large number of features observed off axis that we interpret to be severely faulted or dismembered seamounts supports this conclusion and is consistent with our observations for the off-axis seamount population in area C. Thus no evidence exists for large numbers of recently constructed volcanoes outside the axial zone.

To explain the large proportion of smooth seamount in area B, we first consider the distinguishing characteristics between the hummocky and smooth seamount populations and then the possible controls on their formation. Compared to hummocky seamounts, smooth seamounts can attain larger heights; smooth seamounts are generally flatter; and about one third of smooth seamounts have summit craters (no hummocky seamounts have craters). These different characteristics must reflect the different modes of formation of these two populations of seamounts. Possible controls on the formation of the hummocky- and smooth-textured seamounts at the MAR are discussed by Smith et al. [1995]. On the basis of possible analogs mapped in the Troodos Ophiolite [Schmincke and Bednarz, 1990] and results of laboratory simulations of volcano growth using hot wax extruded under water [e.g., Griffiths and Fink, 1993], Smith et al. [1994] suggested that hummocky seamounts form when eruption rates are low and cooling of the surface is rapid, resulting in features that build bulbous outgrowths. In contrast, smooth seamounts form when eruptions rates are higher and cooling is slower; in this case, features are built from flows which spread outward generating little surface texture.

There are many other possible controls on the surface morphology of features. We list a few of them here, but note again that the hummocky and smooth textures that we are trying to explain are on the scale of tens of meters rather than the meter scale that some of these studies addressed. Morphologic controls include physical parameters such as eruption temperature, lava density, and viscosity, with increased temperatures and decreased viscosity leading to smoother textures [e.g., Bonatti and Harrison, 1988]. Other possible controls include the nature of the surficial plumbing system, with tube-fed flows producing hummocky textures, and surface flows producing smooth textures [e.g., Ballard et al., 1979]. Preexisting topography is also important. Ponding of lava in depressions or on shallow slopes results in smoother textures, while deflection and bending of lava over rough surfaces produces lumpier textures [e.g., Fink and Griffiths, 1992; Wilson and Parfitt, 1993; Bryan et al., 1994].

The above ideas are incorporated into a conceptual model (Figure 14) which illustrates the building of the shallow crust at the slow-spreading Reykjanes Ridge, allowing for the influence of the Iceland hot spot. One of the most important features of slow spreading ridges which leads to abundant seamounts must be a low magma flux that produces small discrete magma bodies [e.g., Smith and Cann, 1993]. If we relate seamount production to the existence of small, ephemeral magma bodies and their accompanying plumbing system, then despite the hot spot influence in the mantle and perhaps lower crust, discrete magma 


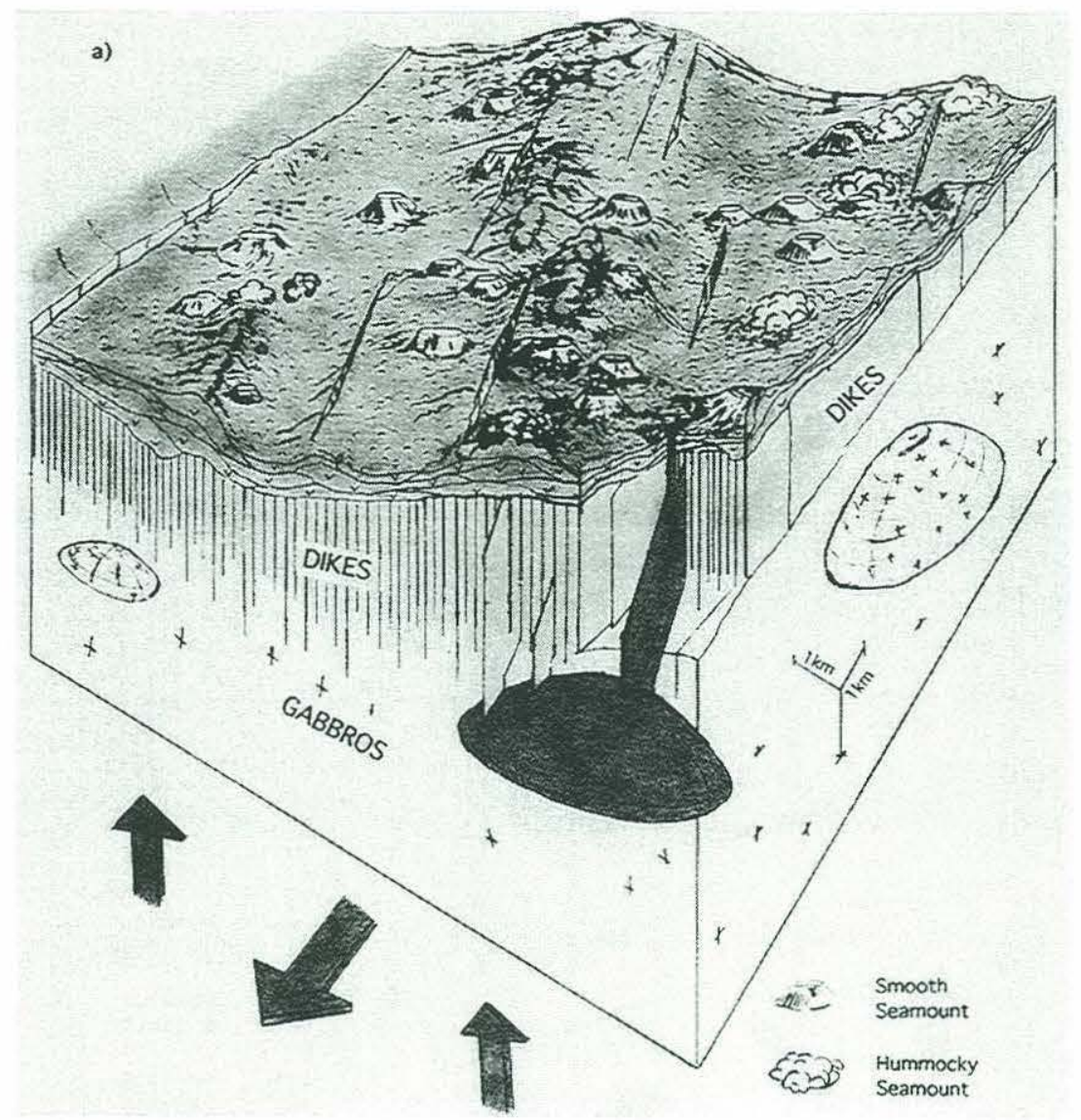

Figure 14. Conceptual view of proposed differences in the shallow crust present beneath (a) area B and (b) area C. In both cases, the right-hand edge of the box is aligned with the strike of the Reykjanes Ridge. Surface topography is an artistic interpretation of surface structure from Hydrosweep data. Shown are flat-topped smooth seamounts, some with summit craters, as well as hummocky seamounts, indicated by a lumpier texture. Also shown are hummocky ridges (linear, lumpy textured features) and faults. The seamounts and hummocky ridges combine to form AVRs which are oriented obliquely to the strike of the Reykjanes Ridge but perpendicular to the spreading direction. Note that faults within the axial zone are parallel to the AVRs, while those near the edge of the axial zone are parallel to the ridge. Subcrustal structure illustrates possible differences in the shallow plumbing system which could account for the observed differences in seamount abundance and surface morphology between these two areas. Scale bars are shown. In both areas we envision a layer of extrusives underlain by a layer of sheeted dikes approximately 1-2 km thick, although dikes extend below this layer. This, in turn, is underlain by gabbros composed of numerous solidified magma bodies. Shown are a few representative cooled magma bodies as well as one active magma body (indicated by dashes) in each area. Eruptions of magma from these small bodies feed the observed surface features though dikes oriented parallel to the AVRs. The active dike in each area is indicated by dashes. The arrows below each figure indicate the flux of magma from directly below the ridge as well as an along-axis asthenospheric flux from the Iceland hot spot. (a) In area B, we observe more, and predominantly smooth, seamounts. This may be due to changes in a number of variables, which might include a larger magma supply, larger and/or shallower magma bodies, and hotter and/or faster eruptions. It is possible that a flux of heat and/or molten material from the Iceland hot spot produces larger degrees of melting and a larger magma supply to the ridge at area $\mathrm{B}$. b) In contrast, in area $\mathrm{C}$ the influence of the hot spot is not as strong as in area B. Therefore shallow crustal magma bodies may be smaller and deeper, erupting more slowly and/or with cooler magma temperatures. This produces fewer, predominantly hummocky seamounts.

bodies will exist in the shallow crust at the Reykjanes Ridge. Beneath area B we visualize a hotter mantle producing larger degrees of partial melting and a larger supply of magma to the ridge. Discrete batches of magma with relatively large volumes rise to high levels in the shallow crust and are linked to the seafloor by one or several short dikes to construct small volcanoes and flows with diverse morphologies. These conditions are consistent with individual eruptions which typically have fast 


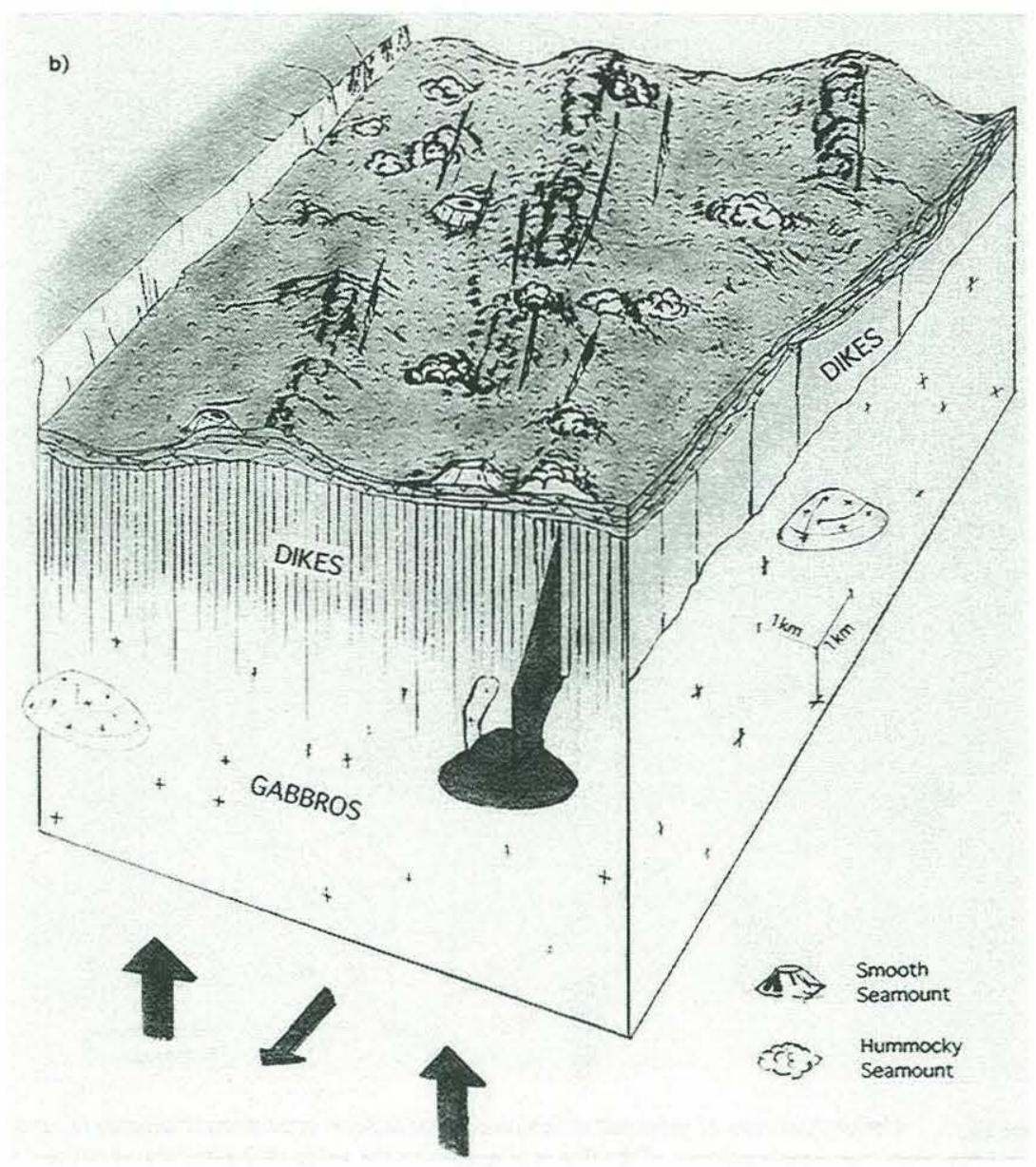

Figure 14. (continued)

effusion rates and are not volume limited. The result is abundant seamounts that are predominantiy smooth textured, have reached their maximum possible height, and have built flat tops. Drainback of the lava in tubes or feeder dikes commonly leads to collapse craters on the tops of smooth seamounts.

In contrast, at area $\mathrm{C}$ we envision that thermal conditions in the mantle are more similar to those farther south at the MAR. In this case, discrete small magma bodies rise within the crust to levels that are deeper than those beneath area B. Long, narrow dikes link the magma bodies to the seafloor. These conditions lead to eruptions that have slow rates and are sometimes volume limited. As the lava erupts slowly, it is cooled rapidly and seamounts grow upward as individual bulbous masses fed from a network of tubes. The result is hummocky seamounts that may not have reached their maximum possible height and therefore have peaky shapes. Drainback of lava may occur for individual bulbs, but summit craters are not formed.

Because we have no side scan sonar images in area $A$ it is difficult to predict the style of seamounts produced there. Seamount abundances in area $\mathrm{A}$ are similar to those in area $\mathrm{C}$ and much less than in area B despite the proximity of area A to Iceland. On the basis of seamount abundances alone it appears that area A has the same supply of magma to the shallow crust as area $C$. How this relates to the overall thermal influence of the hot spot or pulses of plume material that may migrate along the ridge is currently unknown. However, the Reykjanes Ridge continues to be an area of focused research, and many experiments are currently under way which will provide us with important new data to better understand the interaction between the Iceland hot spot and the processes that control crustal accretion at this slow spreading ridge.

\section{Conclusions}

The main conclusions from our work are summarized as follows:

1. Small seamounts, along with small volcanic ridges and flows, pile up to form large axial volcanic ridges at the Reykjanes Ridge. This style of volcanism is similar to that observed at the MAR $\left(24^{\circ}-30^{\circ} \mathrm{N}\right)$ [e.g., Smith and Cann, 1993] and may be common to slow spreading ridges, despite the proximity of the Iceland hotspot.

2. Seamounts at the Reykjanes Ridge are more abundant ( 310 \pm 20 per $10^{3} \mathrm{~km}^{2}$ ), on average, than those observed at the MAR between $24^{\circ}$ and $30^{\circ} \mathrm{N}\left(200 \pm 10\right.$ per $\left.10^{3} \mathrm{~km}^{2}\right)$. However, significant along-axis variations in seamount abundance which 
are not simply related to distance from the hot spot have been observed at the Reykjanes Ridge. We find that the high overall seamount abundance is dominated by area $B\left(400 \pm 30\right.$ per $10^{3}$ $\left.\mathrm{km}^{2}\right)$. In contrast, areas A $\left(240 \pm 30\right.$ per $\left.10^{3} \mathrm{~km}^{2}\right)$ and C $(260 \pm$ 30 per $10^{3} \mathrm{~km}^{2}$ ) have similar abundances which are also comparable to those at the MAR.

3. Variations in the characteristic height of the seamount populations are observed between the Reykjanes Ridge $\left(\beta^{-1}=68\right.$ $\pm 2 \mathrm{~m})$ and the MAR $\left(\beta^{-1}=58 \pm 2 \mathrm{~m}\right)$. Unlike seamount abundances, however, the characteristic height does not vary significantly along the axis of the Reykjanes Ridge. This suggests that there is little change in the variables that control seamount height (e.g., magma pressure, volume, and volatile content).

4. There is a dramatic change in seamount surface morphology between areas $\mathrm{B}$ and $\mathrm{C}$ (there are no side scan data from area $\mathrm{A}$ ). Area $\mathrm{C}$ has $78 \%$ hummocky seamounts, much like the MAR which has $83 \%$ hummocky seamounts, while area B has $83 \%$ smooth seamounts. Hummocky and smooth seamounts have different characteristics. Smooth seamounts can attain larger heights and are flatter, and about one third have summit craters. The surface morphology of the seamounts is most likely controlled by the complex interplay of several variables including magma viscosity and density, eruption rate, and surface cooling rate.

5. The high abundance of seamounts at area B suggests recent increased magmatic activity in this area. It does not appear to be related to higher mantle temperatures associated with proximity to the Iceland hot spot because the same high seamount abundances are not observed in area A. A more likely explanation for the increased seamount production is that area B currently is or recently has been affected by an along-axis propagation of hot spot material [e.g., Vogt, 1971; Vogt and Avery, 1974; Murton and Parson, 1993; Owens, 1994]. The resulting increased magma supply may affect variables such as magma volumes, eruption temperatures, and magma effusion rates, which would explain the dominance of smooth, flat-topped seamounts at area B.

Acknowledgments. We thank W. B. Bryan, J. R. Cann, K. Gillis, S Humphris, G. Ito, and R. Owens for helpful discussions and M. Coffin, J. Goff, and D. Naar for their thorough and informative reviews. NERC funded the collection of the Hydrosweep bathymetry and TOBI sidescan data. We thank E. McAllister, J. Keeton, and R. Owens for help in obtaining the gridded Hydrosweep data. D.K.S. also thanks L. Parson, R. Searle, C. Summerhayes, A. Laughton, B. Murton, and E. McAllister for many interesting discussions at sea. D.K.S. especially thanks J. Keeton, P. Fields, and C. Walker for their initial help with interpreting the Hydrosweep maps. E. P. Oberlander drew Figure 14 and T. Osychny drafted Figure 3. Funding was from the National Science Foundation under contract OCE-9224738. L.S.M. was funded under a National Science Foundation graduate fellowship. WHOI contribution 8838 .

\section{References}

Abers, G. A., B. Parsons, and J. K. Weissel, Seamount abundances and distributions in the southeast Pacific, Earth Planet. Sci. Lett., 87 , $137-151,1988$

Applegate, B., and A. N. Shor, The northern Mid-Atlantic and Reykjanes Ridge: Spreading center morphology between $55^{\circ} 50^{\prime} \mathrm{N}$ and $63^{\circ} 00^{\prime} \mathrm{N}$, J. Geophys. Res., 99, 17,935-17,956, 1994.

Ballard, R. D., R. T. Holcomb, and T. H. van Andel, The Galapagos Rif at $86^{\circ} \mathrm{W}$ : Sheet flows, collapse pits, and lava lakes of the rift valley, $J$. Geophys. Res., 84, 5407-5422, 1979.

Barone, A. M., and W. B. F. Ryan, Single plume model for asynchronous formation of the Lamont seamounts and adjacent East Pacific Rise terrains, J. Geophys. Res., 95, 10,801-10,827, 1990.
Bonatti, E., and C. G. A. Harrison, Eruption styles of basalt in oceanic spreading ridges and seamounts: Effect of magma temperature and viscosity, J. Geophys. Res., 93, 2967-980, 1988.

Bryan, W. B., S. E. Humphris, G. Thompson, and J. F. Casey, Comparative volcanology of small axial eruptive centers in the MARK area, J. Geophys. Res., 99, 2973-2984, 1994.

Bunch, A. W. H., and B. L. N. Kennett, The crustal structure of the Reykjanes Ridge at $59^{\circ} 30^{\prime}$ N, Geophys. J. R. Astron. Soc., 61, $141-$ 166, 1980.

Fink, J. H., and W. Griffiths, A laboratory analog study of the surface morphology of lava flows extruded from point and line sources, $J$. Volcanol. Geotherm. Res., 54, 19-32, 1992.

Fornari, D. J., R. Batiza, and M. A. Luckman, Seamount abundances and distribution near the East Pacific Rise $0^{\circ}-24^{\circ} \mathrm{N}$ based on Seabeam data, in Seamounts, Islands and Atolls, Geophys. Monogr. Ser., vol 43, edited by B. H. Keating, P. Fryer, R. Batiza, and G. W. Boehlert, pp. 13-21, AGU, Washington, D. C., 1987.

Griffiths, R. W., and J. H. Fink, Effects of surface cooling on the spreading of lava flows and domes, J. Fluid Mech., 252, 667-702, 1993.

Hart, S. R., J.-G. Schilling, and J. L. Powell, Basalts from Iceland and along the Reykjanes Ridge: $\mathrm{Sr}$ isotope geochemistry, Nature Phys. Sci., 246, 104-107, 1973.

Jacoby, W. R., Morphology of the Reykjanes Ridge crest near $62^{\circ} \mathrm{N}, J$. Geophys., 47, 81-85, 1980.

Johnson, G. L., and S. P. Jakobsonn, Structure and petrology of the Reykjanes Ridge between $62^{\circ} 55^{\prime} \mathrm{N}$ and $63^{\circ} 48^{\prime} \mathrm{N}$, J. of Geophys., 90 , 10,073-10,083, 1985.

Kong, L. S., R. S. Detrick, P. J. Fox, L. A. Mayer, and W. B. Ryan, The morphology and tectonics of the Mark area from Sea Beam and Sea MARC I observations (Mid-Atlantic Ridge $23^{\circ} \mathrm{N}$ ), Mar. Geophys. Res., 10, 59-90, 1988.

Kuo, B.-Y., and D. W. Forsyth, Gravity anomalies of the ridge-transform system in the South Atlantic between 31 and $34.5^{\circ} \mathrm{S}$ : Upwelling centers and variations in crustal thickness, Mar. Geophys. Res., 10, 205-232, 1988

Laughton, A. S., R. C. Searle, and D. G. Roberts, The Reykjanes Ridge crest and the transition between rifted and non-rifted regions, Tectonophysics, 55, 173-177, 1979.

Lin, J., G. M. Purdy, H. Schouten, J.-C. Sempere, and C. Zervas, Evidence for gravity data for focused magmatic accretion along the Mid-Atlantic Ridge, Nature, 344, 627-632, 1990.

Macdonald, K. C., C. R. Haymon, and A. Shor, A $220 \mathrm{~km}^{2}$ erupted lava field on the East Pacific Rise near lat $8^{\circ} \mathrm{S}$, Geology, 17, 212-216 1989.

McAllister, E., J. Cann, and S. Spencer, The evolution of crustal deformation in an oceanic extensional environment, J. Struct. Geol., 17, 183-199, 1995.

Murton, B. J., and L. M. Parson, Segmentation, volcanism and deformation of oblique spreading centers: A quantitative study of the Reykjanes Ridge, Tectonophysics, 222, 237-257, 1993.

Murton, B. J., I. P. Rouse, N. W. Millard, and C. G. Flewellen, Multisensor, deep-towed instrument explores ocean floor, Eos Trans. AGU, 73 (20), 225,228, 1992.

Owens, R., B. Parsons, L. Parson, and B. Murton, The Reykjanes Ridge: Dynamics of ridge-hotspot interaction from satellite gravity data (abstract), Eos Trans. AGU, 75 (16), Spring Meeting suppl., 335, 1994.

Parson, L. M., et al., En echelon axial volcanic ridges at the Reykjanes Ridge: A life cycle of volcanism and tectonics, Earth Planet. Sci. Lett., 117, 73-87, 1993a.

Parson, L. M. et al., R/V Maurice Ewing cruise EW9008 cruise report, Rep. 237, Deacon Lab., Inst. of Oceanogr. Sciences, Wormley, England, $1993 \mathrm{~b}$.

RRISP Working Group, Reykjanes Ridge Seismic Experiment (RRISP 77), J. Geophys., 47, 228-238, 1980.

Schilling, J.-G., The Icelandic mantle plume: Geochemical evidence along the Reykjanes Ridge, Nature, 242, 565-578, 1973.

Schilling, J.-G., Geochemical and isotopic variation along the MidAtlantic Ridge axis from $79^{\circ} \mathrm{N}$ to $0^{\circ} \mathrm{N}$, in The Geology of North 
America, vol. $M$. The Western North Atlantic Region, edited by P. R. Vogt and B. E. Tucholke, pp. 137-156, Geological Society of America, Boulder, Colo., 1986.

Schmincke, H.-U., and U. Bednarz, Pillow, sheet flow and breccia flow volcanoes and volcano-tectonic hydrothermal cycles in the Extrusive Series of the northeastern Troodos Ophiolite, in Ophiolites: Oceanic Crustal Analogues, Proceedings of the symposium "Troodos 1987", edited by J. Malpas, E. M. Moores, A. Panayiotou and C. Xenophontos, pp. 186-206, Geological Survey Department Ministry of Agriculture and Natural Resources, Nicosia, Cyprus, 1990.

Searle, R. C., and A. S. Laughton, Fine-scale sonar study of tectonics and volcanism on the Reykjanes Ridge, Oceanol. Acta, 4, suppl., 5-18, 1981.

Sempere, J.-C., J. Lin, H. S. Brown, H. Schouten, and G. M. Purdy, Segmentation and morphotectonic variations along a slow-spreading center: The Mid-Atlantic Ridge $\left(24^{\circ} 00^{\prime} \mathrm{N}-30^{\circ} 40^{\prime} \mathrm{N}\right)$, Mar. Geophys. Res., 15, 153-200, 1993.

Shih, J. S. F., T. Atwater, and M. McNutt, A near-bottom geophysical traverse of the Reykjanes Ridge, Earth Planet. Sci. Lett., 39, 75-83, 1978.

Smith, D. K., and J. R. Cann, The role of volcanism in crustal construction at the Mid-Atlantic Ridge $\left(24^{\circ}-30^{\circ} \mathrm{N}\right)$, J. Geophys. Res., 97, 1645-1658, 1992.

Smith, D. K., and J. R. Cann, Building the crust at the Mid-Atlantic Ridge, Nature, 365, 707-715, 1993.
Smith, D. K., and T. H. Jordan, Seamount statistics in the Pacific Ocean, J. Geophys. Res., 93, 2899-2918, 1988

Smith, D. K., et al., Mid-Atlantic Ridge volcanism from deep-towed side-scan sonar images, $25^{\circ}-29^{\circ} \mathrm{N}, \mathrm{J}$. Volcanol. Geotherm. Res., in press, 1995.

Smith, W. H. F., and P. Wessel, Gridding with continuous curvature splines in tension, Geophysics, 55, 293-305, 1990.

Vogt, P. R., Asthenosphere motion recorded by the ocean floor south of Iceland, Earth Planet. Sci, Lett., 13, 153-160, 1971.

Vogt, P. R., and O. E. Avery, Detailed magnetic surveys in the northeast Atlantic and the Labrador Sea, J. Geophys. Res., 79, 363-389, 1974.

White, R. S. Asthenospheric control on magmatism in the ocean basins, in Magmatism in the Ocean Basins, edited by A. D. Saunders and M. J. Norry, Geol. Soc. Spec. Publ. London, 42, 17-27, 1989.

Wilson, L., and E. A. Parfitt, The formation of perched lava ponds on basaltic volcanoes: The influence of flow geometry on cooling-limited lava flow lengths, J. Volcanol. Geotherm. Res., 56, 113-123, 1993.

L. S. Magde and D. K. Smith, Department of Geology and Geophysics, Woods Hole Oceanographic Institution, Woods Hole, MA 02543-1542. (email: lauram@ copper.whoi.edu)

(Received July 5, 1995; revised October 20, 1994 accepted December 29, 1994.) 


\section{CHAPTER 4}

Combined Laboratory and Numerical Studies of the Interaction Between Buoyant and Plate-Driven Upwelling Beneath Segmented Spreading Centers 
Magde, L. S., C. Kincaid, D. W. Sparks, and R. S. Detrick, Combined laboratory and numerical studies of the interaction between buoyant and plate-driven upwelling beneath segmented spreading centers, J. Geophys. Res., 101, 22,107-22,1222, 1996. Copyright by the American Geophysical Union. Reprinted with permission. 


\title{
Combined laboratory and numerical studies of the interaction between buoyant and plate-driven upwelling beneath segmented spreading centers
}

\author{
Laura S. Magde, ${ }^{1}$ Chris Kincaid, ${ }^{2}$ David W. Sparks, ${ }^{3}$ and Robert S. Detrick ${ }^{1}$
}

\begin{abstract}
A combination of laboratory and numerical models are used to examine the mantle flow beneath a segmented ridge generated by the interaction of a linear, buoyant upwelling source with plate-driven flow. In the absence of plate spreading, the linear buoyant source creates a very narrow (across-axis), two-dimensional upwelling pattern. The plate-driven flow consists of a quasi-linear sheet-like upwelling that cuts beneath ridge-transform inside corners and is not centered beneath the spreading segments. When buoyant and plate-driven flows are combined, material rises beneath the inside corners and flows away from the axis asymmetrically. Near the ends of segments, this results in a geometrical misfit between the center of mantle upwelling and the ridge axis. If a similar pattern of mantle flow occurs beneath a segmented mid-ocean ridge, the result will be a thinner crust toward segment ends and possibly a negative correlation between extent of mantle melting and average depth of melting. These results indicate that even with an essentially two-dimensional source, in cases where it is oblique to the actual spreading segments, the upwelling beneath a segmented ridge will appear to be three-dimensional along axis. Since slow spreading ridges are generally more segmented than fast spreading ridges, this effect is likely to be more important at slow spreading ridges.
\end{abstract}

\section{Introduction}

The segmented nature of the world's mid-ocean ridge system suggests that it is not a simple two-dimensional structure but instead is the result of a complex, three-dimensional, timedependent process, driven by a combination of mantle flow beneath the ridges and the variable thermal and mechanical properties of the lithosphere spreading at the surface [e.g., Shaw, 1992, Shaw and Lin, 1993]. The mantle Bouguer anomaly (MBA) "bull's-eye" lows (attributed to thicker crust and/or warmer mantle) and shallower topography observed at the centers of many segments along the Mid-Atlantic Ridge (MAR) are attributed to focusing of mantle upwelling beneath segment centers [Kuo and Forsyth, 1988; Lin et al., 1990]. There is a strong correlation between along-axis variations in crustal thickness and spreading rate. Slow spreading ridges display much greater along-axis variations than fast spreading ridges [e.g., Lin and Phipps Morgan, 1992], but even at fast spreading ridges, there is some evidence for focusing of mantle flow [Wang and Cochran, 1993]. Segment and offset lengths appear to be related to the amount of along-axis variation in MBA and crustal thickness, particularly at slow spreading ridges. At the MAR, there is a systematic increase in the magnitude of the axial MBA variation with increasing segment length and increasing offset

\footnotetext{
${ }^{1}$ Department of Geology and Geophysics, Woods Hole Oceanographic Institution, Woods Hole, Massachusetts.

${ }^{2}$ Graduate School of Oceanography, University of Rhode Island, Narragansett, Rhode Island.

${ }^{3}$ Lamont Doherty Earth Observatory, Palisades, New York.
}

Copyright 1996 by the American Geophysical Union.

Paper number $96 \mathrm{JB} 01910$.

0148-0227/96/96JB-01910\$09.00 length [Lin et al., 1990; Detrick et al., 1995]. This would be consistent with increased focusing of mantle flow beneath longer segments, especially those adjacent to longer offsets, suggesting that the degree of focusing may be related to the details of the spreading center geometry.

Mantle flow beneath mid-ocean ridges is the result of the interaction between the plate-driven and buoyant components of the flow. Even without a segmented ridge, numerical modeling [Parmentier and Phipps Morgan, 1990; Jha et al., 1994; Sparks and Parmentier, 1993] and laboratory experiments [Whitehead et al., 1984; Kincaid et al., 1996] indicate that there will be alongaxis variations in upwelling and crustal production due to focusing of the buoyant flow. However, the plate-driven flow associated with a segmented ridge will further enhance this three dimensionality. In some cases, individual segments, aligned perpendicular to the direction of plate spreading, are highly oblique to the general trend of the plate boundary. If upwelling at great depths is quasi-linear and oriented along the general trend of the plate boundary, then at shallower depths it has to break up into a more three-dimensional pattern and reorient to reach the spreading axis.

This study uses a combination of laboratory and numerical models to examine the mantle flow generated by the interaction of a linear, buoyant upwelling source with the plate-driven mantle flow associated with a segmented ridge. The linear buoyant source was chosen to simulate the local buoyancy associated with upwelling in the upper $100 \mathrm{~km}$ of the mantle. We determine the degree to which a segmented ridge may affect the pattern of upwelling, identify regions where the interaction between a linear source and a segmented ridge may lead to threedimensional behavior, and examine the influence of plate geometry (i.e., transform length) on the degree of along-axis variability. Our experiments show that ridge segmentation can result in significant misalignment between the center of upwelling and the plate boundary, especially near the ends of 
segments. The misalignment is enhanced by increased offset length and increased angle between the overall trend of the plate boundary and the spreading direction. This misfit may result in along-axis variations in crustal production and basalt geochemistry and may explain the relationship between segment offset and the magnitude of along-axis variations in crustal thickness observed at the Mid-Atlantic Ridge.

\section{Previous Studies}

Previous laboratory and numerical studies have demonstrated that upwelling at mid-ocean ridges can be decomposed into the interaction between plate-driven and buoyant flow. Both sources can lead to three-dimensional mantle upwelling. The threedimensional character of the plate-driven flow was demonstrated numerically by Phipps Morgan and Forsyth [1988], who showed that passive, plate-driven flow is determined by spreading velocity and segmentation geometry.

Even in the absence of plate segmentation, the interaction of a buoyant upwelling source with spreading plates has been shown to lead to three-dimensional mantle flow. Laboratory studies investigating plume-like instabilities rising from a linear buoyant source [e.g., Whitehead et al., 1984] suggest that ridge segmentation may arise from the three-dimensional character of a buoyant source rising from below the ridge axis. Numerical studies of mantle flow beneath unsegmented spreading centers have shown that along-axis variations in upwelling rates and melting can develop due to compositional density variations related to melt extraction [Parmentier and Phipps Morgan, 1990], the addition of small amounts of retained melt [Jha et al., 1994], and thermally induced off-axis longitudinal rolls [Rabinowicz et al., 1993; Sparks and Parmentier, 1993]. Both laboratory [Kincaid et al., 1996] and numerical experiments [Parmentier and Phipps Morgan, 1990] predict that along-axis variability in mantle flow will be greatest at slow spreading ridges but decreases with increasing spreading rate.

Comparatively little work has been done on the interaction between a segmented ridge and buoyant mantle upwelling. Modification of the spreading center geometry by Rabinowicz et al. [1993] and Sparks et al. [1993] to include periodic transform offsets separated by several hundred kilometers causes the downwelling limbs of the off-axis thermal rolls to line up with the transform faults. However, such artificial geometries and long segment lengths are not observed in nature. Rouzo et al. [1995] have created segmentation at the $50-100 \mathrm{~km}$ length scale by coupling a pair of diverging plates with convective rolls upwelling from the mantle. However, this segmentation is derived from the three-dimensional character of the upwelling mantle. Our study differs in that it does not seek to create the plate segmentation from segmented mantle upwelling, but instead examines the effect of existing segmentation on the mantle flow.

\section{Methods}

\section{Laboratory Apparatus}

The laboratory apparatus used for these experiments [Kincaid et al., 1995, 1996] was designed to simulate the first-order features of mantle flow beneath a mid-ocean ridge system: (1) large-scale mantle flow driven by coupling with diverging surface plates; (2) a buoyant material rising from depth beneath the plates; and (3) a segmented ridge-transform geometry. No attempt was made to simulate crustal formation or lithospheric thickening away from spreading centers. Instead, the primary intent was to visualize mantle flow in the upper asthenosphere (from a depth of about $100 \mathrm{~km}$ to the base of the lithosphere).

The primary features of the apparatus and the sources of buoyant and plate-driven components of the mantle flow are illustrated in Figure 1. The apparatus consists of a rectangular glass tank of inner dimensions of $96 \times 72 \mathrm{~cm}$ filled with fluid to a depth of $16 \mathrm{~cm}$. The working fluid is a concentrated sucrose solution manufactured by Archer Daniels Midland. Relevant material properties of the solution are listed in Table 1. The temperature-dependent viscosity of the fluid is analogous to thermally activated creep in the mantle and can be approximated by an Arrhenius law, where viscosity $(\mu)$ varies exponentially with inverse temperature (T) [Olson and Kincaid, 1991]:

$$
\mu=\exp \{1888 /(T+93.3)-11.48\} \text {. }
$$

For the range in temperatures used in these experiments, 20$45^{\circ} \mathrm{C}$, the viscosity varies from 178 to $9 \mathrm{~Pa}$-s.

The apparatus is modified from that described by Kincaid et al. [1996] to incorporate three discrete spreading segments and a linear buoyant source oriented along the general trend of the three segments. The forced, plate-driven flow is simulated by dragging six mylar sheets (two for each ridge segment) across the surface of the fluid. Each sheet is threaded around a set of bars which ensure contact with the working fluid. The sheets are pulled around the spreading axis bars, across the fluid to the take-up bars at the tank walls, and up to a receiving roller. For simplicity, only one spreading segment is shown in Figure 1a. However in all of the experiments, the single-ridge system was replaced with the three-ridge system shown in Figure 1b. Heating elements are bolted to the take-up bars so that the mylar and viscously coupled fluid are heated slightly before passing through a scraper system to separate mylar and fluid. The driving force is supplied by a synchronous, high torque DC motor coupled to a gear reducer, allowing for a wide range of spreading rates.

Thermal buoyancy is supplied by a laminated rubber thermal resistance-style strip heater which is located directly below the base of the tank and insulated below and to the sides to insure vertical heat transfer to the underside base of the tank. The magnitude of the buoyant force was monitored by measuring the temperature of the fluid at the base of the tank above the center of the strip heater. In all cases, the voltage to the heater was regulated to maintain a relatively constant $\left( \pm 2^{\circ} \mathrm{C}\right)$ basal temperature to insure a time-independent two-dimensional buoyant source.

The temperature of the fluid reaching the surface of the tank was monitored using a series of small $(2 \times 2 \times 1 \mathrm{~mm})$ platinum resistance temperature detectors (RTDs). These were suspended just below the surface of the fluid along each of the three ridge segments and each of the two transforms. We are able to measure temperature variations very near the fluid surface because the mylar is not held at a constant temperature. Therefore the temperature measurements should be thought of as indicators of variations in delivery of fluid from a deep hot source, rather than being directly analogous to shallow mantle or crustal temperature variations. Temperature information from all RTDs was automatically logged at 5-s intervals. Since this experiment was concerned only with the steady state flow pattern, the temperatures recorded during the initial transient behavior in the tank were not used. Instead, the long-term increase above room temperature at each RTD was determined. 
a)

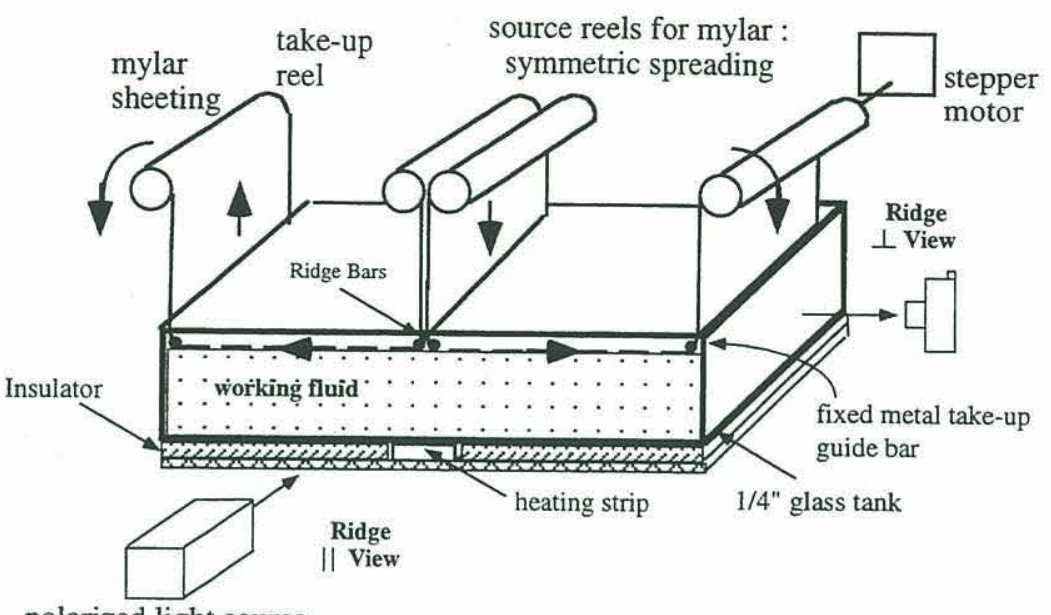

polarized light source

b)

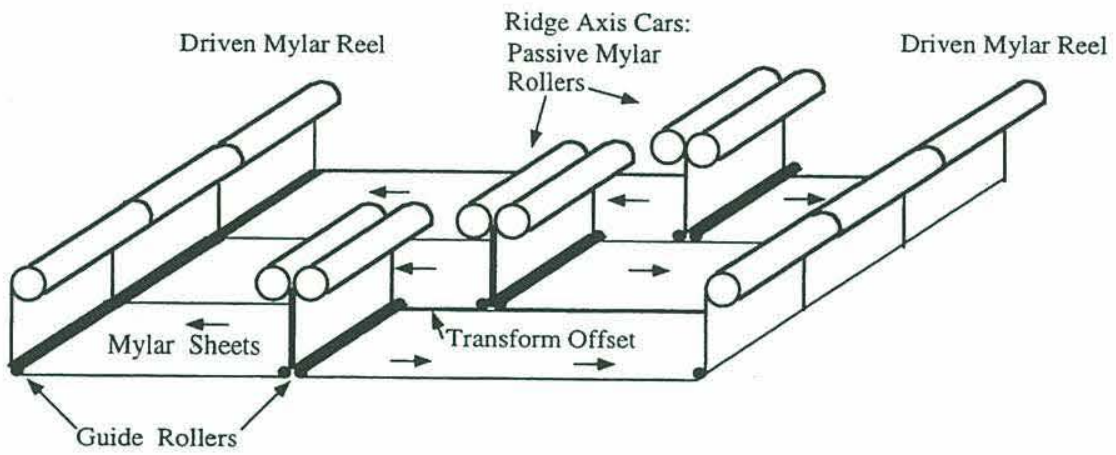

Figure 1. (a) Schematic of laboratory apparatus of Kincaid et al. [1996] showing location of heating strip, mylar drive system, and ridge-perpendicular and ridge-parallel views. Mylar is threaded from spool reels down through the ridge bars and across the fluid surface. The mylar is then passed through a take-up bar and scraper system to separate the mylar and fluid, up to a take-up reel. This system is driven by a DC motor to provide symmetric platedriven flow in the fluid. (b) Schematic of modified ridge-transform apparatus which replaces the single-ridge system in Figure 1a. Here, six reels of mylar supply three ridge segments. Lengths and sense of offsets can be adjusted to create a variety of ridge geometries.

To do this, the data were first filtered with a 9-point running median filter to remove the high-frequency noise. The background temperature reading for each RTD was found by averaging all of the temperature measurements (generally about $45 \mathrm{~min}$ worth) taken before any upwelling material reached the surface. This was then subtracted from the average temperature recorded after the final steady state flow had been reached (generally about $60 \mathrm{~min}$ worth). Standard deviations in temperature varied but were generally between 0.2 and $0.5^{\circ} \mathrm{C}$. Therefore temperature differences greater than $1.0^{\circ} \mathrm{C}$ can be considered significant.

Fluid circulation/temperature patterns were recorded using laser-illuminated images taken with a $35-\mathrm{mm}$ still camera. The images were produced by shinning a vertical plane of laser light $(<1 \mathrm{~cm}$ wide) from a 4-mW He-Ne laser through the tank illuminating a single ridge-perpendicular plane. Exposure times were $15-30 \mathrm{~s}$, during which the fluid did not move significantly. Reflection of the laser light off of tiny bubbles within the fluid creates bright spots in the images. At the start of an experiment, the density of microbubbles is lowest in the fluid near the base of the tank. This region appears dark as does the central upwelling which taps this region of the fluid. Fluid with lower concentrations of microbubbles serve as tracers for fluid circulation patterns when illuminated with laser light. The higher rise rates of microbubbles in the central core of the upwelling also contribute to its darker appearance by reducing the level of reflected laser light.

\section{Numerical Simulations}

Three-dimensional uniform viscosity numerical convection models [Sparks et al., 1993; Kincaid et al., 1996] were used to simulate the laboratory experiments. Finite difference 
Table 1. Properties of Tank and Fluid

\begin{tabular}{lc}
\hline \multicolumn{1}{c}{ Property } & Tank Value to Be Matched in Numerics \\
\hline Horizontal dimensions of tank, $\mathrm{cm}$ & $96 \times 72$ \\
Dimensions of area coupled to plates, cm & $90 \times 60$ \\
Layer depth, cm & 16 \\
Length of ridge segments, cm & 20 \\
Length of transforms, $\mathrm{cm}$ & $\sim 10, \sim 20$, or $\sim 30$ depending on run \\
Width of strip heater, $\mathrm{cm}$ & 10 for RTR1 geometry, 15 otherwise \\
Thermal expansivity, ${ }^{\circ} \mathrm{C}^{-1}$ & $4.6 \times 10^{-4}$ \\
Density at $22^{\circ} \mathrm{C}, \mathrm{kg} / \mathrm{m}^{3}$ & 1422 \\
Thermal diffusivity, $\mathrm{m}^{2} / \mathrm{s}$ & $1.0 \times 10^{-7}$ \\
\hline
\end{tabular}

approximations on a $17 \times 129 \times 65$ grid (corresponding to a $16 \times 90 \times 60 \mathrm{~cm}$ tank) were used to solve the Stokes equations for viscous fluid flow and the time-dependent energy balance of temperature. The flow was decomposed into two components: a plate-driven flow controlled by the moving plate boundary, and a buoyant flow with no-slip top and bottom boundaries. The platedriven flow was calculated for each of the plate geometries studied in the laboratory using a propagator matrix method [see Sparks et al., 1993, Appendix B] for a uniform viscosity layer (simulating the tank) over a half-space. A viscosity increase of a factor of 1000 at the base of the layer, and stress-free side-wall conditions, restricted the return flow to remain within the confines of the simulated tank. The stream function-vorticity formulation for the buoyant flow technique was solved using a multigrid iterative technique [Sparks et al., 1993], again with stress-free side walls.

A fixed temperature $\left(20^{\circ} \mathrm{C}\right)$ was used for the top and bottom boundaries, and the side walls were insulating. To match the laboratory conditions for the strip-heated experiments, all of the fluid in the simulated tank was initially at a uniform $20^{\circ} \mathrm{C}$ except for the region of heating at the bottom boundary where a temperature of $40^{\circ} \mathrm{C}$ was imposed. For the plate-driven-only simulations, a nondiffusive tracer was uniformly spread over the bottom layer of the numerical tank before the start of the experiment and its subsequent position was observed by plotting isosurfaces of tracer concentration.

The shear stress-free condition on the side walls, used to achieve convergence of the numerical method, enhances upwelling where the ridge segments intersect the side walls. The flow a short distance away from these walls is, however, qualitatively very similar to the flow in the tank. Therefore, in our comparisons of the laboratory experiments and the numerical simulations we concentrate on this central region.

\section{Experimental Design}

A total of 19 experiments (Table 2) were run in the laboratory and subsequently simulated using the numerical model. Four different ridge-transform geometries: RTR1, RTR2, RTR3, and RTR4 (Figure 2) were chosen to investigate a variety of ridge

Table 2. Characteristics of Experimental Runs

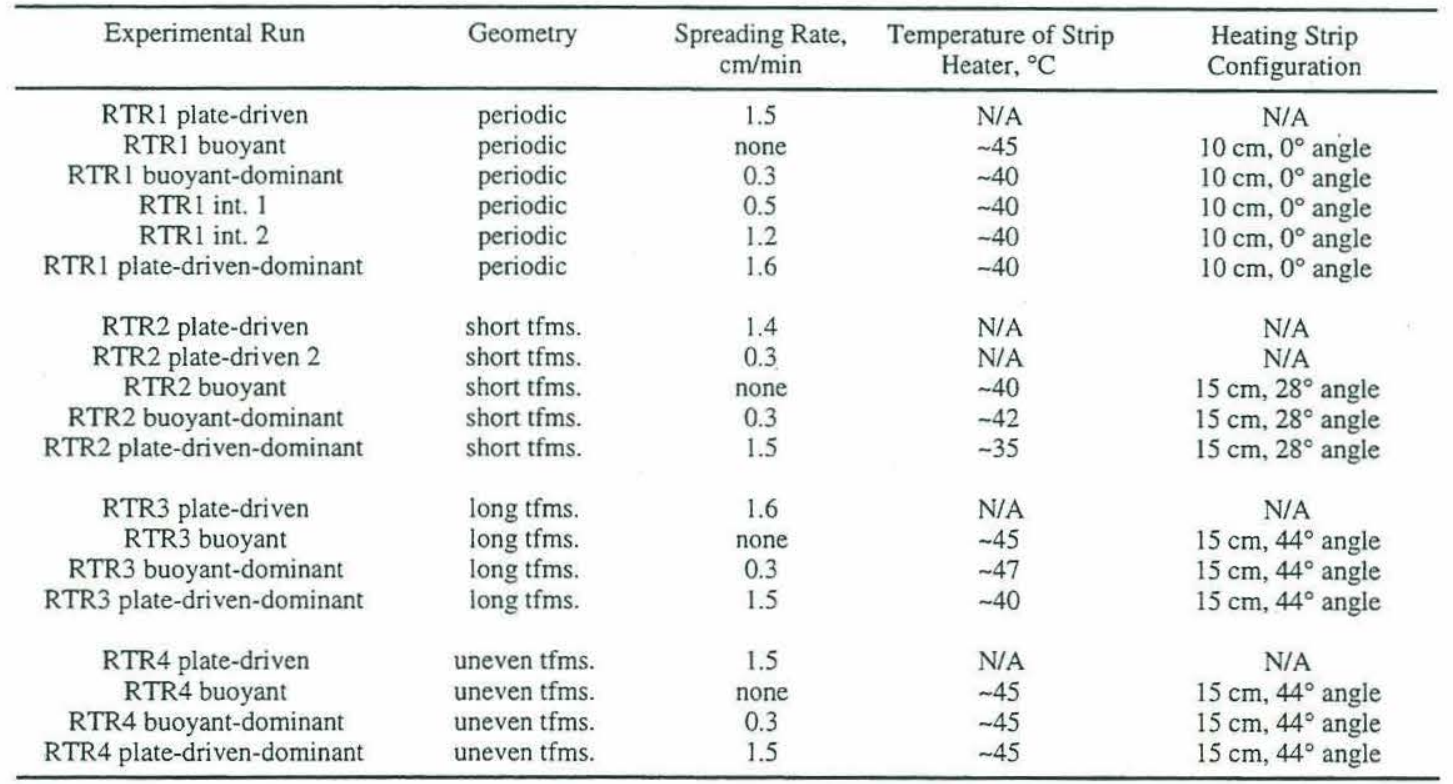

N/A, not applicable; tfms., transforms. 


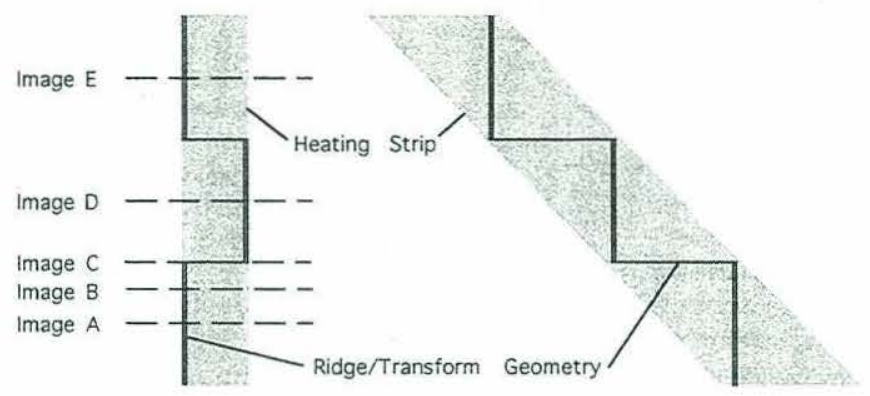

b) RTR2 Geometry

d) RTR4 Geometry

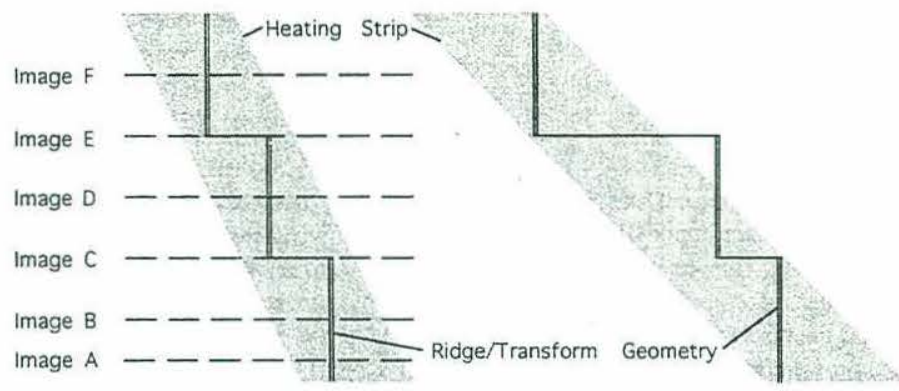

Figure 2. Top views of each of the four ridge-transform and heating strip geometries studied. Spreading ridges are indicated by double lines, transforms by single lines. Spreading is perpendicular to the ridge segments. The location of the heating strip is indicated by the gray shaded area. (a) Dashed lines indicate locations of laser images shown in Figure 4. (b) Dashed lines indicate locations of laser images shown in Figures 6 and 7.

configurations. These included three different ridgelength/transform-length ratios and three different orientation angles between the linear buoyant source (following the overall plate boundary) and the spreading direction (perpendicular to the individual spreading segments). The fixed length of the spreading segments in the tank made it impossible to scale the laboratory apparatus to simulate the return flow at realistic depths $(>150 \mathrm{~km})$ beneath the plates. Instead, only the top (diverging) portion of mantle convection was simulated. The experiments were scaled to a segment length of $125 \mathrm{~km}$ and a linear buoyant source was used to simulate the hot mantle upwelling from a depth of about $100 \mathrm{~km}$ beneath an oceanic spreading center.

The linear buoyant source used in the experiments was chosen to simulate the upwelling within the lower part of the asthenosphere that results from divergence along the plate boundary. In models of purely plate-driven flow beneath segmented spreading centers [Phipps Morgan and Forsyth, 1988], mantle upwelling at depths significantly greater than the offset length forms a nearly two-dimensional sheet aligned with the long wavelength trend of the plate boundary. Since we are modeling only the local buoyant flow associated with upwelling in the upper $100 \mathrm{~km}$ (thermal, compositional and melt gradients near the partially melting zone), we simulate the deeper mantle upwelling with a linear buoyant source that passes through the centers of segments.
Beneath real ocean ridges, along-axis variations will result from a combination of three-dimensional behavior of both the buoyant and the plate-driven components. Several studies [i.e., Kincaid et al., 1995; Jha et al., 1994; Sparks and Parmentier, 1993] have demonstrated that along-axis variations in crustal thickness and melt supply may result from plume-like instabilities in the upwelling mantle. This study investigates the potential for additional, superimposed, along-axis variation resulting from ridge segmentation.

The laboratory experiments are scaled to the mantle through two dimensionless quantities, which describe the strength of convection and plate motion. The strength of this buoyant flow may be characterized by a dimensionless Rayleigh number, $R a$ :

$$
R a=\rho g \alpha \Delta T D^{3} / \kappa \mu
$$

where $\rho, g, \alpha, \Delta T, D, \kappa$, and $\mu$ are density, acceleration of gravity, coefficient of thermal expansion, vertical temperature drop across the fluid, layer thickness, thermal diffusivity, and dynamic viscosity, respectively. Active convection occurs at $R a$ above $6.7 \times 10^{4}$, which can be achieved with a temperature drop of $20^{\circ} \mathrm{C}$ and a fluid viscosity of $50 \mathrm{~Pa}$-s. This value of $R a$ applied to a $100 \mathrm{~km}$ depth scale, implies a $\Delta T=200^{\circ} \mathrm{C}$, and upper mantle viscosity of $3 \times 10^{18} \mathrm{~Pa}-\mathrm{s}$ [e.g., Sleep, 1990; Craig and McKenzie, 1986]. 
In picking a $R a$ for the numerical experiments, the value of the uniform viscosity is chosen to best represent the behavior of the variable viscosity laboratory fluid. Previous strip-heating studies [Kincaid et al., 1996] which compare laboratory and constant viscosity numerical results indicate that the appropriate reference viscosity for use in defining $R a$ should be based on the ambient fluid temperature (e.g., away from the thermal boundary layer). A viscosity value of $50 \mathrm{~Pa}-\mathrm{s}$ (corresponding to $29^{\circ} \mathrm{C}$ fluid) was found to produce a match both in onset time of instabilities and ascent rates between laboratory and numerical plumes [Kincaid et al., 1996] and was used for all simulations presented here.

The magnitude of the plate-driven flow scales to the mantle through the dimensionless Peclet number, $P e$ :

$$
P e=U_{P} D / \kappa
$$

where $U_{p} . D$, and $\kappa$ are plate velocity, fluid thickness, and thermal diffusivity, respectively. Taking a mantle diffusivity of $1.0 \times 10^{-6}$ $\mathrm{m}^{2} / \mathrm{s}$, a mylar half rate of $1.5 \mathrm{~cm} / \mathrm{min}$ corresponds to a mid-ocean ridge spreading with a half rate of $7.9 \mathrm{~cm} / \mathrm{yr}$.

\section{Results}

\section{Buoyant Flow}

For each geometry, a buoyant-only experiment was conducted in which the fluid flow was driven by heat input from the strip heater in the absence of spreading plates. In all cases, the thermal boundary layer became unstable after about $30 \mathrm{~min}$ (at temperatures of about $50^{\circ} \mathrm{C}$ ), and the resulting convection pattern was monitored until it reached a steady state (with basal strip temperatures of $40-45^{\circ} \mathrm{C}$ ).

The initial time-dependent behavior of the buoyant-only flow is similar to previous laboratory studies [e.g., Whitehead et al., 1984; Olson et al., 1988; Kincaid et al., 1996]. The thermal boundary layer initially goes unstable in a series of plumes. The plume heads rise to the surface in about $10 \mathrm{~min}$ and are followed by trailing conduits which merge together into a sheet-like upwelling. The hot material pools beneath the surface of the mylar and spreads outward away from the axis of upwelling. The result is a very narrow $(<1 \mathrm{~cm})$ two-dimensional upwelling (Figure 3). Although the RTDs in this experiment could not be placed directly above the axis of upwelling, previous stripheating experiments [Kincaid et al., 1996] found long-lived temperature variations of $1-2^{\circ} \mathrm{C}$ along axis. However, in relation to the three-dimensional flow driven by the segmented spreading center, these flows are essentially two-dimensional and timeindependent.

The numerical simulations also produce a sheet-like upwelling centered along the heating strip with material moving symmetrically away from the axis of upwelling (Plate 1a). The temperature-dependent viscosity of the tank fluid leads to a narrower upwelling than that produced in the numerical experiments. The numerical experiments also show relatively enhanced upwelling where the heating strip intersects the walls, due to the stress-free condition employed on the side walls.

\section{Plate-Driven Flow}

Similarly, a series of experimental runs were conducted without the strip heater in order to characterize the plate-drivenonly flow for each geometry. In each case, the drive system was turned on to a fast spreading rate $(1.5 \mathrm{~cm} / \mathrm{min})$ and allowed to develop a steady state flow pattern (after about $90 \mathrm{~min}$ ). A second plate-driven-only experiment was run with the RTR2 geometry at a spreading rate of $0.3 \mathrm{~cm} / \mathrm{min}$ (corresponding to a plate half rate of $1.6 \mathrm{~cm} / \mathrm{yr}$ ) to confirm the assumption that the pattern of upwelling in the plate-driven flow is independent of spreading rate. Since there was no heating, flow could not be monitored using the RTDs. However, laser images provided clear images of the flow.

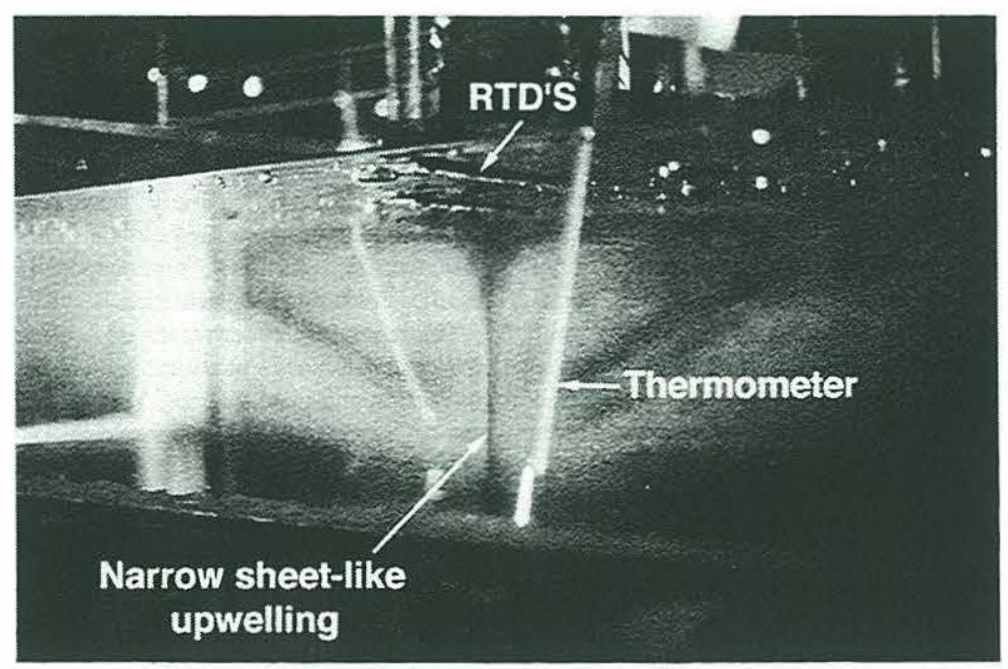

Figure 3. Photograph taken along the axis of the sheet-like upwelling created in the buoyant-only run with strip at $28^{\circ}$ angle and RTDs in the RTR2 geometry. The narrow $(\sim 2 \mathrm{~mm})$ upwelling is centered above the strip heater which makes a $28^{\circ}$ angle with the sides of the tank. The thermometer used to monitor basal fluid temperatures can be seen at the front of the tank. The RTDs along the ridges and transforms of the RTR 2 geometry can be seen at the top of the fluid. Compare to Plate 1a. 

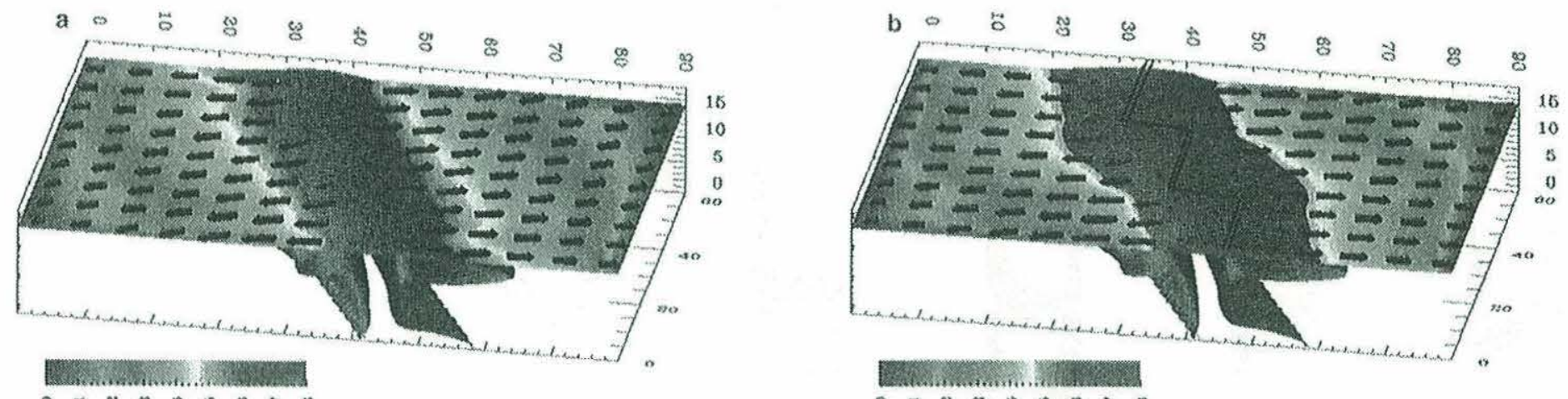

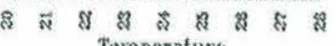

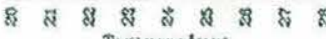

Temperature

Temperature
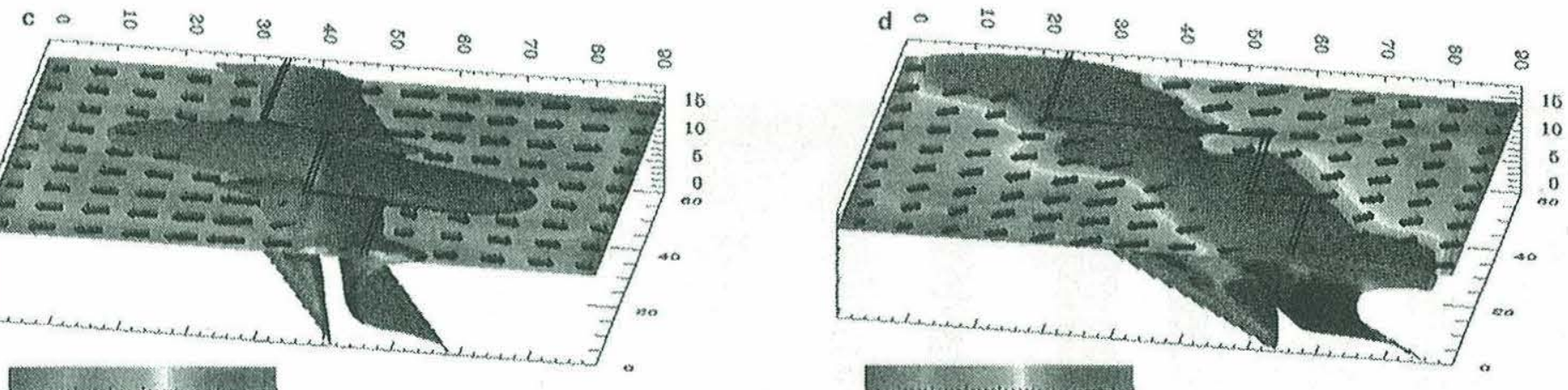

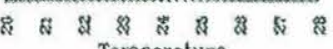

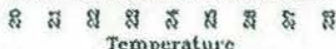

Plate 1. Result of selected numerical simulations of tank. Temperatures on a plane $2 \mathrm{~cm}$ below the surface of the tank are shown. Black arrows indicate the direction and magnitude (proportional to arrow length) of fluid flow. (a) Buoyant-only run with heating strip at $28^{\circ}$ angle (compare to Figure 2). The shaded $26^{\circ} \mathrm{C}$ isothermal surface outlines the hot sheet-like upwelling which is not as narrow as that observed in the variable-viscosity tank. RTR2 geometry in (b) buoyant-dominant and (c) plate-driven-dominant cases. Compare to Figures 6 and 7. The shaded isothermal surface outlines the flow pattern in each case. Locations of ridges (double lines) transforms (single lines) are indicated at the top of the simulated tank. Note that flow is much more asymmetrical in the plate-driven-dominant case. (d) RTR4 geometry in the buoyant-dominant case. Note the difference in temperature and efficiency of mantle delivery between the long and short transforms. The central segment is also very asymmetrical with temperature decreasing near the longer transform. 
a)

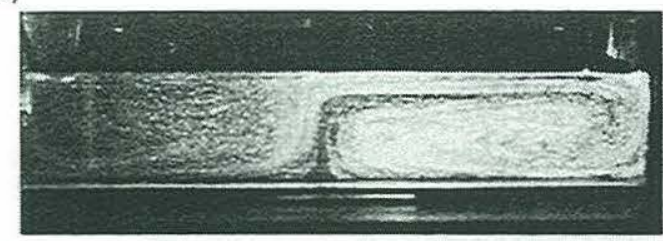

b)

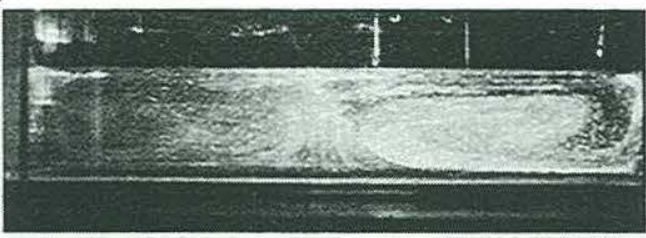

c)

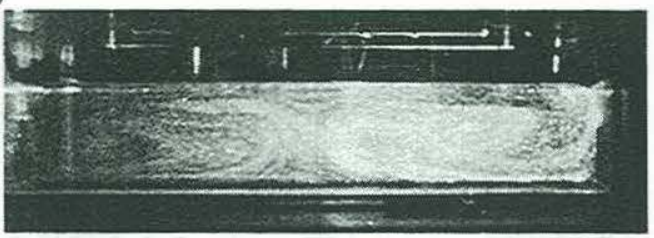

d)

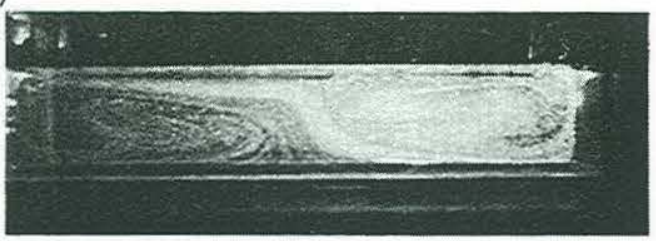

e)

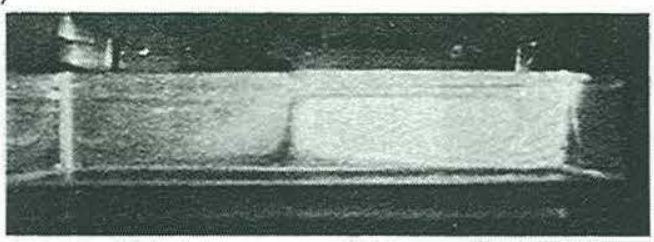

f)

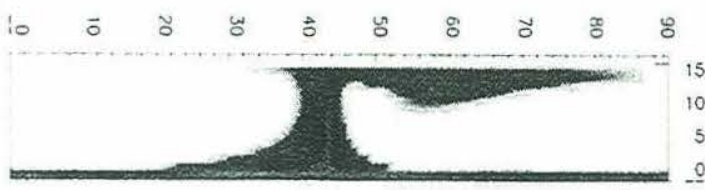

g)

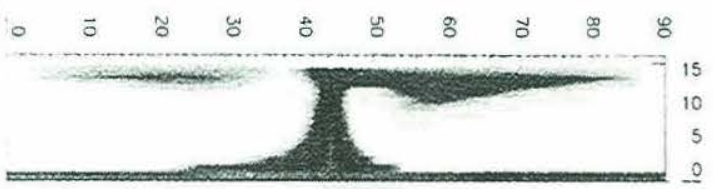

h)

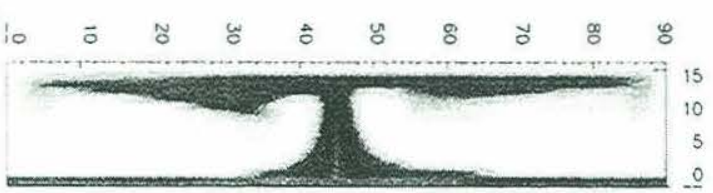

i)
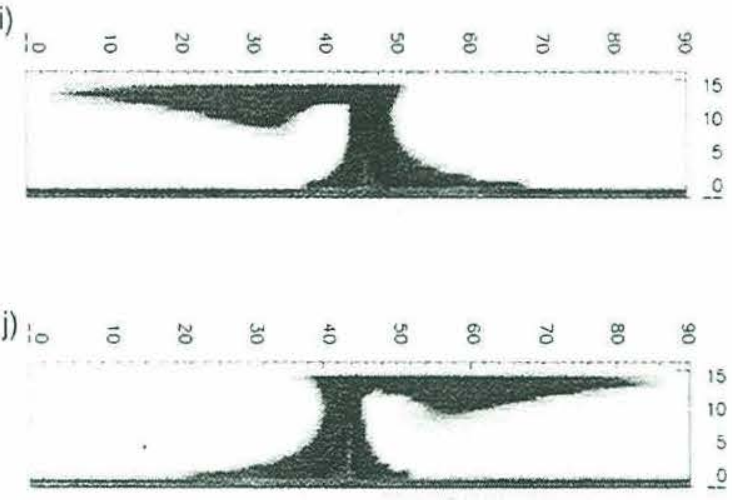

Figure 4. Comparison of laboratory and numerical results showing the steady state flow observed in the RTR1 plate-driven-only experiment. (a)-(e) Laser-illuminated cross sections through laboratory tank. Locations of cross sections are shown in Figure 2a. The view is from the side nearest Figure 4a. Bright spots are created by reflection of laser light off of tiny bubbles suspended in the fluid. Dark areas indicate regions of enhanced fluid velocities where bubbles have been sheared in the direction of flow. (f)-(j) Cross sections through the numerical simulation at locations correspoding to the laser-illuminated images in Figures $4 \mathrm{a}-4 \mathrm{e}$. Areas with significant concentrations of the passive tracer are dark.

Plate spreading at the surface of the tank also drives a roughly linear band of upwelling. The plate-driven flow in an isothermal fluid is illustrated for the RTR1 geometry in Figure 4. In the bottom half of the tank, fluid rises vertically in a continuous curved sheet. Closer to the surface, it is swept horizontally in the direction of the overriding plate. In Figures $4 \mathrm{a}$ and $4 \mathrm{f}$, fluid upwelling from the base of the tank comes to the surface to the right of the first ridge segment axis and is transported entirely to the right. Closer to the transform (Figures $4 \mathrm{~b}$ and $4 \mathrm{~g}$ ) some material is beginning to feel the effect of the central ridge segment and may be moving to the left. At the transform
(Figures $4 \mathrm{c}$ and $4 \mathrm{~h}$ ), material is transported in both directions. In Figures $4 \mathrm{~d}$ and $4 \mathrm{i}$, through the center of the tank, material from the base of the tank upwells to the left of the second ridge segment axis and is transported entirely to the left. Since this ridge configuration is symmetrical, fluid flow in the back half of the tank mirrors flow in the front half of the tank; in Figures $4 \mathrm{e}$ and $4 \mathrm{j}$, material upwells to the right of the third spreading segment axis is transported to the right.

Numerical plate-driven flow patterns for all four experimental geometries are shown in Figure 5. For each plate geometry, the dark sinuous band highlights the region where material is 
a)

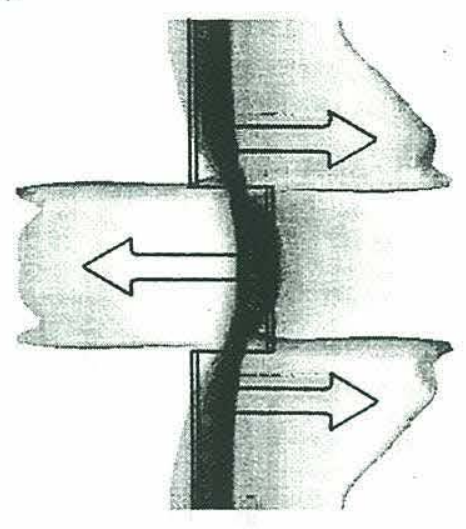

c)

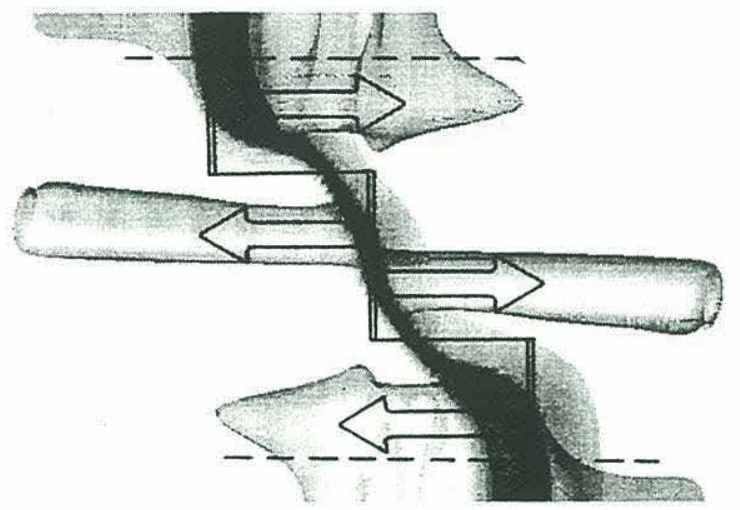

b)

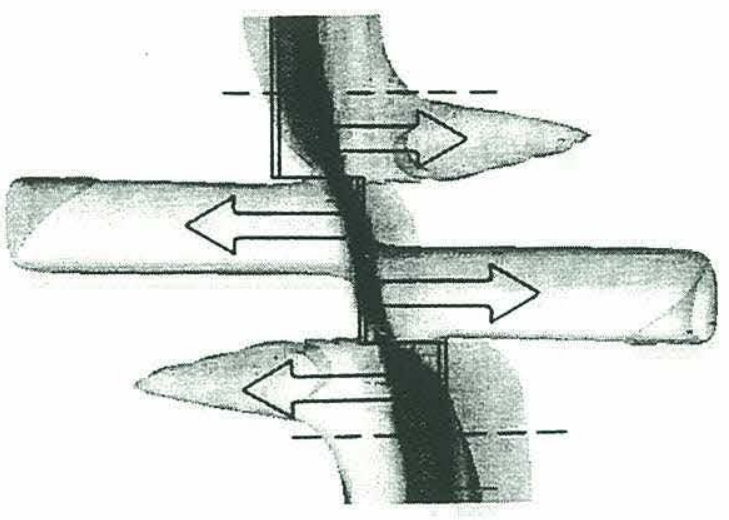

d)

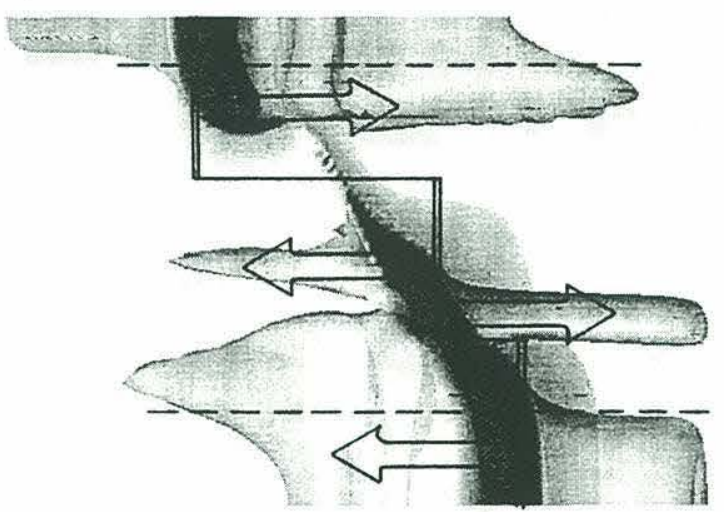

Figure 5. Results of numerical simulations of plate-driven-only flow for (a) RTR1, (b) RTR2, (c) RTR3, and (d) RTR4 plate geometries. The pattern of mantle flow is shown by a concentration isosurface of a nondiffusive tracer, projected onto a horizontal plane. Locations of the ridges and transforms are indicated by black lines. The general direction of fluid flow (and associated tracer transport) is indicated by arrows. Dashed lines mark the regions near the front and back of the tank where the numerical edge effects create a flow pattern which differs from that observed in the laboratory tank. The dark band shows where a high concentration of tracer is present in a twodimensional cross section located $2 \mathrm{~cm}$ from the bottom of the tank. This is the axis of the plate-driven upwelling.

upwelling from the bottom of the tank. In all cases, this band describes a smoothed version of the ridge-transform geometry, cutting across the inside corners of the ridge-transform intersections. The key feature of the upwelling is the along-axis variation in the magnitude of the upwelling (indicated by the width of the dark band). The three-dimensional plate-driven flow causes enhanced upwelling at segment centers and reduced upwelling near transforms. Purely passive flow would have even more along-axis variations; however, the flow in the tank is affected by the two-dimensional return flow imposed by the spreading-perpendicular walls of the tank. If the distance from the spreading axes to these end walls were an order of magnitude larger than the transform lengths, then the segmented nature of the upwelling would extend down to a depth comparable to the offset length.

The transport of material near the surface of the tank is illustrated by the gray surfaces shown in Figure 5. These are horizontal projections of constant-concentration isosurfaces of a nondiffusive tracer. Arrows indicate the primary direction of near-surface flow. Since the upwelling is generally not centered beneath the spreading axes, material is transported away with the plate under which it upwells, resulting in a flow pattern which is decidedly asymmetric with respect to the vertical planes containing each spreading segment. In the RTR2 and RTR3 cases, the band is centered beneath the central segment but cuts to the inside of the first and third segments. In the RTR4 case, the asymmetry of the transform shifts the central segment away from the center of the tank, and the axis of upwelling falls to the left of the central segment. In the longer transform cases (RTR3 and RTR4) no material upwells beneath the transforms.

\section{Combined Buoyant and Plate-Driven Flow}

Spreading rates were chosen to investigate both buoyantdominant and plate-driven-dominant flow. In buoyant-dominant cases, a mylar speed of $0.3 \mathrm{~cm} / \mathrm{min}$ corresponds to a half rate of $1.6 \mathrm{~cm} / \mathrm{yr}$ in the mantle; in plate-driven-dominant cases, a mylar speed of $1.5 \mathrm{~cm} / \mathrm{min}$ corresponds to a half rate of $7.9 \mathrm{~cm} / \mathrm{yr}$. Two 
a)

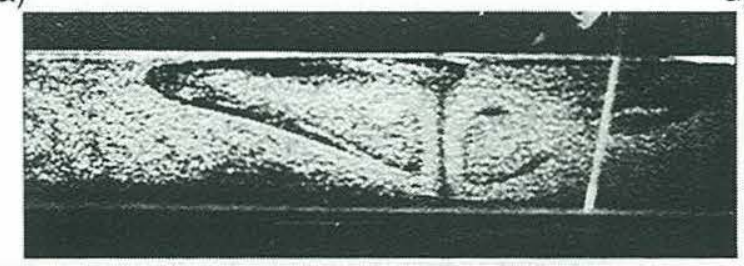

b)

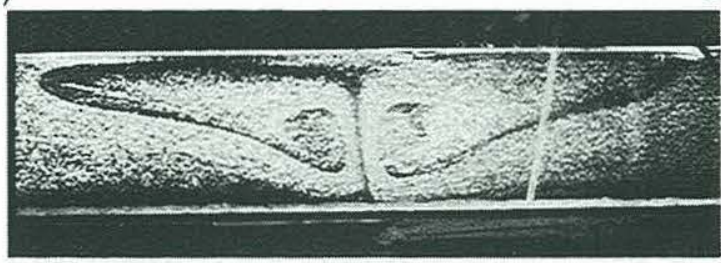

c)

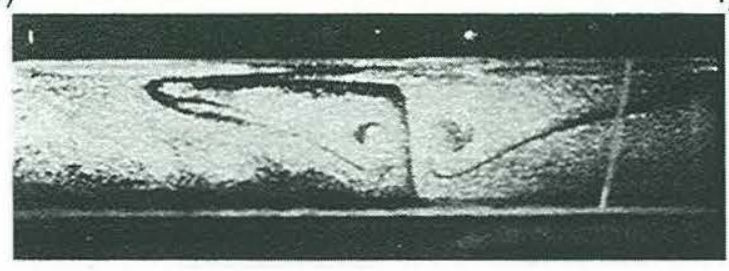

d)

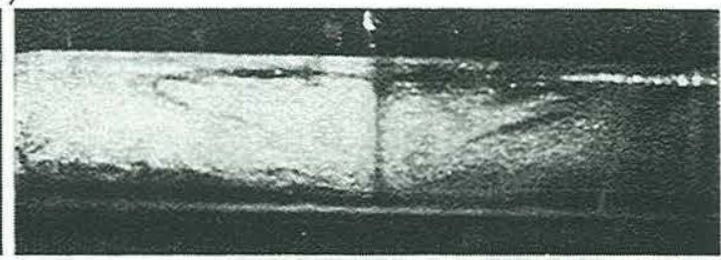

e)

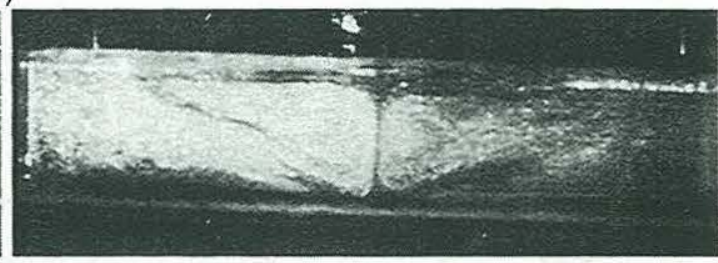

f)

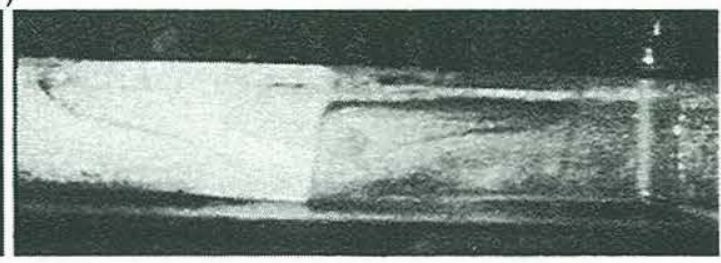

Figure 6. Laser-illuminated images of steady state flow observed in the RTR2 buoyant-dominant experiment. Locations of cross sections are shown in Figure $2 b$. Dark areas highlight the narrow sheet-like upwelling and the hot material pooling at the top of the tank and being transported away by the spreading plates. Compare to Plate lb.

a)

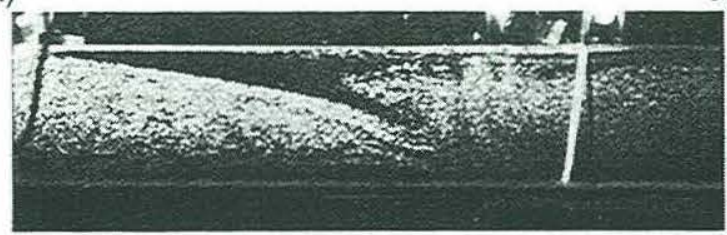

b)

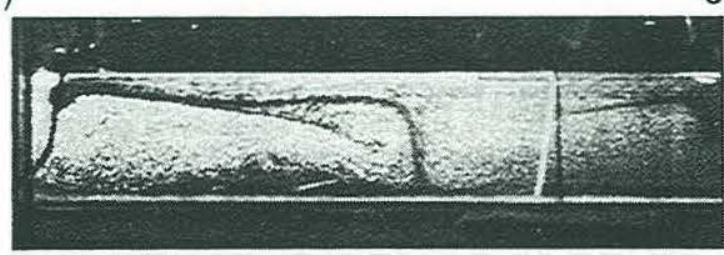

c)

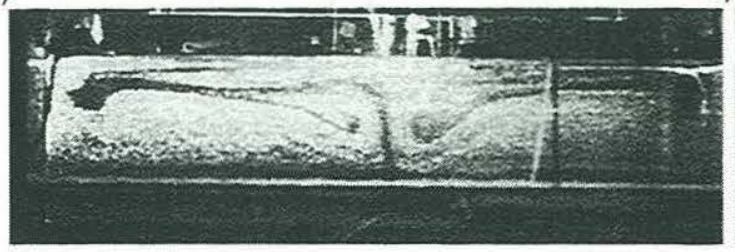

d)

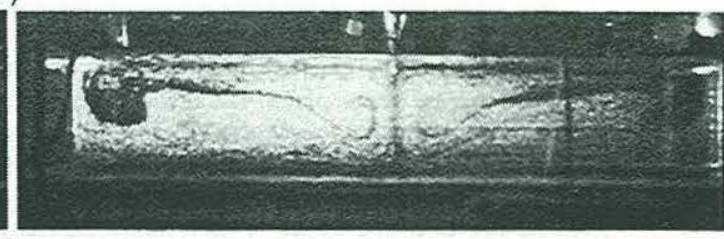

e)

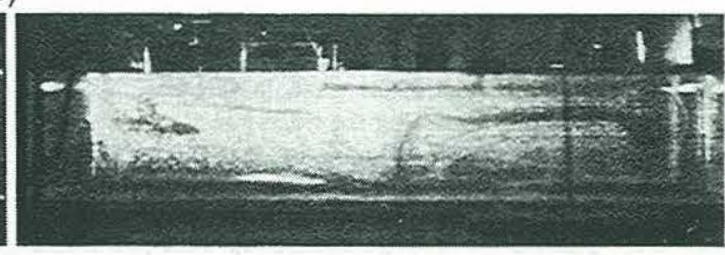

f)

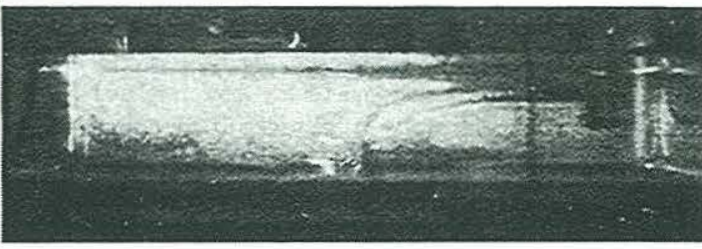

Figure 7. Laser-illuminated images of steady-state flow observed in the RTR2 plate-driven-dominant experiment. Locations of cross sections are shown in Figure $2 \mathrm{~b}$. The flow pattern is similar to the buoyant-dominant case in Figure 6 except that the asymmetry of the flow has been accentuated. Compare to Plate Ic. 
intermediate spreading rate experiments were conducted for the RTR1 geometry, but the relationship to spreading rate was clearly demonstrated in just the two end-member cases. Therefore only these two spreading rates were used for the other geometries. For each of these experiments, the strip heater was turned on before the mylar drive system and allowed to create a thermal boundary layer, generating a buoyant source in a linear region above the strip. When this layer reached a temperature of $\sim 40^{\circ} \mathrm{C}$ (after about 20-25 min), the drive system was turned on. A steady state flow pattern generally developed within about 1 hour and was monitored for an additional hour to allow sufficient time to characterize the flow.

Figures 6-7 and Plates 1b-1d show results from experiments combining segmented plate-driven flow with a linear buoyant source. The axis of upwelling does not follow the ridge segments but rather cuts across the inside corners, following the general trend of the buoyant source. Fluid upwelling to one side of a spreading segment is preferentially transported away in that direction. The asymmetric transport is enhanced when the platedriven component of the flow is stronger.
In the buoyant-dominant case (Figure 6 and Plate 1b), hot fluid rises buoyantly to the surface before being transported away from the spreading axis. Since the axis of upwelling is offset from the ridge axes in the first and third segments (Figures $6 \mathrm{a}, 6 \mathrm{~b}$, and $6 \mathrm{f}$ ), material is transported primarily in one direction. Beneath the center of the central segment (Figure 6d), the axis of upwelling and the ridge axis coincide and material is transported in both directions. The upwelling material near the transforms (Figures $6 \mathrm{c}$ and $6 \mathrm{e}$ ) may be transported in either direction depending on which side of the narrow transform boundary it is on. In the plate-driven-dominant case (Figure 7 and Plate 1c), hot upwelling fluid is swept away before reaching the surface. The only exception is where the axes of upwelling and spreading coincide (Figure 7d). Since the three-dimensional character of the platedriven flow propagates deeper into the tank, regions form (typically near transforms) where hot material never reaches the surface.

Along-axis temperature variations for each of the plate geometries are shown by the open symbols in Figure 8 . Temperature variations do not indicate variations in mantle
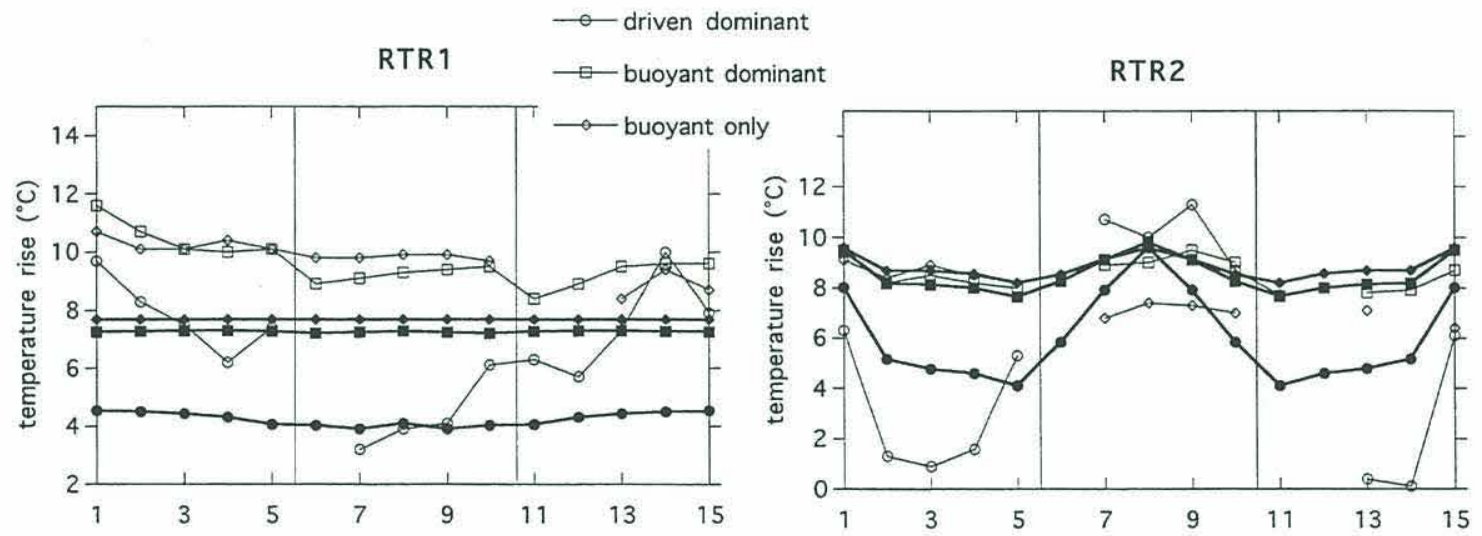

RTR3

RTR4

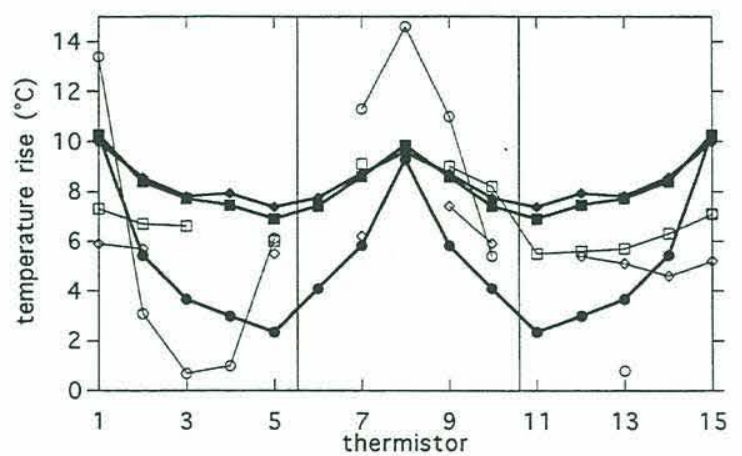

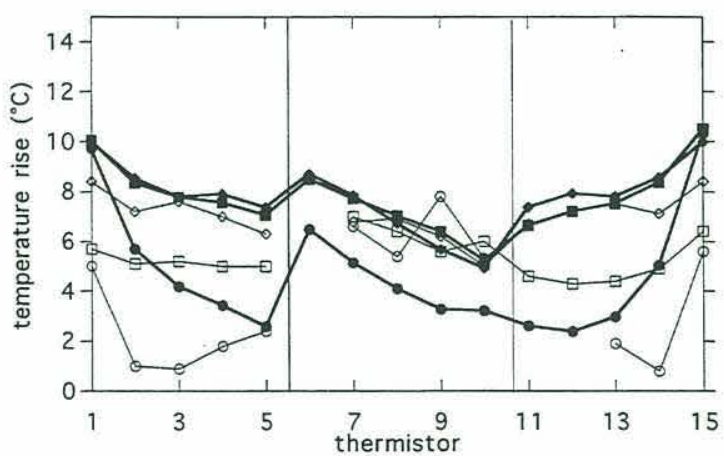

Figure 8. Temperature increase above room temperature (open symbols) recorded at each of the 15 along-axis RTDs. Temperature differences of more than $1^{\circ} \mathrm{C}$ are considered significant; those RTDs without an associated temperature failed during that particular experiment. Vertical lines indicate the location of the two transforms. Numerical predictions of temperature increase (solid symbols) at the same locations (measured in a plane $2 \mathrm{~cm}$ below to surface of the tank). Note that for all geometries, the greatest along-axis variability is seen in the platedriven-dominant cases (circles) and the least along-axis variability is in the buoyant-only cases (diamonds). Although the absolute values of the temperature increase differ between the laboratory and numerical experiments, the pattern of lower temperatures near transforms and higher temperatures near segment midpoints is the same. 


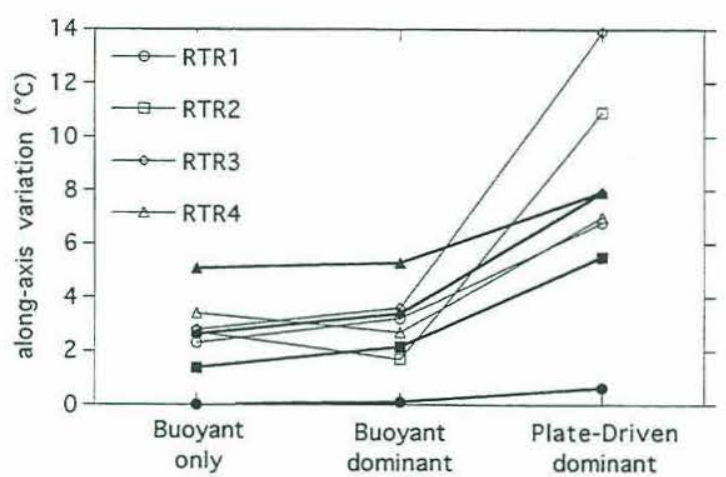

Figure 9. Maximum along-axis temperature variation (computed from Figure 8 ) for each of the geometries. Open symbols represent tank values, while solid symbols represent numerical experiments. Note that the along-axis variation is similar for the buoyant-only and buoyant-dominant cases but increases substantially for the plate-driven-dominant experiments.

temperature. Instead, hotter temperatures indicate efficient transport of upwelling fluid to the ridges. The degree of alongaxis variation in temperature increases with the strength of the plate-driven flow (Figure 9). The buoyant-only and buoyantdominant flow patterns deliver warm fluid to almost all of the RTDs. In these cases, fluid rises to the surface of the tank and spreads out below the plates before being transported away. In contrast, all of the plate-driven-dominant cases have much larger along-axis temperature variations, with colder temperatures recorded along the first and third segments and near the transforms. Somewhat warmer temperatures along the transforms result from transport of warm material along the transform. The results of the numerical experiments (solid symbols in Figures 8 and 9) also show increased along-axis variation with increasing strength of the plate-driven flow. The magnitude of the temperature variation is generally lower than that observed in the tank, but this may be due to the constantviscosity assumption of the numerical experiments.

Figure 10 combines the observed temperature data with the shallow flow patterns, illustrated by isotherms determined from the numerical experiments. The increased transform lengths in the RTR3 and RTR4 geometries increase the geometrical misfit between the buoyant source and the ridge segments. Although warm material is delivered to the shorter transform in the RTR4 geometry, less hot material upwells beneath the longer transform. This can be seen in the low temperatures near the second transform in Figures 8 and 10 as well as the cool temperatures at the intersection between the second and third segments in Plate 1d. These cooler temperatures create a distinct asymmetry alongaxis in the middle segment with colder temperatures and less efficient upwelling near the longer transform.

\section{Discussion}

Figure 11 summarizes the interaction between a linear buoyant source and a segmented ridge for cases of buoyant- and platedriven-dominant flow. In the buoyant-dominant case (Figure 11a), upwelling fluid is delivered to the base of the spreading system faster than the plates can advect the fluid away. Hot, buoyant fluid therefore ponds beneath the plates, and very little axial thermal variability is recorded at the surface. In contrast, when the plate-driven component of the flow dominates, the interaction of a linear upwelling source with a segmented ridge serves as a natural source for axial variability. When upwelling fluid is drawn away as fast as it is buoyantly supplied, flow rapidly advects the deeper temperature structure to the surface. The surface of the tank essentially records a snapshot of the deeper thermal structure. At point A (in Figure $1 \mathrm{lb}$ ), the ridge axis receives hot upwelling fluid, whereas at point 1 , the ridge samples the cooler ambient fluid. If the upwelling is very sheetlike, a large-amplitude along-axis variation is expected.

These results show that when a segmented spreading center is imposed on the system, axial variability increases with increasing

\section{Plate-Driven Dominant}

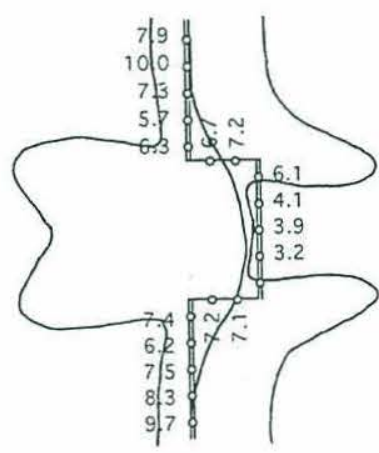

Buoyant Dominant

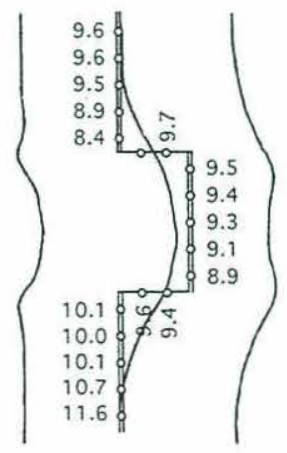

Buoyant Only

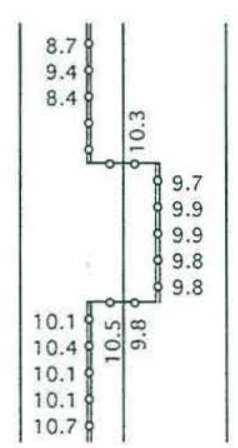

Figure 10a. Results of plate-driven-dominant, buoyant-dominant, and buoyant-only experiments for the RTR 1 geometry. Ridges are indicated by double lines, transforms by single lines. Locations of RTDs are indicated by open circles. The temperature increases from Figure 8 are shown. Note the more uniform temperatures along-axis in the buoyant-only and buoyant-dominant cases as compared to the plate-driven-dominant case. The superimposed curved lines indicate the axis of upwelling from the bottom of the tank (based on both the laboratory and numerical experiments) and shallow flow pattern (which outlines the intersection of a representative isotherm with a plane $2 \mathrm{~cm}$ below the surface of the simulated tank in the numerical experiments) for each case. 
Plate-Driven Dominant

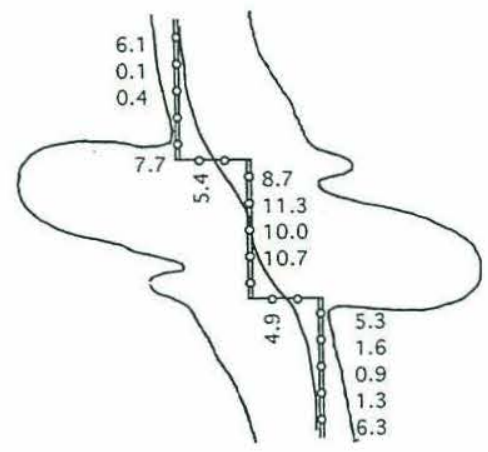

Buoyant Dominant

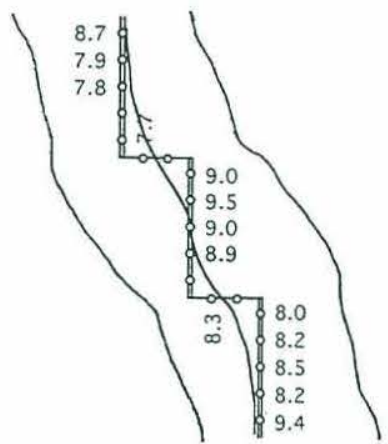

Buoyant Only

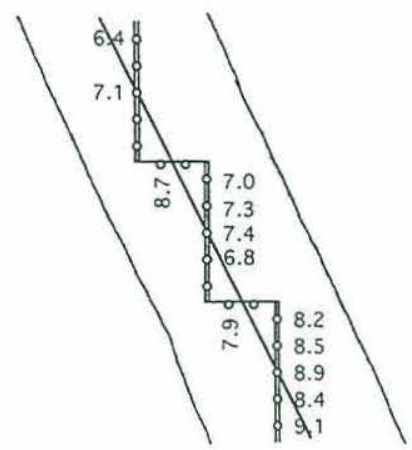

Figure 10b. As in Figure 10a except for RTR2 geometry.

dominance of the plate-driven flow (Figures 9). This is different from previous laboratory studies with this apparatus [Kincaid et al., 1996] which used a linear source and a linear ridge and found that axial variability decreased at faster spreading rates. These two conclusions are not contradictory, but rather are applicable to different tectonic environments. The experiments of Kincaid et al. [1996] suggest that at relatively unsegmented ridges (such as the East Pacific Rise (EPR)) the primary source of along-axis variability is likely to be variations in buoyant supply of material from depth. In contrast, our experiments are more applicable to highly segmented ridges (such as the Mid-Atlantic Ridge (MAR)) where the plate-driven flow can be a significant source of alongaxis variability even in the absence of buoyant source variability.

Our results suggest that transform length and the angle between the plate boundary (trend of the buoyant source) and the spreading direction, produce regions (primarily at segment ends) where little or no mantle is upwelling from below the ridge. Our experimental setup does not address regions near very long transform faults where the assumption of a quasi-linear band of upwelling breaks down. However, at moderate-sized offsets, where a continuous band of buoyant upwelling is a reasonable assumption, our experiments suggest that mantle does not upwell directly beneath segment ends but it instead upwells beneath the inside corners formed by the ridge-transform intersections. This could provide both isostatic support (due to the low density of the hotter mantle) and dynamical support (due to the vertical mantle movement) for the inside-corner topographic highs which are commonly observed at slow spreading ridges.

This geometrical misfit also has implications for the melt supply near transforms. Since the center of mantle upwelling is offset from the ridge axis near segment ends, the melt reaching these indirectly supplied regions must travel laterally either from beneath the inside corner or along the ridge axis (see Figure $11 \mathrm{lb}$ ). In addition, mantle upwelling beneath the inside corners will encounter a thicker lithosphere than mantle upwelling directly beneath the ridge axis. Assuming a constant onset depth for melting, the melting column near transforms will be shorter, resulting in less total melt and thinner crust. Therefore the apparent focusing of crustal accretion toward the centers of segments may result, at least in part, from the obliquity between the upwelling zone and the segmented spreading centers.

Our results also predict a systematic along-axis variation in major element geochemistry. A shorter melting column will result in smaller extents of melting (giving higher sodium content) and greater average depth of melting (leading to higher iron content) [Langmuir et al., 1992] near segment ends. We predict that this negative correlation between extent of melting and mean melting pressure would be most pronounced in regions
Plate-Driven Dominant

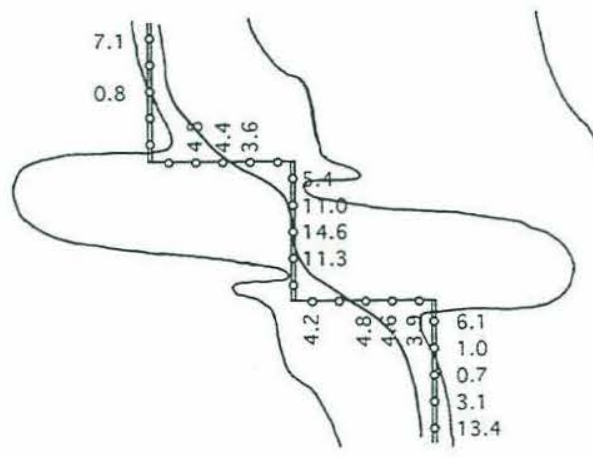

Buoyant Dominant

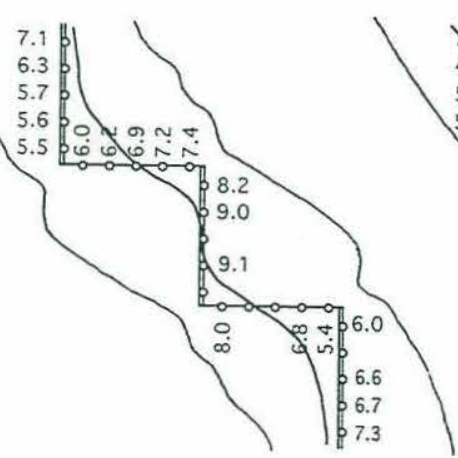

Buoyant Only

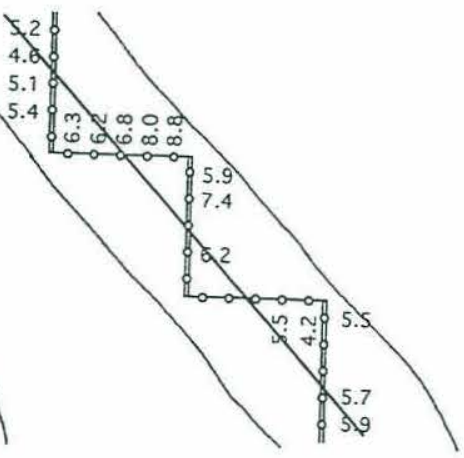

Figure 10c. As in Figure 10a except for RTR3 geometry. 

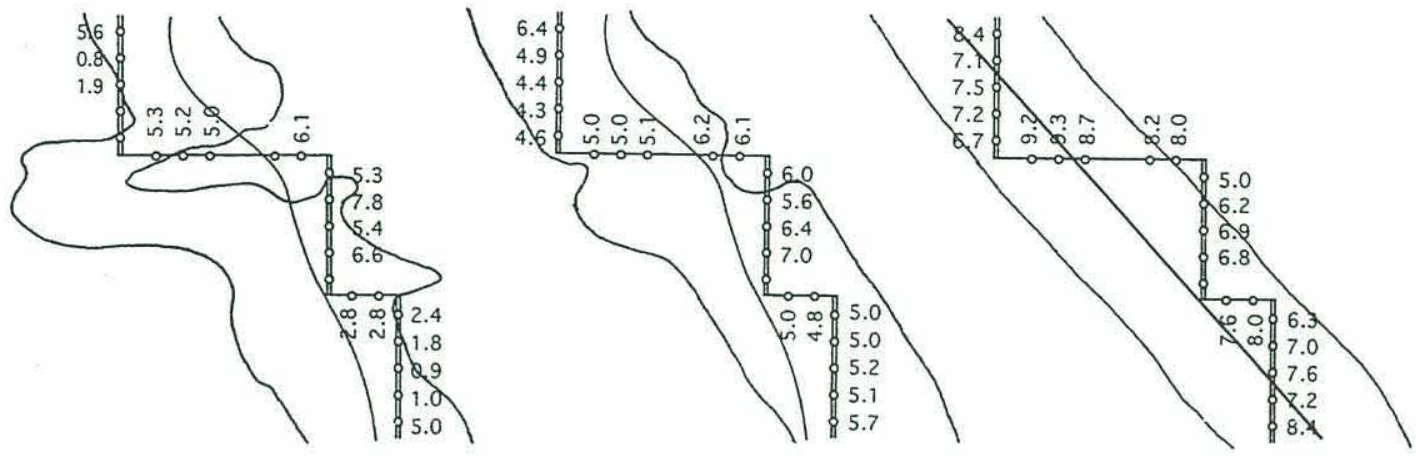

Figure 10d. As in Figure 10a except for RTR4 geometry.

a) Buoyant-dominant:
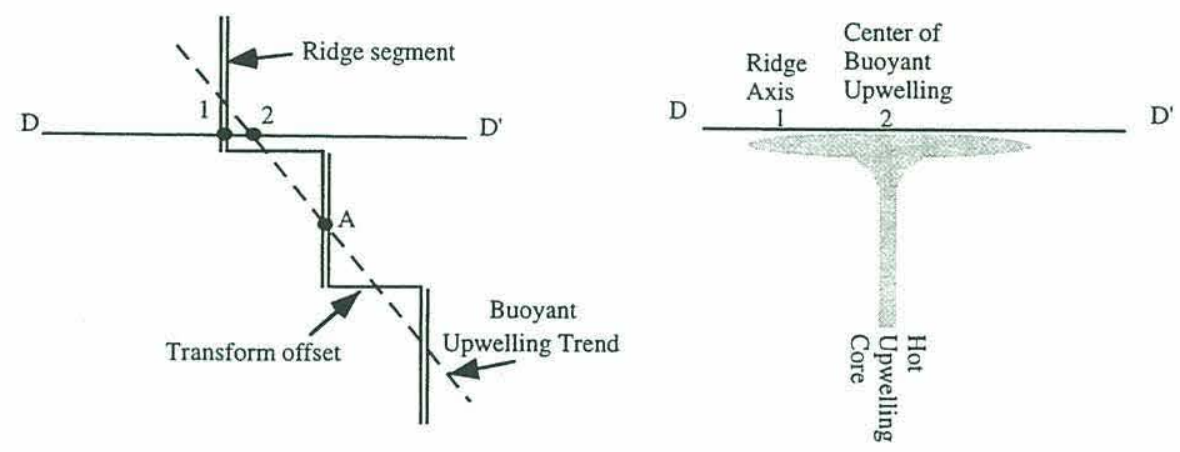

b) Plate-driven-dominant
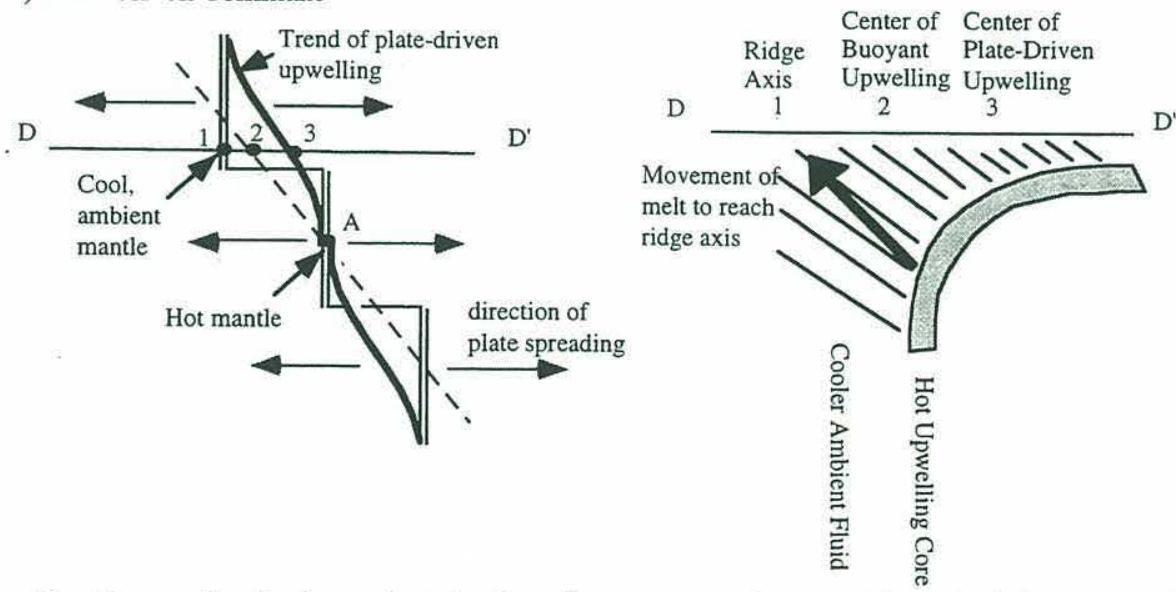

Figure 11. Cartoon showing interaction of a linear buoyant source (centered along the dashed line) with a segmented ridge system in (a) buoyant-dominant and (b) plate-driven-dominant cases in the laboratory tank. (left) A map view. (right) A cross section through the line $\mathrm{DD}^{\prime}$. The gray shaded area indicates the hottest portion of the upwelling fluid. Note that cooler ambient fluid is also entrained alongside the upwelling sheet. The dark sinusoidal line in Figure $11 \mathrm{~b}$ shows the axis of the plate-driven upwelling. The central core of the hot upwelling fluid is midway between the buoyant and plate-driven centers. In the middle of the central segment (point A) in each, the hot upwelling fluid is centered beneath the ridge axis. In contrast, near the transforms (along line DD'), the upwelling center is offset from the ridge axis. In the buoyant-dominant case, the hot material pools at the surface of the tank, but in the plate-driven-dominant case, it is swept away before reaching the surface. Hypothetical melt leaving this center of upwelling must therefore travel laterally to reach the ridge axis. 
(such as the MAR) where the plate boundary trend is oblique to the spreading direction, resulting in many adjacent offsets of moderate length.

Although this study does not focus on the origin of ridge segmentation it does demonstrate that plate-driven flow due to a segmented ridge can contribute to the three dimensionality of the underlying mantle flow. In regions where the overall plate boundary trend is highly oblique to the spreading direction (such as the MAR), the resulting ridge axis may be composed of a series of side-stepping, discrete ridge segments, separated by moderate-length offsets. Assuming that upwelling from depth is oriented roughly along the trend of the plate boundary, the resulting misfit between the buoyant source and the discrete spreading segments will add additional along-axis variation to any three-dimensionality inherited from the buoyant flow. In contrast, at spreading ridges (such as the EPR) which are comparatively unsegmented, except by large transforms, the upwelling zone and the plate boundary will generally be closely aligned and the plate-driven flow will therefore be more twodimensional. Thus both the variation in the magnitude of the plate-driven flow with spreading rate and the variation in segmentation geometry with spreading rate may contribute to a more three-dimensional upwelling pattern at slow spreading ridges and a more sheet-like, two-dimensional pattern of mantle flow at faster spreading ridges.

\section{Conclusions}

1. In both laboratory and numerical experiments, a constantly supplied linear buoyant source creates a stable, sheet-like, twodimensional upwelling pattern. The width of the upwelling is extremely narrow $(<1 \mathrm{~cm})$ in the variable-viscosity laboratory experiments and is broader and more diffuse in the constantviscosity numerical experiments.

2. The interaction between a linear buoyant source and a segmented ridge naturally leads to thermal variability along individual ridge segments. This occurs independent of the degree of three dimensionality in the upwelling source and is due to the geometrical effects of overlying a segmented spreading system on top of a sheet-like upwelling.

3. Our experiments suggest that there may be a misalignment between the center of mantle upwelling and the spreading axis near the ends of segments, especially if the segment offset is large. We predict that melt erupting at segment ends must travel laterally from beneath the inside corner or along the ridge axis. Mantle upwelling beneath inside corners will encounter a thicker lithosphere (causing melting to cease deeper) than mantle upwelling beneath the ridge axis. This predicts thinner crust near segment ends and a negative correlation within individual ridge segments between extent of melting and melting pressure.

4. Slow spreading ridges, like the MAR, are typically more highly segmented by larger offset ridge discontinuities than faster spreading ridges like the EPR. Therefore both the variation in the magnitude of the plate-driven flow with spreading rate and the variation in segmentation geometry with spreading rate may contribute to a more three-dimensional upwelling pattern at slow spreading ridges and a more sheet-like, two-dimensional pattern of mantle flow at faster spreading ridges.

5. The narrowness of the upwelling zone is the only significant difference between the variable-viscosity laboratory experiments and the uniform-viscosity numerical experiments. Future expansion of the numerical models to remove the physical constraints imposed by the tank and to include other processes (such as melt buoyancy, chemical depletion in the mantle, and melt extraction to form a thickening lithosphere) will provide additional insight into how the laboratory observations relate to mid-ocean ridges.

Acknowledgments. We thank Jian Lin, Peter Keleman, Mark Feighner, Gregory Houseman, and one anonymous reviewer for their suggestions on improving this manuscript. William DeLeo helped conduct the laboratory experiments. This work was supported by NSF grant OCE9215544 and EAR grant 93-07400. Woods Hole Oceanographic Institution contribution 9227 .

\section{References}

Craig, C. H., and D. McKenzie, The existence of a thin low-viscosity layer beneath the lithosphere, Earth Planet. Sci. Lett., 78, 420-426, 1986.

Detrick, R. S., H. D. Needham, and V. Renard, Gravity anomalies and crustal thickness variations along the Mid-Atlantic Ridge between $33^{\circ} \mathrm{N}$ and $40^{\circ} \mathrm{N}, J$. Geophys. Res., 100, 3767-3787, 1995.

Jha, K., E. M. Parmentier, and J. Phipps Morgan, The role of mantledepletion and melt-retention buoyancy in spreading center segmentation, Earth Planet. Sci. Lett., 125, 221-234, 1994.

Kincaid, C., G. Ito, and C. Gable, Laboratory investigation of the interaction of off-axis mantle plumes and spreading centres, Nature, 376, 758-761, 1995.

Kincaid, C., D. W. Sparks, and R. S. Detrick, The relative importance of plate-driven and buoyancy-driven flow at mid-ocean ridge spreading centers, J. Geophys. Res., 101, 16,177-16,193, 1996.

Kuo, B.-Y., and D. W. Forsyth, Gravity anomalies of the ridge-transform system in the South Atlantic between 31 and $34.5^{\circ} \mathrm{S}$ : Upwelling centers and variations in crustal thickness, Mar. Geophys. Res., 6, 5198, 1988.

Langmuir, C. H., E. M. Klein, and T. Plank, Petrological systematics of mid-ocean ridge basalts: Constraints on melt generation beneath ocean ridges, in Mantle Flow and Melt Generation at Mid-ocean Ridges, Geophys. Monogr. Ser., vol. 71, edited by J. Phipps Morgan, D. K. Blackman, and J. M. Sinton, pp. 183-280, AGU, Washington, D. C., 1992.

Lin, J., and J. Phipps Morgan, The spreading rate dependence of threedimensional mid-ocean ridge gravity structure, Geophys. Res. Lett. 19, 13-16, 1992

Lin, J., G. M. Purdy, H. Schoutan, J.-C. Sempere, and C. Zervas, Evidence for focused magmatic accretion along the Mid-Atlantic Ridge, Nature, 344, 627-632, 1990.

Olson, P., and C. Kincaid, Experiments on the interaction of thermal convection and compositional layering at the base of the mantle, $J$. Geophys. Res., 96, 4347-4354, 1991.

Olson, P., C. Schubert, C. Anderson, and P. Goldman, Plume formation and lithosphere erosion: A comparison of laboratory and numerical experiments, J. Geophys. Res., 93, 15,065-15,084, 1988.

Parmentier, E. M., and J. Phipps Morgan, Spreading rate dependence of three-dimensional structure in oceanic spreading centers, Nature, 348 , 325-328, 1990

Phipps Morgan, J., and D. W. Forsyth, 3-D flow and temperature perturbations due to transform offset: Effects on oceanic crustal and upper mantle structure, J. Geophys. Res., 93, 2955-2966, 1988.

Rabinowicz, M., S. Rouzo, J.-C. Sempere, and C. Rosemburg, Threedimensional mantle flow beneath mid-ocean ridges, J. Geophys. Res., 98, 7851-7869, 1993

Rouzo, S., M. Rabinowicz, and A. Brials, Segmentation of mid-ocean ridges with an axial valley induced by small-scale mantle convection, Nature, 374, 795-798, 1995.

Shaw, P. R., Ridge segmentation, faulting and crustal thickness in the Atlantic Ocean, Nature, 358, 490-493, 1992.

Shaw, P. R. and J. Lin, Causes and consequences of variations in faulting style at the Mid-Atlantic Ridge, J. Geophys. Res., 98, 21,839-21,851, 1993. 
Sleep, N., Hotspots and mantle plumes: Some phenomenology, $J$. Geophys. Res., 95, 6715-6736, 1990.

Sparks, D. W., and E. M. Parmentier, The structure of three-dimensional convection beneath oceanic spreading centres, Geophys. J. Int., 112, 81-91, 1993.

Sparks, D. W., E. M. Parmentier, and J. Phipps Morgan, Threedimensional mantle convection beneath a segmented spreading center: Implications for along-axis variations in crustal thickness and gravity, J. Geophys. Res., 98, 21,977-21,995, 1993.

Wang, X., and J. R. Cochran, Gravity anomalies, isostasy, and mantle flow at the East Pacific Rise Crest, J. Geophys. Res., 98, 19,505 $19,531,1993$.

Whitehead, J. A., Jr., H. J. B. Dick, and H. Schouten, A mechanism for magmatic accretion under spreading centers, Nature, 312, 146-147. 1984.

R. S. Detrick and L. S. Magde, Department of Geology and Geophysics, Woods Hole Oceanographic Institution, Woods Hole, MA 2543-1542. (email: bobd@copper.whoi.edu; lauram@copper.whoi.edu)

C. Kincaid, Graduate School of Oceanography, University of Rhode Island, Narragansett, RI 02882-1197.

D. W. Sparks, Lamont-Doherty Earth Observatory, Palisades, NY 10964.

(Received November 20, 1995; revised May 20, 1996;

accepted June 4, 1996.) 


\title{
CHAPTER 5
}

\section{Three-Dimensional Mantle Upwelling, Melt Generation, and Melt Migration Beneath Segmented Slow-Spreading Ridges}

\begin{abstract}
In contrast to the along-axis uniformity observed at the East Pacific Rise (EPR), crustal accretion at the Mid-Atlantic Ridge (MAR) appears to be a highly complex and heterogeneous process. Besides spreading rate, one of the first-order differences between the EPR and the MAR is the much higher degree of ridge segmentation observed in the Atlantic. Circular lows in the mantle Bouguer anomaly (MBA bull's-eyes) are common at centers of spreading segments of the MAR, suggesting crustal thickness variations of up to $4 \mathrm{~km}$ along individual segments. We use a three-dimensional numerical model of mantle flow to examine the effect of ridge segmentation on mantle upwelling and the resulting overall crustal production and along-axis variations in crustal thickness. Mantle flow in our model is driven by both buoyant forces and segmented plate spreading. A variety of asthenospheric viscosity structures, plate spreading geometries, and mantle potential temperatures are explored. We find that a combination of buoyant mantle flow and threedimensional melt migration can reproduce crustal thickness variations similar to those inferred from gravity. Buoyant flow gives rise to variations in upwelling velocity at alongaxis wavelengths greater than $150 \mathrm{~km}$, but does not contribute to short wavelength variations. However, three-dimensional melt migration may greatly enhance crustal thickness variations along all segments, independent of the wavelength of buoyant upwelling. We present an idealized model, in which melt first rises vertically and then flows along the base of the lithosphere toward the ridge axis, that easily produces crustal thickness variations greater than $4 \mathrm{~km}$. The models also predict that the average crustal thickness should decrease with increasing amount of segmentation and decreasing spreading rate. Therefore, the thinner, more heterogeneous crust observed at the MAR may result from the combined effects of slower spreading rate and more pervasive ridge segmentation.
\end{abstract}




\section{Introduction}

Both gravity and seismic studies along the Mid-Atlantic Ridge (MAR) suggest that crustal thickness variations of up to $4 \mathrm{~km}$ occur at both transform and non-transform offsets [Kuo and Forsyth, 1988; Lin et al., 1990; Blackman and Forsyth, 1991; Sinha and Louden, 1983; Tolstoy et al., 1993]. The most persuasive evidence of along-axis crustal thickness variations are the mantle Bouguer anomaly (MBA) bull's-eye lows, which correlate with the topographic shallowing observed at the centers of many segments along the Mid-Atlantic Ridge (MAR) [Lin and Phipps-Morgan, 1992]. These gravity lows indicate thicker crust and/or warmer mantle temperatures beneath segment centers. If the entire anomaly is attributed to variations in crustal thickness, the variations range from 1 to $4 \mathrm{~km}$ (Figure 1). The most common explanation for these MBA bull's-eyes is that they are produced by mantle diapirs which increase melt production, leading to enhanced crustal thicknesses above each diapir [Kuo and Forsyth, 1988; Lin et al., 1990]. Mantle diapirs have been simulated in the laboratory [Whitehead et al., 1984; Kincaid et al., 1996]; however, previous modeling studies which include the buoyancy of partial melting [Parmentier and Phipps Morgan, 1990; Jha et al., 1994; Sparks and Parmentier, 1993;

Barnouin-Jha et al., 1997] have shown that convective instabilities in mantle upwelling beneath ridges typically grow at wavelengths of $\sim 150-400 \mathrm{~km}$, much longer than typical segment lengths $(\sim 50 \mathrm{~km})$.

Previous numerical studies that have modeled segmented spreading centers [Phipps Morgan and Forsyth, 1988, Sparks and Parmentier, 1993, Rabinowicz et al., 1993, Sparks et al., 1993] have assumed a periodic pattern of long (100's of km) segments and offsets. In this study, we use four different plate geometries which are characteristic of the MAR (with segments 40-70 km long and a variety of offset lengths) and examine the possibility that more realistic segmentation geometries may excite buoyant mantle instabilities at the observed wavelength. Our models do not predict segment-centered mantle diapirs. Instead, we suggest that these large-amplitude, segment-scale crustal thickness variations may be due to three-dimensional melt migration. In addition, we observe that predicted average crustal thickness varies greatly with mantle properties and ridge segmentation geometry. Our study suggests that at slow-spreading, highly segmented ridges such as the MAR, significantly less magmatic crust may be produced than at faster, less segmented ridges. 


\section{Design of the Mantle Flow Model}

The numerical model used for these studies is adapted from the 3-D finite difference code of Sparks et al. [1993]. All computations were carried out on a 65x129x65 grid which maps to a mantle section 480x960 km and $300 \mathrm{~km}$ deep, a resolution of $7.5 \mathrm{~km}$ horizontally and $4.7 \mathrm{~km}$ vertically. This grid spacing is sufficient to detect wavelengths of buoyant flow down to about $50 \mathrm{~km}$, but we find little power in wavelengths less than 100 $\mathrm{km}$. Because of the high temperature gradients at the top of the melting region, the discretization of the model space leads to an underestimation of the degree of melting by a maximum of $0.67 \%$ (corresponding to $5 \%$ of the total crustal thickness). Since crustal thickness is underestimated in all locations, errors in along-axis variations, particularly at non-transform offsets, are significantly less.

Incompressible mantle flow is decomposed into a plate-driven component and a buoyancy-driven component. A third component of mantle flow, the compressible flow due to the extraction of melt, is small when the melting region is not extremely focused, and has been neglected. The mathematical formulation and numerical methods are discussed further in Appendix A.

We investigate spreading geometries in which several adjacent segments are offset in the same sense. To minimize variations in the distance of the various ridge segments from the edges of the computational domain, the spreading direction is rotated with respect to the rectangular computational domain by an angle, $\theta$..

$$
\tan \theta=\frac{\text { total length of offsets }}{\text { total length of spreading segments }}
$$

$\theta$ is the angle between the spreading direction and a line normal to the long-wavelength orientation of the plate boundary.

Viscosity is taken to be a function of depth to simulate the effects of pressure on rheology. Three different vertical viscosity structures were investigated (Figure 2). In most of our numerical experiments, we simulate a low-viscosity asthenospheric layer by assigning a reference viscosity to the upper $180 \mathrm{~km}$ of the model space which is bounded below by a smooth, but rapid, increase in the viscosity (by a factor of 20) centered about a depth of $150 \mathrm{~km}$ (Figure 2a) [Barnouin-Jha et al., 1997]. This is consistent with pressuredependent rheological laws that show an increase in viscosity by about a factor of 20 over a depth of $100 \mathrm{~km}$ [Scott, 1992]. Changing this profile has only minor effects on our results as discussed below. The buoyant flow component is also bounded above by a rigid 
lithosphere defined by the $1150^{\circ} \mathrm{C}$ isotherm (see Appendix A), so that buoyant flow is confined to the low-viscosity asthenosphere.

The plate-driven component of flow drives passive upwelling of uniform temperature mantle into the bottom of the box. Mantle then leaves through the side-walls. Therefore the model space encompasses a small section of a much larger plate-scale circulation. This study focuses on the role of buoyancy sources that originate in the asthenosphere. The assumption of uniform temperature at the base of the model region ignores along-axis variations in mantle upwelling caused by deep mantle sources (such as mantle plumes).

For each set of conditions (plate geometry, spreading rate, viscosity structure, and reference porosity) we first conduct an experiment without buoyant flow. The steady-state solution is then used as an initial condition for an experiment with buoyant flow and a high reference viscosity ( $5 \times 10^{19} \mathrm{~Pa} \mathrm{~s}$ ). In each subsequent experiment in the series, the viscosity is lowered by approximately a factor of two.

We include three sources of buoyancy [Barnouin-Jha et al., 1997]: temperature variations (thermal expansion coefficient, $\alpha=3 \times 10^{-5}{ }^{\circ} \mathrm{C}^{-1}$ ), preferential depletion of Fe with respect to $\mathrm{Mg}$ in the mantle due to the extraction of melt (10\% depletion is equivalent to a temperature increase of $80^{\circ} \mathrm{C}$ ), and retention of a small fraction of melt (density difference between solid and melt, $\Delta \rho=500 \mathrm{~kg} / \mathrm{m}^{3}$ ). The rate of melt flow depends on the permeability (proportional to the square of the melt retention), and melt retention is determined by an instantaneous balance between the Darcy flux of melt and the melt production in a given mantle column [after Jha et al., 1994]. In this study, the chosen permeabilities result in maximum retained melt fractions of $0-3 \%$ (with most experiments below $2 \%$ ). This was chosen in accordance with laboratory and observational studies suggesting that interstitial melt becomes interconnected at small melt fractions and is quickly extracted [e.g., Daines and Richter, 1988, Johnson and Dick, 1992; McKenzie, 1985] and with geophysical data that precludes the presence of large melt fractions [e.g., Forsyth, 1992; Magde et al., 1995]. We use a solidus with a slope of $3.75^{\circ} \mathrm{C} / \mathrm{km}$ and a melting rate of $0.33 \%$ per $\mathrm{km}$ of adiabatic upwelling (Table 1).

The predicted crustal thickness variations are a function of the three-dimensional distribution of melt production and a model of melt extraction. In order to focus on the contribution of three-dimensional mantle upwelling to crustal thickness variations, in the initial discussion of our results, we use a two-dimensional model of melt migration, as in Sparks et al. [1993]. In this model, crustal thickness at a given point along-axis is taken to 
be the rate of melt production in the plane perpendicular to the axis, divided by the spreading rate. We will address crustal thickness variations due to three-dimensional melt migration in a later section.

\section{Segmentation Geometries}

Four different plate geometries were chosen (Figure 3) to represent a variety of conditions observed in nature. GEOM1, designed to simulate the MAR between the Kane and Atlantis fracture zones, is the reference geometry used in the majority of the experiments. The ratio of segment length to offset length is $2: 1$ and the only wavelength present in the plate-driven flow is the segment length of $71.6 \mathrm{~km}$. GEOM2 is similar to GEOM1 in that the ratio of segment to offset length remains 2:1. However, the segments are only $44.4 \mathrm{~km}$ long which is more representative of the short segments observed along some sections of the MAR. GEOM3 simulates a region (such as the equatorial MAR) where the overall plate boundary is highly oblique to the direction of plate spreading (from (1), $\theta=63.3^{\circ}$ ). The large offsets dominate the system where the segment to offset length ratio is $1: 2$. Segments are $42.9 \mathrm{~km}$ long and offsets are $85.9 \mathrm{~km}$. Finally, GEOM4 superposes two distinct wavelengths ( $\sim 55$ and $\sim 170 \mathrm{~km})$. All of the segments are $56.6 \mathrm{~km}$ in length, but every third offset is $113.1 \mathrm{~km}$, while the intervening offsets are only 28.3 $\mathrm{km}$. Here the rotation angle, $\theta$, is $45^{\circ}$. This geometry simulates moderately oblique sections of the MAR, such as the region between the Hayes and Oceanographer transforms, where large transform faults are separated by shorter offsets.

\section{Wavelength of Mantle Flow and Melting}

In experiments which combine segmented plate-driven flow with moderate buoyant flow, the segmentation geometry has a strong influence on the amplitude and wavelength of along-axis crustal thickness variations (Figure 4). For the first three plate geometries, which have only one segmentation wavelength, the magnitude of the along-axis variations increases with increasing offset length. The extremely short offsets in GEOM2 are the least influential, producing only $3 \%$ crustal thinning at offsets $(0.2 \mathrm{~km}$ of along-axis crustal thickness variation in $7.1 \mathrm{~km}$ average thickness). The longer offsets in GEOM1 and GEOM3 result in $8 \%$ and $24 \%$ thinning, respectively. GEOM4 contains two different segmentation wavelengths, however the longer offsets clearly dominate the system.

Crustal production drops to zero near the $113 \mathrm{~km}$ offsets, but there is no variation at the 28 $\mathrm{km}$ offsets. These large crustal thickness variations associated with the longer transforms 
result in part from the constructive interaction between the segmentation geometry and the wavelength of mantle upwelling variations. However, even in the absence of buoyant flow, the GEOM4 plate-driven flow alone produces $2 \mathrm{~km}$ of crustal thinning (average crustal thickness is $2.5 \mathrm{~km}$ ) at the long transforms.

For modest amounts of buoyant flow (asthenospheric viscosity $>2 \times 10^{19} \mathrm{~Pa}-\mathrm{s}$ ), the along-axis wavelength and magnitude of variations in the amount of melting are controlled by the segmentation geometry. (Although the average crustal thickness is a function of mantle potential temperature, asthenospheric viscosity, and retained melt fraction, see Table 2$)$. The small segment-scale $(\sim 50 \mathrm{~km})$ variations do not arise from strong variations in deep mantle upwelling velocity, but rather from the depression of the top of the melting region beneath offsets. Cooling of the upper mantle at these offsets increases with offset length, but in no case produces more than $\sim 1.5 \mathrm{~km}$ of crustal thinning. At typical non-transform offsets ( $20 \mathrm{~km}$ long) crustal thinning is $<0.5 \mathrm{~km}$, significantly less than the $4 \mathrm{~km}$ inferred from the observed variations in MBA.

In addition to the experiments described in Table 2, we have investigated mantle flow with asthenospheric viscosities as low as $0.5 \times 10^{19} \mathrm{~Pa}-\mathrm{s}$, melt retention as high as $8 \%$, and mantle potential temperatures in the range of $1325^{\circ} \mathrm{C}-1400^{\circ} \mathrm{C}$. Within this range of conditions, none of the four plate segmentation geometries drive mantle diapirs at the segmentation wavelength. In agreement with a previous numerical study [Barnouin-Jha et al., 1997], buoyant mantle instabilities segment the upwelling beneath the ridge at low viscosities, at wavelengths of 150-400 km.

\section{Effect of Mantle Viscosity on Wavelength of Along-Axis Variations}

Two additional asthenospheric viscosity structures were investigated (using GEOM1) to determine the role of asthenospheric thickness and structure on mantle flow. The rheological properties of melting mantle are poorly constrained, but experiments indicate that the presence of a melt phase reduces mantle viscosity [e.g., Hirth and Kohlstedt, 1995] while melt extraction increases viscosity in the residual mantle [e.g., Phipps Morgan, 1987; Hirth and Kohlstedt, 1996]. Numerical experiments were conducted using three different vertical viscosity structures (Figure 2) and GEOM1, in an attempt to determine the role of these rheological variations on the wavelength of upwelling. Structure \#1 (also used in experiments with the other plate geometries) assumes a uniform viscosity within the melting region, and a gradual increase at depth due to increasing pressure. The top of the asthenosphere is defined by the base of a rigid plate 
at the $1150^{\circ} \mathrm{C}$ isotherm, resulting in an asthenospheric layer $\sim 150 \mathrm{~km}$ thick. Structure \#2 assumes the viscosity is influenced primarily by retained melt, with the viscosity decreasing rapidly with height above the onset of melting, resulting in a thin $(\sim 75 \mathrm{~km})$, shallow asthenosphere near the axis, and essentially no asthenosphere off axis where the $1150^{\circ} \mathrm{C}$ isotherm deepens. This viscosity structure is designed to maximize the effect of melt buoyancy on mantle upwelling even though it underestimates the sublithospheric viscosity outside the melting region. Structure \#3 assumes that viscosity is increased by the dehydration of residual mantle during melt extraction. This results in a thin, deeper (below $\sim 75 \mathrm{~km}$ ) asthenosphere bounded by the base of the melting region and an increase with pressure at $\sim 150 \mathrm{~km}$ (as in Structure \#1).

Although the different asthenospheric structures affect the strength of upwelling within the melting region (note the variation in average crustal thickness in Table 2), they do not affect the along-axis wavelength of upwelling. For asthenospheric viscosities of $3 \mathrm{x}$ $10^{18} \mathrm{~Pa}$-s and above, upwelling variations do not occur at wavelengths less than 150-200 $\mathrm{km}$; there are no centers of mantle upwelling with wavelengths comparable to segments $(\sim 50 \mathrm{~km})$.

Previous studies in which convection is driven primarily by thermal buoyancy demonstrate that the minimum wavelength of lateral variations in upwelling velocity is controlled by the thickness of the low-viscosity, convecting layer [Rabinowicz et al., 1993; Sparks et al., 1993; Rouzo et al., 1995]. However, in the regime where melt and/or depletion are the primary sources of buoyancy, the horizontal wavelength is at least twice the height of the melting region [Tackley and Stevenson, 1993; Barnouin-Jha et al., 1997]. This height is reasonably well-constrained to be $50-80 \mathrm{~km}$ by evidence that melting begins in the garnet stability field [Salters and Hart, 1989; Johnson et al., 1990] and by the abundance of dredged harzburgites [c.f. Dick, 1989] which indicate that the maximum extent of melting must be greater than 20-25\% [c.f. Hess, 1992]. We find that variations in the vertical viscosity structure, such as those we have examined, have little effect on the wavelength of crustal thickness variations.

Lateral temperature-related viscosity variations in the asthenosphere should not significantly change our conclusions about the wavelengths of mantle upwelling. The assumption of uniform deep mantle temperature and the fact that the temperature within the melting region is buffered near the solidus limit horizontal gradients in temperature variations below and within the melting region. Therefore, we expect lateral viscosity variations due to temperature to be important only below long transforms, which are 
associated with significant conductive cooling (Figure 4d). Temperature-related viscosity variations may change the mantle flow pattern beneath transforms, but is not expected to have a significant effect on the flow beneath non-transform offsets.

It is possible that lateral viscosity variations associated with the variations in melt fraction and depletion may change the wavelength of buoyant upwelling variations. However, shorter wavelength features are more likely to form at lower asthenospheric viscosities than those that we found were required to satisfy observational constraints on average crustal thickness. The role of rheological variations in melting mantle is an important problem that requires further investigation.

\section{Controls on Average Crustal Thickness}

Besides controlling the wavelength of along-axis variations in crustal thickness, the details of the spreading geometry also have a profound effect on the predicted average crustal thickness. We predict a correlation between the ratio of segment length/offset length and the average crustal thickness (Figure 5). This correlation is most pronounced in experiments with plate-driven-only flow, although it is still significant even in the presence of strong buoyant mantle upwelling. We predict that the initial depth of melting remains quite constant along-axis in all of these runs. However, at highly segmented spreading centers, the lithosphere is thicker on average, and there is greater depression of the top of the melting column beneath longer offsets. Therefore, predicted average crustal thickness decreases with decreasing ratio of segment/offset length.

As mantle potential temperature is increased, the wavelength and amplitude of along-axis variations remain constant, however the average crustal thickness increases due to the increasing height of the melting column (Figure 6). The effect of lowering the reference viscosity is to enhance buoyant upwelling, which allows melt-retention-related and temperature-dependent processes to compete with the plate-driven flow. Average crustal thickness also increases rapidly as the reference viscosity is decreased (Table 2), enhancing buoyant flow. However, while these variations in model parameters change the average crustal thickness and the amplitude of variations, the along-axis wavelength of variations remains the same.

\section{Three-Dimensional Melt Migration}

For crust to be created, melt must migrate vertically out of the melting region, and laterally toward the axis. Models of mantle flow indicate that melt must be extracted from a 
melting zone significantly wider than the $\sim 3 \mathrm{~km}$ wide neo-volcanic zone in order to produce $\sim 6 \mathrm{~km}$ of crust [e.g., Reid and Jackson, 1981; Scott and Stevenson, 1989; Buck and Su, 1989; Sotin and Parmentier, 1989]. There is also evidence, at least in some cases, that there must be lateral motion [Dick, 1989; Spiegelman, 1996]. Fracture zones and nontransform offsets are generally associated with areas of thin $(2-4 \mathrm{~km})$ inferred crust . If the amount of crust reflects melting only in the immediately underlying mantle, we would expect this residual mantle to be only mildly depleted in the trace and major elements that concentrate in the melt. Instead, large degrees of depletion are observed in peridotites recovered from fracture zones [Dick, 1989]. It is difficult to imagine that this cold mantle in the shallow lithosphere has been translated to the fracture zone from a distant, more meltrich area. More likely, some of the melt produced within this mantle has moved away from the fracture zones through along-axis melt migration.

The question of how melt migrates beneath a three-dimensional spreading center is unanswered. We explore one mechanism that suggests an origin for segment-scale melt focusing: the transport of melt along the top of the melting region. It has been suggested that melt moving upward through hot, permeable mantle can collect at an impermeable boundary at the top of the melting column, and then migrate laterally toward the ridge along a sloping boundary layer [Sparks and Parmentier, 1993, Spiegelman, 1993, Sparks and Parmentier, 1994]. Following this idea, we assume that melt travels vertically until it reaches the top of the melting region and then is driven upslope by buoyancy until it reaches the ridge axis (Figure 7). Even the relatively small amount of lithospheric thickening associated with short, non-transform offsets depresses the top of the melting region, and the resulting slope is available to focus melt toward segment centers.

We choose an idealized melt migration model that has some basis in the physics of melt migration and can be easily combined with already complex three-dimensional mantle calculations. In so doing, we have left out much of the detailed physics that may affect the direction of melt migration before the melt arrives at the base of the lithosphere. For example, pressure gradients in the solid flow field act to focus melt toward the axis [Spiegelman and McKenzie , 1987; Phipps Morgan, 1987]. The pressure gradients in our three-dimensional flow fields also have an along-axis component, driving melt toward segment centers. However, these pressure gradients may not be large enough to cause significant melt motions unless the mantle viscosities are on the order of $10^{21} \mathrm{~Pa}-\mathrm{s}$ [Spiegelman and McKenzie , 1987]. The spontaneous concentration of melt production and migration into channels by chemical reactions has been indicated by both theoretical 
studies [Aharanov et al., 1995] and observations of ophiolites [Kelemen et al., 1995]. Such instabilities will introduce strong time-dependence and spatial heterogeneity into the melt extraction process even before melt reaches the base of the lithosphere. Melt extraction through the brittle lithosphere is another poorly understood process. Ideally, we would like to include detailed, time-dependent melt migration and crustal formation into the mantle flow calculations, but the small length and time scales of these processes makes this too computationally costly at this time.

For each of the experiments shown in Figure 4, we calculate three-dimensional melt migration paths along the top of the melting region (Figure 8). Melt is assumed to move along these paths until it reaches the shallowest point of the melting region beneath the ridge axis. All of the melt is then extracted at this point to produce crust (either intrusively or extrusively).

This three-dimensional melt migration scheme results in large along-axis variations within each segment. However, the amplitude of these variations may be reduced by two effects. 1: Lateral melt flow may slow with decreasing dip angle [Sparks and Parmentier, 1994], so that melt may be incorporated into the crust before it reaches the shallowest point of the melting region. 2: The melt may be redistributed within the crust (e.g., by propagation of dikes along-axis [Embley and Chadwick, 1994]; or by lower crustal ductile flow [Buck, 1996]). We attempt to account for both inefficient melt transport and crustal redistribution by smoothing the along-axis crustal profiles over a distance of $30 \mathrm{~km}$ using a four-point boxcar filter and by extracting melt when it comes within $5 \mathrm{~km}$ of the ridge axis (the half-width of a typical axial valley).

This three-dimensional melt migration model produces several kilometers of crustal thickness variations at all of the non-transform offsets (Figure 9). Comparison of GEOM1, GEOM2, and GEOM3 shows that the amplitude of the along-axis variations increases with increasing offset length. The actual amplitude of along-axis crustal thickness variations are somewhat arbitrary; they depend on the amount of smoothing and the width of the melt extraction zone. The important point is that with three-dimensional melt focusing it is easy to create very large along-axis variations in crustal thickness.

In GEOM4, both melt migration models predict very large degrees of crustal thinning associated with the long transforms. This thinning is due to a relatively wide region below the transforms in which the mantle flow field generates no melt (Figure 4d). Dredging studies find peridotites suggesting there may indeed be extremely thin crust near transforms [c.f., Aumento and Loubot, 1971; Karson et al., 1984; Rona et al., 1987; Dick, 
1989] as discussed below. However the large width of this region of little or no crustal production could be due to unmodeled rheological variations in the asthenosphere and brittle lithosphere near large offsets. This region of reduced upwelling and little or no crustal production may be considerably narrower in a model that can resolve the sharp horizontal gradients in viscosity across a transform fault [Blackman and Forsyth, 1995]. This is unlikely to be a factor near short offsets across which there is little variation in lithospheric thickness.

\section{Discussion}

The results of these experiments suggest that segment-centered mantle diapirs are unlikely to be the primary mechanism for creating segment-centered gravity bull's-eyes. We find that variations in buoyant mantle upwelling occur at wavelengths considerably longer than typical segment lengths. Furthermore, experimental determinations of a large increase in mantle viscosity due to dehydration at the onset of melting [Hirth and Kohlstedt, 1996] imply that buoyant diapirs could not form in the melting region. Therefore, while our model of mantle processes produces results that are in general agreement with observations of segmented ridge, we cannot identify the cause of short-wavelength segmentation.

One possible explanation is that melt migration within the body of the melting region focuses at some inherent wavelength [Spiegelman, 1993; Kelemen et al., 1995; Aharanov et al., 1995]. Another alternative is that short-wavelength ridge segmentation originates in the brittle lithosphere. Observational evidence suggests that the migration of non-transform offsets may be controlled by the relative length of the two adjacent segments [Macdonald et al., 1991] or by the regional bathymetric gradient [Escartin, 1996]. Both hypotheses imply a lithospheric control of the short-wavelength segmentation. One possibility is that lithospheric segmentation is inherited from continental break-up or plate reorganization effects. Three-dimensional mantle convection patterns may then determine which offsets develop into long-lived transforms while intervening segment boundaries develop into less stable non-transform offsets.

Recent data collected along the South-West Indian Ridge (SWIR) are consistent with the idea that small-scale segmentation originates in the lithosphere, and that melt focusing is a result of the degree of segmentation. The $\sim 1000 \mathrm{~km}$ long section between 16 and $25^{\circ} \mathrm{E}$ is composed of twelve segments segmented by small ( $<10 \mathrm{~km}, 1.5 \mathrm{~m}$. y.) nontransform discontinuities. Since this section of the SWIR is spreading very slowly $(0.7$ 
$\mathrm{cm} / \mathrm{yr}$ half-rate), buoyant flow would be expected to be even more important here than at the MAR. Yet, only two of these segments, show even small-amplitude MBA bull's-eyes [Grindlay et al., 1997]. This pattern of segmentation and gravity anomalies argues against the idea that segmentation is driven by focused mantle upwelling. Furthermore, our proposed mechanism for focused melt flow would not be very effective at producing large crustal thickness variations, because of the very small variations in lithospheric thickness at these offsets (which are $\sim 1 / 4$ the age of typical non-transform offsets at the MAR).

Our results also suggest that the correlation between MBA, segment length, and offset length [e.g., Detrick et al., 1995] may not indicate a simple relationship between segment size and mantle diapir size (as suggested by Lin et al., 1990), but, rather, a more complicated relationship between mantle upwelling, melt migration, and plate segmentation. The models with geometry GEOM3 indicate that long transform length alone is not sufficient to produce large along-axis variations in mantle upwelling. The transforms must also be spaced widely enough (as they are in GEOM4) that they can interact positively with the wavelength of mantle instabilities. When transforms are $<\sim 150$ $\mathrm{km}$ apart, a correlation between offset length and MBA amplitude would not be observed. When transforms are spaced $>\sim 200 \mathrm{~km}$ (such as Oceanographer and Hayes) they can have a large effect on mantle flow [Magde et al., 1997], and lead to the observed association of large MBA bull's-eyes with longer offsets [Detrick et al., 1995]. Even where widelyspaced long transforms have a large effect on mantle flow, intervening shorter offsets have little influence. However, these short offsets can still have a substantial effect on alongaxis crustal thickness variations if three-dimensional melt migration transports melt laterally toward segment midpoints.

Another implication of our experimental results is that regional crustal thickness may vary systematically with variations in mantle properties (such as mantle potential temperature, asthenospheric viscosity, and mantle permeability) as well as variations in plate geometry. If mantle viscosity is relatively high, so that the flow field is close to passive upwelling, crustal production increases with increasing spreading rate [Reid and Jackson, 1981]. These results appear to be at odds with seismic observations suggesting that the crust is produced with uniform thickness worldwide [Raitt, 1963; Chen, 1992; White et al., 1992]. However, seismic velocities for partially serpentinized peridotite are very similar to those of unaltered gabbro [Christensen and Salisbury, 1982]. Therefore, if the upper mantle is at least partially serpentinized, the seismic moho may overestimate magmatic crustal thicknesses [Hess, 1962; Clague, 1977], especially at slow spreading 
centers. Alternatively, in regions of discontinuous magma supply (such as the MAR), the lower crust may be composed of interspersed bodies of gabbro and peridotite, again leading to seismic overestimation of magmatic crustal thickness [Cannat, 1993; 1995]. The routine dredging of serpentinized peridotite from fracture zones [c.f., Aumento and Loubot, 1971; Karson et al., 1984; Rona et al., 1987] supports this hypothesis. The inclusion of serpentinized peridotite in seismic estimates of slow-spreading crustal thickness is in agreement with studies of abyssal peridotites which find larger extents of melting in the Pacific as compared to the Atlantic, and suggests that crustal thickness may not be uniform worldwide [Niu and Hekinian, 1996].

Furthermore, we note that seismic studies tend to be conducted at the centers of segments, and may therefore be biased toward overestimating crustal thicknesses, particularly at slow-spreading ridges where gravity [e.g., Blackman and Forsyth, 1991;

Kuo and Forsyth, 1988; Lin et al., 1990] and seismic [Sinha and Louden, 1983; Tolstoy et al., 1993] studies suggest that crustal thickness varies significantly. There is also a distinct lack of seismic studies at very highly segmented ridges. One recent seismic study of the Southwest Indian Ridge (SWIR) near $57^{\circ} \mathrm{E}$ finds only $4 \mathrm{~km}$ of crust extending off axis to ages of at least $15 \mathrm{Ma}$ [Muller, et al., 1996]. Further study may reveal additional ridges which produce thin crust.

Our models make specific predictions of where plate geometry may effect crustal thickness. Smaller ratios of segment/offset length produce both weaker plate-driven upwelling and stronger thermal effects near large offsets. This result suggests that the magmatic crustal thickness should decrease in areas where the ridge is more highly segmented, even along ridges with uniform mantle properties and spreading rates. The degree of melting appears to be markedly lower in the highly segmented section of the SWIR than in unsegmented areas. West of $16^{\circ} \mathrm{E}$, the ridge trend is highly oblique to the spreading direction and the recovery of both alkaline basalts and a large fraction $(11 \%)$ of diopside from the ridge crests suggest a low degree of melting. To the east, the ridge is linear and unsegmented, and dredges recover abundant Mid-Ocean ridge basalt (MORB) with only $5 \%$ diopside [H. Dick, personal communication, 1997].

\section{Conclusions}

1. Our model, including buoyant mantle flow and approximate three-dimensional melt migration, can produce large variations in crustal thickness near both transforms and nontransform offsets. 
2. These models indicate that diapiric upwelling is unlikely create the along-axis variations in crustal thickness. Under the conditions in which diapiric upwelling does occur, the wavelengths $(150-400 \mathrm{~km})$ are much longer than the typical segmentation wavelength $(\sim 50$ $\mathrm{km})$.

3. The predicted average crustal thickness is strongly dependent on plate geometry, mantle properties, and spreading rate. In highly segmented ridges, thick, cold lithosphere at offsets depresses the melt region resulting in a positive correlation between average crustal thickness and ridge/offset ratio. The combination of increased cooling at offsets and decreased plate-driven upwelling may reduce crustal thicknesses as much as $75 \%$ at highlysegmented, slow-spreading ridges such as the equatorial MAR.

\section{Appendix A.}

The rotation of the spreading direction with respect to the axes of the computational domain was necessary to allow buoyant flow calculations in relatively large domains for plate geometries that are not periodic in a direction perpendicular to spreading (i.e. do not have equal lengths of left- and right-stepping offsets). Periodic segmentation geometries [as in Phipps Morgan and Forsyth, 1988; Sparks et al., 1993; Rabinowicz et al., 1993] allow the application of periodic or symmetry boundary conditions on the spreadingparallel vertical edges of the computational region. This condition also maximizes the distance between the spreading centers and the spreading-perpendicular edges of the region (Figure A1a). The 'center of spreading', a line which represents the center of the spreading system within the region, is kept parallel to one of the axes of the domain (i.e., the $y$ axis).

The angle of rotation, $\theta$, (Figure A1c) is determined by the total offset length to total segment length ratio. In this case, each spreading segment is equidistant from the $x$ boundaries. Since the plate spreading component of flow is only calculated once for each geometry and can use a much larger box, it is still done as periodic, in a ridge-parallel box (Figure A1b; Appendix B of Sparks et al., 1993), with velocities imposed on the top surface of the box. The results are then interpolated onto the rotated grid used in the convection calculation. The change in plate thickness across an offset will affect the underlying passive flow [Blackman and Forsyth, 1992] to a depth that increases with increasing offset length. Our assumption of a flat-plate in the passive flow probably leads to an overestimation of the lateral extent of cooling near long offsets.

The buoyant flow is solved separately for a viscosity-layered medium, and added to the plate spreading flow. The buoyant component is periodic in both the $x$ and $y$ 
directions. Note that the addition of plate-driven flow retains periodicity in the $y$ direction but creates outflow through both of the $x$-boundaries. We define a three-dimensional vorticity, $\vec{\omega}$, and three-dimensional potential (stream function), $\vec{\psi}$, as,

$$
\nabla \times \vec{u}=\vec{\omega}
$$

where $\vec{u}$ is the buoyant flow velocity vector. Substituting for the stress tensor in the balance of pressure gradients, and setting horizontal gradients of viscosity to zero, yields two second-order vector equations:

$$
\begin{gathered}
\eta \nabla^{2} \vec{\omega}=2 \frac{\partial \eta}{\partial z} \frac{\partial \vec{\omega}}{\partial z}-\frac{\partial^{2} \eta}{\partial z^{2}}\left(\vec{\omega}+2 \frac{\partial^{2} \vec{\psi}}{\partial z^{2}}\right)-\nabla \times(\rho \vec{g}) \\
\nabla^{2} \vec{\psi}=-\vec{\omega}
\end{gathered}
$$

Here, $z$ is vertical distance (positive downward), $\eta$ is mantle viscosity, $\rho$ is mantle density, and $\vec{g}$ is the acceleration of gravity (pointing downward).

These equations are solved in a region bounded by no-slip boundaries at a depth of $300 \mathrm{~km}$ and at the base of a thermally-defined sloping lithosphere. Horizontal viscosity gradients at the sharp imposed transition between the asthenosphere and lithosphere base are ignored. This assumption leads to inaccuracies in the buoyant flow velocities near this boundary. However, the decoupling of the buoyant and passive components of the flow causes the buoyant flow velocities to vanish at this boundary. Therefore the total flow velocities near the lithosphere, which are what determine the temperature and the melting field, are not effected by errors in the buoyant flow calculation.

The lack of horizontal viscosity gradients within the asthenosphere cause the vertical components of (A2) and (A3) to vanish, and effectively decouple the horizontal components from each other. However, each component of vorticity is coupled to the component of the stream function in the same direction, through the viscosity gradient terms on the right hand side of (A2), and through the no-slip boundary conditions [see Appendix A of Sparks et al., 1993 for details on these boundary conditions]. Therefore the vorticity and stream function are solved iteratively, with under-relaxation on the updating of the vorticity term. 
The viscosity derivatives on the right-hand side of (A2) limit the usable viscosity structures to second-order smooth functions, with point-to-point viscosity variations less than a factor of 2. However, with the viscosity structures used in this work (Figure 2), the additional coupling due to vertical viscosity gradients cause little or no reduction of the convergence rate (compared to the uniform viscosity experiments of Sparks et al., [1993]). Therefore, relatively fast solution of large problems is preserved: typically, a $65 \times 129 \times 65$ run that achieves steady-state in 1500 time steps will run in less than 6 hours on an HP $715 / 80$ workstation.

Melt is assumed to be extracted from the mantle by flowing through a permeable, viscously deforming mantle [e.g., Ahern and Turcotte, 1979, McKenzie, 1984]. The meltfilled porosity (retained melt fraction), $\phi$, at each depth $(z)$ within a melting column is approximated by the equation

$$
\frac{k_{0} \Delta \rho g}{\mu} \phi^{2}+W \phi-\int_{z_{0}}^{z} \Gamma d \zeta=0
$$

$W$ is the solid mantle upwelling velocity, $\Delta \rho$ is the density difference between solid and melt, $\Gamma$ is the melting rate, $z_{0}$ is the depth of initial melting, and $\mu$ is the melt viscosity. The mantle permeability is taken to be proportional to $\phi^{2}$, where $k_{0}$ is a poorly-known constant depending on grain size and pore geometry. (A4) is derived by assuming that the vertical melt flux is equal to the integrated melting rate in the underlying column, and that the mantle obeys Darcy's law for flow through a permeable medium. This method was also employed in Jha et al. [1994] and Barnouin-Jha et al., [1997].

This approximation assumes that melt flow is (a) not affected by solid pressure gradients, (b) rapid with respect to mantle flow, and (c) very rapid outside actively melting regions (perhaps migrating through a transient crack network). These assumptions lead to there being no horizontal component of melt flow. At the mantle viscosities investigated here, pressure gradients that can drive lateral migration of melt [e.g., Spiegelman and McKenzie, 1987; Ribe, 1986] will be relatively small. Within the bulk of the melting region, the horizontal component of mantle flow due to plate spreading is $<10 \%$ of the upwelling rate. As a result, the melt fraction can be calculated from the instantaneous distribution of melting rate. This simplification does not allow the calculation of timedependent migration effects, such as solitary waves [e.g., Scott and Stevenson, 1984; 
McKenzie, 1984; Spiegelman, 1993]. However, it does provide a reasonable approximation of the time-averaged melt fraction available to drive buoyant mantle flow, and it eliminates the need to track the advection of melt at a much finer time scale than is required for the rest of the problem.

The equations for potential temperature, $\mathrm{T}$,

$$
\frac{\partial T}{\partial t}+\vec{u} \cdot \nabla T=\kappa \nabla^{2} T-\frac{L}{C} \Gamma
$$

the equilibrium degree of melting, $\mathrm{F}$,

$$
F=\frac{T^{\prime}-T_{\text {solidus }}}{\Delta T}
$$

and the mantle depletion, $\xi$,

$$
\frac{\partial \xi}{\partial t}+\vec{u} \cdot \nabla \xi=\Gamma
$$

are coupled through the melting rate, $\Gamma$, which is defined as the material derivative of $F$. In (A5), $\kappa$ is the thermal diffusivity, $L$ is latent heat of fusion and $C$ is specific heat. In (A6), $T^{\prime}$ is true temperature, taken to be potential temperature plus a linearized adiabatic gradient of $0.5{ }^{\circ} \mathrm{C} / \mathrm{km}$. $F$ is taken to vary linearly with true temperature above the solidus. The constant of proportionality, $\Delta T$, is taken to be $600^{\circ} \mathrm{C}$, yielding a $\partial T / \partial F$ of $6^{\circ} \mathrm{C} / \%$, a reasonable number for fractional melting [Langmuir et al., 1992]. The mantle solidus is given by

$$
T_{\text {solidus }}=1100^{\circ} \mathrm{C}+\left(3.75^{\circ} \mathrm{C} / \mathrm{km}\right) z
$$

Advection of depleted mantle (A7) is solved by a first order characteristic scheme. The same scheme is used to calculate $\vec{u} \cdot \nabla F$. Taking the material derivative of (A6) and substituting for $\Gamma$ in (A5) yields an evolution equation for temperature in the melting region:

$$
\left(1+\frac{L}{C \Delta T}\right) \frac{\partial T}{\partial t}=\kappa \nabla^{2} T-\vec{u} \cdot \nabla T-\frac{L}{C} \vec{u} \cdot \nabla F
$$


This is solved using explicit time stepping with centered finite differencing of the diffusion term and upwind differencing of the advection term. The inverse of the prefactor on the left-hand side of (A9) is the fraction of available energy which is partitioned into temperature changes, while the rest is absorbed as latent heat. For $L / C$ of $600 \mathrm{~kJ} / \mathrm{kg}$, energy is partitioned equally into melting production and temperature changes.

Acknowledgments. We thank Robert Lowell, Donna Blackman, Robert Detrick, Jian Lin, Marcia McNutt, Greg Hirth, and one anonymous reviewer for their suggestions for improving this manuscript. We also thank Robert Detrick, Javier Escartin, and Jian Lin for the data used to generate Figure 1. This work was supported under NSF grant OCE9215544 and OCE94-02922. Woods Hole Oceanographic Institution contribution 9426.

\section{References}

Aharanov, E., J. Whitehead, P. B. Kelemen, and M. Spiegelman, Channeling instability of upwelling melt in the mantle, J. Geophys. Res., 100, 20,433-20,450, 1995.

Ahern, J. L., and D. L. Turcotte, Magma migration beneath an ocean ridge, Earth and Planet. Sci. Lett., 45, 115-122, 1979.

Aumento, F., and H. Loubat, The Mid-Atlantic Ridge near $45^{\circ}$ N. Serpentinized ultramafic inclusions, Can. J. Earth Sci., 8, 631-663, 1971.

Barnouin-Jha, K., E. M. Parmentier, and D. W. Sparks, Buoyant mantle upwelling and crustal production at oceanic spreading centers: on-axis segmentation and off-axis melting, J. Geophys. Res., in press, 1997.

Blackman, D. K., and D. W. Forsyth, Isostatic compensation of tectonic features of the Mid-Atlantic Ridge: 25-27³0'S, J. Geophys. Res., 96, 11741-11758, 1991.

Blackman, D. K. and D. W. Forsyth, The effects of plate thickening on three-dimensional, passive flow of the mantle beneath mid-ocean ridges, in Mantle Flow and Melt Generation Beneath Mid-Ocean Ridges, Geophys. Monogr. Ser., J. Phipps Morgan, D. K. Blackman, and J. M. Sinton eds., American Geophysical Union, Washington D.C., 311-326, 1992.

Buck, W. R. Along-axis crustal flow and ridge topographic segmentation, EOS Trans. Amer. Geophys. Un., 77, S276, 1996.

Buck, R., and W. Su., Focused mantle upwelling below mid-ocean ridges due to feedback between viscosity and melting, Geophys. Res. Lett., 16, 641-644, 1989. 
Cannat, M. Emplacement of mantle rocks in the seafloor at mid-ocean ridges, J. Geophys. Res., 98, 4163-4172, 1993.

Cannat, M. et al., thin crust, ultramafic exposures, and rugged faulting patterns at the Mid-

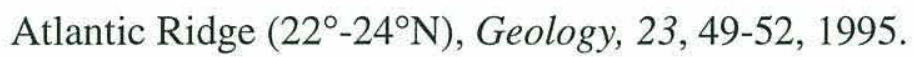

Chen, Y., Oceanic crustal thickness versus spreading rate, Geophys. Res. Lett., 19, 753756, 1992.

Christensen, N. I., and M. H. Salisbury, Lateral heterogeneity in the seismic structure of the oceanic crust inferred from velocity studies in the Bay of Islands ophiolite, Newfoundland, Geophys. J. R. Astr. Soc., 68, 675-688, 1982.

Clague, D. A., and P. F. Straley, Petrologic nature of the oceanic Moho, Geology, 5, 133-136, 1977.

Daines, M. J., and F. M. Richter, An experimental method for directly determining the interconnectivity of melt in a partially molten system, Geophys. Res. Lett., 15, 1459-1462, 1988.

Detrick, R. S., H. D. Needham, and V. Renard, Gravity anomalies and crustal thickness variations along the Mid-Atlantic Ridge between $33^{\circ} \mathrm{N}$ and $40^{\circ} \mathrm{N}$, J. Geophys. Res., 100, 3767-3787, 1995.

Dick, H. J. B., Abyssal peridotites, very slow spreading ridges and ocean ridge magmatism, in Magmatism in the Ocean Basins, A. D. Sounders and M. J. Norry eds., Geological Society Special Publication No. 42, 71-105, 1989.

Escartin, J., Ridge segmentation, tectonic evolution and rheology of slow-spreading crust, $\mathrm{Ph}$.D. thesis, Massachusetts Institute of Technology-Woods hole Oceanographic Institution Joint Program in Oceanography, 1996.

Embley, R. W., and W. W. Chadwick Jr., Volcanic and hydrothermal processes associated with a recent phase of seafloor spreading at the northern Cleft segment: Juan de Fuca Ridge, J. Geophys. Res., 99, 4741-4760, 1994.

Forsyth, D., Geophysical constraints on mantle flow and melt generation beneath midocean ridges, in Mantle Flow and Melt Generation Beneath Mid-Ocean Ridges, Geophys. Monogr. Ser., J. Phipps Morgan, D. K. Blackman, and J. M. Sinton eds., American Geophysical Union, Washington D.C., 1-65, 1992.

Fujimoto, H., N Seama, J. Lin, T. Matsumoto, T. Tanka, and K. Fujika, Gravity anomalies of the Mid-Atlantic Ridge north of the Kane transform fault, Geophys. Res. Lett., 3431-3434, 1996. 
Grindlay, N. R., J. A. Madsen, C. Rommevaux-Jestin, and J. Sclater, A new perspective on mid-ocean ridge segmentation: Results from the ultra-slow spreading Southwest Indian Ridge, Nature, submitted, 1997.

Hess, H. H., The history of the ocean basins, in Petrological Studies: A volume in honor of A. F. Buddington, E. E. J. Engel, H. L. James, and B. F. Leonard, eds., Geological Society of America, 599-620, 1962.

Hess, P. C., Phase equilibria constraints on the origin of ocean floor basalts, in Mantle Flow and Melt Generation Beneath Mid-Ocean Ridges, Geophys. Monogr. Ser., J. Phipps Morgan, D. K. Blackman, and J. M. Sinton eds., American Geophysical Union, Washington D.C., 67-102, 1992.

Hirth, G., and D. Kohlstedt, Experimental constraints on the dynamics of the partially molten upper mantle: Deformation in the diffusion creep regime, J. Geophys. Res., 100, 1981-2001, 1995.

Hirth, G., and D. Kohlstedt, Water in the oceanic upper mantle: Implications for rheology, melt extraction and the evolution of the lithosphere, Earth Plant. Sci. Lett., 144, 93108, 1996.

Jha, K., E. M. Parmentier, and J. Phipps Morgan, The role of mantle-depletion and meltretention buoyancy in spreading-center segmentation, Earth Planet. Sci. Lett., 125, 221-234, 1994.

Johnson, K. T. M., and H. J. B. Dick, Open system melting and temporal and spatial variation of peridotite and basalt at the Atlantis II Fracture Zone, J. Geophys. Res., 97, 9219-9241, 1992.

Johnson, K. T. M., H. J. B. Dick, and N. Shimizu, Melting in the oceanic upper mantle: An ion microprobe study of diopsides in abyssal peridotites, J. Geophys. Res., 95, 2661-2678, 1990.

Karson, J. A., P. J. Fox, H. Sloan, K. T. Crane, W. S. F. Kidd, E. Bonatti, J. B. Stroup, D. J. Fornari, D. Elthon, P. Hamlyn, J. F. Casey, D. G. Gallo, D. Needham, and R. Sartori, The geology of the Oceanographer transform: The ridgetransform intersection, Mar. Geophys. Res., 6, 109-141, 1984.

Kelemen, P. B., N. Shimizu, and V. J. M. Salters, Extraction of mid-ocean-ridge basalt from upwelling mantle by focused flow of melt in dunite channels, Nature, 375, 747-753, 1995. 
Kincaid, C., D. W. Sparks, and R. S. Detrick, The relative importance of plate-driven and buoyancy-driven flow at mid-ocean ridge spreading centers, J. Geophys. Res., 101, 16,177-16,193, 1996.

Kuo, B.-Y., and D. W. Forsyth, Gravity anomalies of the ridge-transform system in the South Atlantic between 31 and $34.5^{\circ} \mathrm{S}$ : Upwelling centers and variations in crustal thickness, Mar. Geophys. Res., 10, 205-232, 1988.

Langmuir, C. H., E. M. Klein, and T. Plank, Petrological systematics of Mid-Ocean Ridge basalts: Constraints on melt generation beneath ocean ridges, in Mantle Flow and Melt Generation Beneath Mid-Ocean Ridges, Geophys. Monogr. Ser., J. Phipps Morgan, D. K. Blackman, and J. M. Sinton eds., American Geophysical Union, Washington D.C., 183-280, 1992.

Lin, J., and J. Phipps-Morgan, The spreading rate dependence of three-dimensional MidOcean Ridge gravity structure, Geophys. Res. Lett., 19, 13-16, 1992.

Lin, J., G. M. Purdy, H. Schouten, J.-C. Sempere, and C. Zervas, Evidence from gravity data for focused magmatic accretion along the Mid-Atlantic Ridge, Nature, 344, 627-632 1990.

Macdonald, K. C., D. S. Scheirer, and S. M. Carbotte, Mid-ocean ridges: Discontinuities, segments, and giant cracks, Science, 253, 986-994, 1991.

Magde, L. S., R. S. Detrick, and the TERA Group, Crustal and upper mantle contribution to the axial gravity anomaly at the southern East Pacific Rise, J. Geophys. Res., 100, 3747-3766, 1995.

Magde, L. S., D. W. Sparks, and R. S. Detrick, The relationship between buoyant mantle flow, melt migration, and the mantle Bouguer anomaly patterns observed along the MAR from $33^{\circ} \mathrm{N}$ to $35^{\circ} \mathrm{N}$, Earth Planet. Sci. Lett., in press, 1997.

McKenzie, D. The generation and compaction of partially molten rock, J. Petrol., 25, 713$765,1984$.

McKenzie, D., ${ }^{230} \mathrm{Th}-{ }^{238} \mathrm{U}$ disequilibrium and the melting processes beneath ridge axes, Earth Planet. Sci. Lett., 72, 149-157, 1985.

Muller, M. R., C. J. Robinson, T. A. Minshull, R. S. White, and M. J. Bickle, Thin crust beneath Ocean Drilling Program borehole 735B at the Southwest Indian Ridge?, Earth Planet. Sci. Lett., submitted, 1996.

Niu, Y. and R. Hekinian, Spreading rate dependence of the extent of mantle melting beneath ocean ridges, Nature, submitted, 1996. 
Parmentier, E. M., and J. Phipps Morgan, Spreading rate dependence of three-dimensional structure in oceanic spreading centers, Nature, 348, 325-328, 1990.

Phipps Morgan, J., Melt migration beneath mid-ocean spreading centers, Geophys. Res. Lett., 14, 1230-1241, 1987.

Phipps Morgan, J., and D. W. Forsyth, 3-D flow and temperature perturbations due to transform offset: Effects on oceanic crustal and upper mantle structure, J. Geophys. Res., 93, 2955-2966, 1988.

Rabinowicz, M., S. Rouzo, J.-C. Sempere, and C. Rosemburg, Three-dimensional mantle flow beneath mid-ocean ridges, J. Geophys. Res., 98, 7851-7869, 1993.

Raitt, R. W., The crustal rocks, in The Sea, M. N. Hill, ed., Wiley-Interscience, New York, 85-102, 1963.

Reid, I., and H. R. Jackson, Oceanic spreading rate and crustal thickness, Mar Geophys. Res., 5, 165-171, 1981.

Ribe, N. M., Melt segregation by dynamic forcing, Geophys. Res. Lett., 13, 1462-1465, 1986.

Rona, P. A., L. Widenfalk, and K. Bostrom, Serpentinized ultramafics and hydrothermal activity at the Mid-Atlantic Ridge crest near $15^{\circ} \mathrm{N}$, J. Geophys. Res., 92, 14171427, 1987.

Rouzo, S., M. Rabinowicz, and A. Briais, Segmentation of mid-ocean ridges with an axial valley induced by small-scale mantle convection, Nature, 374, 795-798, 1995.

Salters, V. J. M., and S. R. Hart, The hafnium paradox and the role of garnet in the source of mid-ocean-ridge basalts, Nature, 342, 420-422, 1989.

Scott, D. R., and Stevenson, D. J., Magma solitons, Geophys. Res. Lett., 11, 11611164, 1984.

Scott, D. R., Small-scale convection and mantle melting beneath mid-ocean ridges, in Mantle Flow and Melt Generation Beneath Mid-Ocean Ridges, Geophys. Monogr. Ser., J. Phipps Morgan, D. K. Blackman, and J. M. Sinton eds., American Geophysical Union, Washington D.C., 327-352, 1992.

Sinha, M. C., and K. E. Louden, The Oceanographer fracture zones, I, Crustal structure from seismic refraction studies, Geophys. J. R. Astron. Soc., 75, 713-736, 1983.

Sotin, C., and Parmentier, E. M., Dynamical consequences of compositional and thermal density stratification beneath spreading centers, Geophys. Res. Lett., 16, 835-838, 1989. 
Sparks, D. W., and E. M. Parmentier, The structure of three-dimensional convection beneath oceanic spreading centers, Geophys. J. Int., 112, 81-91, 1993.

Sparks, D. W., and E. M. Parmentier, The generation and migration of partial melt beneath oceanic spreading centers, in Magmatic Systems, Academic Press, edited by M. P. Ryan, 55-76, 1994.

Sparks, D. W., E. M. Parmentier, and J. Phipps Morgan, Three-dimensional mantle convection beneath a segmented spreading center: Implications for along-axis variations in crustal thickness and gravity, J. Geophys. Res., 98, 21,977-21,205, 1993.

Spiegelman, M., Geochemical consequences of melt transport in 2-D: The sensitivity of trace elements to mantle dynamics, Earth Planet. Sci. Lett., 139, 115-132, 1996.

Spiegelman, M., Physics of melt extraction: theory, implications and applications, Phil. Trans. R. Soc. London A, 342, 23-41, 1993.

Spiegelman, M., and D. McKenzie, Simple 2-D models for melt extraction at mid-ocean ridges and island arcs, Earth Plant. Sci. Lett., 83, 137-152, 1987.

Tackley, P. J., and D. J. Stevenson, A mechanism for spontaneous self-perpetuating volcanism on the terrestrial planets, in Flow and Creep in The Solar System: Observations, Modeling and Theory, D. B. Stonne and S. K. Runcorn eds., 307$321,1993$.

Tolstoy, M, A. J. Harding, and J. A. Orcutt, Crustal thickness on the Mid-Atlantic Ridge: Bull's eye gravity anomalies and focused accretion, Science, 262, 726-729, 1993.

White, R. S., D. McKenzie and R. K. O'Nions, Oceanic crustal thickness from seismic measurements and rare earth element inversions, J. Geophys. Res., 97, 1968319716, 1992.

Whitehead, Jr., J. A., H. J. B. Dick, and H. Schouten, A mechanism for magmatic accretion under spreading centers, Nature, 312, 146-147, 1984. 
Table 1: Model Parameters

\begin{tabular}{lc}
\hline \multicolumn{1}{c}{ Parameter } & Value \\
\hline Thermal diffusivity $\kappa, \mathrm{m}^{2} / \mathrm{s}$ & $10^{-6}$ \\
Latent heat of fusion $L, \mathrm{~kJ} / \mathrm{kg}$ & 500 \\
Mantle density $\rho, \mathrm{kg} / \mathrm{m}^{3}$ & 3300 \\
Specific heat $\mathrm{c}_{\mathrm{p}}, \mathrm{kJ} / \mathrm{kg}^{\circ} \mathrm{C}$ & 1.25 \\
Thermal expansion coefficient $\alpha,{ }^{\circ} \mathrm{C}^{-1}$ & $3 \times 10^{-5}$ \\
Compositional density parameter $\beta$ & 0.024 \\
Density difference between solid and melt & \\
\multicolumn{1}{c}{$\Delta \rho, \mathrm{kg} / \mathrm{m}^{3}$} & 500 \\
Temperature at base of lithosphere, ${ }^{\circ} \mathrm{C}$ & 1150 \\
Adiabatic gradient, ${ }^{\circ} \mathrm{C} / \mathrm{m}$ & 0.5 \\
\hline
\end{tabular}


Table 2: Experimental Parameters and Results

\begin{tabular}{|c|c|c|c|c|c|c|}
\hline $\begin{array}{c}\text { mantle } \\
\text { potential } \\
\text { temp, }{ }^{\circ} \mathrm{C}\end{array}$ & $\begin{array}{c}\text { reference } \\
\text { viscosity, } \\
\text { Pa-s x } 10^{19}\end{array}$ & $\begin{array}{c}\text { reference } \\
\text { permeabilit } \\
y, \\
\mathrm{~m}^{2} \times 10^{-8}\end{array}$ & $\begin{array}{l}\text { max. melt } \\
\text { retention, \% }\end{array}$ & $\begin{array}{l}\text { average } \\
\text { crust, } \mathrm{km}\end{array}$ & $\begin{array}{c}\text { along-axis } \\
\text { variation, } \\
\text { km }\end{array}$ & $\begin{array}{l}\text { wavelength of along- } \\
\text { axis variations }\end{array}$ \\
\hline & & & GEOM 1 & & & \\
\hline 1400 & N/A & N/A & N/A & 6.9 & 0.20 & segment only \\
\hline 1375 & N/A & N/A & N/A & 5.2 & 0.20 & segment only \\
\hline 1350 & N/A & N/A & N/A & 3.9 & 0.20 & segment only \\
\hline 1325 & N/A & N/A & N/A & 2.7 & 0.20 & segment only \\
\hline 1400 & 5 & 1.0 & 1.0 & 9.3 & 0.30 & segment only \\
\hline 1400 & 2.5 & 1.0 & 1.2 & 14.5 & 0.50 & mostly segment \\
\hline 1400 & 1 & 1.0 & 1.8 & 19.7 & 17 & rolls dominate \\
\hline 1375 & 5 & 1.0 & 0.9 & 7.1 & 0.3 & segment only \\
\hline 1375 & 2.5 & 1.0 & 1.1 & 8.6 & 0.45 & segment only \\
\hline 1375 & 1 & 1.0 & 1.5 & 14.7 & $0.5 ; 7.0$ & segment and rolls \\
\hline 1350 & 5 & 1.0 & 0.9 & 5.2 & 0.35 & segment only \\
\hline 1350 & 2.5 & 1.0 & 1.0 & 6.2 & 0.50 & segment only \\
\hline 1350 & 1 & 1.0 & 1.2 & 9.8 & $0.5 ; 1.5$ & segment and rolls \\
\hline 1325 & 5 & 1.0 & 0.8 & 3.5 & 0.35 & segment only \\
\hline 1325 & 2.5 & 1.0 & 0.9 & 4.3 & 0.5 & segment only \\
\hline 1325 & 1 & 1.0 & 1.1 & 6.6 & $0.5 ; 2$ & segment and rolls \\
\hline 1350 & 5 & 0.2 & 1.9 & 5.3 & 0.20 & segment only \\
\hline 1350 & 2.5 & 0.2 & 2.3 & 6.9 & 0.80 & segment only \\
\hline 1350 & 1 & 0.2 & 3.5 & 12.6 & $1.5 ; 4.0$ & segment and rolls \\
\hline 1400 & 5 & 0.2 & 2.3 & 10.0 & 0.40 & segment only \\
\hline 1400 & 2.5 & 0.2 & 3.1 & 14.0 & 1.0 & mostly segment \\
\hline \multirow[t]{2}{*}{1400} & 1 & 0.2 & 5.4 & 24.9 & $1.5 ; 10.0$ & segment and rolls \\
\hline & & & GEOM 2 & & & \\
\hline 1350 & N/A & N/A & N/A & 3.5 & 0.05 & segment only \\
\hline 1350 & 5 & 0.2 & 1.8 & 5.1 & 0.08 & segment only \\
\hline 1350 & 2.5 & 0.2 & 2.2 & 7.1 & 0.20 & primarily segment \\
\hline 1400 & N/A & 0.2 & 1.6 & 6.3 & 0.02 & segment only \\
\hline 1400 & 5 & 0.2 & 2.2 & 9.4 & 0.10 & mostly segment \\
\hline \multirow[t]{2}{*}{1400} & 2.5 & 0.2 & 3.0 & 13.6 & $0.25 ; \quad 0.60$ & segment and rolls \\
\hline & & & GEOM 3 & & & \\
\hline 1350 & N/A & N/A & N/A & 0.2 & 0.02 & segment only \\
\hline 1350 & 5 & 0.2 & 1.2 & 1.9 & 0.4 & segment only \\
\hline 1350 & 2.5 & 0.2 & 1.7 & 4.1 & 1.0 & segment only \\
\hline 1400 & N/A & 0.2 & .85 & 1.7 & 0.03 & segment only \\
\hline 1400 & 5 & 0.2 & 1.8 & 6.5 & 0.40 & segment only \\
\hline \multirow[t]{2}{*}{1400} & 2.5 & 0.2 & 2.5 & 9.7 & $0.5 ; 3.0$ & segment and rolls \\
\hline & & & GEOM 4 & & & \\
\hline 1350 & N/A & N/A & N/A & 2.5 & 2 & scale of long tfms \\
\hline 1350 & 5 & 0.2 & 1.9 & 4.1 & 5 & scale of long tfms \\
\hline 1350 & 2.5 & 0.2 & 2.4 & 5.8 & 9 & scale of long tfms \\
\hline 1400 & N/A & 0.2 & 1.6 & 4.9 & 2.0 & scale of long tfms \\
\hline 1400 & 5 & 0.2 & 2.4 & 8.5 & 7.0 & scale of long tfms \\
\hline 1400 & 2.5 & 0.2 & 3.1 & 12.9 & 16 & scale of long tfms \\
\hline
\end{tabular}


Table 2: (continued)

\begin{tabular}{|c|c|c|c|c|c|c|}
\hline & & & Structure & (GEOM & & \\
\hline & & Viscosity & \# 2 & 1) & & \\
\hline 1350 & N/A & N/A & N/A & 1.8 & 0.08 & segment only \\
\hline 1350 & 5 & 0.2 & 1.2 & 2.2 & 0.15 & segment only \\
\hline 1350 & 2.5 & 0.2 & 1.3 & 2.6 & 0.20 & segment only \\
\hline 1350 & 1 & 0.2 & 1.7 & 4.0 & 0.40 & segment only \\
\hline \multirow[t]{3}{*}{1350} & 0.75 & 0.2 & 2.0 & 4.9 & 0.60 & segment only \\
\hline & & & Structure & (GEOM & & \\
\hline & & Viscosity & \# 3 & 1) & & \\
\hline 1350 & N/A & N/A & N/A & 7.4 & 0.20 & segment only \\
\hline 1350 & 5 & 0.2 & 2.0 & 7.6 & 0.25 & segment only \\
\hline 1350 & 2.5 & 0.2 & 2.0 & 7.9 & 0.25 & segment only \\
\hline 1350 & 1 & 0.2 & 2.2 & 8.7 & 0.35 & segment only \\
\hline 1350 & 0.5 & 0.2 & 2.5 & 10.3 & 0.50 & segment only \\
\hline
\end{tabular}


a)
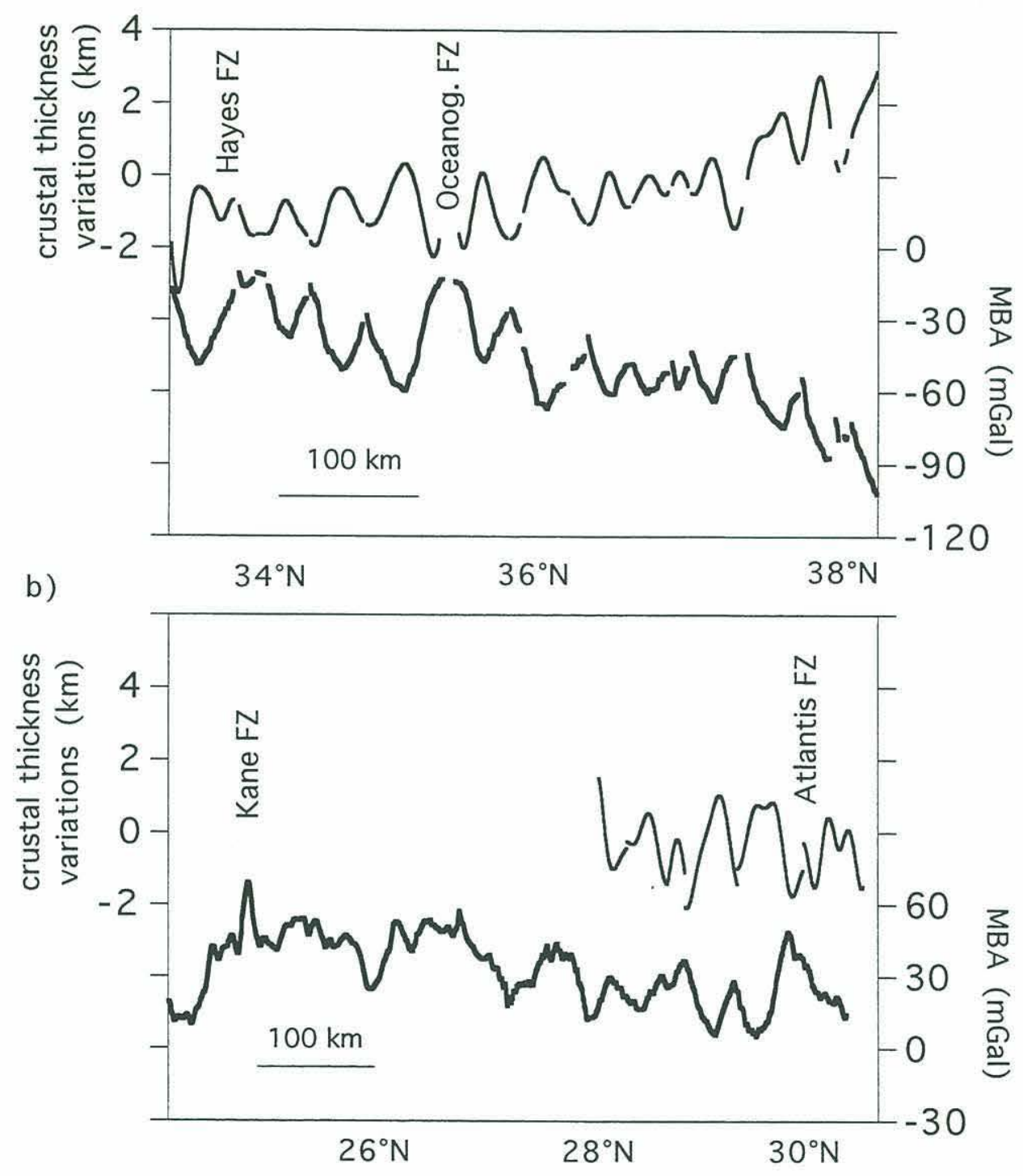

Figure 1. a) Along-axis MBA and inferred crustal thickness variations for the MAR between 33 and $48^{\circ} \mathrm{N}$. Data from Detrick et al. [1995]. b) Along-axis MBA for the MAR between 25 and $30^{\circ} \mathrm{N}$. Data from Escartin [1996] based on the original data of Lin et al. [1990] and Fujimoto et al., [1996]. Inferred along-axis crustal thickness variations between 28 and $30^{\circ} \mathrm{N}$ from Lin et al., [1990]. 


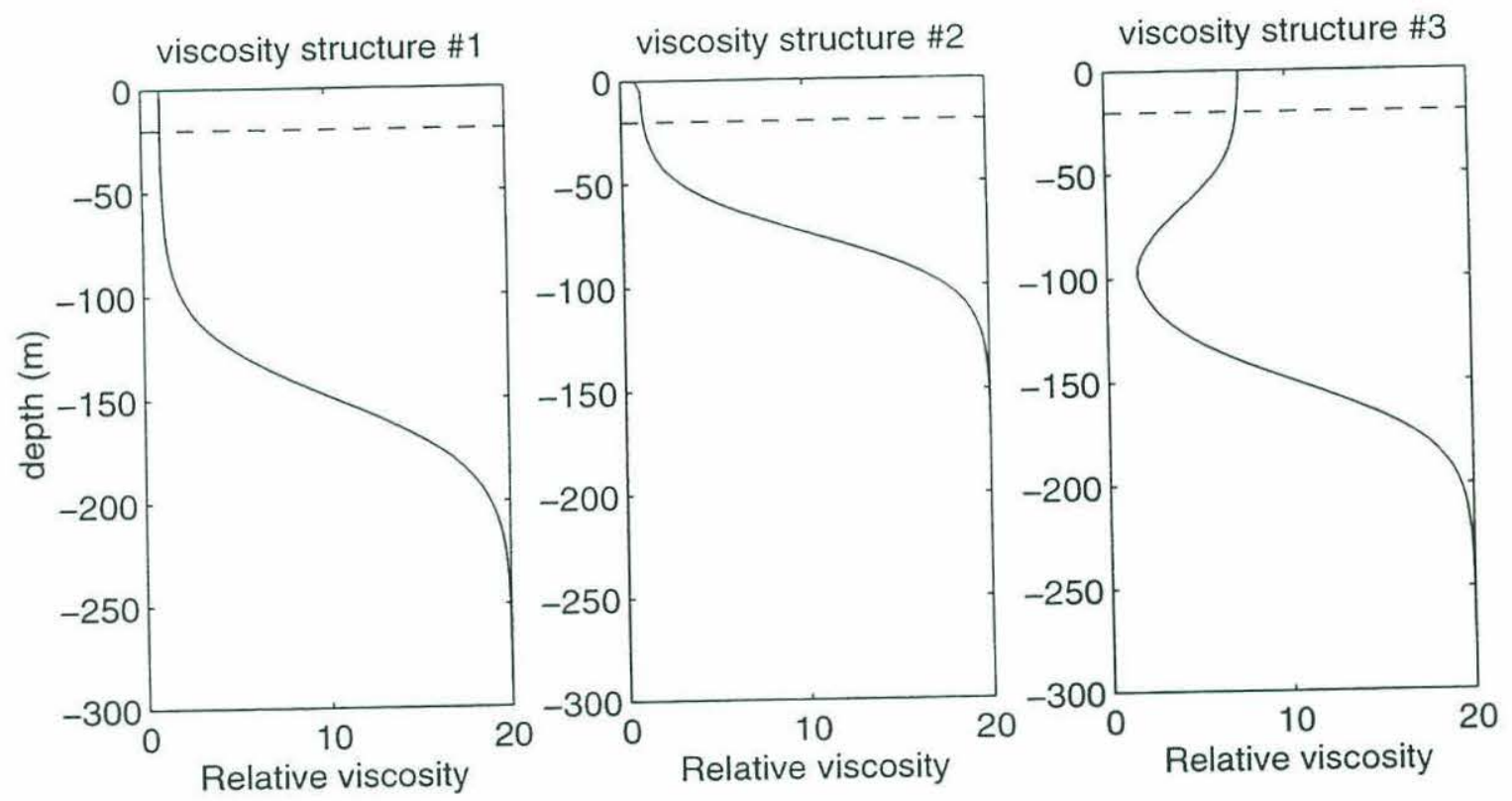

Figure 2. Relative viscosity profiles as a function of depth for the three viscosity structures investigated. The dashed lines at $20 \mathrm{~km}$ depth indicate the approximate location of the $1150^{\circ} \mathrm{C}$ isotherm directly below axis, above which there is no buoyant flow. (Note that the depth of this isotherm increases with distance from the spreading axis.) Viscosities are scaled by a reference viscosity (values given in Table 1). 


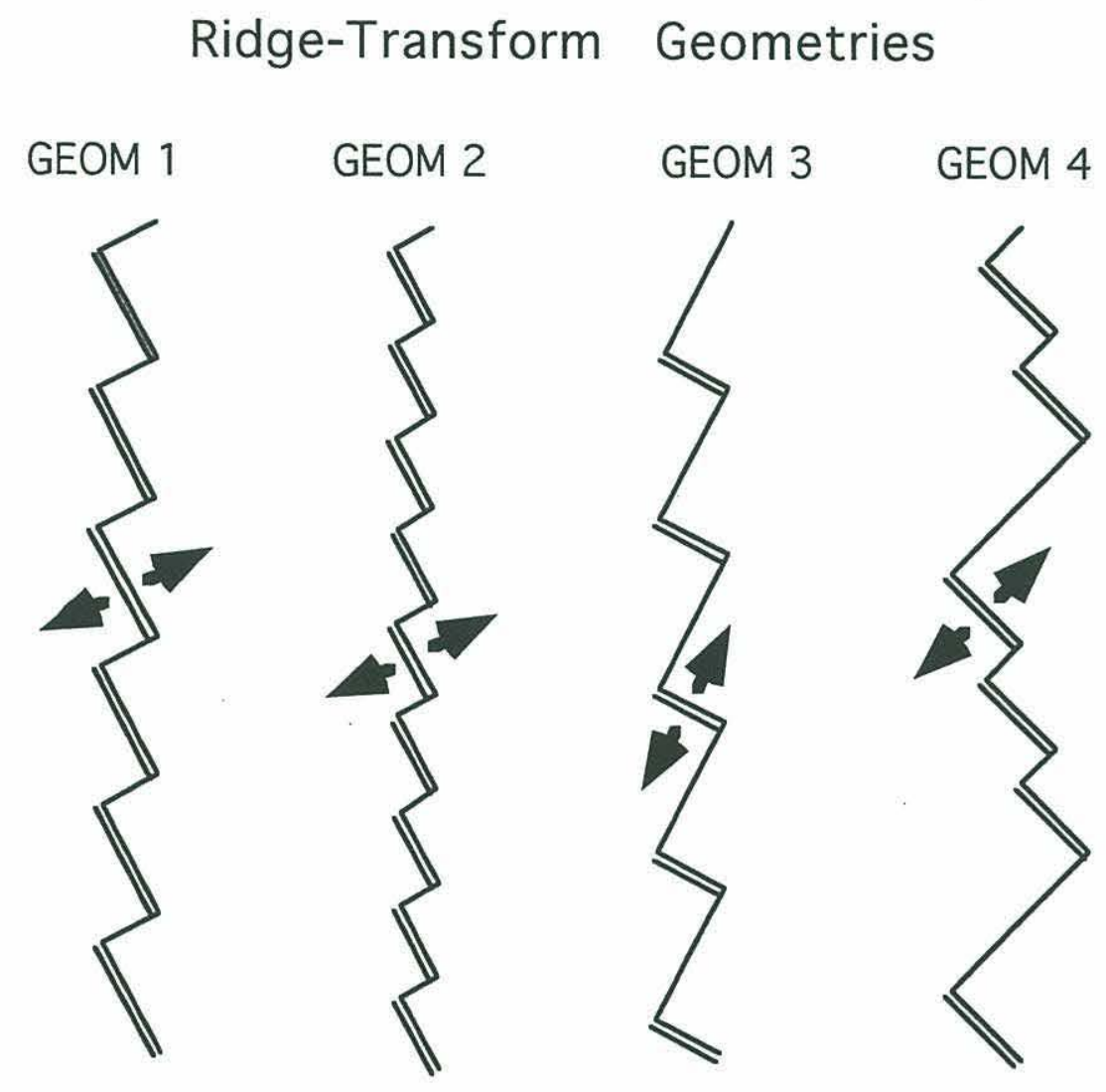

Figure 3. The four spreading plate geometries used in the experiments. Double lines indicate ridge segments; single lines indicate offsets. Arrows show spreading direction. 
Figure 4. Results of experiments run with mantle potential temperature $=1350^{\circ} \mathrm{C}$, reference viscosity $2.5 \times 10^{19} \mathrm{~Pa}$-s, reference permeability $=0.2 \times 10^{-8} \mathrm{~m}^{2}$, and vertical viscosity structure \#1, and a) GEOM1, b) GEOM2, c) GEOM3, and d) GEOM4. Top) Along-axis crustal thickness variations assuming a two-dimensional melt migration model. Crustal thickness produced along each ridge segment is positioned above the corresponding segment. Middle) Horizontal cross-section through flow model at a depth of $47 \mathrm{~km}$. Arrows show horizontal component of mantle velocity (plotted at every fourth grid-point). Shading indicates retained melt fraction so that the entire gray area represents the width of the melting region at this depth. Color changes are at intervals of 0.005. Superimposed on the cross section is the plate spreading geometry. Bottom) Vertical cross section through the center of the model (at $x=480 \mathrm{~km}$ ). Arrows and shading are as in the horizontal sections, and black lines are isotherms. The apparent along-axis flow near the surface is entirely due to the orientation of this cross-section, which projects a component of the plate-spreading velocity into this plane. The variation in vertical velocities in this projection is larger than that in the plane of an individual ridge segment. Note along-axis crustal thickness variations are plotted as a function of distance along-axis and not of distance along this central plane. The initial depth of melting is nearly constant along-axis while the final depth of melting is depressed beneath offsets. Segment-scale $(\sim 50 \mathrm{~km})$ mantle diapirs are not predicted with any of the geometries. However the long offsets in GEOM4 are sufficiently far apart to produce long-wavelength variations in mantle upwelling, effectively separating the melting region into distinct regions. Note that the large offsets in GEOM3 depress the top of the melting region, thereby reducing the overall crustal thickness. In contrast, the small offsets in GEOM2 have very little effect on crustal production. 
a)
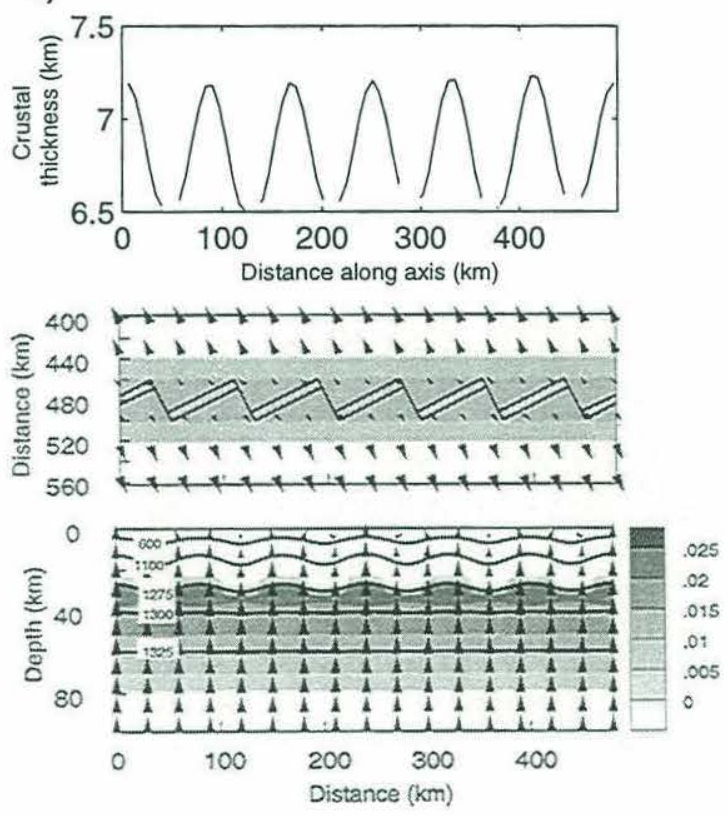

c)
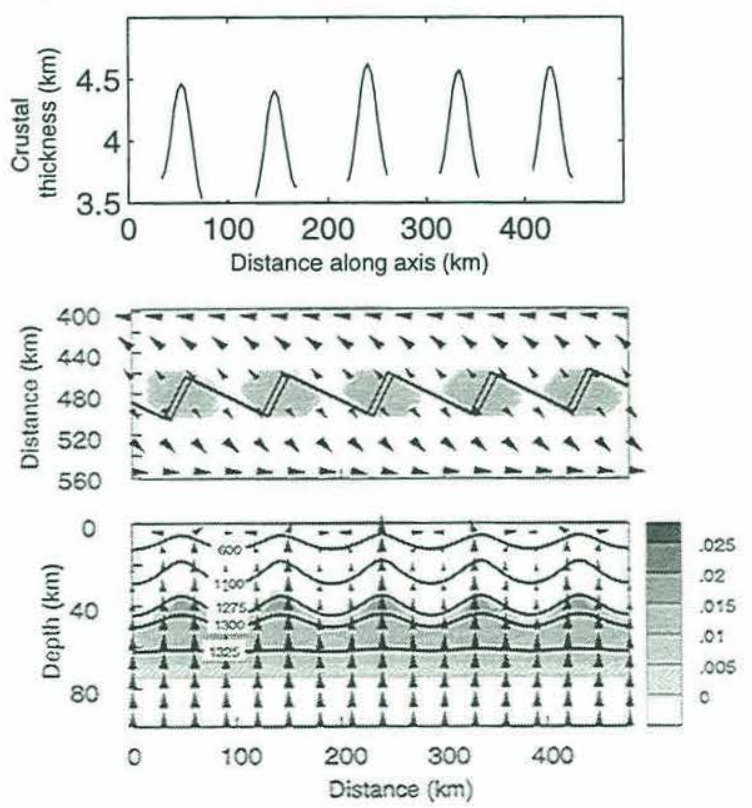

b)
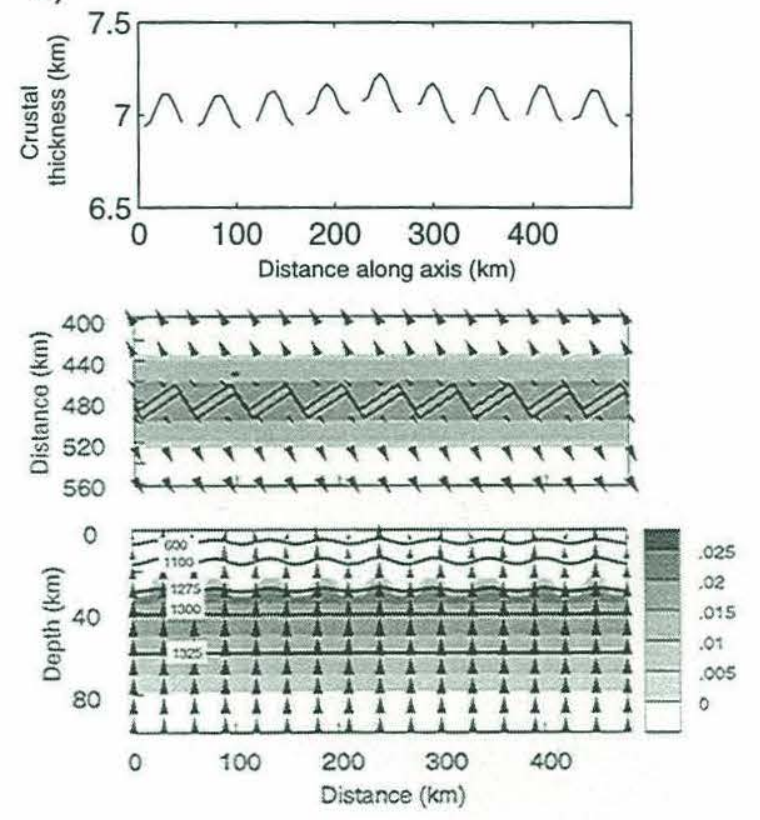

d)
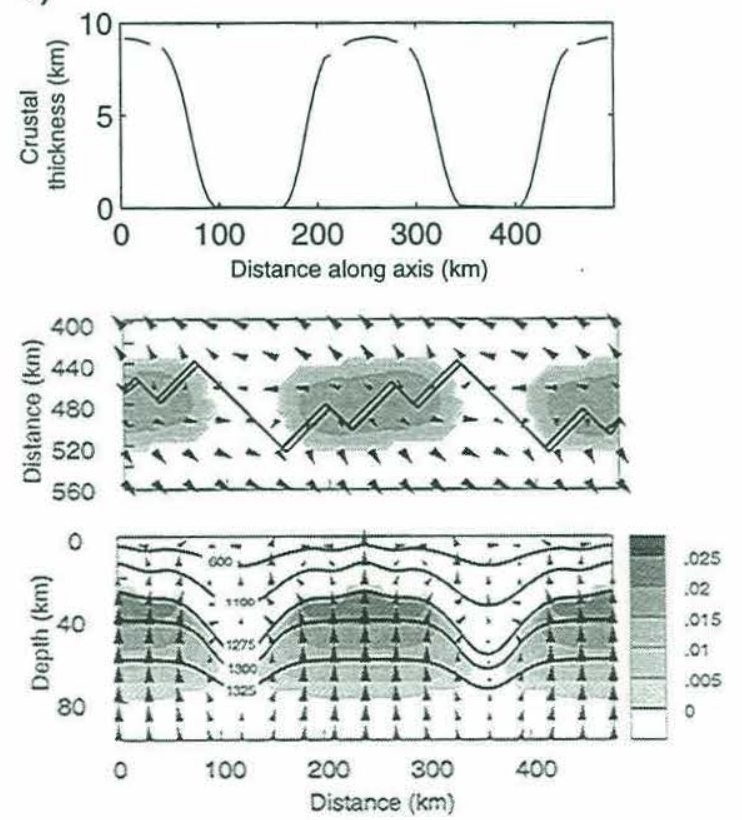


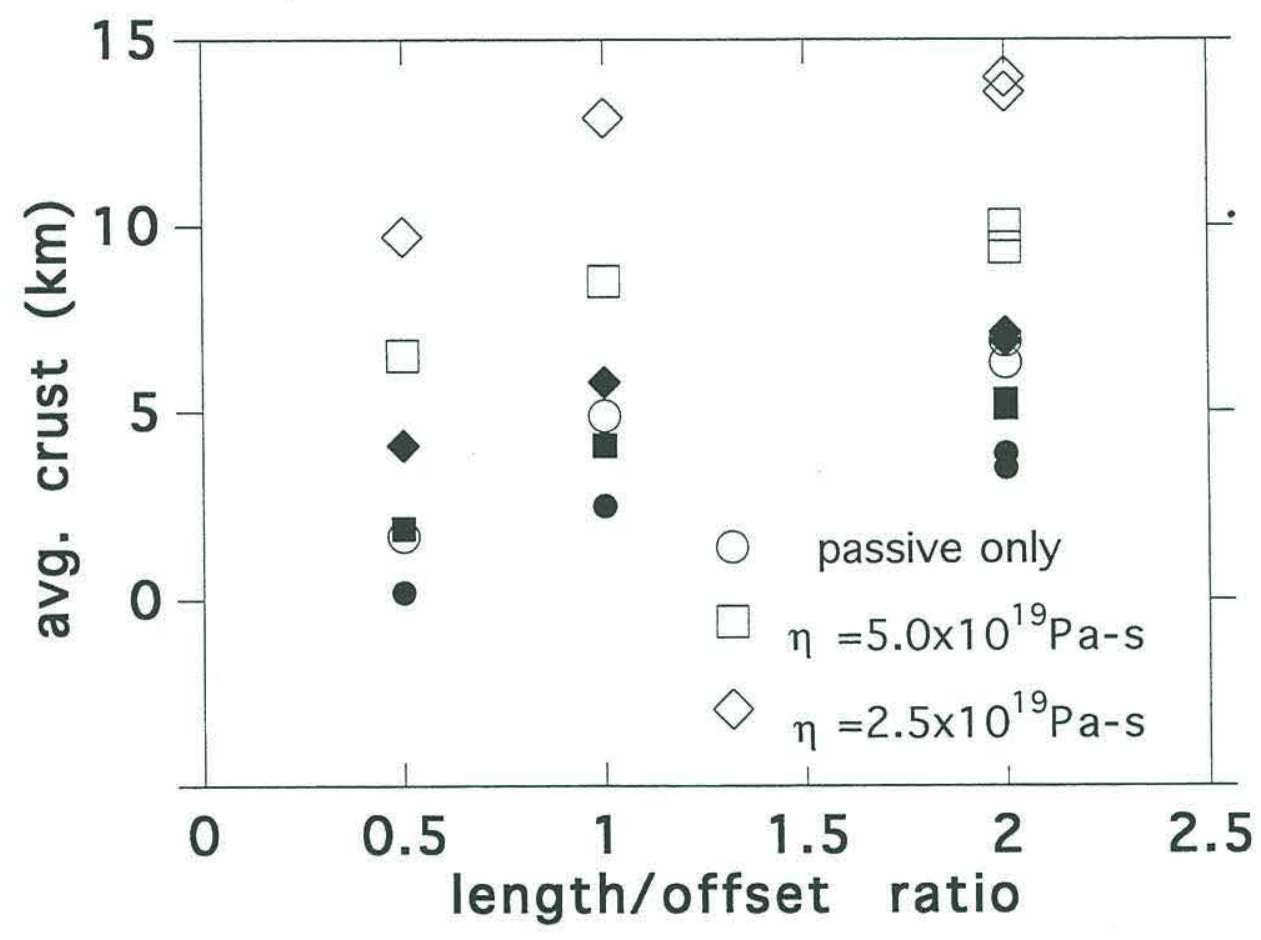

Figure 5. Relationship between plate geometry and average crustal thickness for mantle potential temperatures of $1350^{\circ} \mathrm{C}$ (solid symbols) and $1400^{\circ} \mathrm{C}$ (open symbols). All experiments were run using viscosity structure \#1 and a reference permeability of $1.0 \times 10^{-}$ $8 \mathrm{~m}^{2}$. Melt production depends strongly on length/offset ratios and decreases sharply for length/offset ratios less than 1 . 


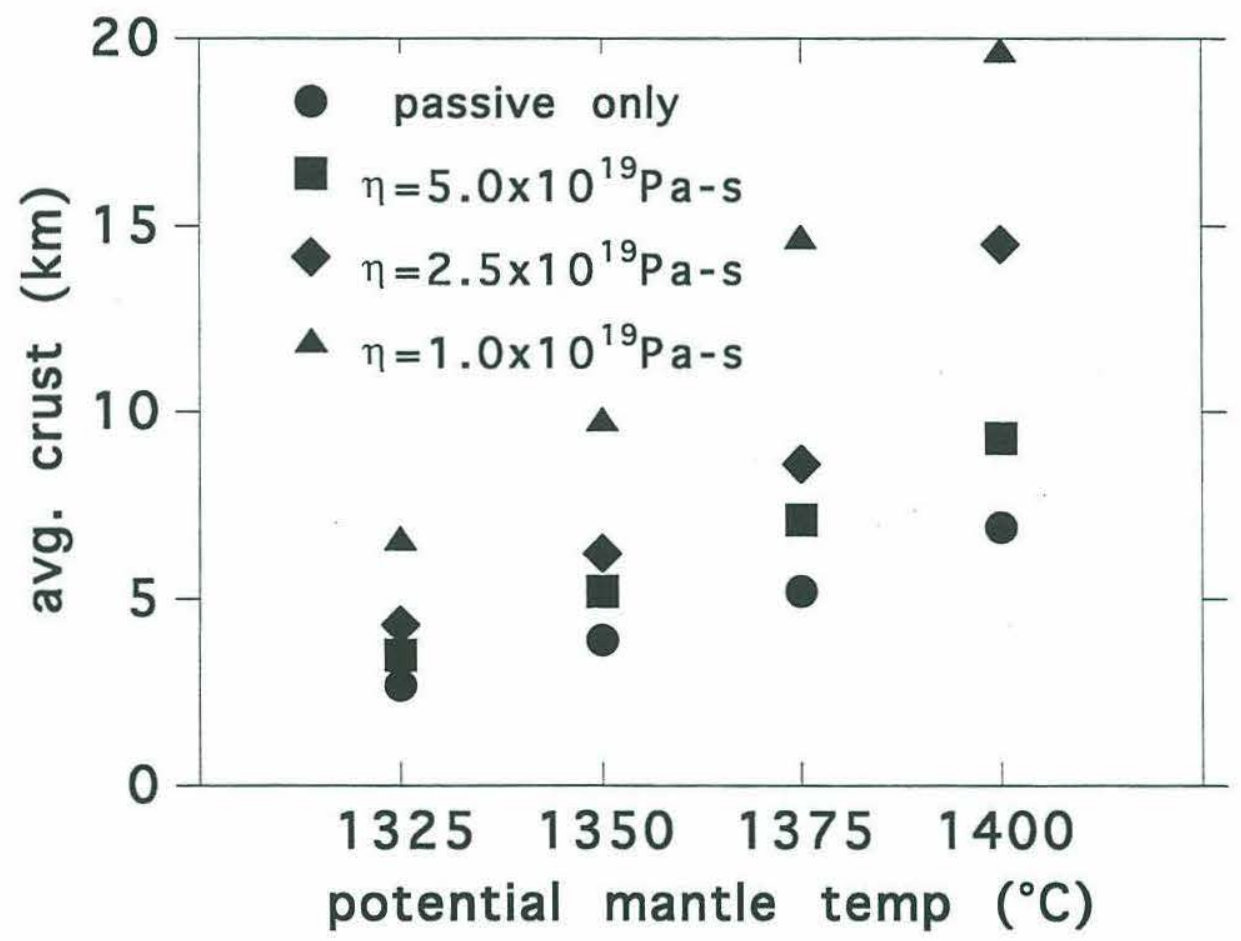

Figure 6. Increase in average crustal thickness with increasing mantle potential temperature. All experiments use GEOM1, viscosity structure \#1, and a reference permeability of $1.0 \times 10^{-8} \mathrm{~m}^{2}$. 


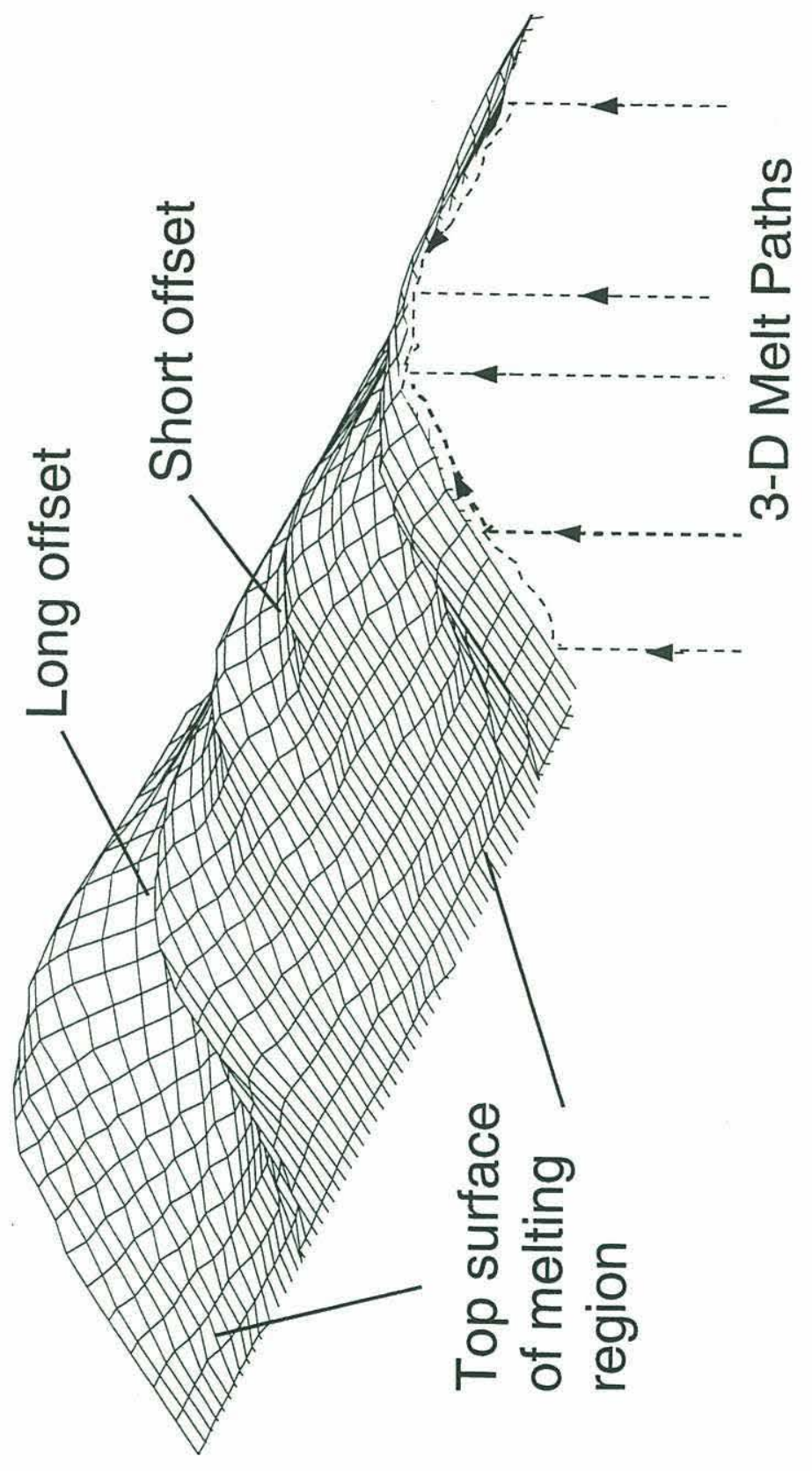

Figure 7. Three-dimensional representation of the top surface of the melting region beneath a segmented spreading center. In our three-dimensional melt-migration model, melt rises vertically to this surface and then migrates upslope along this surface until it reaches a ridge axis. Note that saddles form between each of the segments which act to focus melt toward segment midpoints. 

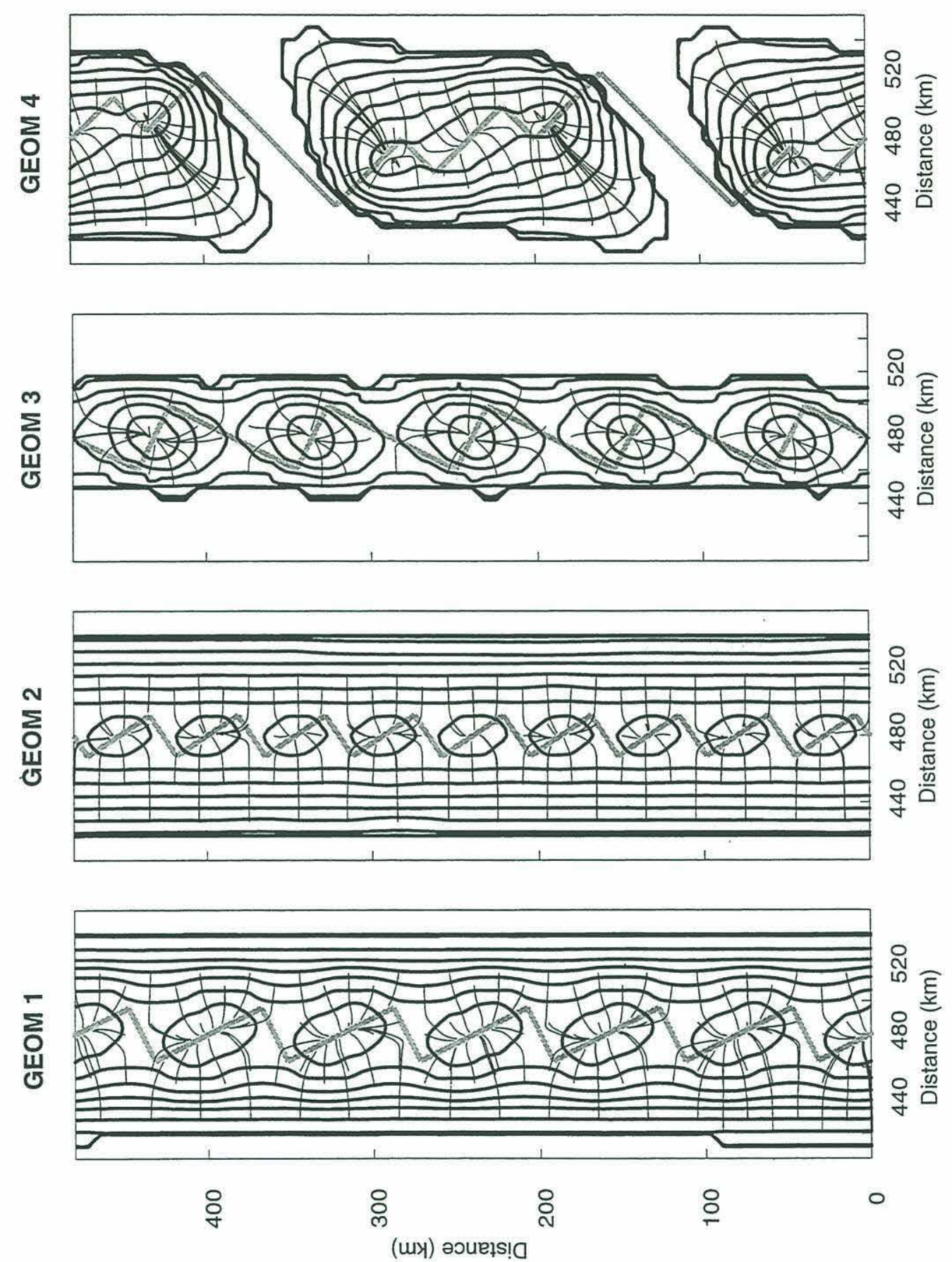

Figure 8. Application of our three-dimensional melt migration model to each of the experiments shown in Figure 4. Contours show depth to the top of the melting region (contour interval $=5 \mathrm{~km}$, between 70 and $30 \mathrm{~km}$ ). Thick, gray line segments indicate the plate boundary. Curved lines show selected trajectories followed by parcels of melt which rise to the base of the melting-region surface and then travel upslope to the ridge axis. Note that trajectories can cross beneath offsets but terminate at ridge segments. 


\section{GEOM1}
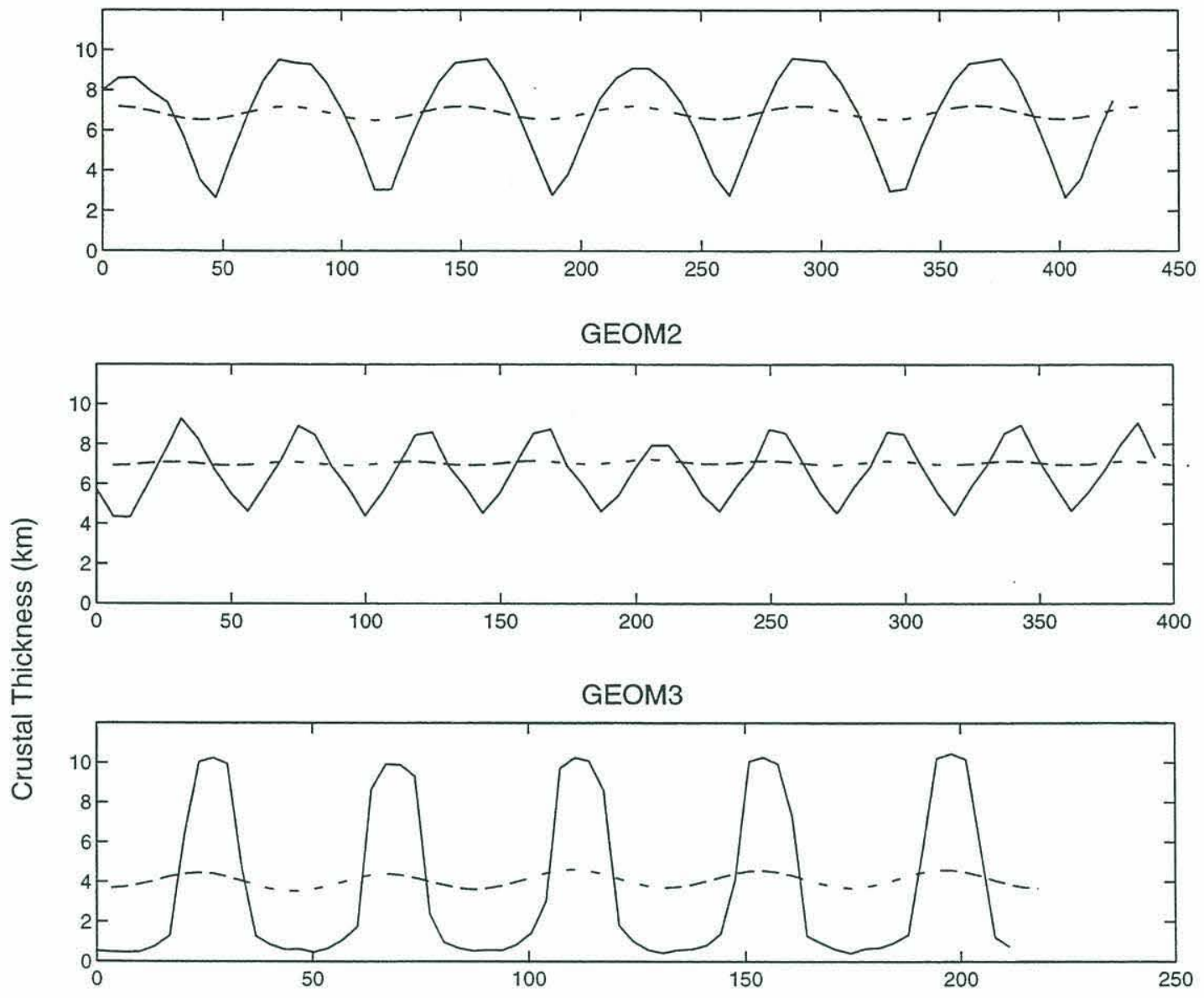

GEOM4

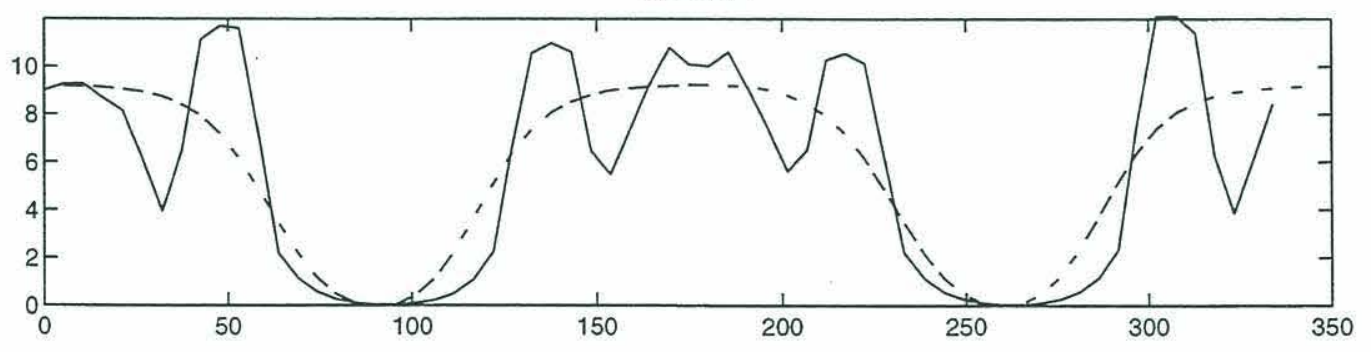

Distance Along Axis (km)

Figure 9. Along-axis crustal thickness profiles predicted for each of the experiments shown in Figures 4 and 8. Dashed profiles assume two-dimensional melt migration as in Figure 5. Solid profiles were calculated from the three-dimensional melt migration model, using a melt extraction distance of $5 \mathrm{~km}$, and smoothing over $30 \mathrm{~km}$ with a 4-point boxcar filter. 
a)

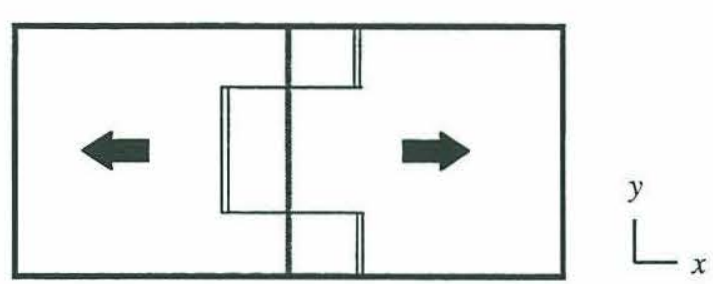

b)

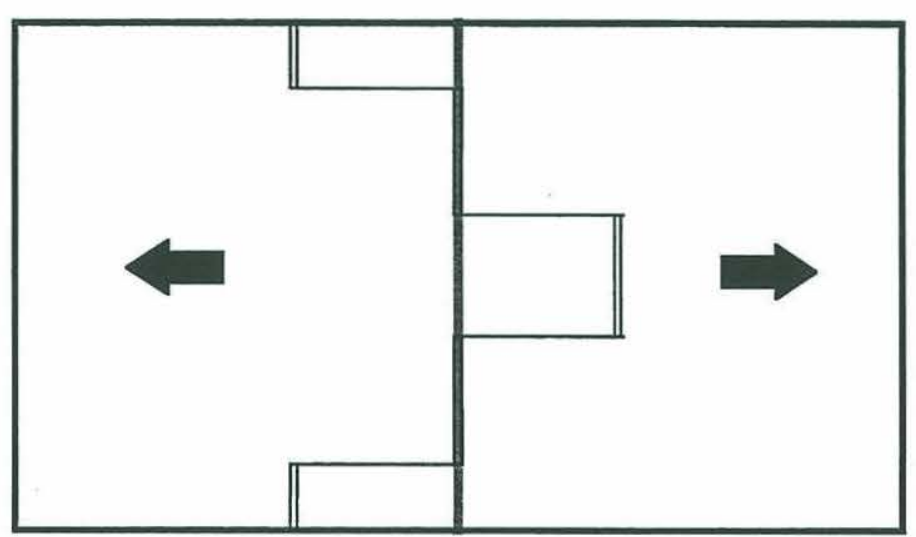

c)

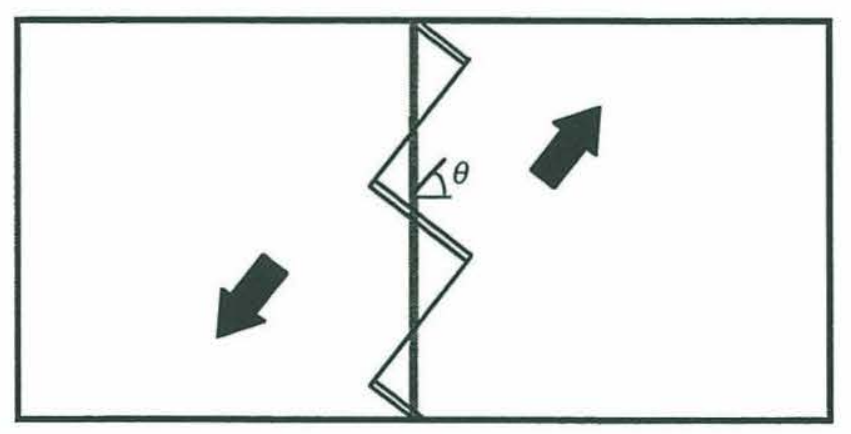

Figure A1. Map view of three different plate spreading geometries within a periodic rectangular computational region. The thick gray line represents the "center of spreading". Spreading segments and offsets are shown by double and single lines, respectively. a) Segments perpendicular to the spreading direction (indicated by arrows), as in previous studies. b) Ridge-parallel box used to generate passive flow for three consecutive segments that are offset in the same sense. c) Rotated geometry which would be used for a buoyant flow calculation for the same geometry as in $\mathrm{b}$. 


\title{
CHAPTER 6
}

\section{The relationship between buoyant mantle flow, melt migration, and gravity bull's-eyes at the Mid-Atlantic Ridge between $33^{\circ} \mathrm{N}$ and $35^{\circ} \mathrm{N}$}

\begin{abstract}
Crustal thickness and mantle Bouguer anomaly (MBA) patterns along the MidAtlantic Ridge (MAR) between the Oceanographer and Hayes transforms $\left(33-35^{\circ} \mathrm{N}\right)$ are predicted from a three-dimensional mantle flow model driven by plate spreading and mantle density variations, assuming a two- or three-dimensional model of melt extraction. Our two-dimensional melt extraction model focuses melt to the nearest ridge segment by assuming that melt moves only vertically and parallel to the spreading direction. In contrast, the three-dimensional model assumes melt migrates vertically to the top of the melting region and then up the local slope of this surface. The shape of this surface, which is controlled by enhanced conductive cooling at ridge offsets, directs melt toward the center of segments. Our results suggest that buoyant mantle flow driven by temperature variations and a small retained melt fraction $(<2 \%)$ enhances overall crustal production and produces long wavelength variations in MBA and crustal thickness relative to purely platedriven mantle flow. Three-dimensional mantle flow with two-dimensional melt migration predicts little or no crustal thinning associated with small non-transform offsets. However, our simple model of three-dimensional melt migration shows that even a moderate amount of along-axis melt focusing can produce the observed segment-scale variations in MBA and crustal thickness. We therefore suggest that the along-axis crustal thickness and gravity variations observed at the MAR are the combined result of three-dimensional buoyant mantle upwelling (controlling long wavelength features) and three-dimensional melt migration (controlling short wavelength features including the gravity bull's eyes).
\end{abstract}

\section{Introduction}

The segmented nature of the world's mid-ocean ridge system indicates that it is not a simple two-dimensional structure, but is instead a three-dimensional system with large along-axis variations in mantle and crustal densities and crustal thickness. Gravity data are often used to constrain variations in crustal thickness and mantle density [Kuo and 
Forsyth, 1988; Prince and Forsyth, 1988]. Some of the most dramatic features are the Mantle Bouguer Anomaly (MBA) "bull's eyes" observed beneath segment mid-points along slow-spreading ridges. These anomalies are generally attributed to along-axis crustal thickness variations, due either to block faulting [Mutter and Karson, 1992] or focused mantle upwelling [Lin et al., 1990; Blackman and Forsyth, 1991; Detrick et al., 1995]. However, along-axis variations in crustal thickness may also be created through threedimensional melt migration [Whitehead et al., 1984]. This study combines a threedimensional mantle convection model (combining both buoyant and plate-driven flow) with simple models of two- and three-dimensional melt migration to quantitatively investigate the relative contribution of focused mantle upwelling and melt migration to the observed MBA anomalies.

\section{Study Area}

The chosen study area is the Oceanographer-to-Hayes section of the Mid-Atlantic Ridge (MAR), extending from $33^{\circ}$ to $35^{\circ} \mathrm{N}$. This section of the MAR is composed of five segments (OH-1 through $\mathrm{OH}-5)$, ranging in length from 95 to $8 \mathrm{~km}$, and spreading symmetrically at a half-rate of $1.5 \mathrm{~cm} / \mathrm{yr}$. The topography and gravity in this region are well documented [Detrick et al., 1995]. Figure 1a shows a plan view of the MBA, calculated by subtracting the gravitational effect of a $6 \mathrm{~km}$ thick crust from the free-air anomaly [Detrick et al., 1995]. The crustal and mantle densities are taken to be 2700 and $3300 \mathrm{~kg} / \mathrm{m}^{3}$. Gravity lows indicate some combination of lower mantle densities (due to temperature and/or compositional effects) and lower density and/or thicker crust.

The two prominent long-wavelength features in the observed MBA are the regional increase from north to south (i.e. the anomaly becomes more positive) and the signal associated with the $200 \mathrm{~km}$ spacing of the transforms [Detrick et al, 1995]. Shorterwavelength features include gravity lows or bull's-eyes centered over segments $\mathrm{OH}-1, \mathrm{OH}-$ 2 , and $\mathrm{OH}-3$, but not over the two smaller segments $(\mathrm{OH}-4$ and $\mathrm{OH}-5)$. There is a distinct asymmetry in MBA across the rift valley near the transforms, with relatively high MBA values at the inside corners [Tucholke and Lin, 1994]. The along-axis MBA is inversely correlated with axial depth. The axis deepens and the MBA anomaly becomes more positive from north to south. Within individual segments, there is also an asymmetric along-axis gradient, with more positive MBA and deeper topography near the larger offsets. 
If the entire MBA anomaly is attributed to differences in crustal thickness, predicted variations of $>4 \mathrm{~km}$ would be associated with each of the transforms, while more modest variations in crustal thickness of $1-3 \mathrm{~km}$ would be predicted at the smaller non-transform offsets [Detrick et al., 1995]. A near-axis seismic line along segment OH-1 indicates crustal thicknesses of $10 \mathrm{~km}$ at the center of the segment, $6 \mathrm{~km}$ at the southern segment boundary, and $4 \mathrm{~km}$ at the Oceanographer transform [Sinha and Louden, 1983].

\section{Methods}

Mantle convection and the resulting crustal production beneath this portion of the MAR are simulated in a region $512 \times 1028 \mathrm{~km}$ and $300 \mathrm{~km}$ deep. We use a 65x129x65node finite difference model [Sparks et al., 1993; Barnouin-Jha et al., 1997; Magde and Sparks, 1996]. The grid is rotated to an angle of $42^{\circ}$ with respect to the spreading direction to make the plate boundary periodic and minimize the effect of the boundary conditions. Mantle flow is decomposed into a passive plate-driven component and a buoyant component. The passive flow is calculated using a propagator matrix method on a large grid orthogonal to the spreading direction. The central region of the passive flow is extracted, rotated and interpolated onto the finite difference grid. The stream functionvorticity formulation for buoyant flow is solved on this grid using a multigrid iterative technique and periodic boundary conditions. The grid spacing of $8 \mathrm{~km}$ horizontally and $4.7 \mathrm{~km}$ vertically is sufficient to resolve wavelengths of buoyant flow down to about 50 $\mathrm{km}$, but we find little power in wavelengths less than $100 \mathrm{~km}$. Similar studies with better resolution [Sparks et al., 1993, Barnouin-Jha et al., 1997, Magde and Sparks, 1996] did not produce wavelengths different from those found in this study. Details of the numerical techniques are given in Magde and Sparks [1996] and [Sparks et al., 1993].

Viscosity is a function of depth, with asthenospheric viscosities in the upper 180 $\mathrm{km}$ bounded below by a smooth, but rapid, increase in viscosity (by a factor of 20) centered about a depth of $200 \mathrm{~km}$ (Figure 2). Buoyant flow is confined to the lowviscosity asthenosphere by the $1150^{\circ}$ isotherm, producing an asthenospheric layer $\sim 180 \mathrm{~km}$ thick. Previous experiments have shown that the wavelength of buoyant mantle instabilities is unchanged even when an asthenospheric layer is half this thickness [Magde and Sparks, 1996]. Buoyancy is supplied by temperature variations (thermal expansion coefficient $\left.=3 \times 10^{-5}{ }^{\circ} \mathrm{C}^{-1}\right)$, mantle depletion $(10 \%$ depletion is equivalent to a temperature increase of $80^{\circ} \mathrm{C}$ ), and retained melt (density difference between solid and melt $=500$ 
$\mathrm{kg} / \mathrm{m}^{3}$ ). We use a solidus with a slope of $3.75^{\circ} \mathrm{C} / \mathrm{km}$ and a melting rate of $0.33 \%$ per $\mathrm{km}$ of adiabatic upwelling.

The retained melt fraction is calculated assuming a balance between melt production and vertical flow, following the method in Jha et al. [1994]. For our two-dimensional model of melt migration, crustal thickness at a given point on a segment is taken to be the rate of melt production in the plane perpendicular to the axis, divided by the spreading rate. Three-dimensional melt migration is subsequently simulated by allowing melt transport along the base of the lithosphere [Sparks and Parmentier, 1991; Spiegelman, 1993; Sparks and Parmentier, 1994]. Melt is assumed to rise vertically to the top of the melting region and then to migrate upslope along the top of the melting region until it comes within $6 \mathrm{~km}$ (horizontal distance) of the ridge axis (half the width of the axial valley in this region), where it is extracted [Magde and Sparks, 1996].

We ran experiments for mantle potential temperatures between 1350 and $1400^{\circ} \mathrm{C}$, asthenospheric viscosities between $10^{20}$ and $10^{19} \mathrm{~Pa}$-s, and mantle permeabilities which produce maximum retained melt fractions of between 0 and $4.0 \%$. The strength of the buoyant upwelling increases as viscosity decreases and as retained melt fraction and mantle temperature increase. The predicted MBA due to mantle density and crustal thickness variations is calculated using a fourier-transform method [described in Sparks et al, 1993, Appendix C].

\section{Predicted MBA with Two-dimensional Melt Migration}

Using our two-dimensional model of melt migration, our simulations predict large MBA highs associated with the Oceanographer and Hayes transforms, with the largest signal over the longer Oceanographer transform (Figure 1b, Figure 3). Between these two transforms is a broad MBA low, centered over the southern portion of segment $\mathrm{OH}-1$ and the northern part of $\mathrm{OH}-2$. The predicted MBA is not separated into the three distinct lows observed over segments $\mathrm{OH}-1, \mathrm{OH}-2$ and $\mathrm{OH}-3$. This pattern is due to the wavelength of the buoyant upwelling, which matches well the spacing of the two transforms, but is considerably longer than the spacing of non-transform offsets. These along-axis wavelengths are consistent with those found in previous studies of buoyant flow beneath spreading centers [Parmentier and Phipps Morgan, 1990; Sparks et al., 1993, Rabinowicz et al., 1993, Barnouin-Jha et al, 1997].

While the MBA and topography patterns described above are common to all of the simulations, the amplitude of the predicted MBA and topography variations and the crustal 
thickness depend on the prescribed model parameters. Simulations with more buoyant flow (generated either by decreasing the asthenospheric viscosity or increasing the amount of melt retention) display more along-axis variation in crustal thickness, and predicted gravity (Figure 3). The variation in MBA over the transforms increases markedly in simulations that have more than about $2 \%$ maximum retained melt fraction, or mantle viscosities below $5 \times 10^{19} \mathrm{~Pa}$-s. The predicted average crustal thickness decreases with decreasing mantle temperature and increasing mantle viscosity.

Our simulations predict wider and larger amplitude gravity and crustal thickness variations associated with the Hayes and Oceanographer transforms than is inferred from gravity and seismic data [Detrick et al., 1995; Sinha and Louden, 1983]. The amplitude of these transform-centered MBA highs can be reduced in our models by reducing the buoyant component of mantle upwelling. However, this will simultaneously reduce overall crustal production. In the case of a $1375^{\circ} \mathrm{C}$ mantle potential temperature and no buoyant flow (plate-driven upwelling only), the amplitude of the MBA variations matches well at the two transforms, but the crustal thickness averaged over the entire region is only $3.9 \mathrm{~km}$. We have chosen to include buoyant mantle upwelling in order to form an average crustal thickness closer to $6 \mathrm{~km}$, in accordance with seismic observations. If the seismic moho does not accurately represent magmatic crustal thickness [Hess, 1962; Clague and Straley, 1977; Cannat, 1993; 1995], then magmatic crustal thickness may be significantly lower than $6 \mathrm{~km}$, and simulations with less buoyant flow or lower mantle temperature would provide a better match to the observed MBA and crustal thickness variations at the transforms.

\section{Predicted MBA with Three-dimensional Melt Migration}

Since three-dimensional mantle convection does not appear to produce shortwavelength variations in crustal thickness, we suggest that three-dimensional melt migration may create these segment-scale variations. This hypothesis is consistent with our emerging understanding of the properties and behavior of partially molten mantle. Trace element geochemistry suggests that melt migration trajectories are very different from mantle flow paths [Spiegelman, 1996]. Experimental work on mantle rheology indicates that mantle viscosity may increase significantly with the onset of melting, due to dehydration [Hirth and Kohlstedt, 1996]. This would greatly reduce buoyant flow at depths shallower than $\sim 80 \mathrm{~km}$, inhibiting short-wavelength mantle diapirs. In addition, major elements indicate that the extents and depths of melting appear to be uniform along 
the entire length of the segments [Langmuir et al., 1996], which would be consistent with along-axis pooling of melt.

Our simple model of three-dimensional melt migration along the top of the melting region successfully focuses melt toward the centers of each segment (Figure 4). Even the relatively small amount of lithospheric thickening associated with the non-transform offsets depresses the top of the melting region and creates a gradient that can drive melt to the centers of segments. In the case where there is no axial redistribution of melt, very large crustal thickness variations are predicted, up to $10 \mathrm{~km}$ at both the transform and nontransform offsets (Figure 5, curve E). However, along-axis diking events (of the type described by Embley and Chadwick, [1994]) and/or lower crustal ductile flow [Buck , 1996] may redistribute magma back toward the segment ends. To simulate this process, we convolve the crustal thickness function with a 7-point boxcar filter. This corresponds to dikes of up to $50-60 \mathrm{~km}$ in length and produces a reasonable fit to the along-axis variations in the observed MBA gravity near the non-transform offsets (Figure 1c and Figure 5, curve F).

As in the case of two-dimensional melt migration, predicted MBA and crustal thickness variations are too large at the Hayes and Oceanographer transforms. These largeamplitude crustal thickness variations are due to a combination of the long wavelength variations in buoyant mantle flow and the large topography on the melt region which drives melt away from the transforms, indicating that one or both of these effects may be overestimated at long transforms. However, it is also possible that some of the discrepancy is due to overestimation of magmatic crustal thicknesses based on the observed MBA. If the lower crust near fracture zones consists partially of peridotite [e.g. Cannat, 1993; 1995], then the mantle Bouguer anomalies may not accurately reflect the degree of crustal thinning at fracture zones [e.g., Morris and Detrick, 1991].

We find that our simulations predict MBA bull's eyes which are elongated in the across-axis direction relative to the observed pattern (Figure 1). This arises, in large part, because we assume that the along-axis crustal thickness variations are preserved indefinitely as the crust moves off axis. However, examination of remnant offsets preserved off-axis demonstrates than the non-transform offsets migrate over time [e.g., Gente et al, 1995]. The location of the thick crust associated with segment centers has therefore migrated up and down along the axis. Furthermore, geologic evidence [Escartin, 1996] suggests that along-axis crustal thickness variations are significantly modified by tectonic faulting as crust moves out of the axial valley. These processes will all tend to 
produce more circular MBA bull's eyes. Our experiments also do not predict the smallscale asymmetry in MBA observed across the rift valley adjacent to the transforms. However, geological evidence suggests that this asymmetry results from tectonic processes, such as unroofing of the inside corner by a low-angle detachment fault [Dick et al., 1991; Escartin and Lin, 1995], which are not included in our models.

\section{Implications}

These models suggest that there is a component of buoyant upwelling beneath the MAR that results in enhanced overall crustal production and increased long-wavelength (> $100 \mathrm{~km}$ ) variations in crustal thickness and mantle density. However, upwelling is roughly uniform between the two large transform offsets and relatively unaffected by the presence of smaller non-transform offsets (Figure 6). This buoyant flow pattern does not include individual mantle diapirs rising beneath each segment, as has been proposed to explain the MBA bull's eyes observed along the MAR [Lin et al., 1990; Parmentier and Phipps Morgan, 1990]. Instead, we suggest that short wavelength MBA patterns can be produced by three-dimensional melt migration.

We propose an alternative (Figure 7b) to the mantle diapir hypothesis (Figure 7a). Buoyant mantle flow may be responsible for long wavelength crustal thickness variations and the spacing of long-lived transform faults along the MAR, but individual mantle diapirs are not required to produce MBA bull's-eyes at each segment. Highly three-dimensional melt migration through a more two-dimensional solid mantle flow can focus melt toward the centers of segments. Subsequent diking and faulting events and/or solid-state flow in the crust may then redistribute the melt. We therefore suggest that the along-axis MBA variations observed at slow-spreading ridges such as the MAR may not directly reflect the underlying pattern of mantle upwelling. Instead, variations in crustal accretion represent the combined effects of three-dimensional mantle upwelling, melt migration, and subsequent crustal deformation.

Acknowledgments. We thank Marc Parmentier, Gregory Neumann, Norman Sleep, Garrett Ito, Jian Lin, Greg Hirth, Roger Buck, Roger Searle, and one anonymous reviewer for their suggestions for improving this manuscript. This work was supported under NSF grant OCE92-15544. Woods Hole Oceanographic Institution contribution 9186. 


\section{References}

Barnouin-Jha, K., E. M. Parmentier, and D. W. Sparks, Buoyant mantle upwelling and crustal production at oceanic spreading centers: on-axis segmentation and off-axis melting, J. Geophys. Res., in press, 1997.

Blackman, D. K. and D. W. Forsyth, Isostatic compensation of tectonic features of the Mid-Atlantic Ridge: 25-27³0'S, J. Geophys. Res., 96, 11741-11758, 1991.

Buck, W. R. Along-axis crustal flow and ridge topographic segmentation, EOS Trans. Amer. Geophys. Un., 77, S276, 1996.

Cannat, M. Emplacement of mantle rocks in the seafloor at mid-ocean ridges, J. Geophys. Res., 98, 4163-4172, 1993.

Cannat, M. et al., thin crust, ultramafic exposures, and rugged faulting patterns at the MidAtlantic Ridge $\left(22^{\circ}-24^{\circ} \mathrm{N}\right)$, Geology, 23, 49-52, 1995.

Clague, D. A., and P. F. Straley, Petrologic nature of the oceanic Moho, Geology, 5, 133-136, 1977.

Detrick, R. S., H. D. Needham, and V. Renard, Gravity anomalies and crustal thickness variations along the Mid-Atlantic Ridge between $33^{\circ} \mathrm{N}$ and $40^{\circ} \mathrm{N}$, J. Geophys. Res., 100, 3767-3787, 1995.

Dick, H. J. B., et al., Lithostratigraphic evolution of an in-situ section of oceanic layer 3, Proc. Ocean Drill. Prog. Sci. Results, 118, 359-398, 1991.

Embley, R. W., and W. W. Chadwick Jr., Volcanic and hydrothermal processes associated with a recent phase of seafloor spreading at the northern Cleft segment: Juan de Fuca Ridge, J. Geophys. Res., 99, 4741-4760, 1994.

Escartin, J., Ridge segmentation, tectonic evolution and rheology of slow-spreading crust, $\mathrm{Ph} . \mathrm{D}$. thesis, Massachusetts Institute of Technology-Woods hole Oceanographic Institution Joint Program in Oceanography, 1996.

Escartin, J. and J. Lin, Ridge offsets, normal faulting, and gravity anomalies of slow spreading ridges, J. Geophys. Res., 100, 6163-6177, 1995.

Gente, P., et al., Characteristics and evolution of the segmentation of the Mid-Atlantic Ridge between $20^{\circ} \mathrm{N}$ and $24^{\circ} \mathrm{N}$ during the last 10 million years, Earth Planet. Sci. Lett. 129, 55-71, 1995.

Hess, H. H., The history of the ocean basins, in Petrological Studies: A volume in honor of A. F. Buddington, E. E. J. Engel, H. L. James, and B. F. Leonard, eds., Geological Society of America, 599-620, 1962. 
Hirth, G., and D. Kohlstedt, Water in the oceanic upper mantle: Implications for rheology, melt extraction and the evolution of the lithosphere, Earth Plant. Sci. Lett., 144, 93108, 1996.

Jha, K., E. M. Parmentier, and J. Phipps Morgan, The role of mantle-depletion and meltretention buoyancy in spreading-center segmentation, Earth Planet. Sci. Lett., 125, 221-234, 1994.

Kuo, B.-Y. and D. W. Forsyth, Gravity anomalies of the ridge-transform system in the South Atlantic between 31 and $34.5^{\circ} \mathrm{S}$ : Upwelling centers and variations in crustal thickness, Mar. Geophys. Res., 10, 205-232, 1988.

Langmuir, C. H., J. Reynolds, H. Bougault, T. Plank, L. Dosso, D. Desonie, E. Gier, and Y. Niu, A petrological traverse along the Mid-Atlantic Ridge across the Azores hot spot, Journal of Conference Abstracts, 1, 813-814, 1996.

Lin, J., G. M. Purdy, H. Schouten, J.-C. Sempere, and C. Zervas, Evidence from gravity data for focused magmatic accretion along the Mid-Atlantic Ridge, Nature, 344, 627-632 1990.

Magde, L. S., and D. W. Sparks, Three-dimensional mantle upwelling, melt generation, and melt migration beneath segmented slow-spreading ridges, J. Geophys. Res., submitted, 1996.

Morris, E. and R. S. Detrick, Three-dimensional analysis of gravity anomalies in the MARK area, Mid-Atlantic Ridge 23№, J. Geophys. Res., 96, 4355-4366, 1991.

Mutter J. and J. Karson, Structural processes at slow-spreading ridges, Science, 257, 627-634, 1992.

Parmentier, E. M. and J. Phipps Morgan, Spreading rate dependence of three-dimensional structure in oceanic spreading centers, Nature, 348, 325-328, 1990.

Phipps Morgan, J. and D. W. Forsyth, Three-dimensional flow and temperature perturbations due to a transform offset: Effects on oceanic crustal and upper mantle structure, J. Geophys. Res., 93, 2955-2966, 1988.

Prince, R. A. and D. W. Forsyth, Horizontal extent of anomalously thin crust near the Vema fracture zone from the three-dimensional analysis of gravity anomalies, $J$. Geophys. Res., 93, 8051-8063, 1988.

Rabinowicz, M., S. Rouzo, J.-C. Sempere, and C. Rosemburg, Three-dimensional mantle flow beneath mid-ocean ridges, J. Geophys. Res., 98, 7851-7869, 1993.

Sinha, M. C. and K. E. Louden, The Oceanographer fracture zones - I. Crustal structure from seismic refraction studies, Geophys. J. R. Astron. Soc., 75, 713-736, 1983. 
Sparks, D. W. and E. M. Parmentier, Melt extraction from the mantle beneath spreading centers, Earth Planet. Sci. Lett., 105, 368-377, 1991.

Sparks, D. W., E. M. Parmentier, and J. Phipps Morgan, Three-dimensional mantle convection beneath a segmented spreading center: Implications for along-axis variations in crustal thickness and gravity, J. Geophys. Res., 98, 21,977-21,205, 1993.

Sparks, D. W. and E. M. Parmentier, The generation and migration of partial melt beneath oceanic spreading centers, in Magmatic Systems, ed. M. P. Ryan, Academic Press, 55-76, 1994.

Spiegelman, M., Geochemical consequences of melt transport in 2-D: The sensitivity of trace elements to mantle dynamics, Earth Planet. Sci. Lett., 139, 115-132, 1996.

Spiegelman, M., Physics of melt extraction: theory, implications and applications, Phil. Trans. R. Soc. London A, 342, 23-41, 1993.

Tucholke, B. E. and J. Lin, A geological model for the structure of ridge segments in slow spreading ocean crust, J. Geophys. Res., 99, 11937-11958, 1994. 


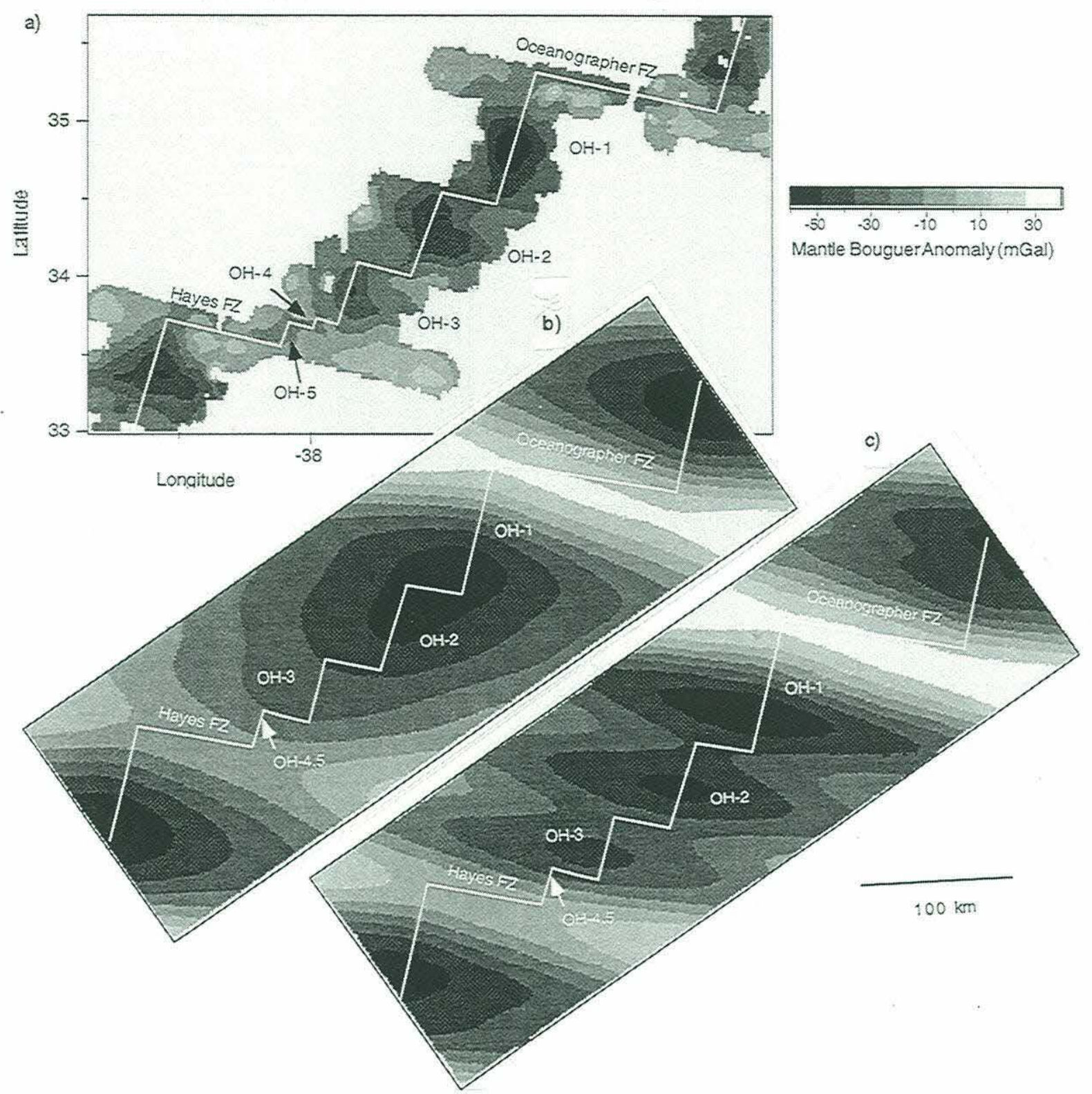

Figure 1. a) Observed MBA between the Oceanographer and Hayes fracture zones. Grid interval $1 \mathrm{~km}$; color change every $12.5 \mathrm{mGal}$. White lines show the location of the plate boundary. b) Predicted MBA in the absence of three-dimensional melt migration, simulation A (see text and Figure 3). The area shown is a $168 \times 512 \mathrm{~km}$ subsection of the total $1028 \times 512 \mathrm{~km}$ model region. Grid interval $8 \mathrm{~km}$; color change every $12.5 \mathrm{mGal}$. White lines indicate the ridge-transform geometry used to drive the plate-driven component of the simulation. A-A' indicates location of cross-section shown in Figure 6. c) Predicted MBA including three-dimensional melt migration (Simulation F in figure 5). Color scheme identical to part b). 


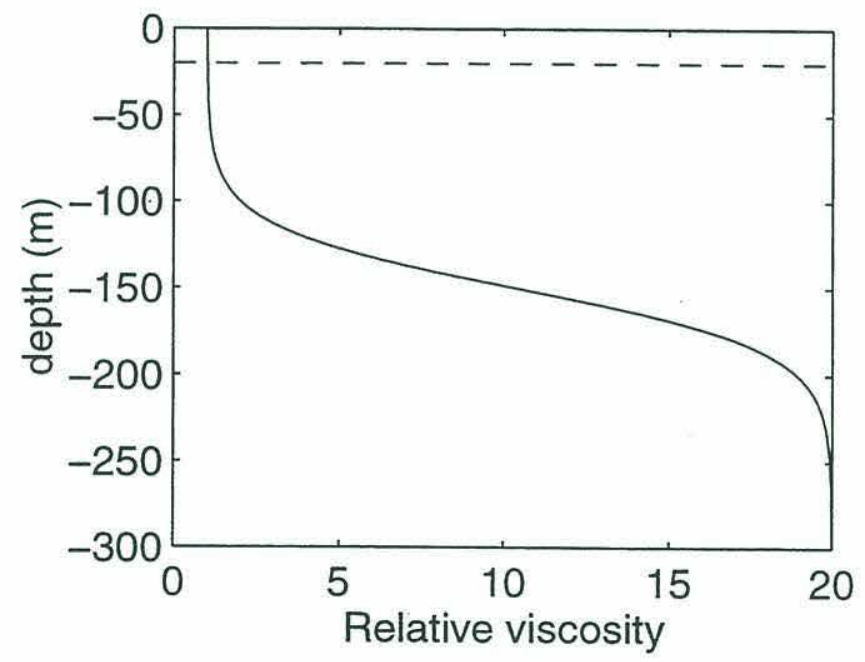

Figure 2. Model viscosity structure as a function of depth. The dashed line at $20 \mathrm{~km}$ depth represents the approximate location of the $1150^{\circ} \mathrm{C}$ isotherm above which there is no buoyant flow. (Note that the actual depth of this isotherm increases with distance from the spreading axis.) The reference viscosity corresponds to a value of 1 in this figure. 


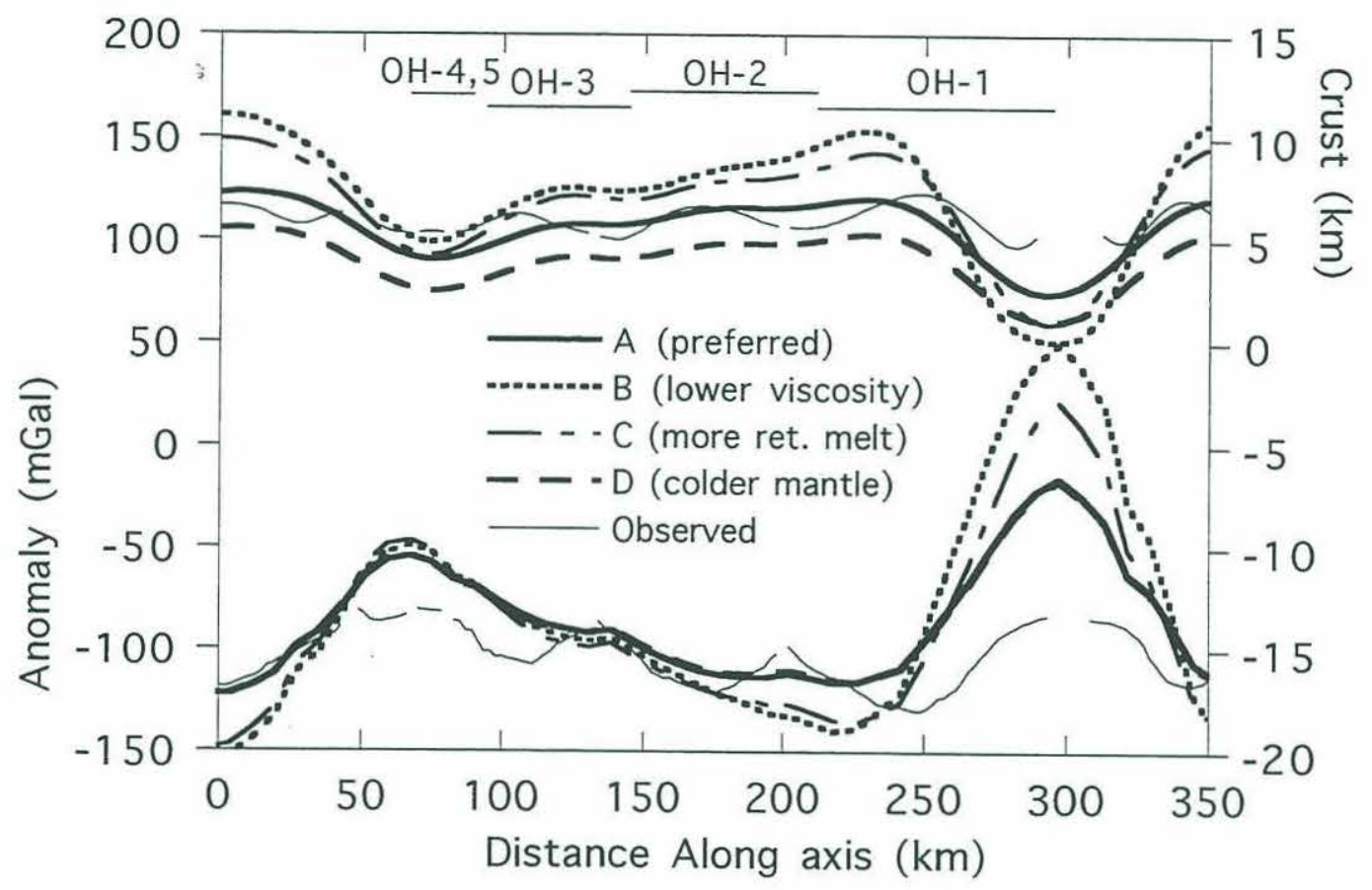

Figure 3. Observed along-axis MBA gravity and crustal thickness variations (thin solid line) compared with those predicted for a series of simulations using two-dimensional melt migration. Simulation A produces the best fit to the data: Mantle potential temperature $\left(\mathrm{T}_{\mathrm{m}}\right)$ $=1375^{\circ} \mathrm{C}$, maximum retained melt $(\phi)=0.1 \%$, reference viscosity $(\eta)=5 \times 10^{19} \mathrm{~Pa}-\mathrm{s}$, and average crustal thickness $(C)=5.6 \mathrm{~km}$. Simulation $B: T_{m}=1375^{\circ} C, \phi=0.1 \%, \eta=$ $2.5 \times 10^{19}$ Ps-s, and $\mathrm{C}=7.1 \mathrm{~km}$. Simulation $\mathrm{C}$ : $\mathrm{T}_{\mathrm{m}}=1375^{\circ} \mathrm{C}, \phi=3.3 \%, \eta=5 \times 10^{19} \mathrm{~Pa}-\mathrm{s}$, and $\mathrm{C}=6.8 \mathrm{~km}$. Simulation $\mathrm{D}: \mathrm{T}_{\mathrm{m}}=1350^{\circ} \mathrm{C}, \phi=0.1 \%, \eta=5 \times 10^{19}$ Ps-s, and $\mathrm{C}=4.0$ $\mathrm{km}$. The gravity-derived crustal thickness variation is calculated from the MBA corrected for mantle temperature variations predicted by a passive-flow model [Phipps Morgan and Forsyth, 1988]. 


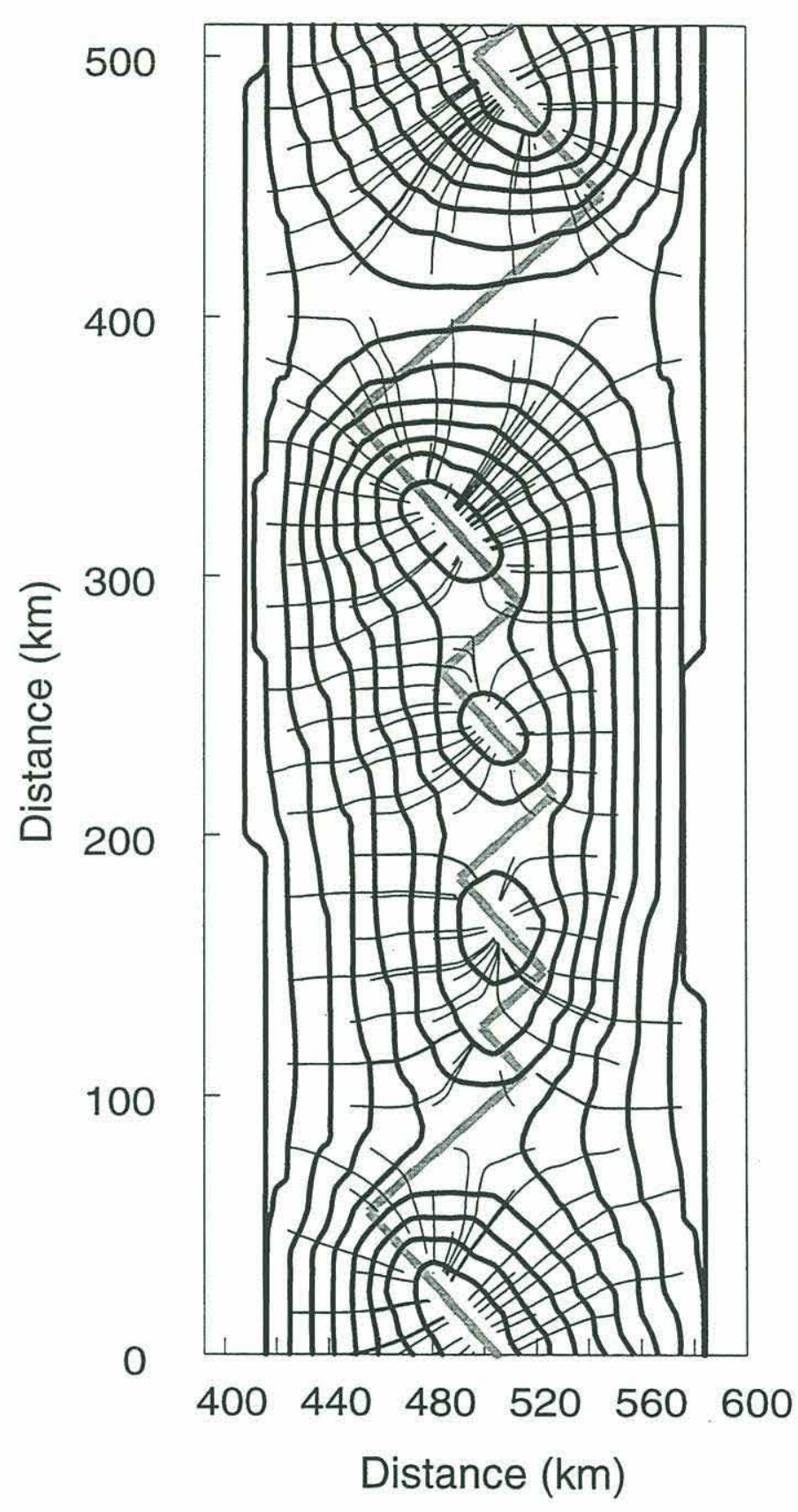

Figure 4. Three-dimensional melt migration paths which focus melt toward segment midpoints. Contours indicate the depth to the top of the melting region (contour interval = $5 \mathrm{~km}$ ). Thick, gray line segments indicate the plate boundary. Curved thin lines show the selected trajectories followed by parcels of melt while they travel upslope to the ridge axis. Note that melt can cross beneath offsets but stops once it comes within $6 \mathrm{~km}$ of a ridge segment. 


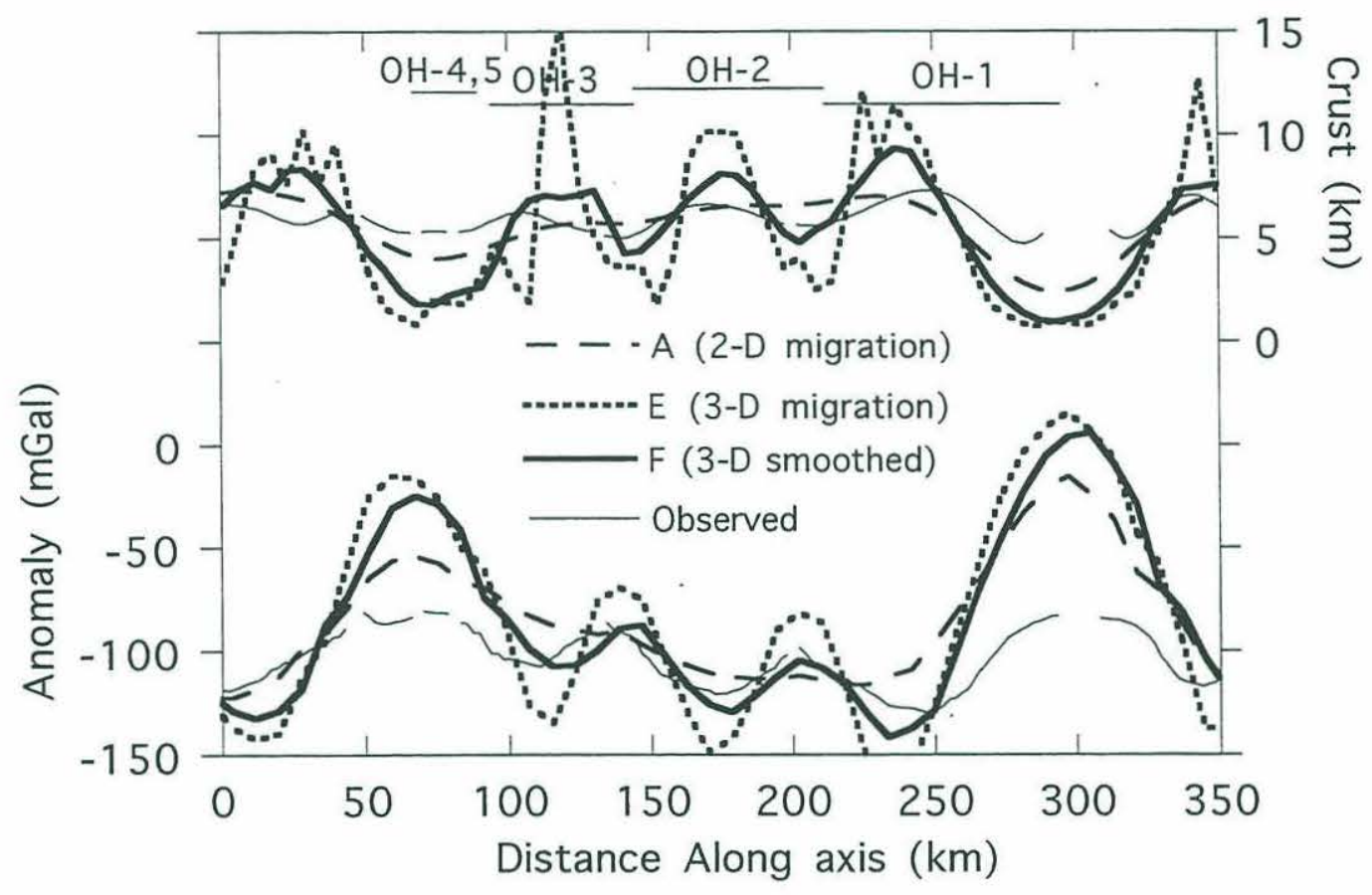

Figure 5. Observed along-axis MBA gravity and crustal thickness variations (thin solid line) compared with those predicted for simulations including melt migration. All are based on Simulation A described in Figure 3. Curve A is with two-dimensional melt migration. Curve $\mathrm{E}$ has three dimensional melt migration without smoothing. Curve F includes smoothing to simulate dikes of 50-60 km and produces a reasonable fit to the observed data near the non-transform offsets. 


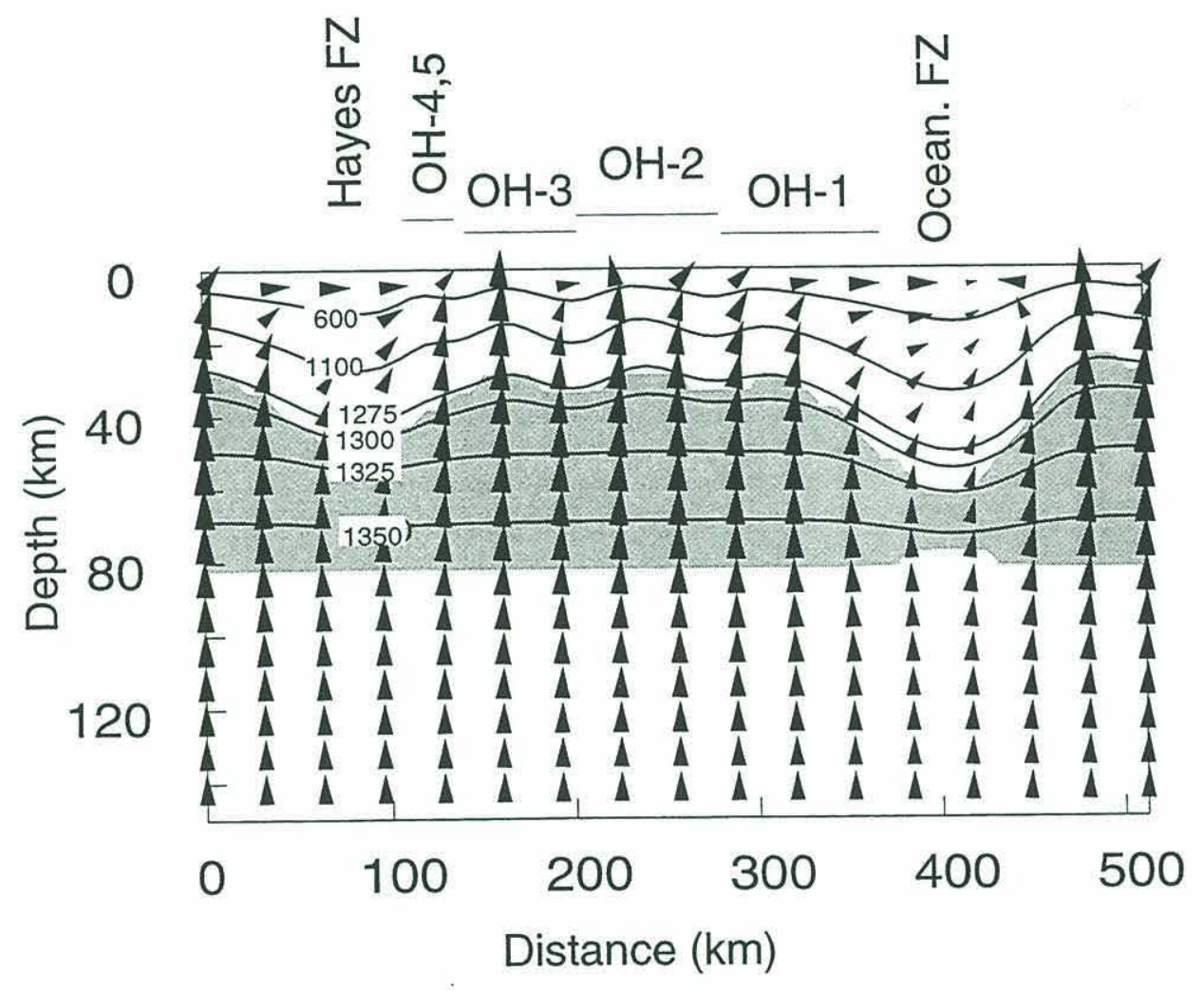

Figure 6. Vertical cross section through the mantle flow simulation shown in Figures 1b and $1 \mathrm{c}$, through $\mathrm{A}-\mathrm{A}^{\prime}$. The top half of the model region is shown. Vertical exaggeration is $2: 1$. The arrows show the direction and amplitude of mantle velocity within the plane. The melting region is shaded and temperature is contoured. There is no indication of individual mantle diapirs associated with each segment. However, even the relatively small amount of lithospheric thickening associated with the short non-transform offsets creates a gradient at the top of the melting region which drives melt migration toward segment centers. The apparent lateral mantle flow near the surface is due to the fact that this section is not perpendicular to the spreading direction. 

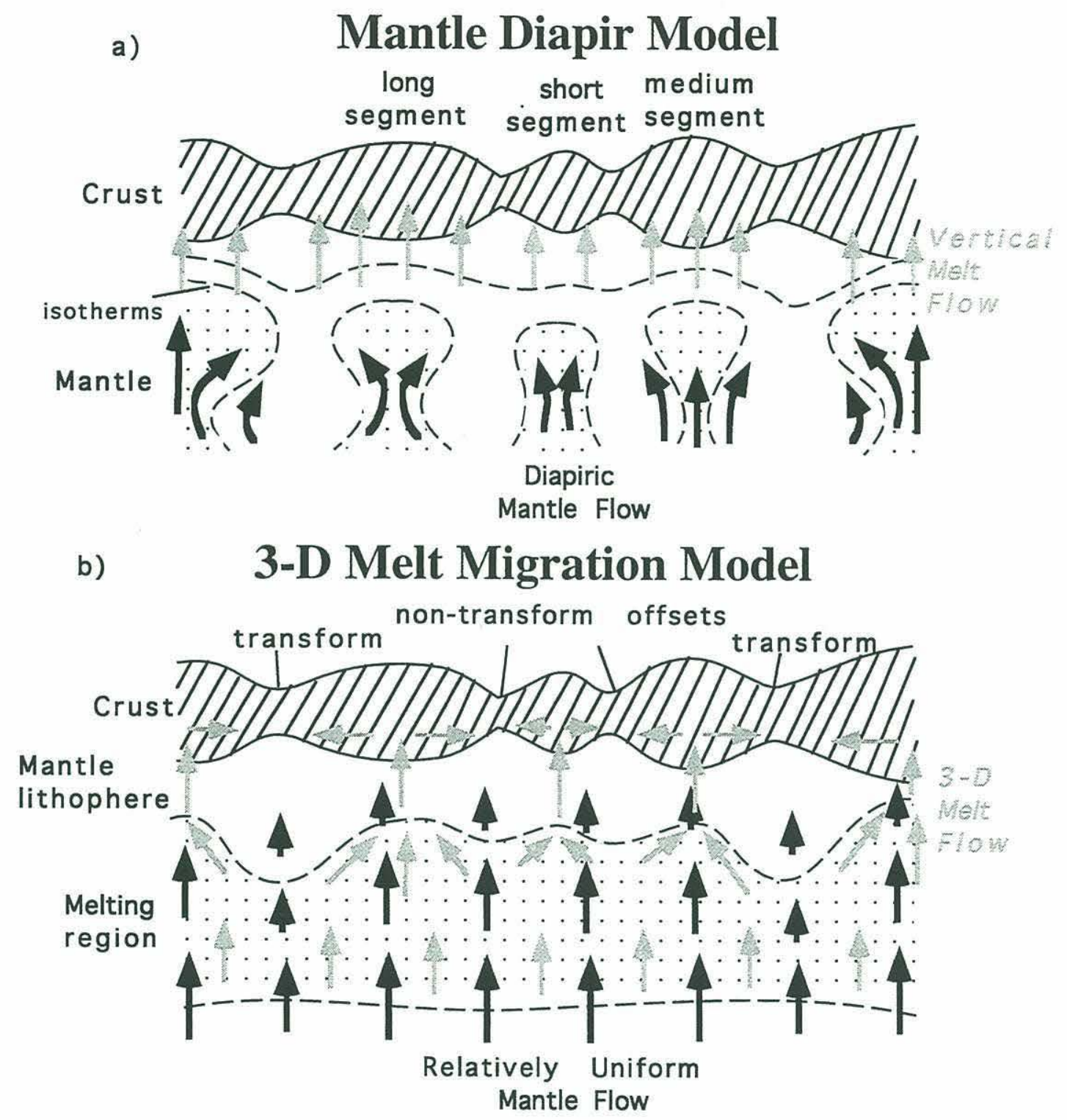

Figure 7. a) Old mantle-diapir model in which crustal thickness variations are controlled by three-dimensional mantle upwelling and vertical melt migration is implied [Lin et al., 1990]. Mantle flow is indicated with black arrows while melt migration is indicated with gray arrows. b) New model in which mantle upwelling is relatively uniform except near large transforms. Again, mantle flow is indicated with black arrows while melt migration is indicated with gray arrows. Focusing of melt toward the centers of segments is accomplished through three-dimensional melt migration through channels upwelling through the mantle and/or in a layer at the base of the lithosphere. Dikes, lower-crustal flow, and/or tectonic events then redistribute the melt throughout each segment. 


\section{CHAPTER 7}

\section{Conclusions}

\section{Summary of Findings}

Lithospheric segmentation may have a profound effect on both mantle flow and melt migration beneath mid-ocean ridges. The effect of segmentation is likely to be quite small at fast-spreading ridges which have relatively rapid mantle upwelling and significant reserves of melt residing in long-lived crustal magma chambers [c.f. Detrick et al., 1987; Detrick et al., 1993; Kent et al., 1994]. However, ridge segmentation may be very important at slow-spreading ridges where mantle upwelling is primarily plate-driven and horizontal melt focusing may be driven by temperature gradients near the top of the melting region.

Through modeling of observed gravity and topography anomalies at the East Pacific Rise (EPR), Chapter 2 suggests that there is significant across-axis focusing of melt into a narrow column (or series of channels) $10 \mathrm{~km}$ wide and extending up to $70 \mathrm{~km}$ beneath the ridge axis. In the absence of plate segmentation, it appears that this column is essentially two-dimensional with little along-axis variation. Recent numerical modeling by Eberle et al. [1997] suggests that maintaining a narrow column of low-density mantle (with enhanced vertical upwelling velocities) requires unreasonably large viscosity contrasts $(>5$ orders of magnitude) between the upwelling column and the surrounding mantle. Thus, a uniform-density column with melt dispersed uniformly through a mantle matrix does not seem likely. Instead, local isostatic support for the axial topographic high could be supplied by the concentration of melt into narrow, very low-viscosity, channels. However, this hypothesis requires a mechanism to efficiently suck melt horizontally from a wider melting zone into the much narrower zone of concentrated melt channels.

Alternatively, the axial topographic high may be created by the flexure of a variablethickness plate loaded from below by a relatively wide zone of low-density mantle. Buck [1997] has shown that the mantle load may be 3-4 times wider than the axial high if the plate thins significantly in a narrow region near the axis.

In contrast to the smooth lavas flows observed at the EPR [e.g., Macdonald et al., 1989], surface features observed at the Reykjanes Ridge suggest that melt delivery beneath this slow-spreading ridge is highly discontinuous and three-dimensional. Chapter 3 shows 
that despite the proximity to the Iceland hot spot, melt delivery seems to occur in a manner very similar to that observed all along the Mid-Atlantic Ridge (MAR), via small ephemeral magma bodies. The location of individual eruptive events are then controlled by the lithospheric segmentation of the axial volcanic ridges.

Chapter 4 demonstrates that even when the upwelling from $\sim 100 \mathrm{~km}$ depth is essentially two-dimensional, segmented ridges may make the along-axis expression of the upwelling highly three dimensional. The mis-match between the axis of mantle upwelling and the location of individual spreading segments causes a decrease in mantle upwelling near ridge-transform offsets and a tendency for the upwelling mantle to be centered beneath inside corners. The resulting along-axis variability increases with increased dominance of the plate-driven component of the flow and with increased offset length. These results suggest that the highly three-dimensional crustal accretion observed at the MAR may result, at least in part, from the highly segmented nature of the ridge axis.

This hypothesis is confirmed in Chapters 5 and 6 where numerical modeling is used to quantitatively examine the effect of lithospheric segmentation on both mantle upwelling and melt migration. Although widely-spaced $(>150 \mathrm{~km})$ offsets may have a significant effect on mantle flow, closely spaced ( $50 \mathrm{~km})$ non-transform offsets, such as those observed throughout the MAR, do not appear to induce three-dimensional mantle upwelling. The primary result of such short-wavelength segmentation is to perturb the top surface of the melting region. Even the small amount of cooling beneath non-transform offsets is sufficient to depress the melting region and create a topographic gradient which may drive melt toward the centers of segments. This allows for significant along-axis variations in crustal accretion through the focusing of melt toward segment centers. Thus, the segment-centered gravity bull's-eyes observed at the MAR may reflect threedimensional melt migration rather than segment-centered mantle diapirs. Once again, lithosphere segmentation appears to have a profound effect on both mantle flow and melt delivery. Three-dimensional crustal accretion may therefore be a consequence of ridge segmentation, not a cause.

\section{Future Work}

These and other studies have begun to unravel the connection between lithospheric segmentation and the three-dimensional patterns of mantle upwelling and melt migration beneath mid-ocean ridges. However, many questions remain unanswered and much work remains to be done. Although it appears that mantle diapirs are not required to produce 
observed variations in crustal thickness, they have not been eliminated as a possibility. In some areas, such segment-centered diapirs may indeed exist. Gravity data alone is not sufficient to image such diapirs, but geochemical and seismic studies have this potential. One possible direction for future work is through observational studies which may be able to distinguish between different modes of mantle convection. High-resolution sampling of basalts and peridotites exposed along the axis of a single spreading segment combined with systematic analyses of both major and trace elements may provide constraints on degrees of melting, efficiency of melt extraction, and lengths of melt migration paths. Along-axis refraction experiments may be able to constrain crustal thickness and density variations which can then be used to carefully subtract the crustal contribution from the observed gravity leaving a residual gravity signal which may be attributed to mantle variations. Tomographic experiments may also be able to directly image low-velocity zones in the upper mantle (attributable to high temperatures and/or retained melt) as well as seismic anisotropy which may indicate the direction of mantle flow.

The distribution of retained melt in the mantle and crust and the residence time of magma in crustal or sub-crustal magma chambers also remain important questions, as do the mantle and melt flow patterns. One avenue of study which is just beginning to be explored involves the detailed temporal and thermal relationship between episodes of magma-body emplacement, volcanic eruptions, tectonic faulting, and hydrothermal activity. Submersible and deep-towed studies can constrain the surface expression of individual eruptive events, but the development of a magma-intrusion model may provide a more quantitative physical basis for the analysis of this type of observational data. Such a model may be used to link the timing of melt delivery to crustal magma chambers with episodes of crustal accretion via diking events and seafloor eruptions. Combined observation and modeling studies may also be able to investigate the connection between the location of the magmatic intrusions and the distribution of hydrothermal activity alongaxis.

Additional theoretical studies will also be important. One of the most obvious directions for future modeling will come with the development of a fully three-dimensional variable viscosity mantle convection model. Experiments similar to those involved in Chapters 5 and 6 can then be done incorporating temperature-, melt-, and depletion-related viscosity changes. Such codes will likely be computationally accessible in the near future, however their utility in matching real-world conditions may be limited by our knowledge of how temperature and melt-retention actually effect mantle rheology. Continued high- 
temperature/high-pressure laboratory studies will be required to address these issues and provide constraints for the numerical models. Once the details are worked out, a range of mantle conditions may be found in which segment-centered mantle diapirs do form and we will then be able to determine if there are any ridge environments in which the mantlediapirs may be important.

The integration of mantle flow models with seismic methods would be another avenue of research. Geodynamic models, derived from first principles, predict parameters such as temperature $(\mathrm{T})$, melt production $(\mathrm{M})$, retained melt fraction $(\Phi)$, composition $(\mathrm{C})$, and mantle flow velocities $(U)$. Some of this information may be used to make predictions of observables such as topography, gravity, and magmatic crustal thickness. However, geodynamic parameters are not as readily compared to other types of observational data (such as that derived from seismic studies). Seismic imaging, on the other hand, uses data to constrain seismic parameters such as the velocity, attenuation, and anisotropy of $\mathrm{P}$ and $\mathrm{S}$ waves $\left(\mathrm{V}_{\mathrm{p}}, \mathrm{Q}_{\mathrm{p}}, \Phi_{\mathrm{p}}, \mathrm{V}_{\mathrm{s}}, \mathrm{Q}_{\mathrm{s}}, \Phi_{\mathrm{s}}\right)$, which are sensitive to variation in temperature, retained melt fraction, composition, and mantle flow directions. The seismic parameters therefore provide information applicable to geodynamic modeling, but direct comparison is difficult.

One possible integrated approach would be a hypothesis testing method. This would start with a hypothetical set of conditions (e.g. spreading rate and configuration, mantle viscosity, and other properties) and run a geodynamic model based on these assumptions. The results of the geodynamic model would then be mapped into seismic properties. Actual seismic data would be inverted and tested against the geodynamically predicted model properties to see if the two are consistent. Small perturbations in the initial conditions (e.g. mantle temperature, retained melt fraction, etc.) could then be incorporated into a new geodynamical model which may produce a better fit. Alternatively, a new seismic mapping scheme could be developed. Ultimately, a self-consistent mantle flow model may be developed which will simultaneous satisfy both nature's physical laws and the observed seismic constraints.

\section{References}

Buck, W. R., Narrow flexural response to a broad load: Implications for axial highs and mantle dynamics at fast-spreading mid-ocean ridges, J. Geophys. Res., submitted, 1997.

Detrick, R. S., et al., Multichannel seismic imaging of a crustal magma chamber along the East Pacific Rise, Nature, 326, 35-41, 1987. 
Detrick, R. S., et al., Seismic structure of the southern East Pacific Rise, Science, 259, 499-503, 1993.

Eberle, M. A., D. W. Forsyth, and E. M. Parmentier, Constraints on viscosity structure of the mantle from the shape and gravity signature of the axial topographic high on the East Pacific Rise, J. Geophys. Res., submitted, 1997.

Kent, G. M., et al., The uniform accretion of oceanic crust south of the Garrett Transform at $14^{\circ} 15^{\prime} \mathrm{S}$ on the East Pacific Rise, J. Geophys. Res., 99, 9097-9116, 1994.

Macdonald, K. C., C. R. Haymon, and A. Shor, A $220 \mathrm{~km}^{2}$ erupted lava field on the East Pacific Rise near lat 8 S, Geology, 17, 212-216, 1989. 